July $1999 \quad$ • NREL/SR-500-25949

\title{
Analysis and Tests of Pultruded Blades for Wind Turbine Rotors
}

\author{
M.C. Cheney \\ PS Enterprises \\ Glastonbury, Connecticut
}

T. Olsen, G. Quandt, P. Arcidiacono

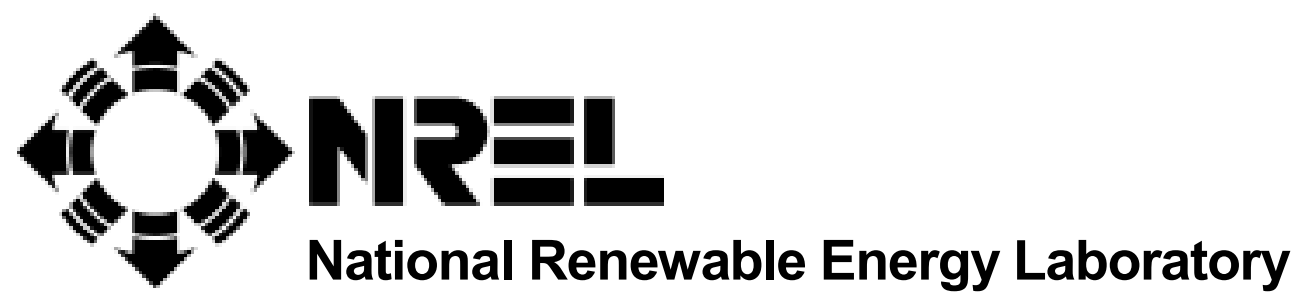

1617 Cole Boulevard

Golden, Colorado 80401-3393

NREL is a U.S. Department of Energy Laboratory

Operated by Midwest Research Institute $\bullet$ Battelle $\bullet$ Bechtel

Contract No. DE-AC36-98-G010337 
July $1999 \quad$ • NREL/SR-500-25949

\title{
Analysis and Tests of Pultruded Blades for Wind Turbine Rotors
}

\author{
M.C. Cheney \\ PS Enterprises \\ Glastonbury, Connecticut
}

T. Olsen, G. Quandt, P. Arcidiacono

NREL Technical Monitor: P. Migliore

Prepared under Subcontract No. AAA-4-12272-04

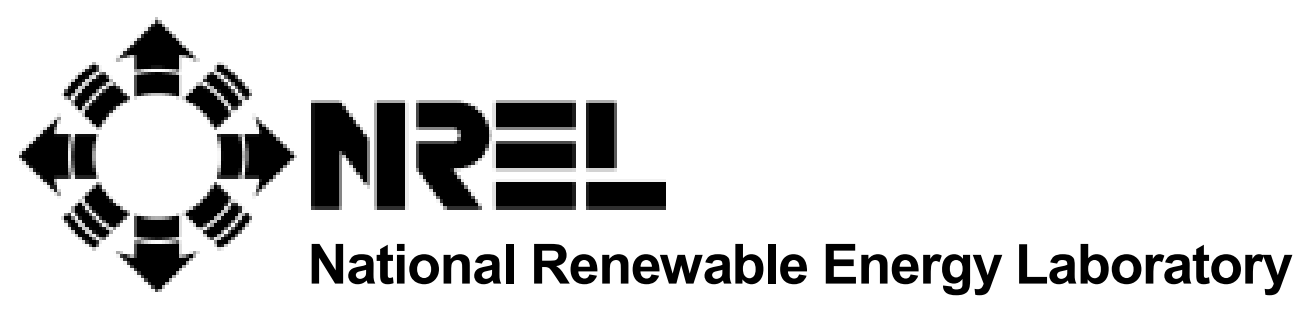

1617 Cole Boulevard

Golden, Colorado 80401-3393

NREL is a U.S. Department of Energy Laboratory

Operated by Midwest Research Institute $\bullet$ Battelle $\bullet$ Bechtel

Contract No. DE-AC36-98-G010337 


\section{NOTICE}

This report was prepared as an account of work sponsored by an agency of the United States government. Neither the United States government nor any agency thereof, nor any of their employees, makes any warranty, express or implied, or assumes any legal liability or responsibility for the accuracy, completeness, or usefulness of any information, apparatus, product, or process disclosed, or represents that its use would not infringe privately owned rights. Reference herein to any specific commercial product, process, or service by trade name, trademark, manufacturer, or otherwise does not necessarily constitute or imply its endorsement, recommendation, or favoring by the United States government or any agency thereof. The views and opinions of authors expressed herein do not necessarily state or reflect those of the United States government or any agency thereof.

Available to DOE and DOE contractors from:

Office of Scientific and Technical Information (OSTI)

P.O. Box 62

Oak Ridge, TN 37831

Prices available by calling 423-576-8401

Available to the public from:

National Technical Information Service (NTIS)

U.S. Department of Commerce

5285 Port Royal Road

Springfield, VA 22161

$703-605-6000$ or $800-553-6847$

or

DOE Information Bridge

http://www.doe.gov/bridge/home.html

Printed on paper containing at least $50 \%$ wastepaper, including $20 \%$ postconsumer waste 


\section{FOREWORD}

The National Renewable Energy Laboratory's (NREL's) National Wind Technology Center is supporting the efforts of its industry partners to develop advanced, utilityscale wind turbines. Part of the research being conducted focuses on innovative components and subsystems that eventually may be incorporated into these advanced turbines. PS Enterprises, Inc. (PSE) chose to investigate a flexible, downwind, free-yaw, five-blade rotor system employing pultruded blades.

Studies conducted by PSE showed that, for a given rotor solidity, increasing the number of blades reduced the rotor weight. And from previous experience with both helicopter and wind turbine rotors, it was known that the pultrusion process resulted in blades having a very low cost-per-unit- weight. Indeed, pultruded blades were employed on wind turbines by StormMaster, Windtech, Dynergy, and Bergey Windpower. However, in some cases, problems were reported with yaw instability and occasional tower strikes. Furthermore, because pultruded blades are constrained to constant cross sections, without taper or twist, they are known to suffer a degradation in aerodynamic performance. So the challenge of the PSE project was to design and test a dynamically- and structurally-stable rotor that demonstrated the anticipated weight and cost savings while maintaining reasonable aerodynamic performance.

PSE assembled a diverse group of consultants from around the United States to work on the project. The expertise of the project participants included aerodynamics, mechanical design, structural dynamics and testing. They worked closely with NREL to accomplish design reviews, modal tests, blade structural tests and field tests. This approach had the effect of adding logistics challenges to the acknowledged technical difficulties.

It can be said with virtual certainty that engineering projects of this nature always encounter unexpected difficulties and frequently fall short of the original goals and objectives. In this project, a gearbox failure and subsequent runaway led to an early curtailment of the field-test program. Nevertheless, PSE and its consortium of consultants, completed an exceptional amount of work, the results of which demonstrate great promise for the proposed rotor concept. And to their credit, it was completed within the negotiated budget.

NREL and the U.S. Department of Energy are pleased to support research activities of the quality represented by this project and documented in this report.

Paul G. Migliore, Ph. D.

NREL Senior Project Leader 


\section{PREFACE}

This project, supported by NREL under Subcontract No. AAA-4-12272-04, was undertaken to assess the feasibility of using pultruded blades for wind turbine rotors. It represents a more rigorous engineering investigation of pultruded wind turbine blades compared to that performed on the initial rotors using this technology. The early operating experience of these rotors, although it showed pultrusions as a promising new blade technology, was plagued with design and quality control problems. Adequate engineering analysis and component testing had not been performed due to the 'rush to install' mentality of the taxcredit years. This contract helped fill in much of that needed work. The authors would like to recognize the contract monitor, Paul Migliore, for his support and guidance during the course of the contract. Several key industry consultants also made important contributions to this contract. Our thanks go to Ken Deering, Craig Hansen, Tom Knapp, Michael Selig, and Mike Zuteck. 


\section{SUMMARY}

A preliminary design study and proof of concept test were conducted to assess the feasibility of using pultruded blades for wind turbine rotors. A $400 \mathrm{~kW}$ turbine was selected for the design study and a scaled $80 \mathrm{~kW}$ rotor was fabricated and field tested as a demonstration of the concept. The design studies continued to support the premise that pultruded blades offer the potential for significant reductions in rotor weight and cost. The field test provided experimental performance and loads data that compared well with predictions using the FLEXDYNE aeroelastic analysis. The field test also demonstrated stable yaw behavior and the absence of stall flutter over the wind conditions tested. During the final year of the contract, several studies were conducted by a number of independent consultants to address specific technical issues related to pultruded blades that could impact the commercial viability of turbines using this technology. The issues included performance, tower strikes, yaw stability, stall flutter, fatigue, and costs. While the performance of straight pultruded blades was projected to suffer a penalty of about $13 \%$ over fully twisted and tapered blades, the study showed that an aerodynamic fairing over the inner $40 \%$ could recover $85 \%$ of that loss while still keeping the blade cost well below that of conventional blades. Other results of the study showed that with proper design, rotors using pultruded blades could operate without aeroelastic problems, have acceptable fatigue life, and cost less than half that of rotors employing conventionally manufactured blades. 


\section{TABLE OF CONTENTS}

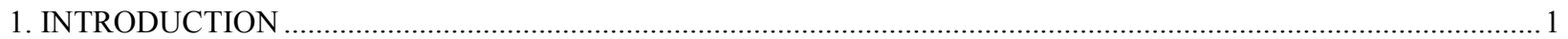

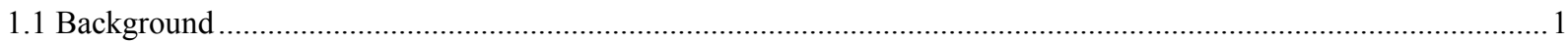

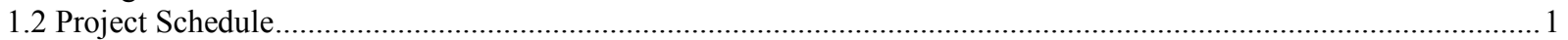

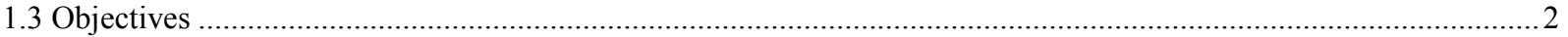

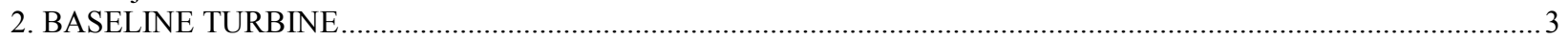

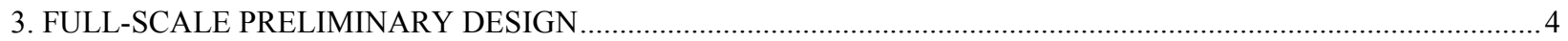

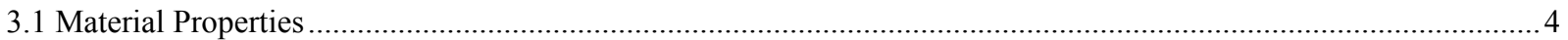

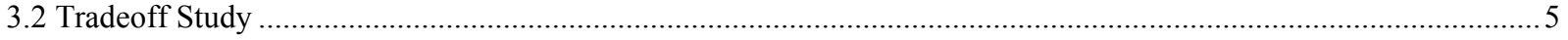

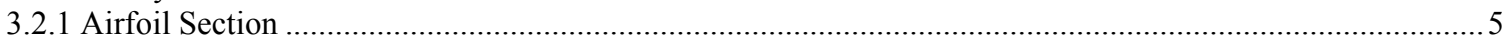

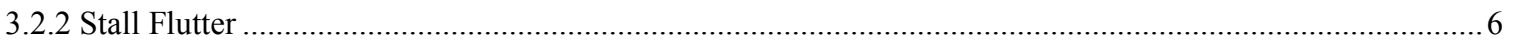

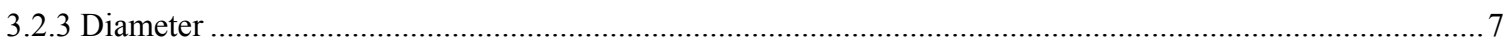

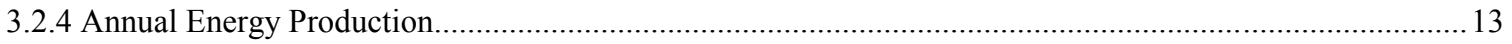

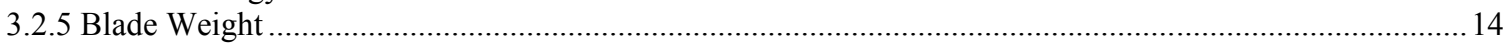

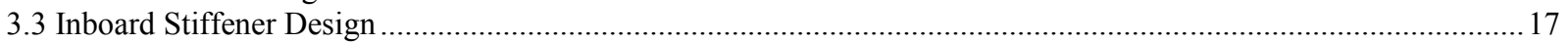

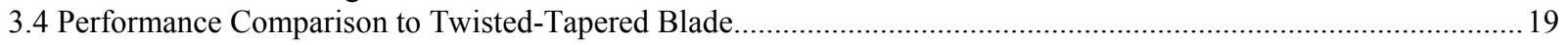

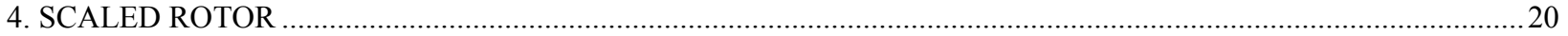

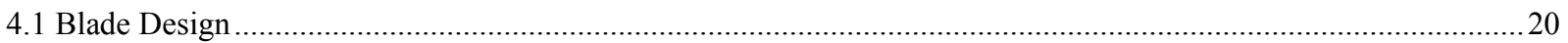

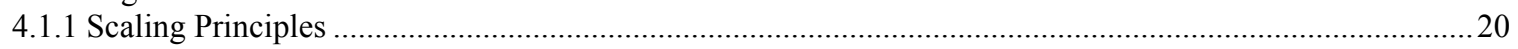

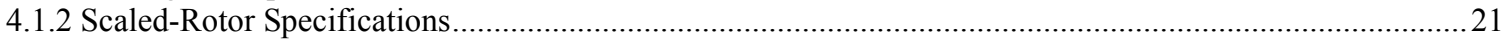

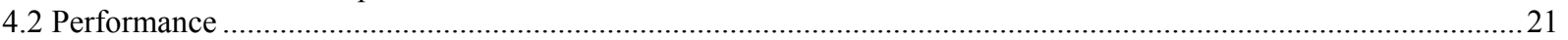

4.3 Spoiler-Flap

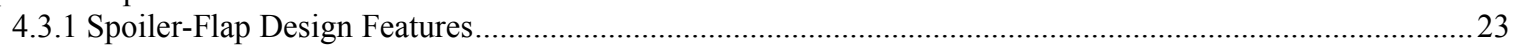

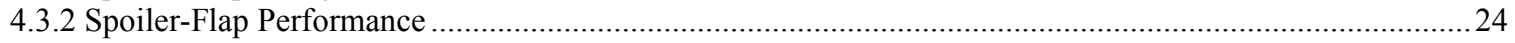

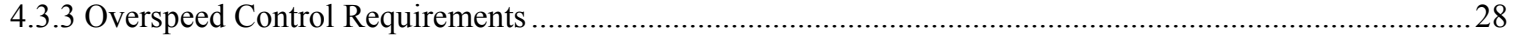

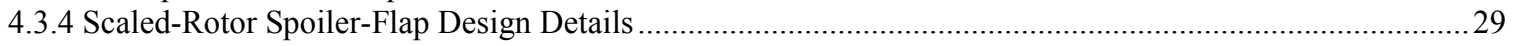

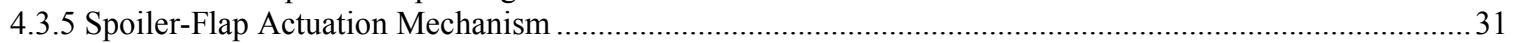

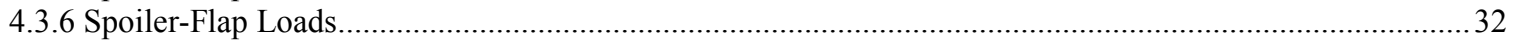

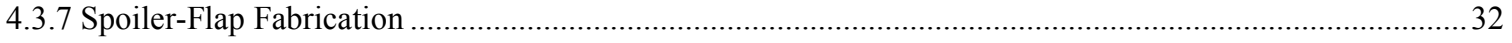

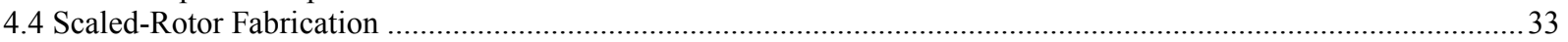

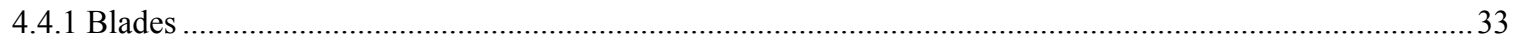

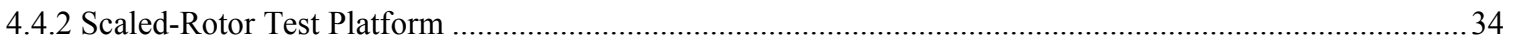

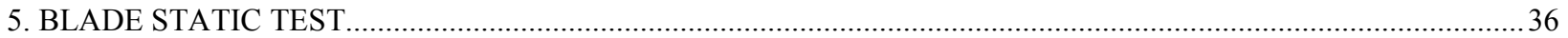

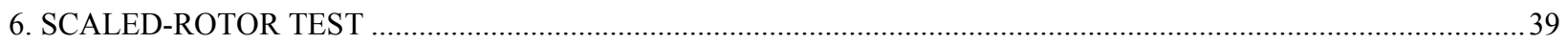

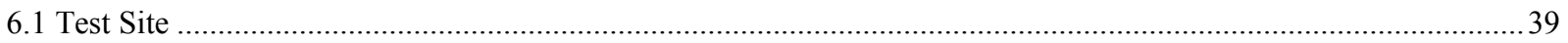

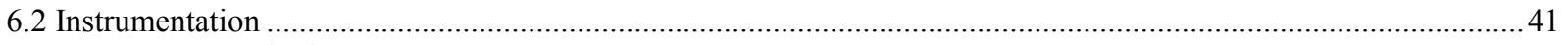

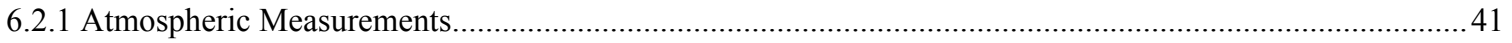

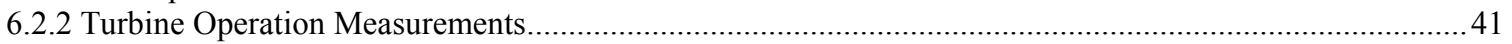

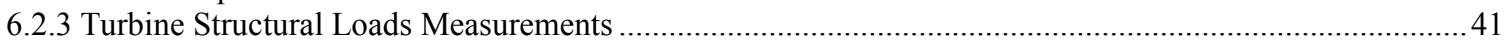

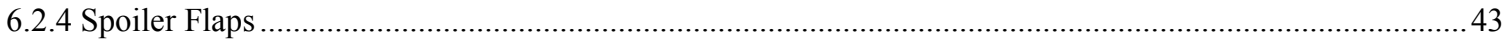

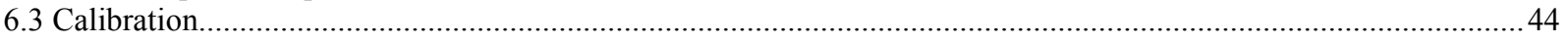

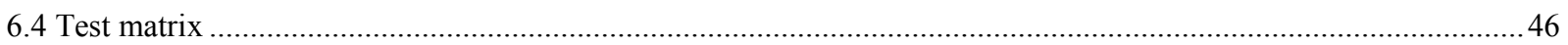

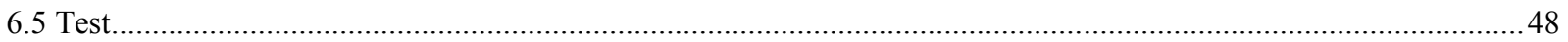

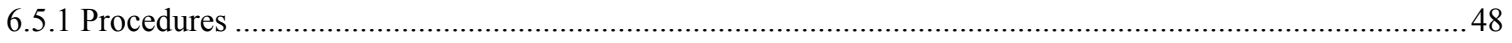

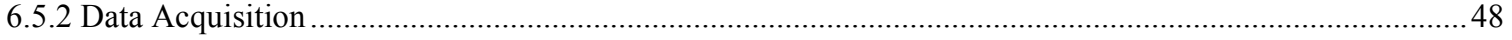

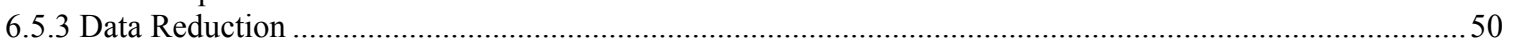

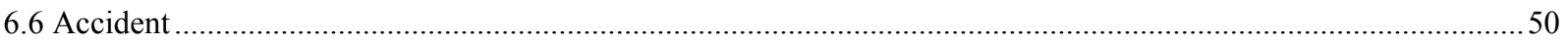

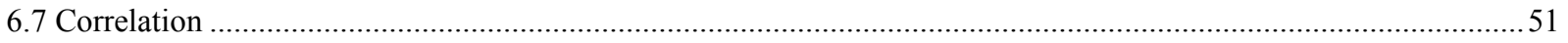

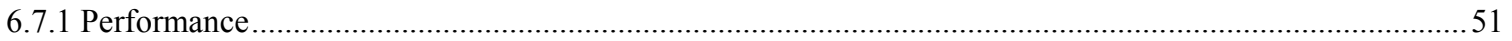

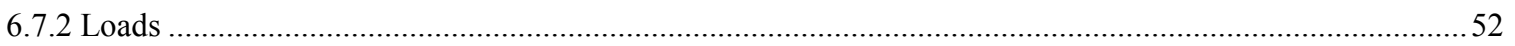

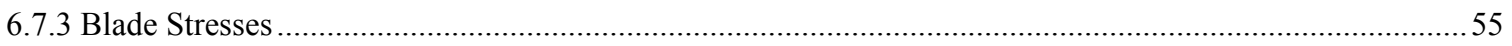

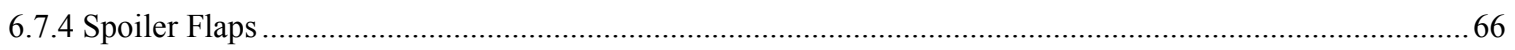

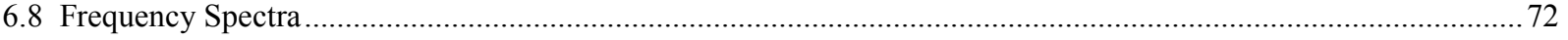

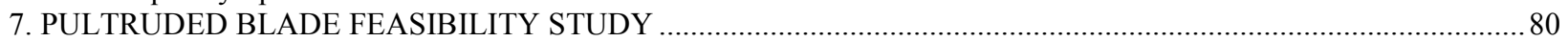

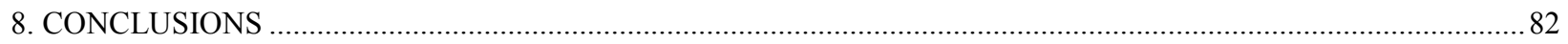

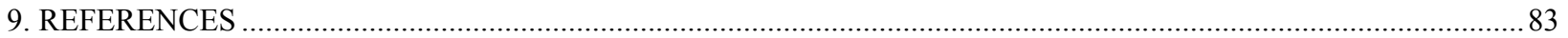




\section{LIST OF FIGURES}

Figure

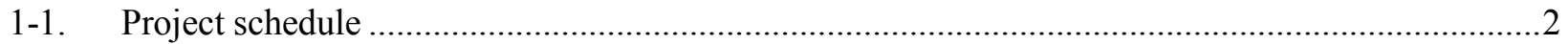

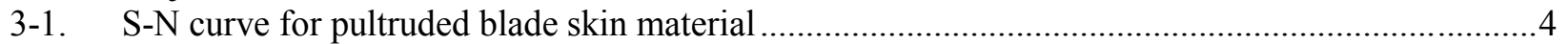

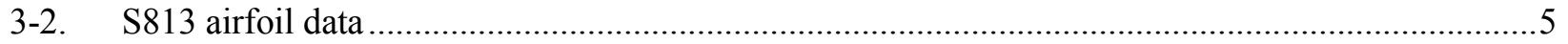

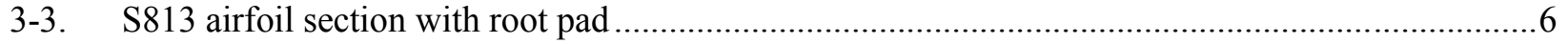

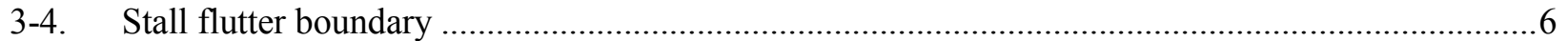

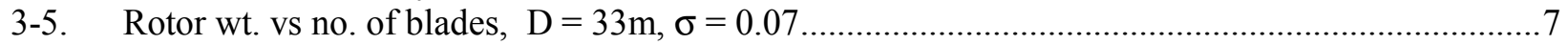

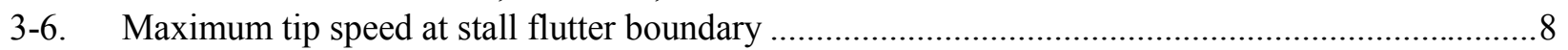

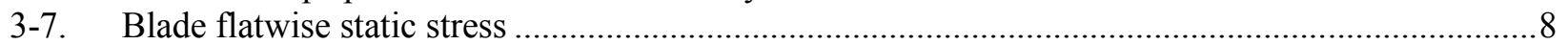

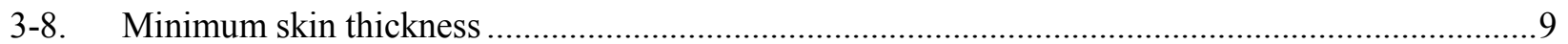

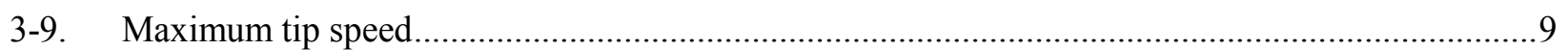

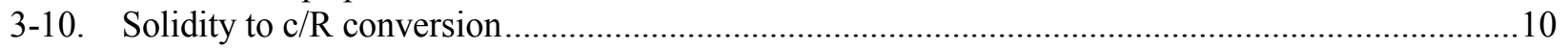

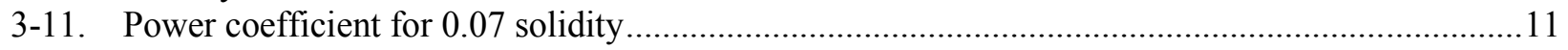

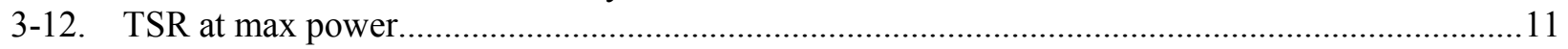

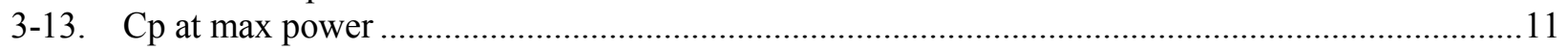

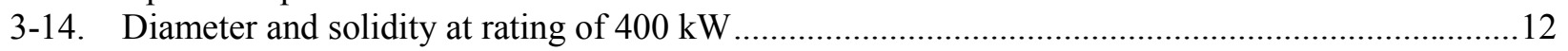

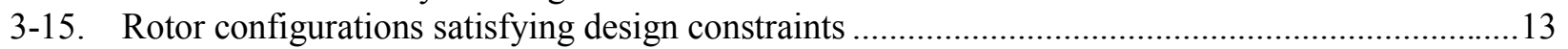

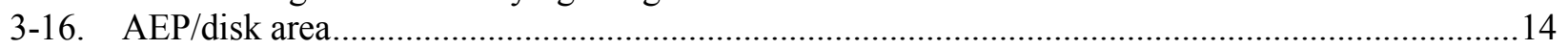

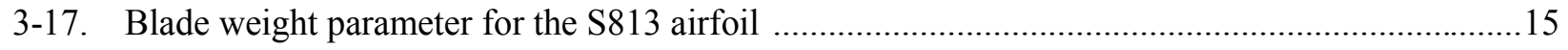

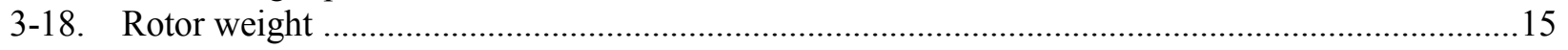

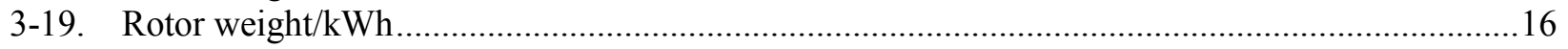

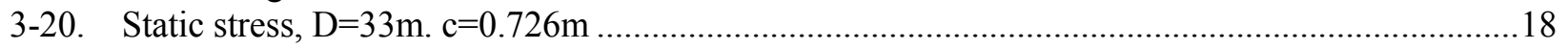

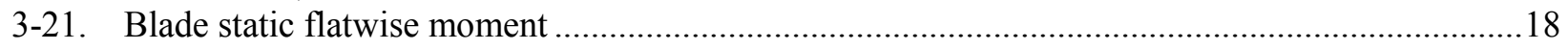

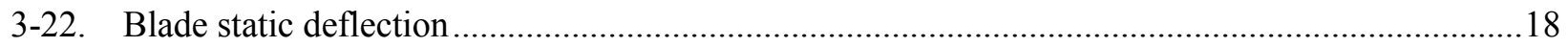

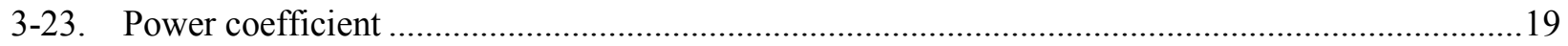

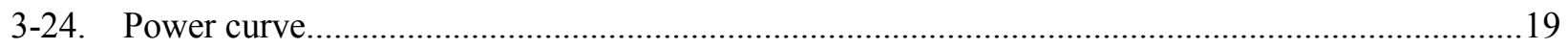

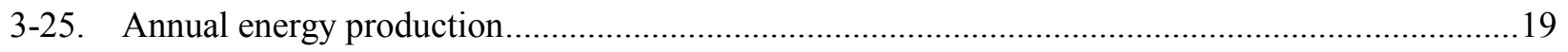

4-1. Power curve prediction, PSE scaled rotor, sea level ................................................................22

4-2. Power curve prediction, PSE scaled rotor, Cabazon site ........................................................23

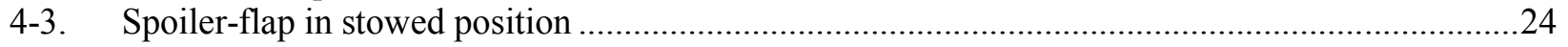

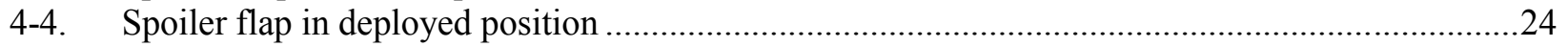

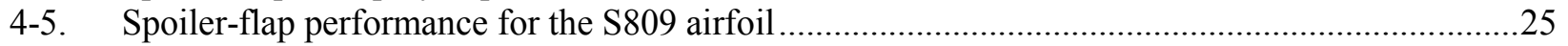

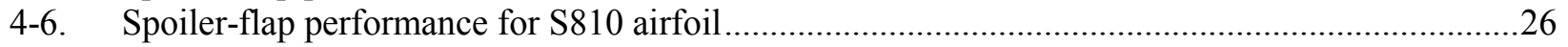

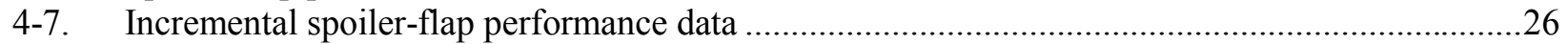

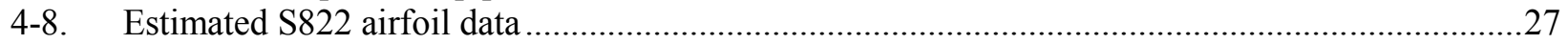

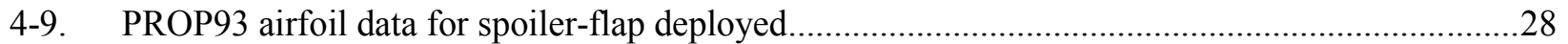

4-10. Effect of spoiler-flap span on torque coefficient..................................................................29

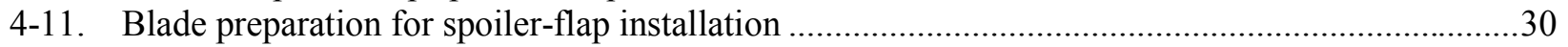

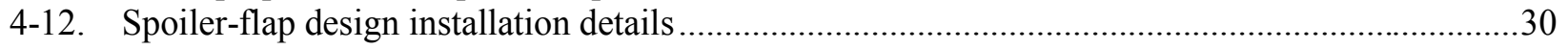

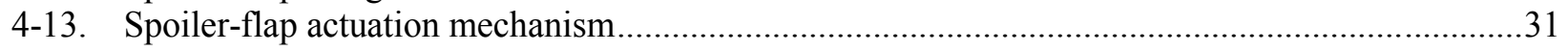

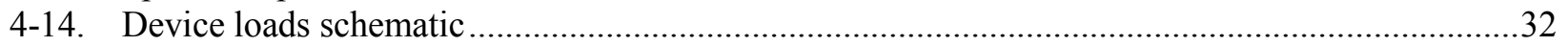

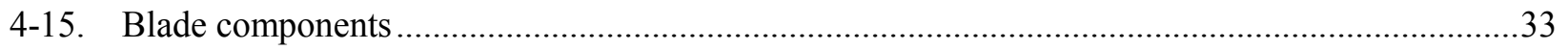

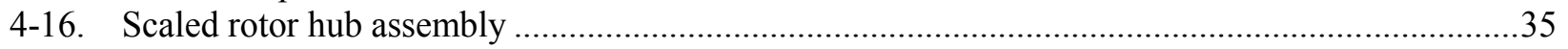

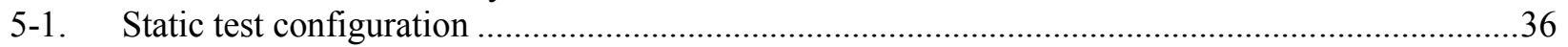

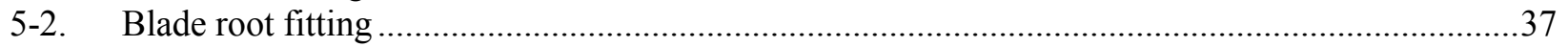

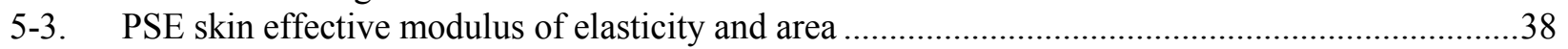

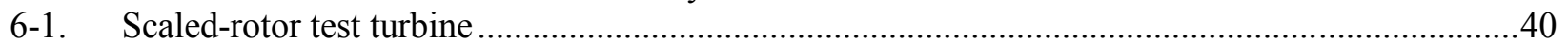

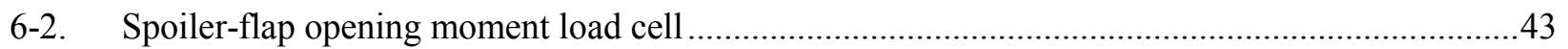




\section{LIST OF FIGURES}

Figure

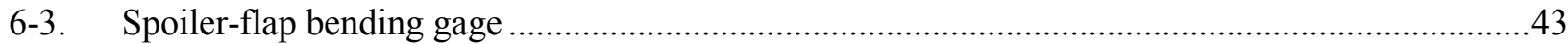

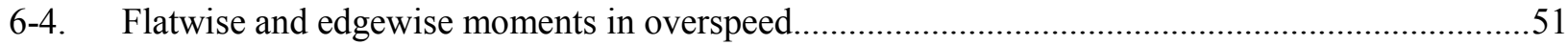

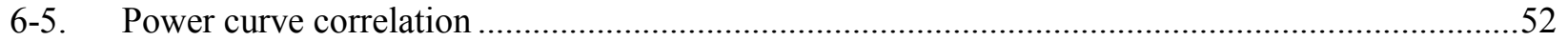

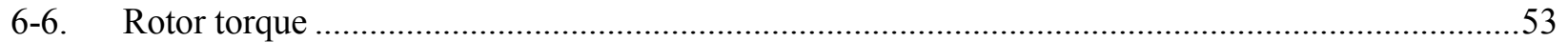

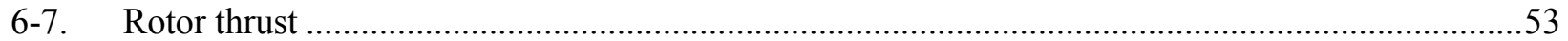

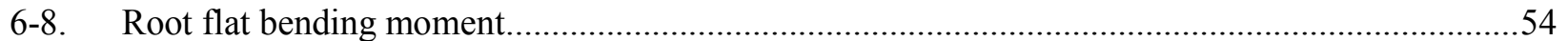

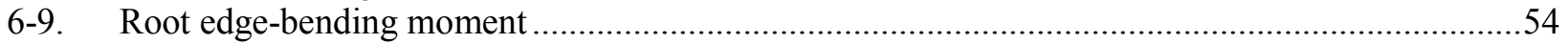

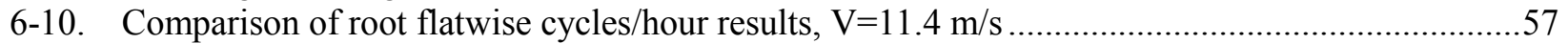

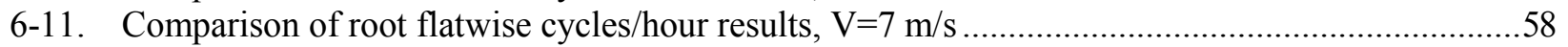

6-12. Comparison of root flatwise cycles/hour results using random wind .......................................59

6-13. Comparison of root edgewise cycles/hour results using test wind..............................................59

6-14. Comparison of root edgewise cycles/hour results using random wind .....................................60

6-15. Root flatwise moment time history for revs 185-215: test....................................................60

6-16. Root flatwise moment time history for revs 185-215: Flexdyne ............................................61

6-17. Root edgewise moment time history for revs 185-215: test ..............................................61

6-18. Root edgewise moment time history for revs 185-215: Flexdyne ..........................................62

6-19. Root flatwise moment time history for revs 210-213: test..................................................62

6-20. Root edgewise moment time history for revs 210-213: Flexdyne ........................................63

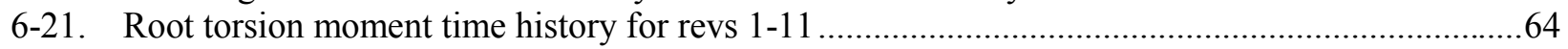

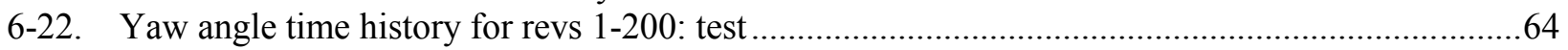

6-23. Yaw angle time history for revs 1-200: Flexdyne (with test wind) ...........................................65

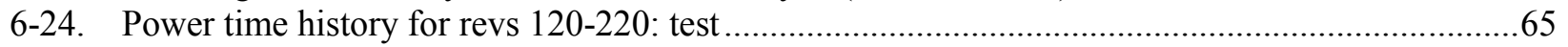

6-25. Power time history for revs 120-220: Flexdyne (with test wind) ............................................66

6-26. Spoiler-flap performance comparison..................................................................................67

6-27. Brake dynamics including hinge moments, return spring, no damping .......................................68

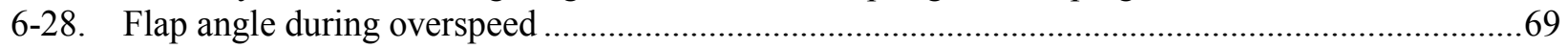

6-29. Spoiler-flap dynamics for the first 50 -sec of the runaway event .......................................... 70

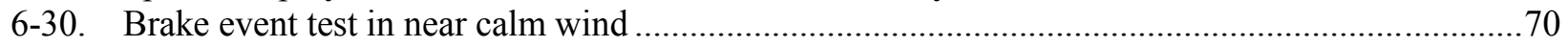

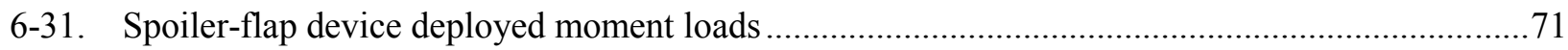

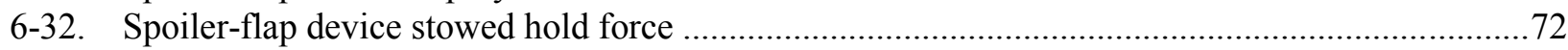

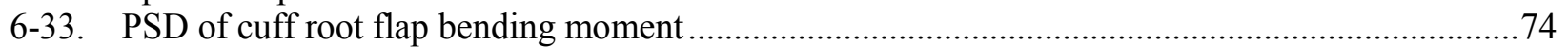

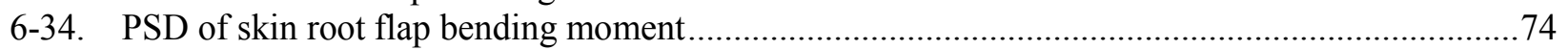

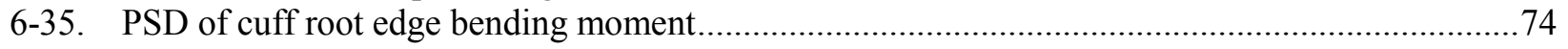

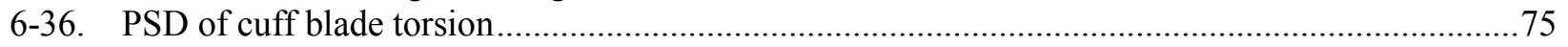

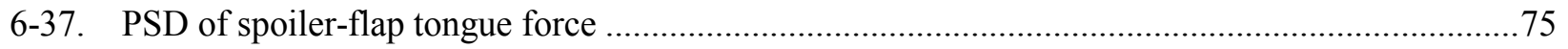

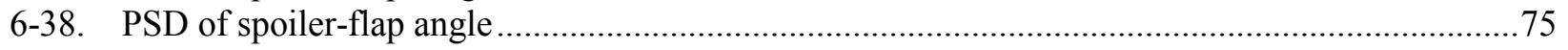

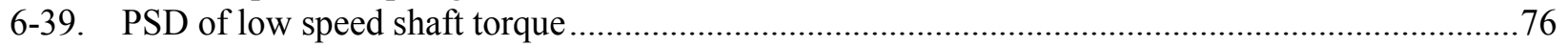

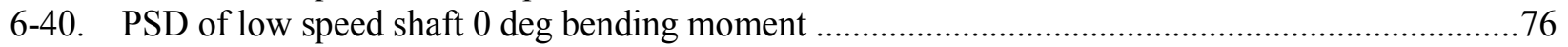

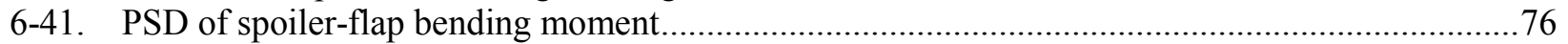

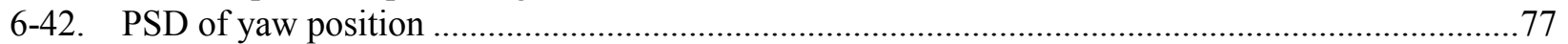

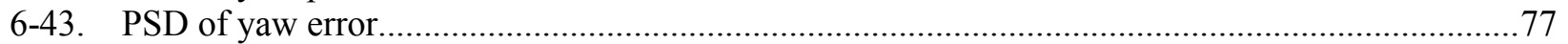

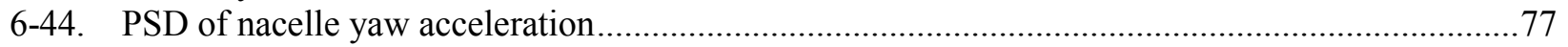

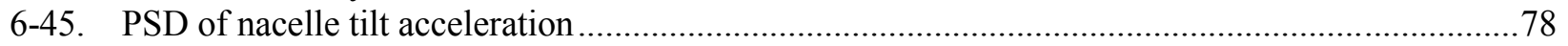

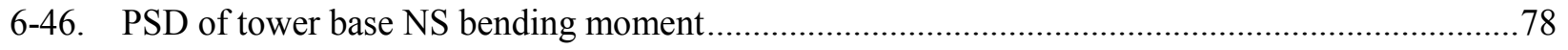

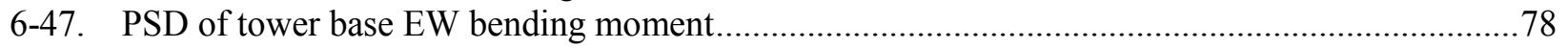

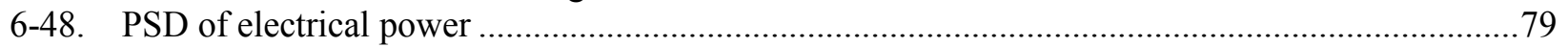

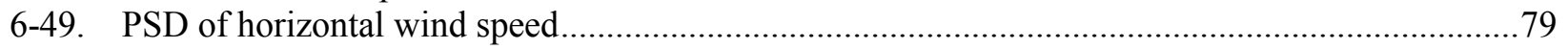

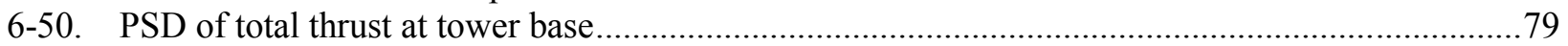




\section{LIST OF TABLES}

Table

Page

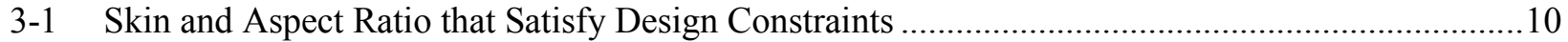

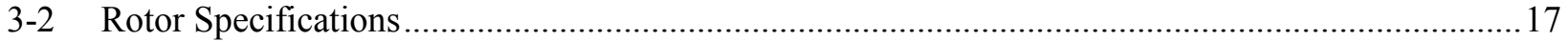

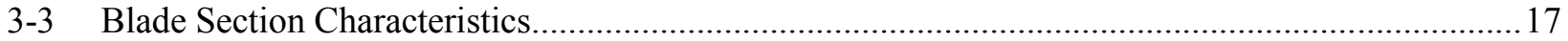

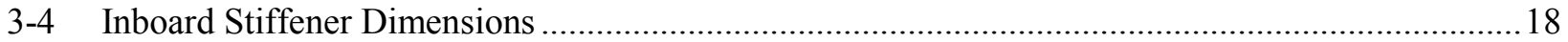

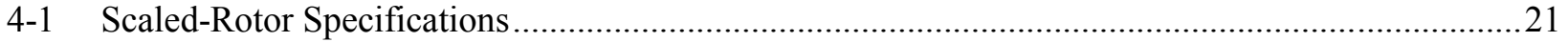

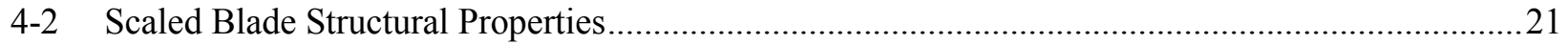

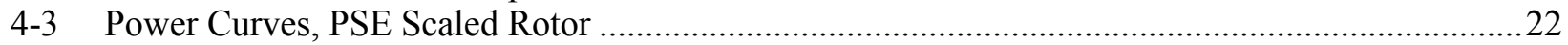

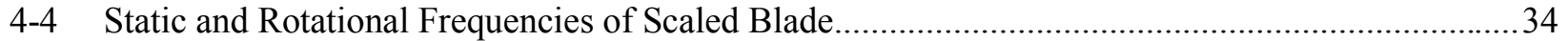

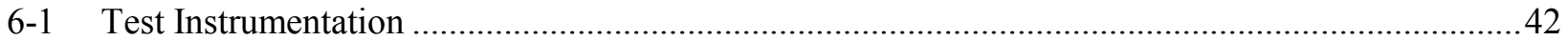

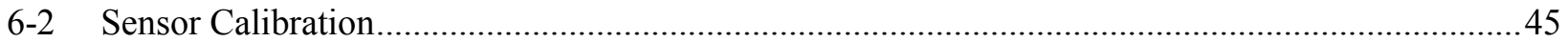

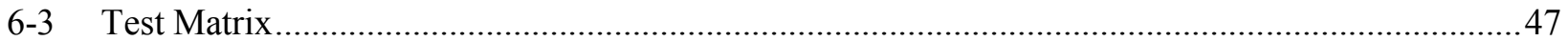

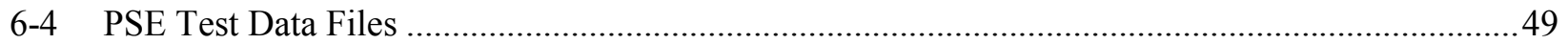

7-1 Weight and Cost Comparison of Pultruded and Non-pultruded Rotors.......................................... 81 


\section{NOMENCLATURE}

\begin{tabular}{|c|c|}
\hline ADAMS & $\begin{array}{l}\text { Automated Dynamic Analysis of Mechanical Systems } \\
\text { advanced data acauisition system }\end{array}$ \\
\hline ADAS & advanced data acquisition system \\
\hline AEP & annual energy production, $\mathrm{kWh}$ \\
\hline $\mathrm{AOA}$ & angle of attack, degrees \\
\hline $\mathrm{b}$ & number of blades \\
\hline c & blade chord \\
\hline $\mathrm{C}_{\mathrm{d}}$ & drag coefficient \\
\hline $\mathrm{C}_{\mathrm{hm}}$ & spoiler flap hinge moment coefficient \\
\hline $\mathrm{C}_{\mathrm{n}}$ & spoiler flap normal force coefficient \\
\hline $\mathrm{C}_{1}$ & lift coefficient \\
\hline $\mathrm{C}_{\mathrm{p}}$ & power coefficient \\
\hline $\mathrm{C}_{\mathrm{q}}$ & torque coefficient \\
\hline $\mathrm{C}_{\mathrm{s}}$ & suction coefficient \\
\hline $\mathrm{D}$ & rotor diameter, meters \\
\hline DAM & data acquisition module \\
\hline $\mathrm{E}$ & modulus of elasticity, psi \\
\hline ERDA & Energy Research and Development Center \\
\hline FD & Flexdyne Aeroelastic Analysis \\
\hline $\mathrm{ft}$ & foot \\
\hline $\mathrm{ft}-\mathrm{lb}$ & foot-pound \\
\hline$F_{\text {mag }}$ & spoiler-flap reaction magnet force \\
\hline $\mathrm{F}_{\mathrm{N}}$ & spoiler-flap normal force aerodynamic pressure \\
\hline G & shear modulus of elasticity, psi \\
\hline $\mathrm{h}$ & tower height, meters \\
\hline $\mathrm{Hz}$ & Hertz, cycles/second \\
\hline I & area moment of inertia, in^4 \\
\hline $\mathrm{I}_{\mathrm{p}}$ & polar moment of inertia, $1 \mathrm{~b}-\sec ^{\wedge} 2$ \\
\hline in. & inch \\
\hline $\mathrm{J}$ & polar area of inertia, in^4 \\
\hline ksi & $1000 \mathrm{psi}$ \\
\hline $\mathrm{kWh}$ & kilowatt-hours \\
\hline LVDT & linear voltage digital transducer \\
\hline MSU & Montana State University \\
\hline M & million \\
\hline $\mathrm{M}_{\mathrm{a}}$ & inertial force at spoiler flap due to rotation and mass \\
\hline $\mathrm{m}$ & meters \\
\hline $\mathrm{mm}$ & millimeters \\
\hline $\mathrm{m} / \mathrm{s}$ & meters per second \\
\hline MW & megawatt \\
\hline NREL & National Renewable Energy Lab \\
\hline NWTC & National Wind Technology Center \\
\hline OSU & Ohio State University \\
\hline PSD & power spectral density \\
\hline PSE & PS Enterprises, Inc. \\
\hline $\mathrm{P}_{\text {span }}$ & spoiler flap reaction to inertial loads \\
\hline Q & rotor torque, $\mathrm{ft}-\mathrm{lb}$ or meter-newton \\
\hline q & dynamic pressure, psi \\
\hline
\end{tabular}




$\begin{array}{ll}\mathrm{R} & \text { radius, meters } \\ \mathrm{RN} & \text { Reynolds Number } \\ \mathrm{rpm} & \text { revolutions per minute } \\ \mathrm{RV} & \text { reduced velocity } \\ \mathrm{R}_{\mathrm{V}} & \text { spoiler-flap reaction shear force at inboard and outboard ribs } \\ \mathrm{S} & \text { second } \\ \mathrm{TS} & \text { tip speed, } \mathrm{ft} / \mathrm{sec} \\ \mathrm{TSR} & \text { tip speed ratio, } \mathrm{TS} / \mathrm{V} \\ \mathrm{T}_{\mathrm{q}} & \text { spoiler flap reaction torque inboard and outboard } \\ \mathrm{t}(\mathrm{s}) & \text { airfoil skin thickness, in. } \\ \mathrm{UTRC} & \text { United Technologies Research Center } \\ \mathrm{V} & \text { wind speed, } \mathrm{m} / \mathrm{s} \text { or } \mathrm{ft} / \mathrm{sec} \\ \mathrm{W} & \text { blade weight, lb/in. } \\ \mathrm{W} & \text { blade weight, lbs } \\ \mathrm{WSU} & \text { Witchita State University } \\ \sigma & \text { rotor solidity, bc/ } \pi \mathrm{R} \\ \Omega & \text { rotational speed, radians/sec } \\ 0 & \text { degree }\end{array}$




\section{Introduction}

\subsection{Background}

The major incentive for pursuing pultruded blade technology was to reduce wind turbine cost of energy. The initial blades manufactured in 1980 by Morrison Molded FiberGlass (now Strongwell, Inc.) for the United Technologies Research Center in the early eighties did indeed demonstrate the low cost of this method. In a production mode there is little labor involved and the cost of the product boils down primarily to the cost of glass and resin. It was shown that blades could be made for under $\$ 4 / 1 \mathrm{~b}$. At that time nearly all blades made for the wind industry used hand-lay-up methods and cost around $\$ 10 / \mathrm{lb}$.

By virtue of the constant cross section of pultrusions, blades were more flexible for the same amount of material compared to conventional blades because the structure could not be tapered. This led to much more aeroelastically active blades, which in turn led to operational problems. Experience of turbines employing this technology during the eighties had not been good. This included tower strikes, upwind running, and stall flutter. Rotors of this era were extremely flexible, and the problems they experienced were a direct result of that flexibility. Since the potential for achieving significant reductions in cost of energy was evident due to the low manufacturing cost of pultruded blades, it was logical to pursue solutions to operational problems.

PS Enterprises (PSE) was awarded a contract under the "Innovative Subsystems Program" to conduct a feasibility study of using pultruded blades for utility-scale wind turbine rotors. The work consisted of the preliminary design of a $400 \mathrm{~kW}$ rotor and a field test of a dynamically scaled version of that design. In addition, several consultants were employed to study specific technical issues related to pultruded blades as well as cost compared to conventional designs. The results of those consultant studies were presented in two reports: "The Feasibility of Pultruded Blades for Wind Turbine Rotors", Reference 1, and "Stability Analysis Report", Reference 2. This report is the final summary report for all activities conducted under the subcontract.

\subsection{Project Schedule}

The subcontract began in September 1994. The initial project plan called for two field tests: 1) a baseline rotor test to establish benchmark performance and loads data; and 2) a test of a rotor scaled down from the utility-size rotor developed during the design phase of the project. Comparisons would then be made between the results of the two tests. At the Kickoff Meeting it was agreed that the contract could not support two field tests, so the plan was adjusted to include just the scaled rotor test and to expand the design activities. The project also included a static test of one of the spare blades pultruded for the scaled rotor test. This test was conducted at the NREL static test facility. Later in the contract, a task was added to perform a focused study where independent industry consultants were called in to examine specific technical issues related to the feasibility of the pultruded blade concept. The schedule is presented in Figure 1-1. 


\begin{tabular}{|c|c|c|c|c|c|c|c|c|c|c|c|c|c|c|c|c|c|c|c|c|}
\hline \multirow[b]{2}{*}{ WBS } & \multirow[b]{2}{*}{ TASK } & \multicolumn{2}{|c|}{1994} & \multicolumn{4}{|c|}{1995} & \multicolumn{4}{|c|}{1996} & \multicolumn{4}{|c|}{1997} & \multicolumn{5}{|c|}{1998} \\
\hline & & Q3 & Q4 & Q1 & Q2 & Q3 & Q4 & Q1 & Q2 & Q3 & Q4 & Q1 & Q2 & Q3 & Q4 & Q & $Q$ & & 23 & Q4 \\
\hline 1.0 & PROJECT WORK PLAN \& KICKOFF MTG & & $\sqsupset$ & & & & & & & & & & & & & & & & & \\
\hline 2.0 & BASELINE TURBINE CHARACTERIZATION & & $\square$ & & & & & & & & & & & & & & & & & \\
\hline 3.0 & PRELIM. DESIGN OF UTILITY-SCALE TURBINE & & & & & & & & & & & & & & & & & & & \\
\hline 4.0 & DESIGN, FAB \& TESTING OF SCALED ROTOR & & & & & & & & & & & & & & & & & & & \\
\hline 5.0 & PULTRUDED BLADE FEASIBILITY STUDY & & & & & & & & & & & & & & & & & & & \\
\hline 6.0 & FINAL REPORT & & & & & & & & & & & & & & & & & & & \\
\hline
\end{tabular}

Figure 1-1. Project schedule

During the course of the subcontract several key changes were made to the original plan. These were:

- Cancel the baseline rotor test and expand the design activity.

- Change the basic approach of the utility-scale design from a high tip speed, highly loaded rotor to a low tip speed, low disk-loaded rotor.

- Eliminate extended testing of the scaled rotor to measure performance at high winds due to a transmission failure.

- Add task to compare performance and costs of pultruded-blade rotor with that of two contemporary turbines. Examine specific design and stability issues relative to the feasibility of pultruded blades.

\subsection{Objectives}

The project focused on the development of pultruded blades for wind turbines. The primary objectives were to:

1. Complete the preliminary design of a utility-scale rotor demonstrating significantly reduced cost per $\mathrm{kWh}$;

2. Demonstrate, through a field test of a scaled rotor, that turbines using light weight pultruded blades are stable, achieve projected performance, and have acceptable fatigue life;

3. Demonstrate a new spoiler flap overspeed control device; and

4. Complete an independent study to address important issues regarding pultruded blades, i.e. weight, cost, performance, stability, and fatigue life, and demonstrate the feasibility of rotors using such blades. 


\section{Baseline Turbine}

The baseline turbine, the PSE-52, evolved from a United Technologies Research Center (UTRC) design initiated under an ERDA project in the middle 70s and developed further by Windtech and PS Enterprises. It used a highly flexible rotor similar to that used in helicopters where blade stiffness was derived principally by centrifugal forces. It is believed to be the first turbine blade manufactured using pultrusion technology. The rotor diameter of the PSE-52 was $15.8 \mathrm{~m}(52 \mathrm{ft})$ and it rated at $80 \mathrm{~kW}$. It incorporated a unique pendulum control device on the rotor that adjusted blade pitch for startup, normal operation, and overspeed control. The initial units were manufactured and placed in service in 1983 in Tehachapi, CA. The total rotor weight was $800 \mathrm{lbs}$ and the complete head assembly was $4800 \mathrm{lbs}$. The complete system cost, including the $55 \mathrm{ft}$ tower, was only $\$ 23,000$, which was believed to be the lowest cost $/ \mathrm{kW}$ turbine available at that time.

The system experienced a series of problems related to the control system and the high blade flexibility. These included tower strikes, stall flutter, and overspeed control. A more detailed description of the turbine, its performance, costs, and operating history is provided in an interim contract report, Reference 3. 


\section{Full-Scale Preliminary Design}

\subsection{Material Properties}

The two primary resin systems used for pultrusions are polyester and vinyl ester. Composites using these resins have very similar structural properties, however polyester yields a smoother finish and cost slightly less. The reinforcement can be one, or a mix, of various fibers such as fiberglass (E or S type), graphite, boron, or kevlar. The most common of these, and the lowest cost, is E-type fiberglass. The material used for this design was E-glass/polyester, which has the following properties when pultruded:

- Density $=.065 \mathrm{lb} / \mathrm{in}^{\wedge} 3$

- $\quad$ Bending modulus, $\mathrm{E}=3.0$ million psi

- Shear modulus, $\mathrm{G}=1.11$ million psi

- $\quad$ Yield stress $=80,000 \mathrm{psi}$

- $\quad$ Static design stress $=30,000$ psi

- $\quad$ Fiber volume $=42 \%$

- 0 deg fiber $=57 \%$

- $\quad+/-45$ deg fiber $=26 \%$

- $\quad$ Random mat $=17 \%$

The stress values shown above were determined from fatigue tests of similar material performed at Montana State University, Reference 4. The S-N curve resulting from those tests is shown in Fig. 3-1.

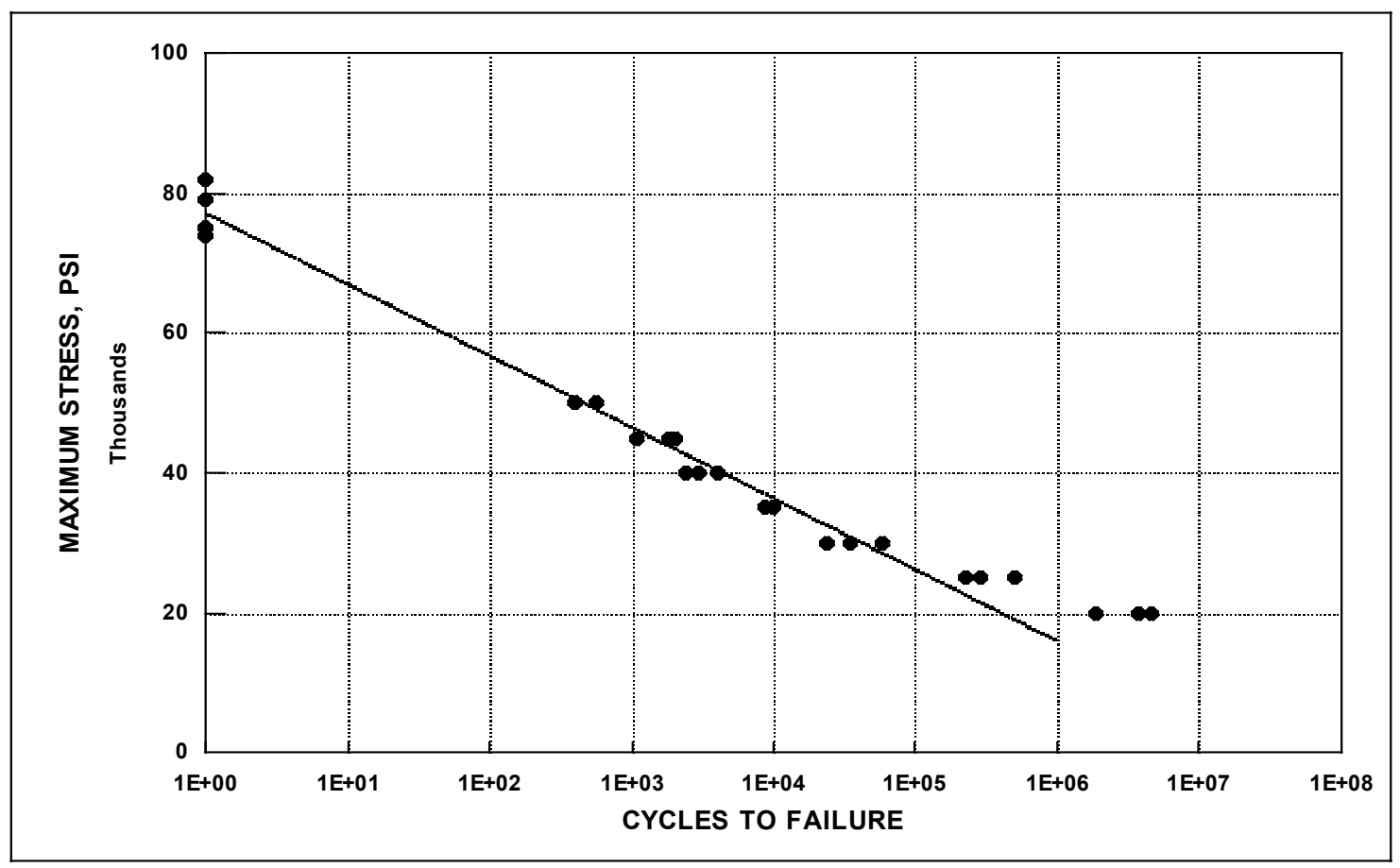

Figure 3-1. S-N curve for pultruded blade skin material 


\subsection{Tradeoff Study}

The contract workplan called for the preliminary design of a utility-scale wind turbine rotor and then to field test a scale model of that rotor on an available $80 \mathrm{~kW}$ test platform. A turbine rating of $400 \mathrm{~kW}$ was selected since it represented an average size for utility turbines at that time in the industry. This would result in a dimensional scale factor of 2.2 for the test rotor.

The remaining rotor parameters to be determined are

- Airfoil

- Diameter

- Tip Speed

- Number of Blades

- Solidity

- Pitch

- Blade Section Design

The only structural constraints placed on the blade were that 1) the stall flutter index, reduced velocity, not exceed 1.5, and 2) the static stress at $62 \mathrm{~m} / \mathrm{s}$ wind speed not exceed 30,000 psi. The objective of the trade-off study was to determine the lowest cost per $\mathrm{kWh}$ of the rotor. From earlier experience it was known that pultruded products, when supplied in production quantities, were generally a fixed $\$ / 1 \mathrm{~b}$ value, although for small cross sections, or low pounds/hour yield, the cost per pound would increase. Utility size blades are classified as a large pultrusion and therefore the cost per pound would be at the low rate. The minimum $\$ / \mathrm{kWh}$ rotor would, therefore, be equivalent to the minimum weight $/ \mathrm{kWh}$ rotor.

\subsubsection{Airfoil Section}

The Reynolds Number range for the utility size turbine under consideration would be from 2 to 4 million over the principal working portion of the blade. Since a pultruded blade section must be uniform from root to tip, a compromise airfoil must be selected: one that would provide acceptable performance while also providing sufficient flatwise blade stiffness. With guidance from NREL, a $16 \%$ airfoil was chosen to best satisfy those requirements, and from the NREL inventory of high performance wind turbine airfoils, the S813 airfoil was selected. The S813 airfoil data measured in the Ohio State University wind tunnel, Reference 5, is presented in Figure 3-2. The minimum Cd is 0.0094. A sketch of the S813 profile (with root pads) is shown in Figure 3-3.
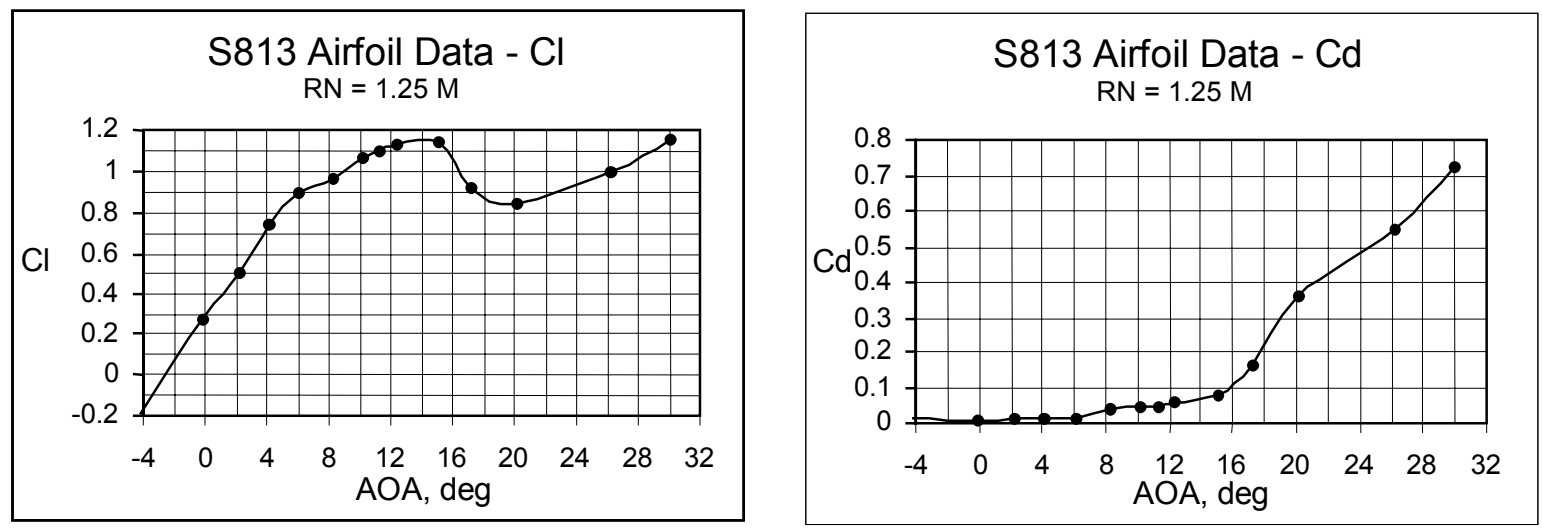

Figure 3-2. S813 airfoil data 


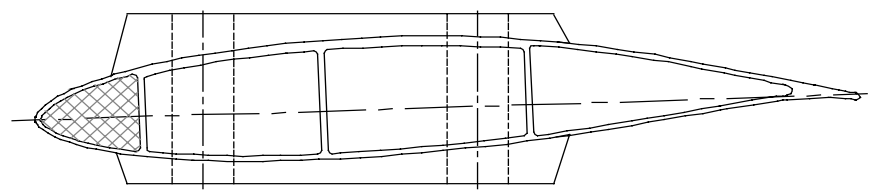

Figure 3-3. S813 airfoil section with root pad

\subsubsection{Stall Flutter}

Stall flutter is a phenomenon experienced mostly in rotating blade machinery, e.g., helicopters, propellers, and wind turbine rotors, in which the interaction between the flow field and the blade torsional motion can lead to unstable torsion oscillations under stalled flow conditions. This type of flutter does not involve flatwise motion, as with classical flutter, and is generally not influenced by the center of gravity location, except if the location effects the torsional natural frequency. There is some evidence that the location of the elastic axis has an effect and that more aft locations are detrimental. An index for stall flutter has been established, called reduced velocity, which is the ratio of the blade speed at $75 \%$ radius divided by the product of the first mode torsional frequency and the semi-chord. The higher the reduced velocity, the more susceptible the blade is to flutter, and the risk increases the more the static stall angle is exceeded. Figure 3-4 shows an approximate flutter boundary as a function of reduced velocity (RV) and blade angle of attack above the static stall angle. The boundary was determined from propeller experiments. Normal design practice for rotary wings is to design for a reduced velocity of 1.5 or lower. This criterion was used for this design study.

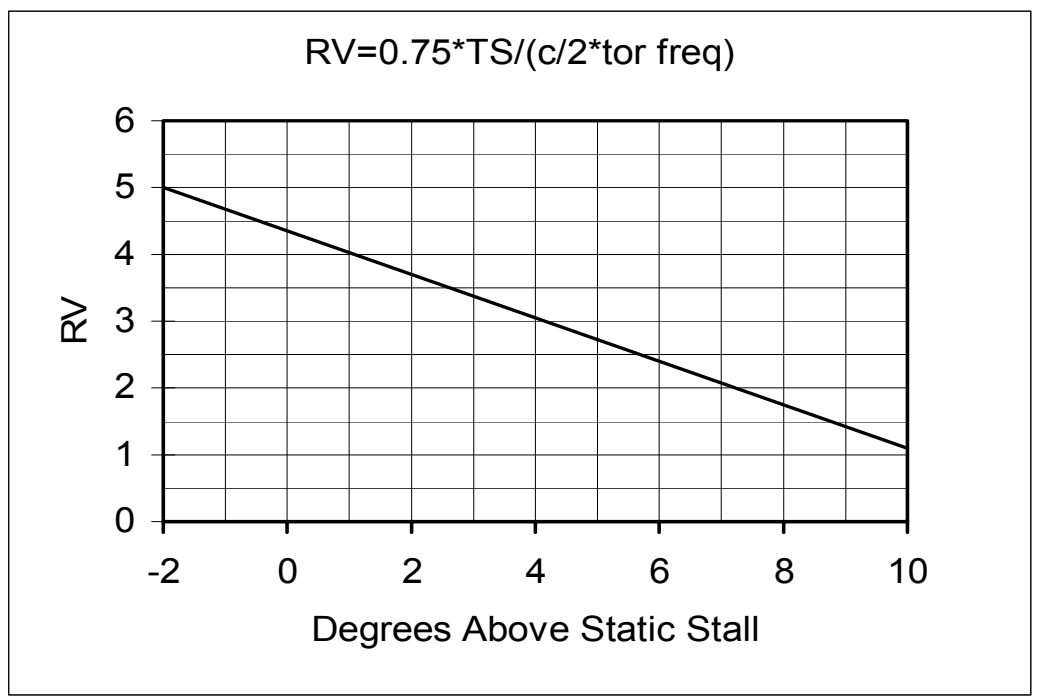

Figure 3-4. Stall flutter boundary 


\subsubsection{Diameter}

The $400 \mathrm{~kW}$ rating can be achieved at various combinations of diameter, tip speed, solidity, and pitch. The objective of the trade-off study is to achieve the lowest total blade weight per $\mathrm{kWh}$. It is easily shown that the total blade weight decreases as number of blades increases when the total blade area, blade section material properties, and non-dimensional parameters remain the same. The non-dimensional parameters are thickness ratio and skin thickness relative to chord. The effect of increasing number of blades on rotor weight is demonstrated in Figure 3-5 for a $33 \mathrm{~m}$ rotor having 0.07 solidity. Of course as the number of blades increases at constant solidity, the chord drops. The minimum chord dimension is determined by either of the two design constraints, reduced velocity or static stress.

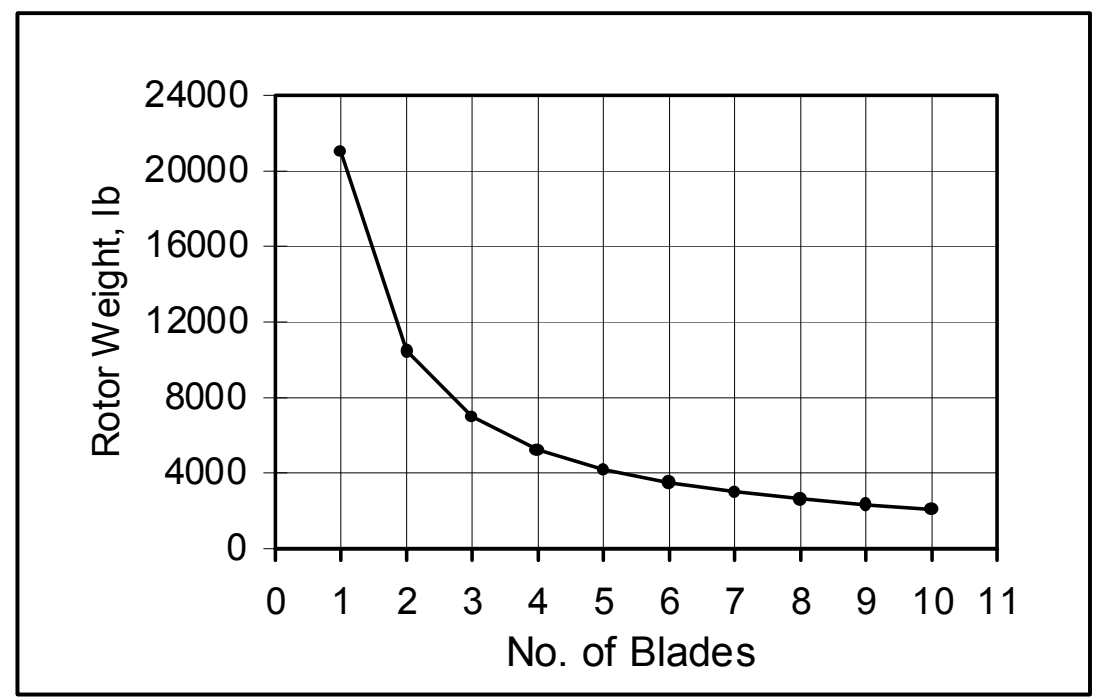

Figure 3-5. Rotor wt. vs no. of blades, $D=33 \mathrm{~m}, \sigma=0.07$

Reducing blade chord, or increasing blade aspect ratio, results in higher flexibility of all the blade modes, including torsion. The design approach was to determine the maximum aspect ratio (minimum c/R) which satisfied both design constraints. As described in Section 3.2.2 above, the stall flutter boundary is a function of both tip speed and torsional frequency. Torsional frequency is a function of blade material properties, aspect ratio, and skin thickness. Using the material properties from Section 3.1, the torsional frequencies were calculated over a range of aspect ratios and skin thicknesses. The reduced velocities were then determined at various tip speeds. The combinations that produce the maximum allowable reduced velocity of 1.5 are shown in Figure 3-6. The results shown, except for tip speed, are all nondimensional. 


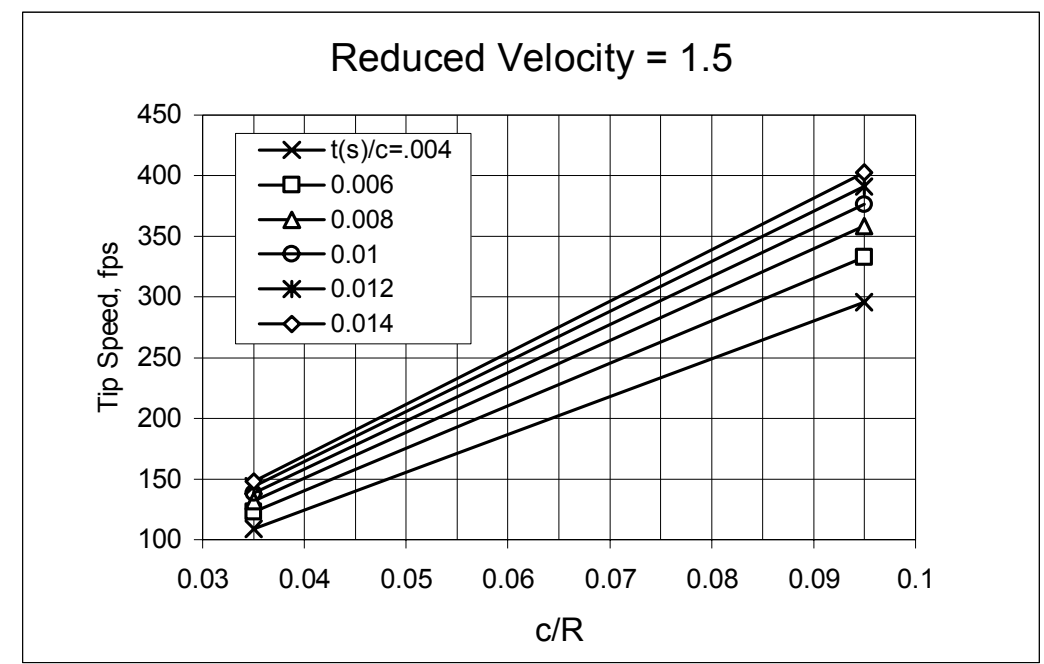

Figure 3-6. Maximum tip speed at stall flutter boundary

To find the blade static stress at the design condition, which is to survive a Class II wind $(62 \mathrm{~m} / \mathrm{s})$, an iterative 20-segment beam analysis was used to determine the stabilized deflected position of the blade assuming a steady wind. The steady-state drag coefficient used in this analysis was 1.5. To reduce the stress rise at the blade/hub interface, several plies of unidirectional fiberglass were added to the blade upper and lower surfaces out to 35\% radius. The ply thickness was tapered from the root to the $35 \%$ span location so as to produce a relatively constant stress over that region at the design condition. The results are shown in Figure 3-7 using the same blade non-dimensional parameters used in Figure 3-6.

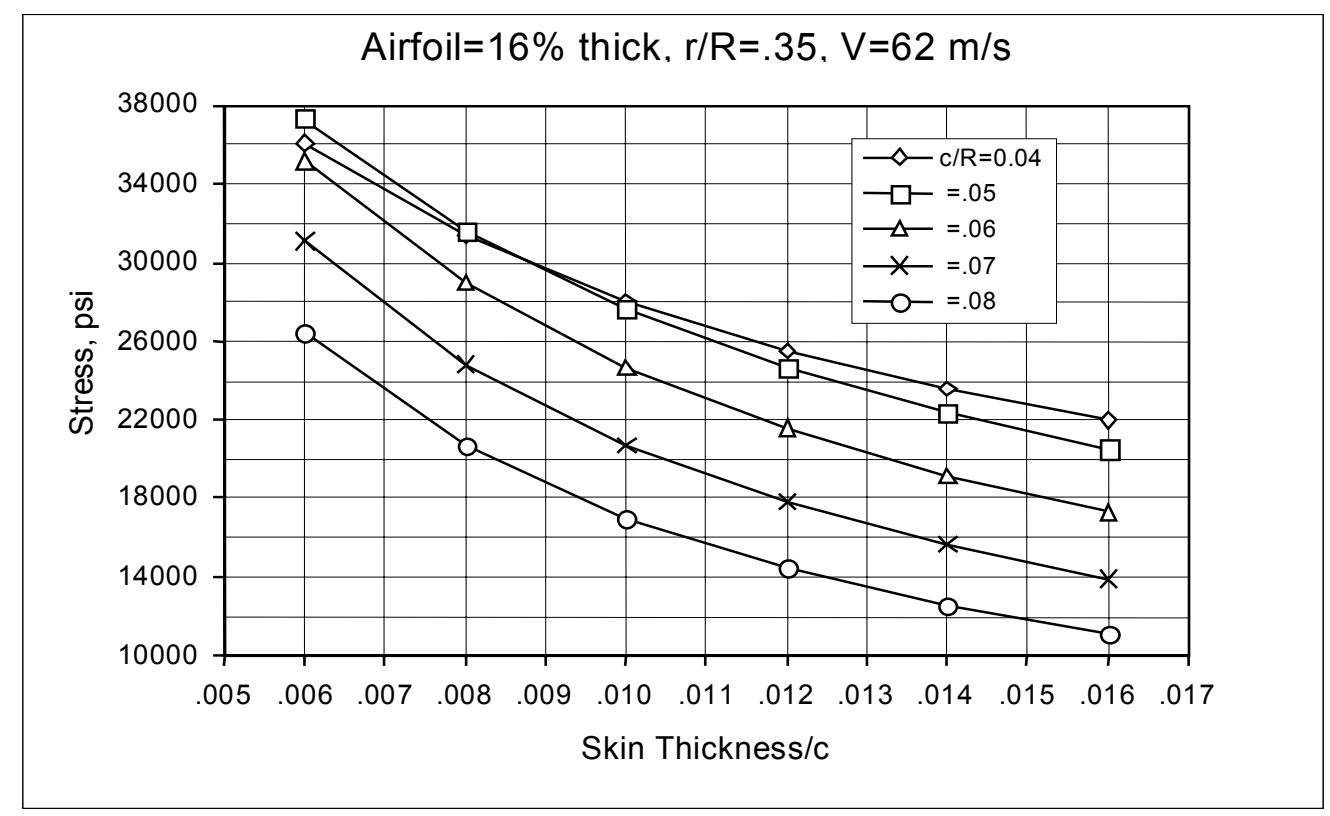

Figure 3-7. Blade flatwise static stress 
The material yield stress measured in Montana State University tests was approximately 80,000 psi as shown in Figure 3-1. Using a safety factor of 2.5 gives an allowable design stress of 32,000 psi. A stress limit of 30,000 psi was selected for this design study, and the skin thicknesses that satisfy this constraint are shown in Figure 3-8. Plotted also are the skin thicknesses for a more conservative stress level of 25,000 psi.

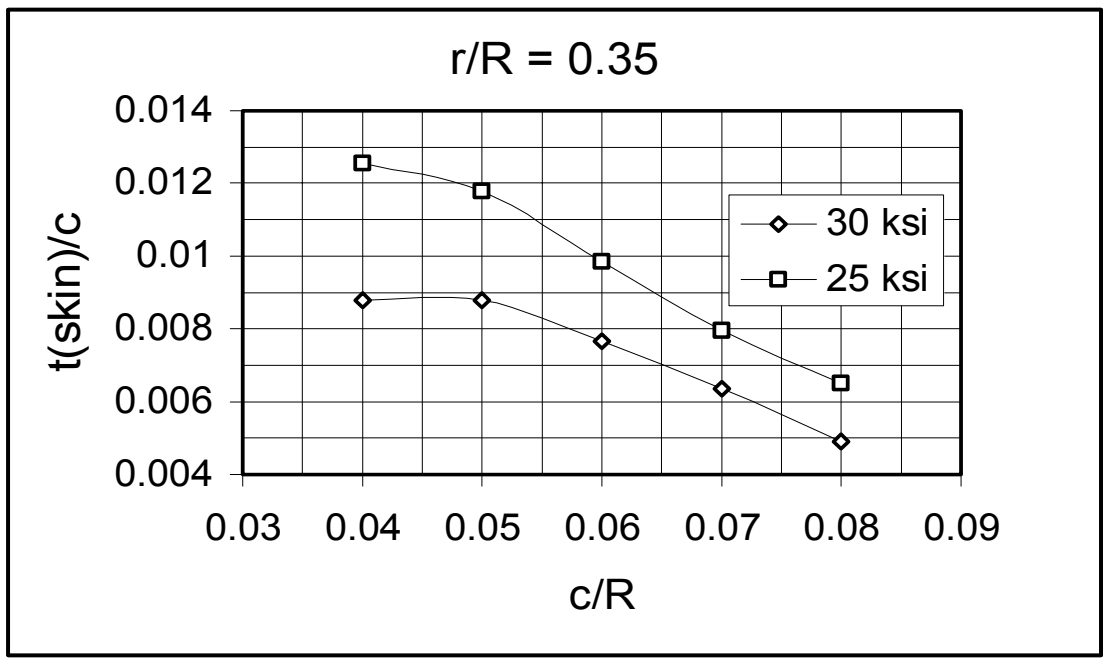

Figure 3-8. Minimum skin thickness

The minimum skin values from Figure3-8 are then matched with the corresponding values on the maximum tip speed chart, Figure 3-6, to determine the specific tip speed and non-dimensional skin thickness that satisfy the design constraints for any aspect ratio. These points are plotted versus $\mathrm{c} / \mathrm{R}$ on Figure 3-9.

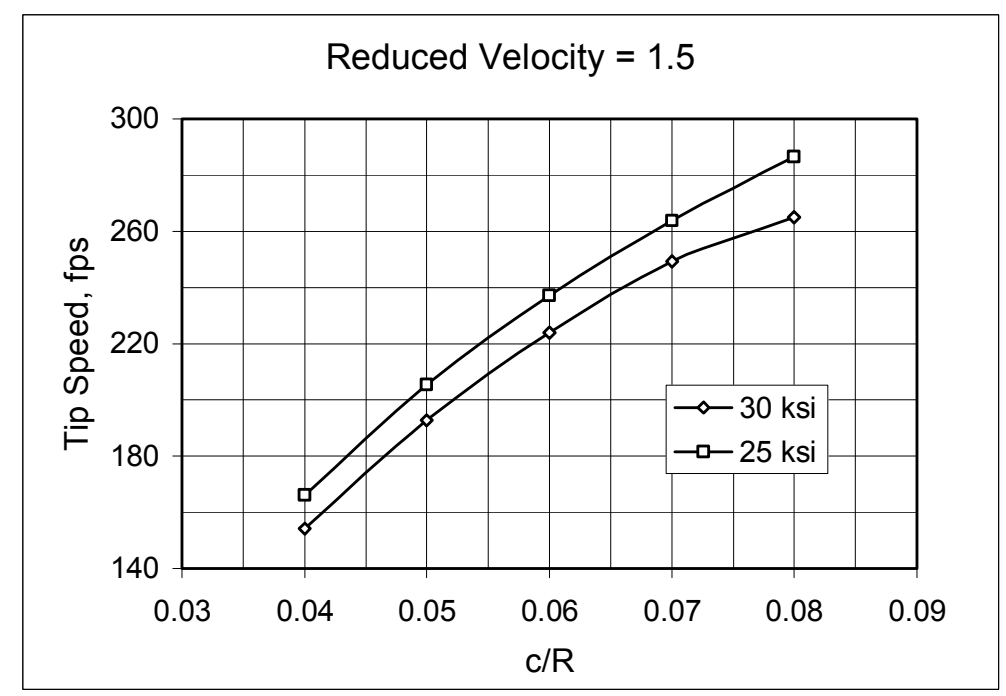

Figure 3-9. Maximum tip speed 
Table 3-1 presents the skin thickness and $\mathrm{c} / \mathrm{R}$ values for several tip speeds that satisfy the 30,000 psi static stress condition and the 1.5 reduced velocity constraint. Also shown are the rotor solidities that would result using blades with the given $\mathrm{c} / \mathrm{R}$ value.

Table 3-1. Skin Thickness and Aspect Ratio that Satisfy Design Constraints

\begin{tabular}{|c|c|c|c|c|c|}
\hline Tip Speed & $\mathrm{t}(\mathrm{s}) / \mathrm{c}$ & $\mathrm{c} / \mathrm{R}$ & $\sigma$ for $\mathrm{b}=3$ & $\sigma$ for $\mathrm{b}=4$ & $\sigma$ for $\mathrm{b}=5$ \\
\hline 160 & 0.0089 & 0.0414 & 0.0396 & 0.0527 & 0.0659 \\
\hline 180 & 0.0089 & 0.0459 & 0.0438 & 0.0584 & 0.0730 \\
\hline 200 & 0.0086 & 0.0517 & 0.0493 & 0.0658 & 0.0822 \\
\hline 220 & 0.0078 & 0.0587 & 0.0561 & 0.0748 & 0.0935 \\
\hline 240 & 0.0067 & 0.0671 & 0.0641 & 0.0854 & 0.1068 \\
\hline
\end{tabular}

The trade-off process is now reduced to selecting the combination of rotor solidity, diameter, and tip speed that produces a maximum power of $400 \mathrm{~kW}$, satisfies the design constraints defined above, and yields the lowest blade weight $/ \mathrm{kWh}$.

In the discussion that follows the rotor parameters, solidity and $\mathrm{c} / \mathrm{R}$ are used frequently. For convenience, their relationship with blade number is shown graphically in Figure 3-10.

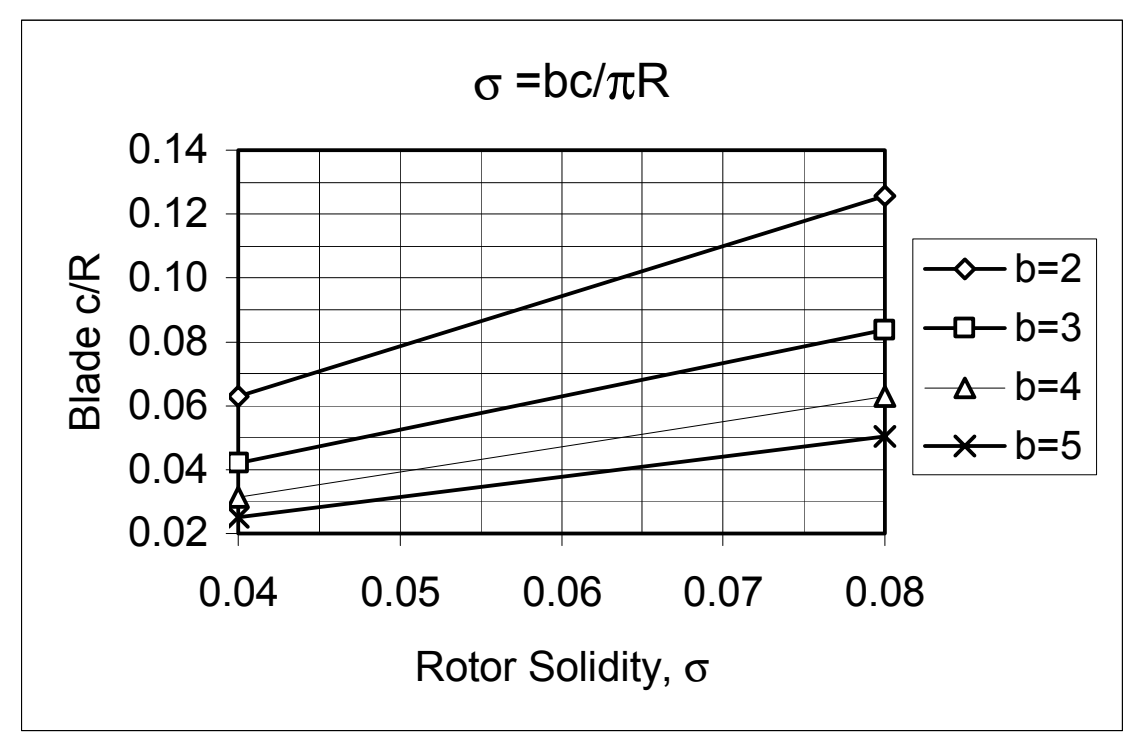

Figure 3-10. Solidity to c/R conversion

The PROP93 computer code, Reference 6, was used to calculate power, and for this study no losses were taken. Power coefficient $(\mathrm{Cp}$ ) versus tip speed ratio (TSR) curves for several solidities and pitches were generated for this trade-off study, and a sample curve set is shown in Figure 3-11.

Although blade number has a slight effect on performance, for expediency the $\mathrm{Cp}$ calculations were performed for three blades only. The improvement in $\mathrm{Cp}$ is approximately $1 \%$ per added blade at the same solidity. The Cp and TSR at maximum power can be determined by maximizing the value $(\mathrm{TS} / \mathrm{TSR})^{\wedge} 3 * \mathrm{Cp}$ for each pitch. The tip speed ratios and power coefficients at maximum power are given in Figures 3-12 and 3-13, respectively. 


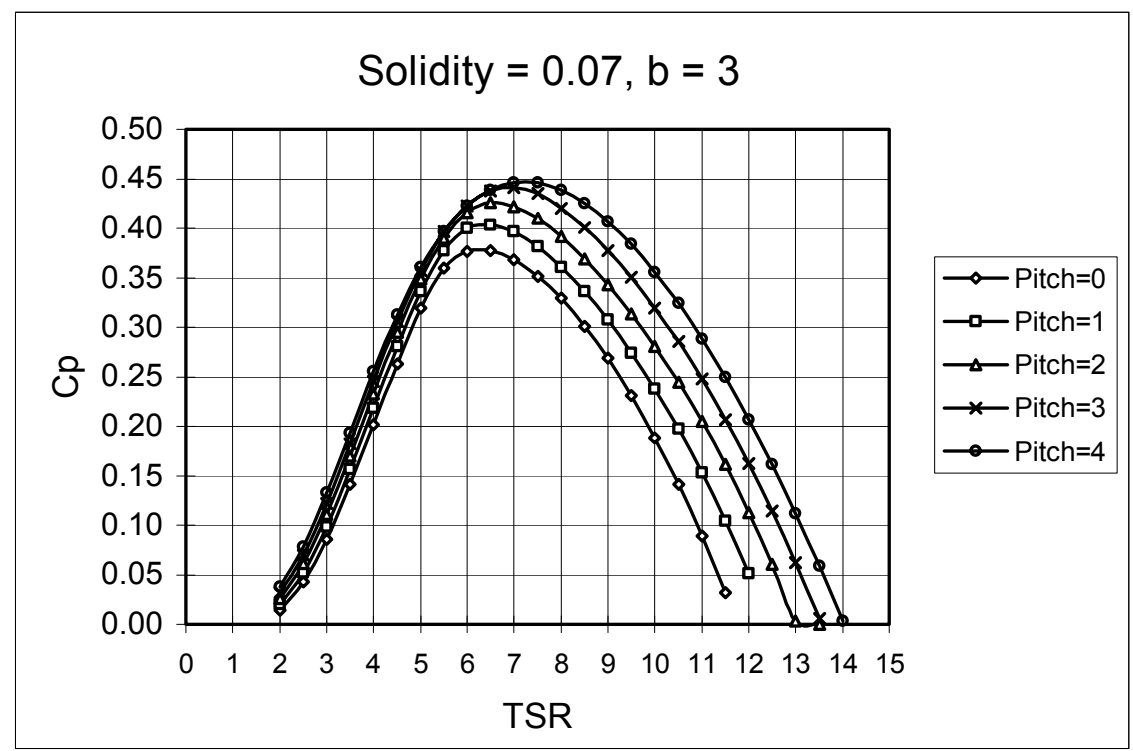

Figure 3-11. Power coefficient for 0.07 solidity

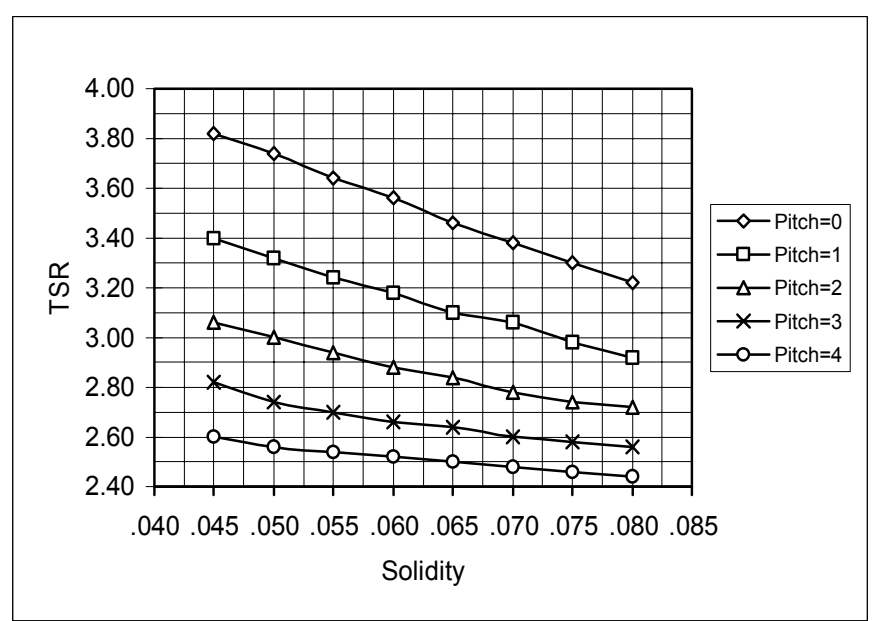

Figure 3-12. TSR at max power

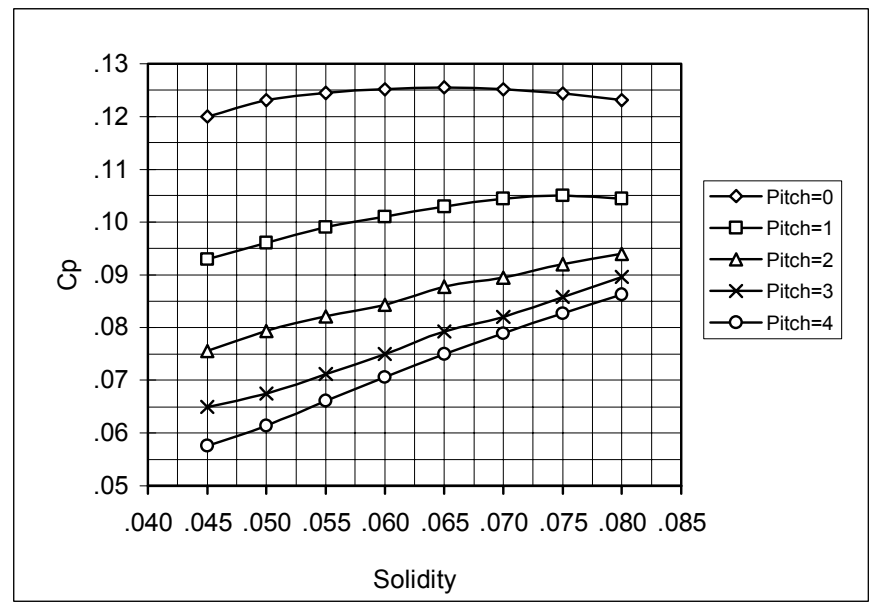

Figure 3-13. Cp at max power 
Knowing these quantities and the rated power of $400 \mathrm{~kW}$, the rotor diameter can be solved from Cp for a given tip speed. Results for four tip speeds are given in Figure 3-14.
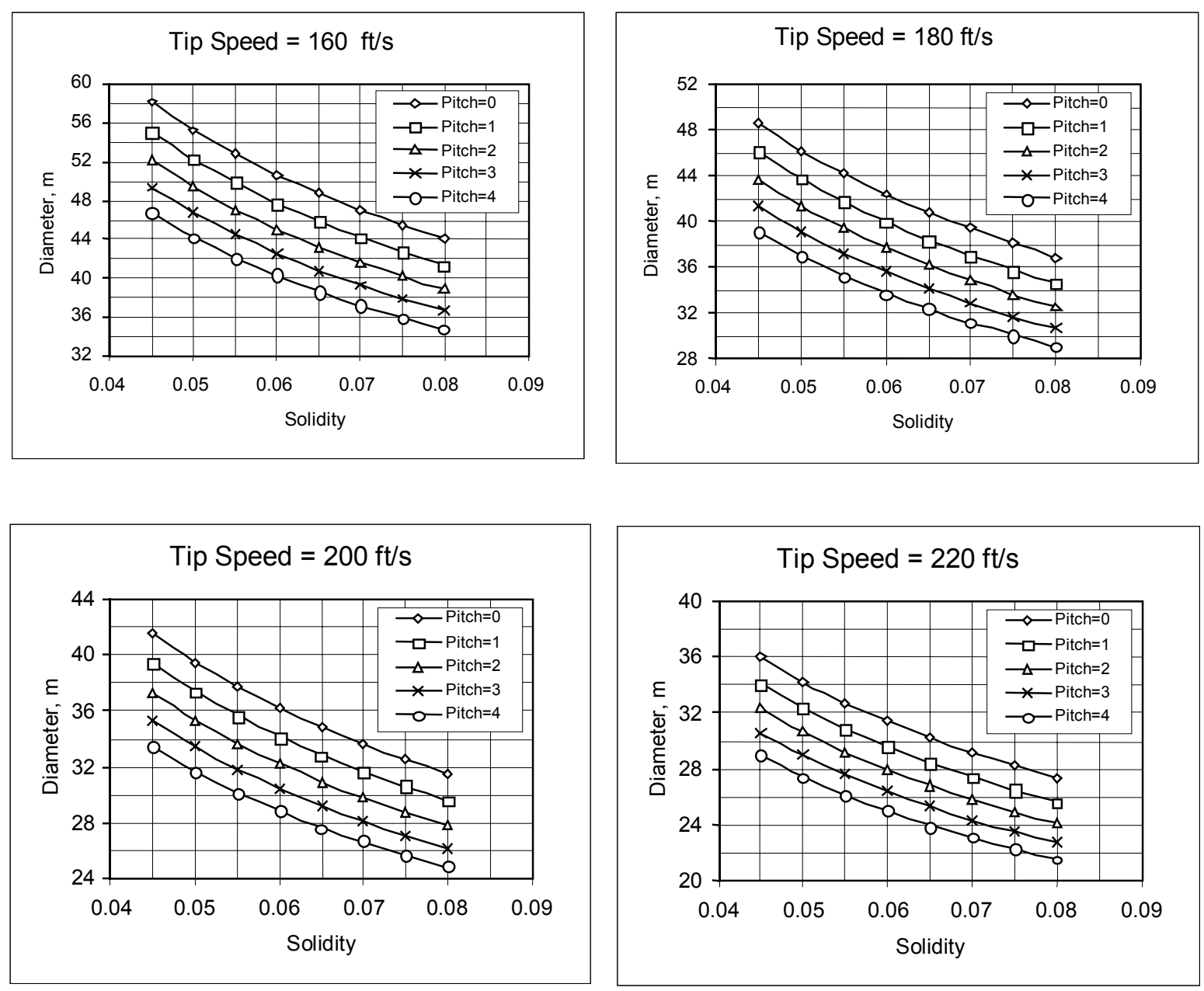

Figure 3-14. Diameter and solidity at rating of $400 \mathrm{~kW}$

The diameter solutions are determined by entering each chart at the solidity calculated (or from Figure 3-10) from the allowable $\mathrm{c} / \mathrm{R}$ obtained from Figure 3-9. These results are given in Figure 3-15. These are the final diameter solutions that produce a maximum power of $400 \mathrm{~kW}$ and satisfy the design constraints relative to stall flutter and static stress. 

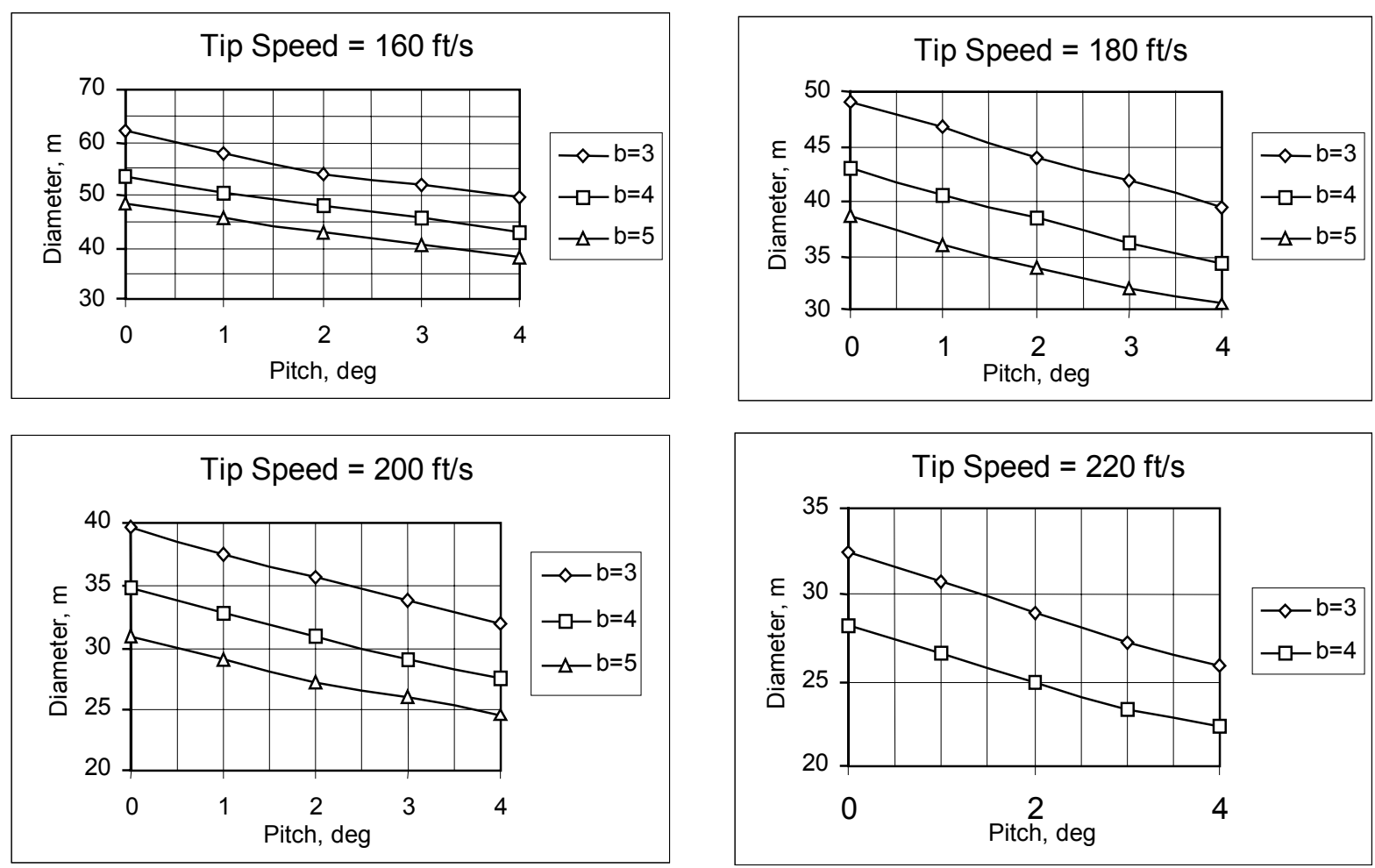

Figure 3-15. Rotor configurations satisfying design constraints

\subsubsection{Annual Energy Production}

A standard Rayleigh distribution at a mean wind speed of $5.8 \mathrm{~m} / \mathrm{s}$ at $10 \mathrm{~m}$ was used to determine annual energy production (AEP). The wind shear exponent was 0.14 , and the tower height was set at $55 \mathrm{~m}$ which gives a mean wind speed of $7.36 \mathrm{~m} / \mathrm{s}$ at hub height. The values of AEP/disk area are presented in Figure 3-16 for the selected tip speeds. 


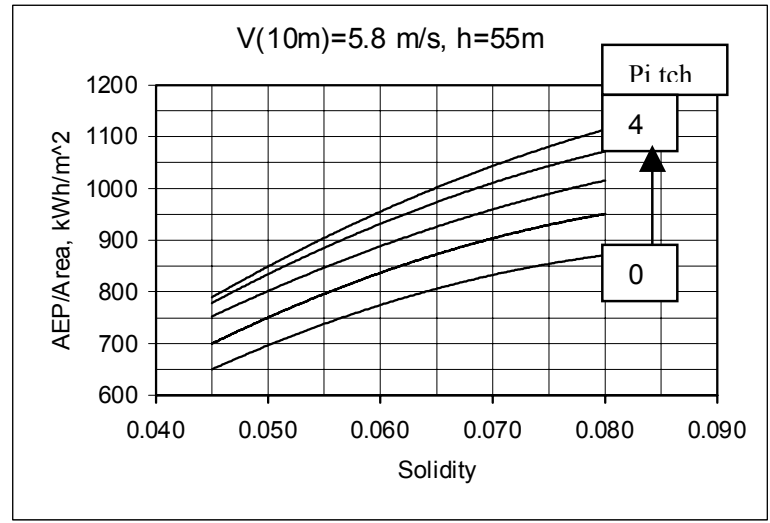

a) Tip speed $=160 \mathrm{ft} / \mathrm{s}$

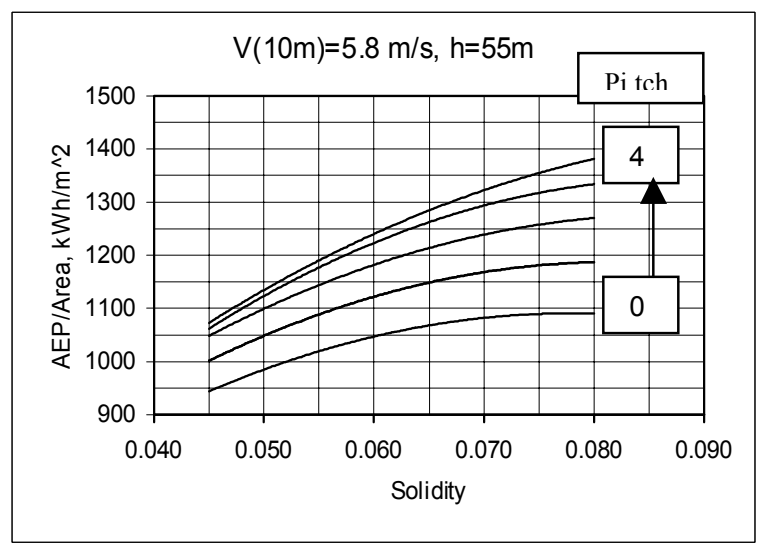

c) Tip speed $=200 \mathrm{ft} / \mathrm{s}$

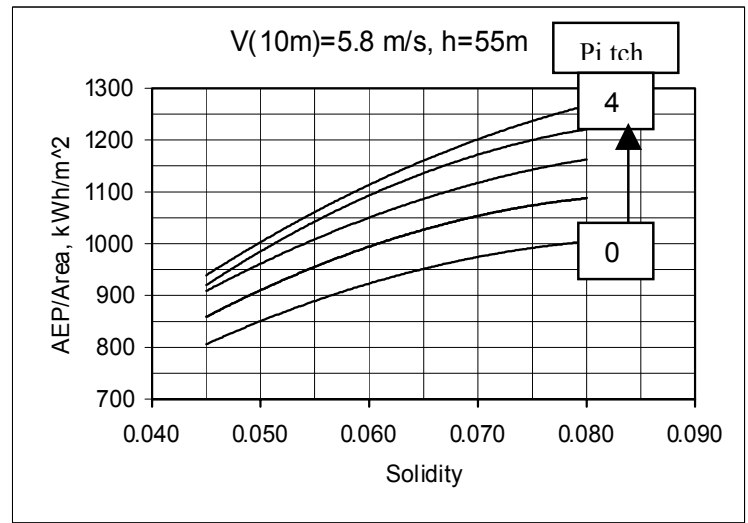

b) Tip speed $=180 \mathrm{ft} / \mathrm{s}$

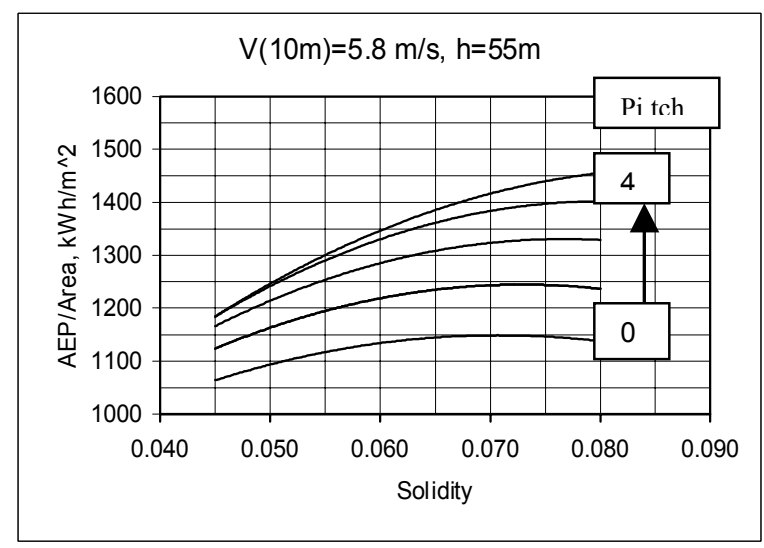

d) Tip speed $=220 \mathrm{ft} / \mathrm{s}$

Figure 3-16. AEP/disk area

\subsubsection{Blade Weight}

The weight of a constant section blade is directly proportional to its planform area times its chord at a fixed value of non-dimensional skin thickness. For the S813 airfoil, the weight parameter, $\mathrm{W} / \mathrm{Rc}^{\wedge} 2$, is given in Figure 3-17. The total blade weight, W, includes ballast installed in the leading edge cavity to provide a $35 \%$ chordwise center-of-gravity location. 


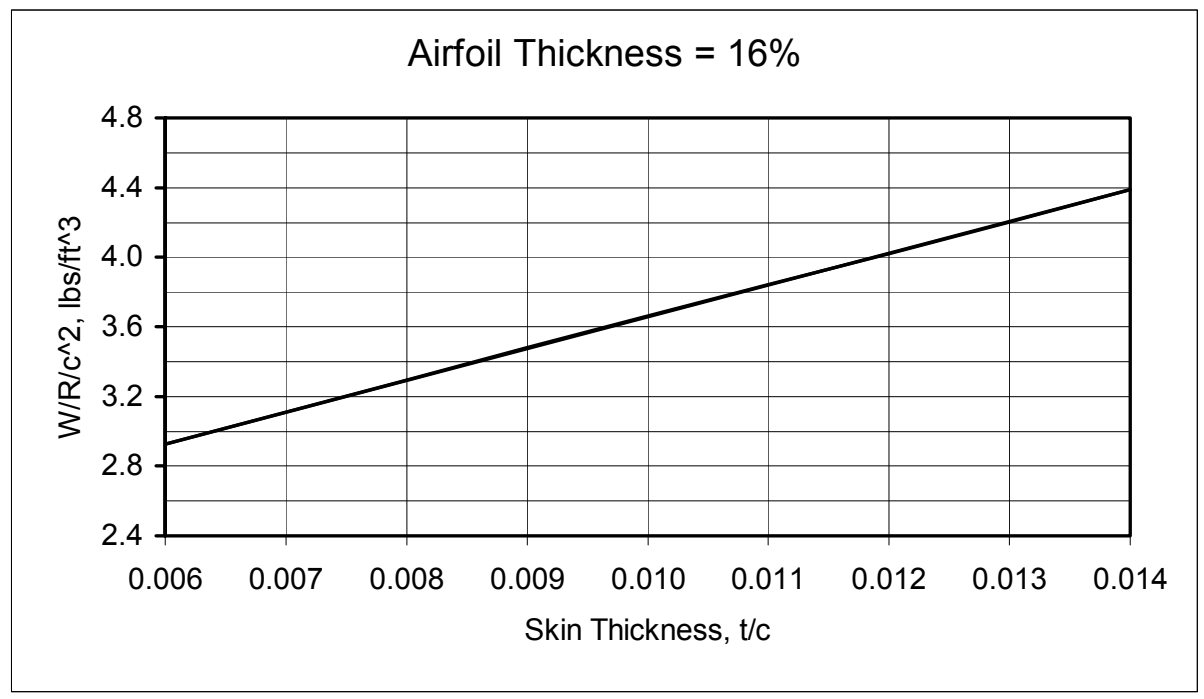

Figure 3-17. Blade weight parameter for the S813 airfoil

Combining the rotor parameters from Figure 3-15 with the generalized weight parameter from Figures 3-17 gives the total rotor weight in Figure 3-18. These results can then be combined to produce the desired figure of merit, Weight $/ \mathrm{kWh}$. These results are shown in Figure 3-19. This weight parameter can be easily converted to Cost $/ \mathrm{kWh}$ by multiplying by the pultrusion cost (for blades this size it is $\$ 2-\$ 3 / 1 b)$.
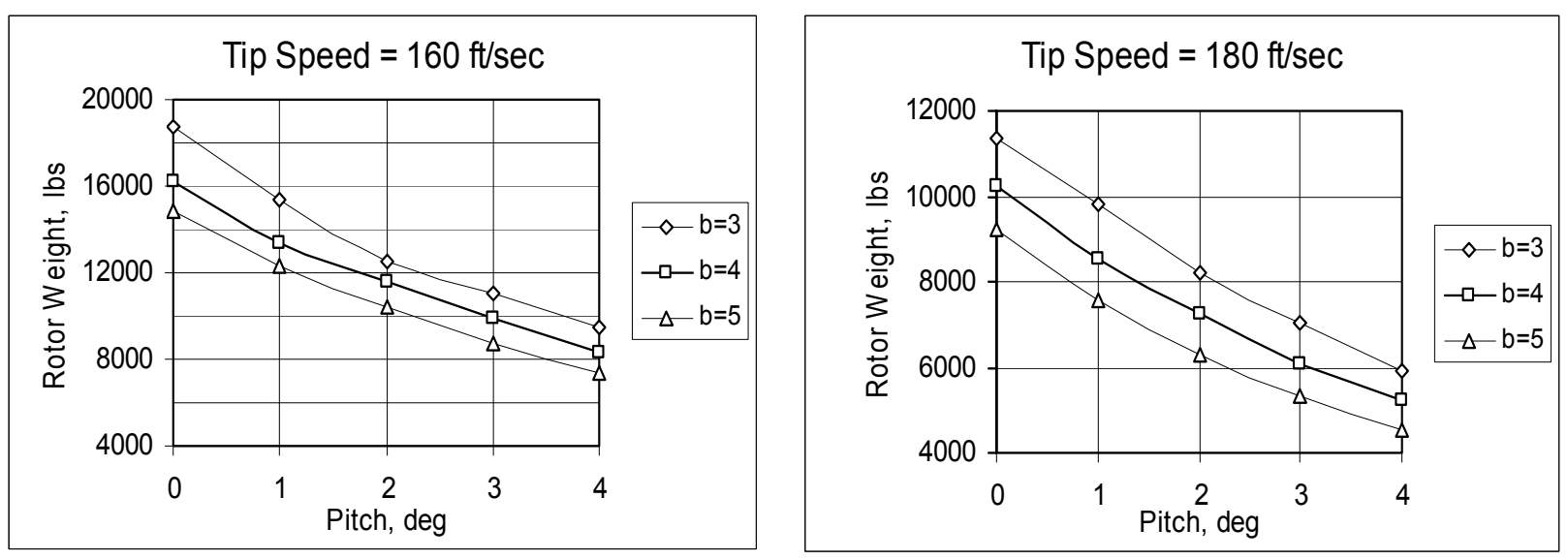

Figure 3-18. Rotor weight 

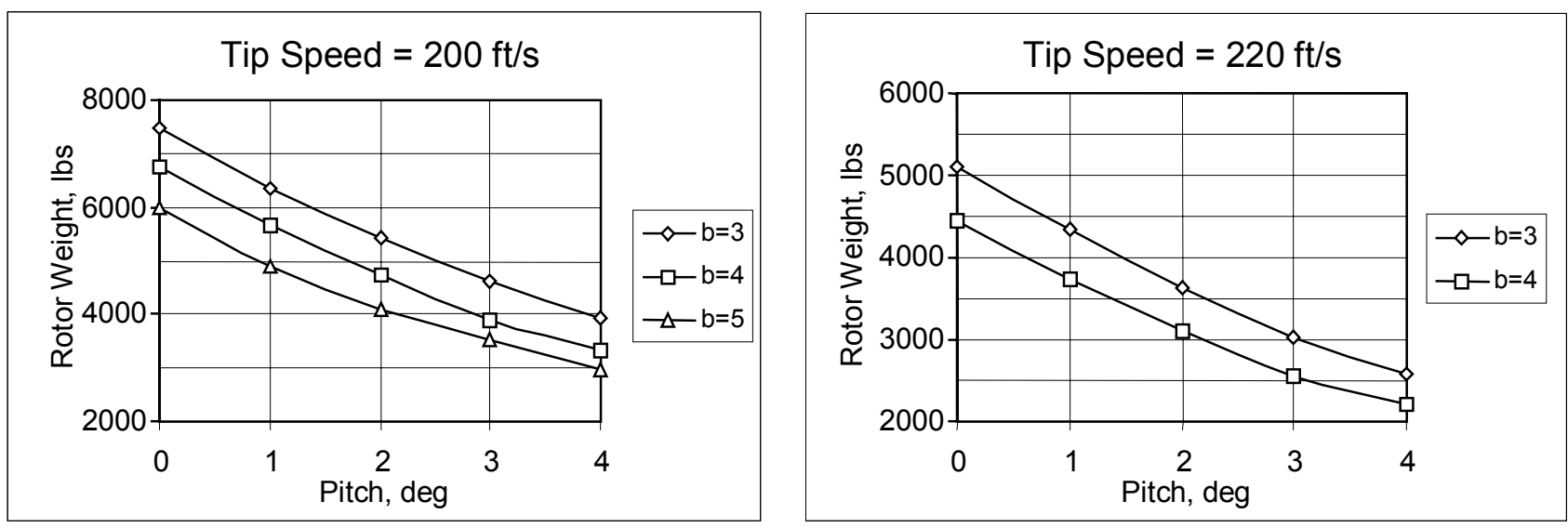

Figure 3-18. Rotor weight (concluded)
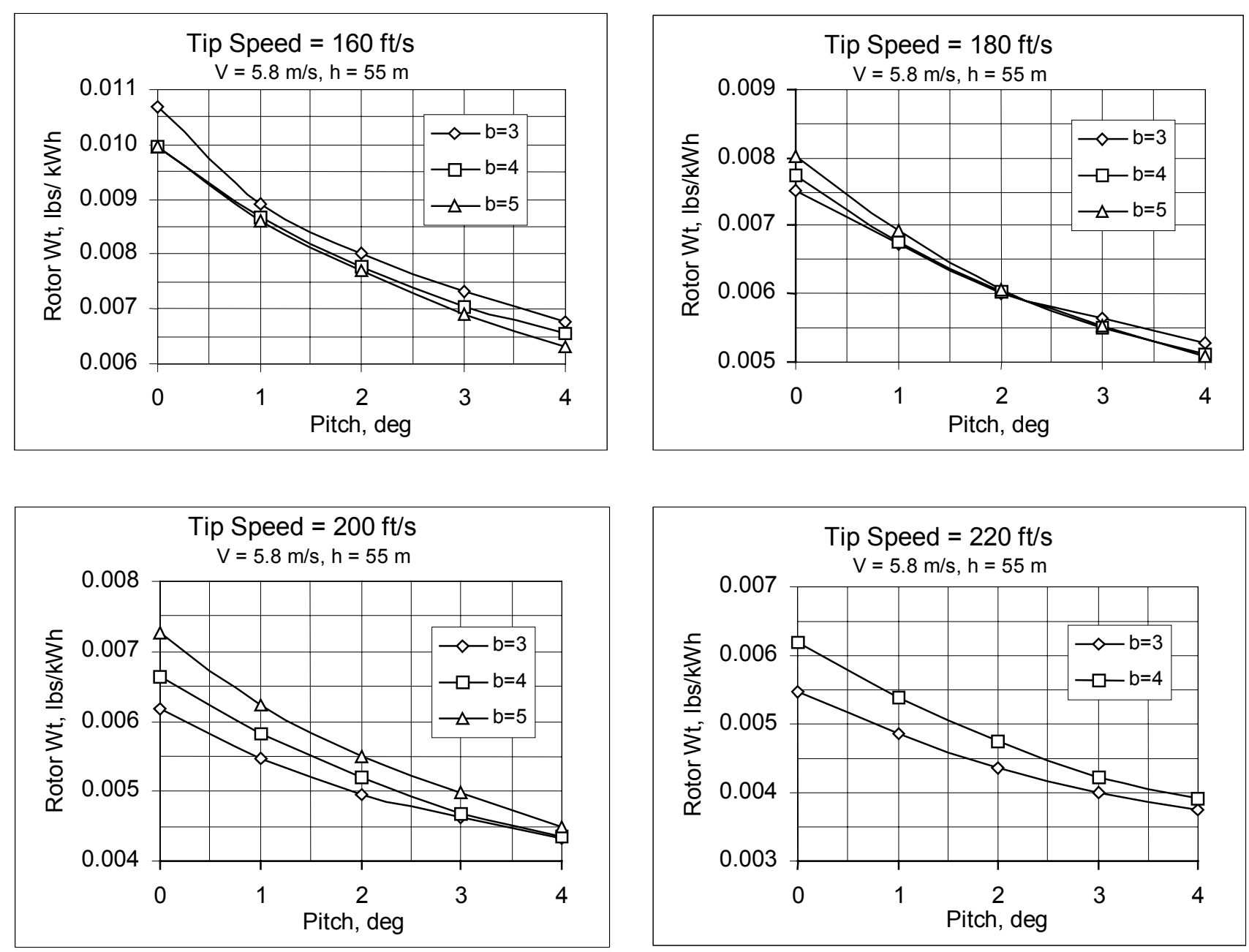

Figure 3-19. Rotor weight/kWh

At this wind site and tower height, the figures reveal clear weight lowering trends with tip speed and operating pitch. At the lowest tip speed examined, increasing number of blades shows a slight improvement in weight per kWh, however at the higher tip speeds, this trend is reversed. The improving 
trend with tip speed would be reduced or reversed at lower wind sites or for shorter towers. This would occur since the delayed rotor stall, caused by the higher tip speeds, would have less impact at lower average winds.

In selecting the final rotor parameters, there are additional issues that must be considered which may favor values not consistent with those produced by the weight optimization. These include cost of supporting components, ease of handling, maintenance, low wind site, noise, and aesthetics. We selected a design that would perform well at lower wind sites and that would more closely match the industry trend of larger diameter per rated $\mathrm{kW}$. When also considering noise and blade handling issues, low tip speed and weight per blade became important. This led to the selection of a rotor having a tip speed of $180 \mathrm{ft} / \mathrm{s}$ and five blades which yields the lowest per-blade weight. The final rotor specifications are summarized in Table 3-2.

Table 3-2. Rotor Specifications.

\begin{tabular}{|l|l|}
\hline Diameter & $33 \mathrm{~m}$ \\
\hline Solidity & 0.07 \\
\hline Number of blades & 5 \\
\hline Blade chord & $0.726 \mathrm{~m}$ \\
\hline Blade c/R & 0.044 \\
\hline Blade skin, $\mathrm{t}(\mathrm{s}) / \mathrm{c}$ & 0.012 \\
\hline Airfoil & $\mathrm{S} 813$ \\
\hline Tip Speed & $180 \mathrm{ft} / \mathrm{s}$ \\
\hline Rated power & $400 \mathrm{~kW}$ \\
\hline Blade weight & $1224 \mathrm{lbs}$ \\
\hline
\end{tabular}

Details of the blade weight and stiffness characteristics are listed in Table 3-3.

Table 3-3. Blade Section Characteristics.

\begin{tabular}{|c|c|c|c|c|c|r|r|}
\hline \multicolumn{2}{|c|}{ Radial Station, $r / R:$} & $\mathrm{w}$ & $\mathrm{El}$ (flat) & $\mathrm{El}(\mathrm{edge})$ & $\mathrm{GJ}$ & $\mathrm{c} / \mathrm{l}$ (flat) & \multicolumn{1}{c|}{$\mathrm{p}$} \\
\hline From: & To: & $\mathrm{lb} / \mathrm{in}$ & $\mathrm{lb}-\mathrm{in}^{\wedge} 2$ & $\mathrm{lb}-\mathrm{in}^{\wedge} 2$ & $\mathrm{lb}-\mathrm{in}{ }^{\wedge} 2$ & $1 / \mathrm{in}^{\wedge} 3$ & $\mathrm{lb}-\mathrm{sec}^{\wedge} 2$ \\
\hline 0.023 & 0.0615 & 3.331 & $1.07 \mathrm{E}+09$ & $6.51 \mathrm{E}+09$ & $8.16 \mathrm{E}+08$ & 0.0130 & 0.440 \\
\hline 0.062 & 0.1000 & 2.961 & $8.27 \mathrm{E}+08$ & $5.95 \mathrm{E}+09$ & $6.72 \mathrm{E}+08$ & 0.0154 & 0.412 \\
\hline 0.100 & 0.1500 & 2.772 & $7.13 \mathrm{E}+08$ & $5.67 \mathrm{E}+09$ & $6.00 \mathrm{E}+08$ & 0.0160 & 0.398 \\
\hline 0.150 & 0.2000 & 2.401 & $5.11 \mathrm{E}+08$ & $5.11 \mathrm{E}+09$ & $4.63 \mathrm{E}+08$ & 0.0205 & 0.371 \\
\hline 0.200 & 0.2500 & 2.220 & $4.21 \mathrm{E}+08$ & $4.84 \mathrm{E}+09$ & $3.98 \mathrm{E}+08$ & 0.0231 & 0.358 \\
\hline 0.250 & 0.3000 & 2.037 & $3.36 \mathrm{E}+08$ & $4.56 \mathrm{E}+09$ & $3.33 \mathrm{E}+08$ & 0.0265 & 0.346 \\
\hline 0.300 & 0.3500 & 1.849 & $2.55 \mathrm{E}+08$ & $4.28 \mathrm{E}+09$ & $2.67 \mathrm{E}+08$ & 0.0323 & 0.332 \\
\hline 0.350 & 1.0000 & 1.666 & $1.82 \mathrm{E}+08$ & $4.01 \mathrm{E}+09$ & $2.05 \mathrm{E}+08$ & 0.0389 & 0.321 \\
\hline
\end{tabular}

\subsection{Inboard Stiffener Design}

Straight blades that have a uniform section over the full span experience a significant stress rise at the hub interface under static loading. This is less severe under rotating conditions due to the benefits of centrifugal stiffening. To alleviate the stress rise, a series of unidirectional fiberglass plies are bonded to the upper and lower surfaces of the blade from the root out to $35 \%$ radius. Plies are dropped off at each 
$5 \%$ radial interval providing a smooth transition from the thick root pad at the hub to the base blade at $35 \%$. The chord dimension of the plies is $55 \%$ of the blade chord. Table 3-4 presents the ply dimensions for the $33 \mathrm{~m}$-rotor blade. The dimensions shown are for each blade surface.

Table 3-4. Inboard Stiffener Dimensions.

\begin{tabular}{|l|r|r|r|r|r|r|r|}
\hline & Pad & Ply \# 1 & Ply \# 2 & Ply \# 3 & Ply \# 4 & Ply \# 5 & Ply \# 6 \\
\hline Starts at, \%R & 0.023 & 0.062 & 0.100 & 0.150 & 0.200 & 0.250 & 0.300 \\
\hline Starts at, m & 0.38 & 1.01 & 1.65 & 2.48 & 3.30 & 4.13 & 4.95 \\
\hline Thickness, t/c & 0.0274 & 0.0213 & 0.0182 & 0.0121 & 0.0091 & 0.0061 & 0.0030 \\
\hline Thickness, mm & 19.83 & 15.42 & 13.17 & 8.75 & 6.59 & 4.42 & 2.17 \\
\hline Ply chord, mm & 398 & 398 & 398 & 398 & 398 & 398 & 398 \\
\hline
\end{tabular}

The blade flatwise stress distribution for the $62 \mathrm{~m} / \mathrm{s}$ static wind condition is given in Figure 3-20. The curve demonstrates that the skin stress is well below the maximum design level of 30,000 psi. The blade bending moment and deflection for this same wind condition are shown in Figures 3-21 and 3-22, respectively.

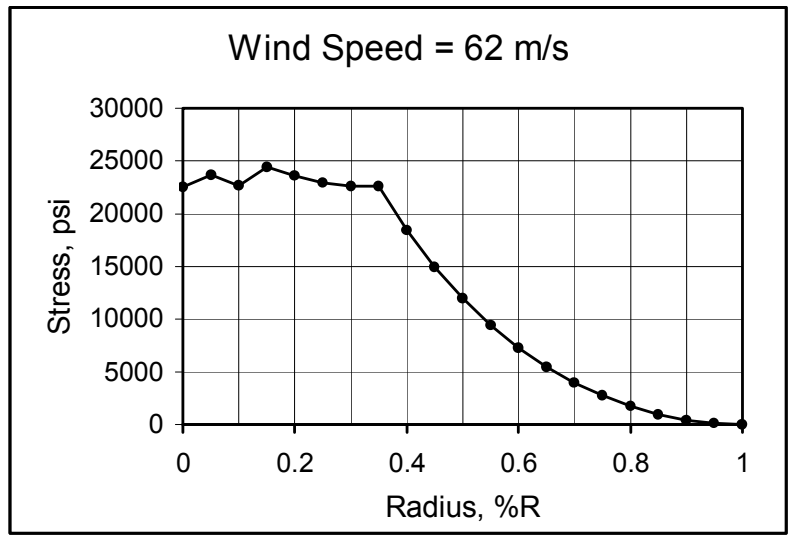

Figure 3-20. Static stress, $D=33 m . c=0.726 m$

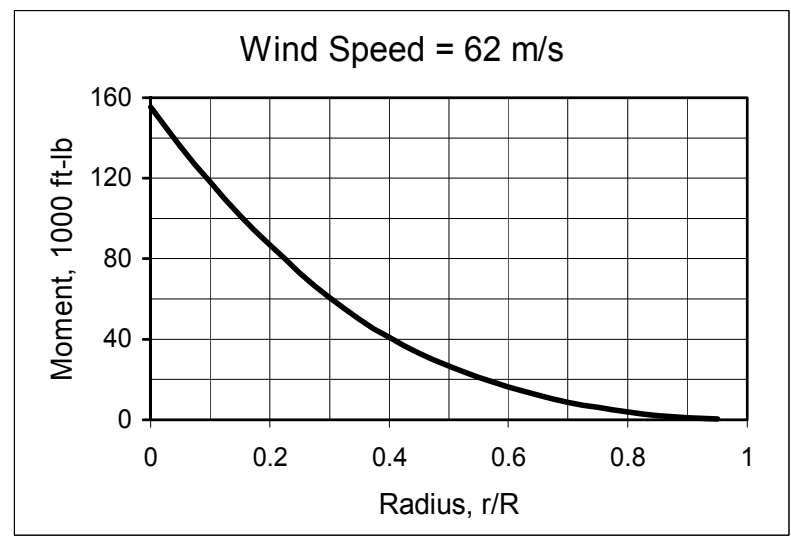

Figure 3-21. Blade static flatwise moment

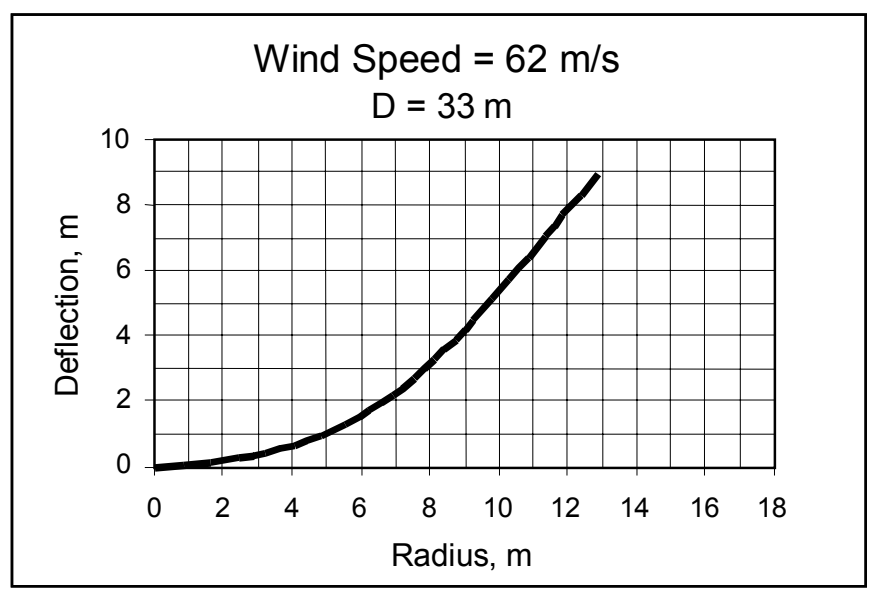

Figure 3-22. Blade static deflection 


\subsection{Performance Comparison to Twisted-Tapered Blade}

It is well established that rotors with straight blades are less efficient than those having twist and taper. A comparison of the performance of the selected pultruded-blade rotor with that of a rotor having $10 \mathrm{deg}$ twisted and 3 to 1 tapered blades is shown in Figures 3-23 to 3-25. The same diameter, pitch, and solidity (based upon c at $75 \% \mathrm{R}$ ) was used for both rotors.

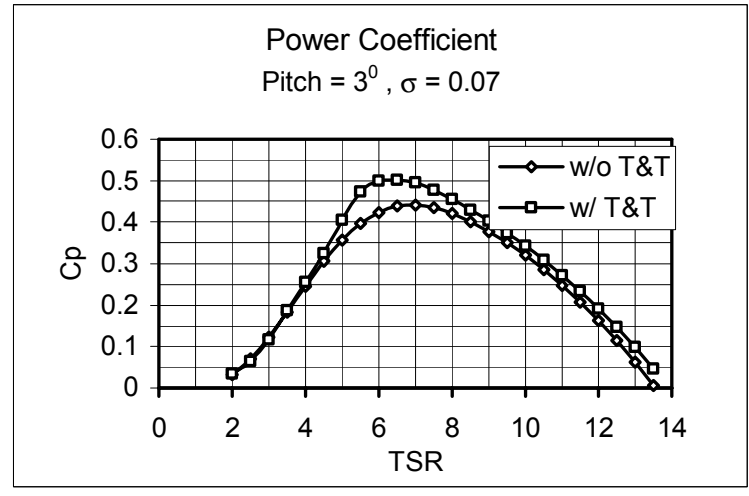

Figure 3-23. Power coefficient

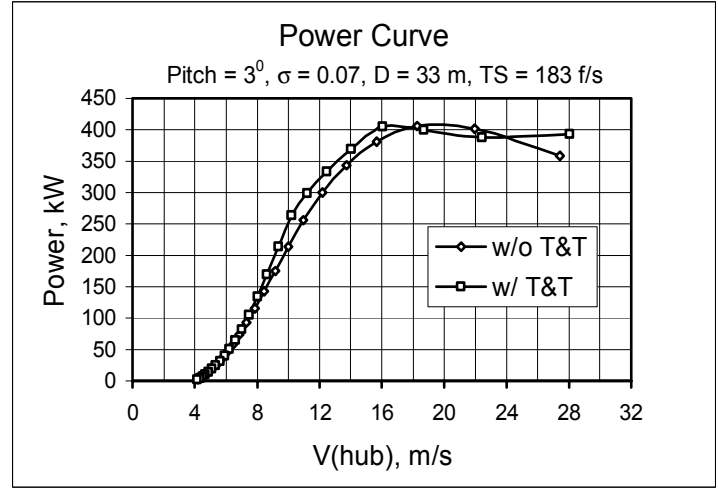

Figure 3-24. Power curve

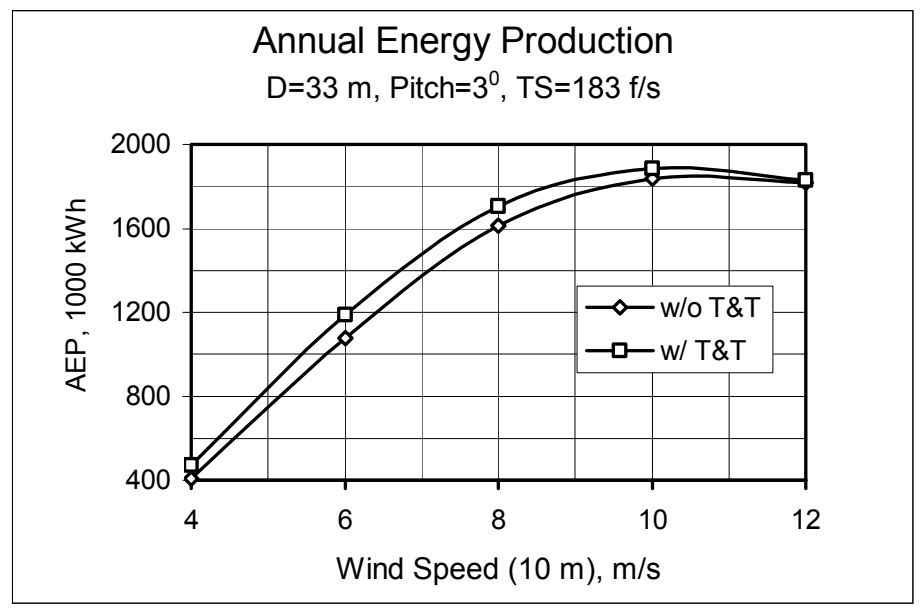

Figure 3-25. Annual energy production

The energy production results presented in Figure 3-25 assume no rotor losses and a wind shear exponent of 0.14 . The improvement of the twisted-tapered rotor is approximately $10 \%$ at an average wind speed of $6 \mathrm{~m} / \mathrm{s}$. The major impact projected for pultruded blades is to reduce weight and cost over conventional stiff rotors used in the industry. That comparison was made in the related study, Reference 1, and is summarized later in this report. 


\section{Scaled Rotor}

The scope of this subcontract did not encompass full-scale hardware. To simulate the operating characteristics and performance of the utility-grade rotor described in the previous section, a scaled-down rotor was fabricated and tested. An available $92 \mathrm{~kW}$ turbine installed in Palm Springs was selected to be used as the test platform. This was a system that was operated with a downwind two-bladed flexible rotor having a diameter of $15.8 \mathrm{~m}$. There were two major modifications required to the head assembly before the scaled rotor could be tested: 1) the low-speed brake that was installed on the transmission shaft between the transmission and hub could not be used because the exposed shaft was needed to install instrumentation sliprings, and 2) the step-up ratio of the transmission had to be changed to provide the necessary full-scale rotor tip speed.

\subsection{Blade Design}

The objective of the scaled-rotor test was to simulate the aeroelastic behavior and performance of the fullscale design. Except for the effects of gravity and Reynolds number, this can by achieved by 1) operating at the same tip speed, and 2) fabricating the blade from the same materials as the full-scale blade and reducing all dimensions of the airfoil by the scale factor. The scale factor is the ratio of the full-scale diameter to the test-rotor diameter. In order to achieve a rotor speed that would produce the same fullscale tip speed, the transmission manufacturer, Nuttall Gear, provided a replacement high speed pinion gear that increased the step-up ratio from 1:19 to 1:26.4. This resulted in a rotor shaft speed of $69 \mathrm{rpm}$. The maximum diameter allowed without exceeding the transmission torque rating was $15.4 \mathrm{~m}(51 \mathrm{ft})$. This produced a tip speed of $184 \mathrm{ft} / \mathrm{s}$ which was only slightly above the selected full-scale value.

\subsubsection{Scaling Principles}

To simulate the full-scale structural response to a given wind condition, the scaled blade bending frequencies relative to its rotor speed, and its mode shapes, must be the same. When developing the equations of motion for the various bending modes of the blade, it is possible to write them in nondimensional terms. If the coefficients of the independent variable terms and the non-dimensional aerodynamic forcing function are the same for both rotor sizes, then the solutions to the equations, i.e. the blade responses, will be the same. It can be shown that the frequency of any bending mode, when divided by the rotational speed, is a function of the tip speed, the blade aspect ratio, the airfoil and skin thickness ratios, and the material properties. These quantities are the same for both sizes, thus producing the same non-dimensional frequencies. The aerodynamic term in the equation of motion is a function of aspect ratio, tip speed ratio, airfoil data, and blade pitch. These are also the same for both sizes and therefore the aeroelastic responses will be the same. Small differences in the airfoil data could exist due to Reynolds number effect, which may have a small effect on blade response. The scaled blade will therefore be aeroelastically similar to the full-scale blade, and any design-related problems experienced with the scaled rotor would translate directly to the same problem with the full-scale system. Similarly, favorable operating characteristics demonstrated with the scaled design would be expected to carry over to the fullscale system. 


\subsubsection{Scaled-Rotor Specifications}

Scaling down the full-scale blade dimensions by the diameter ratio yields the scaled-rotor specifications listed in Table 4-1.

Table 4-1. Scaled-Rotor Specifications.

\begin{tabular}{|l|l|}
\hline Diameter & $15.5 \mathrm{~m}$ \\
\hline Solidity & 0.07 \\
\hline Number of blades & 5 \\
\hline Blade chord & $0.343 \mathrm{~m}$ \\
\hline Blade c/R & 0.044 \\
\hline Blade skin, t(s)/c & 0.01 \\
\hline Airfoil & $\mathrm{S} 822$ \\
\hline Tip Speed & $184 \mathrm{ft} / \mathrm{sec}$ \\
\hline Rated power & $85 \mathrm{~kW}$ \\
\hline Blade weight & $128 \mathrm{lbs}$ \\
\hline
\end{tabular}

Material properties measured for the pultruded scaled blade were slightly different than those used in the trade-off study listed in Section 3.1. The initial design assumed a shear modulus of 1.5 million psi which resulted in a lower skin thickness requirement. The measured torsional frequency of the pultruded blade was approximately $20 \%$ less than predicted which indicates the shear modulus was significantly lower than 1.5 million. Using the actual torsional frequency yields a reduced velocity value of 1.95 , which is above the desired design level of 1.5. To increase the shear modulus, thus lowering the reduced velocity, the percentage of $+/-45$ deg fiber would be increased. This is accompanied by a reduction in the 0 deg fiber content. This was done to achieve the properties listed in Section 3.1. The bending and shear moduli used for the scaled blade were 3.79 million psi and 0.8 million psi, respectively. The detailed structural properties are presented in Table 4-2.

Table 4-2. Scaled Blade Structural Properties.

\begin{tabular}{|c|c|c|c|c|c|c|c|}
\hline \multicolumn{2}{|c|}{ Radial Station, $\mathrm{r} / \mathrm{R}$} & $\mathrm{w}$ & $\mathrm{El}$ (flat) & $\mathrm{El}(\mathrm{edge})$ & $\mathrm{GJ}$ & $\mathrm{c} / \mathrm{l}(\mathrm{flat})$ & $\mathrm{I}$ sub $\mathrm{p}$ \\
\hline From: & To: & lb/in & lb-in^2 & lb-in^2 & lb-in^2 & $1 /$ in^3 & lb-sec 2 \\
\hline 0.023 & 0.062 & 1.190 & $1.45 \mathrm{E}+08$ & $4.82 \mathrm{E}+08$ & $8.02 \mathrm{E}+07$ & 0.0639 & 0.0296 \\
\hline 0.062 & 0.100 & 0.532 & $2.51 \mathrm{E}+07$ & $2.60 \mathrm{E}+08$ & $1.86 \mathrm{E}+07$ & 0.2214 & 0.0176 \\
\hline 0.100 & 0.150 & 0.508 & $2.25 \mathrm{E}+07$ & $2.52 \mathrm{E}+08$ & $1.67 \mathrm{E}+07$ & 0.2304 & 0.0173 \\
\hline 0.150 & 0.200 & 0.463 & $1.78 \mathrm{E}+07$ & $2.37 \mathrm{E}+08$ & $1.31 \mathrm{E}+07$ & 0.2784 & 0.0166 \\
\hline 0.200 & 0.250 & 0.440 & $1.55 \mathrm{E}+07$ & $2.29 \mathrm{E}+08$ & $1.13 \mathrm{E}+07$ & 0.3059 & 0.0162 \\
\hline 0.250 & 0.300 & 0.418 & $1.34 \mathrm{E}+07$ & $2.21 \mathrm{E}+08$ & $9.54 \mathrm{E}+06$ & 0.3389 & 0.0159 \\
\hline 0.300 & 0.350 & 0.394 & $1.13 \mathrm{E}+07$ & $2.13 \mathrm{E}+08$ & $7.75 \mathrm{E}+06$ & 0.3897 & 0.0155 \\
\hline 0.350 & 1.000 & 0.372 & $9.34 \mathrm{E}+06$ & $2.06 \mathrm{E}+08$ & $6.02 \mathrm{E}+06$ & 0.4434 & 0.0152 \\
\hline
\end{tabular}

\subsection{Performance}

Preliminary performance estimates were made for the PSE Scaled Rotor using $7.77 \mathrm{~m}(25.5 \mathrm{ft})$ radius, $69 \mathrm{rpm}, 0^{\circ}$ coning, $3^{\circ}$ pitch, and 5 untwisted, constant chord blades with smooth S822 airfoils and $0.343 \mathrm{~m}$ (13.46 in) chord. Since Ohio State University (OSU) wind tunnel data were available for the S813 airfoil, its aerodynamic data was substituted for the S822. The two airfoils are nearly identical, with the S813 being tailored to higher Reynolds numbers in the range seen by the PSE full-scale design. These estimates were expected to be somewhat optimistic because no stiffener degradation was included for the 
inboard $35 \%$ of the blades. This model met the design goal of $80 \mathrm{~kW}$ peak power. The power curve calculations are presented in Table 4-3 for both sea level and Cabazon, CA test site densities, and the curves are plotted in Figures 4-1 and 4-2.

Table 4-3: Power Curves, PSE Scaled Rotor.

\begin{tabular}{|c|c|c|c|c|}
\hline \multicolumn{5}{|c|}{ S813: OSU } \\
\hline $\mathrm{V}$ & \multicolumn{2}{|c|}{ Sea Level: $1.225 \mathrm{~kg} / \mathrm{m}^{\wedge} 3$} & \multicolumn{2}{|c|}{ Cabazon: $1.164 \mathrm{~kg} / \mathrm{m}^{\wedge} 3$} \\
\hline$(\mathrm{m} / \mathrm{s})$ & $2 \mathrm{deg}$ & 3 deg & 2 deg & $3 \mathrm{deg}$ \\
\hline & & & & \\
\hline 4 & -0.6 & -0.1 & -0.6 & -0.1 \\
\hline 6 & 8.1 & 9.1 & 7.7 & 8.6 \\
\hline 8 & 24.3 & 25.6 & 23.1 & 24.3 \\
\hline 10 & 44.0 & 45.3 & 41.8 & 43.0 \\
\hline 12 & 59.2 & 61.7 & 56.2 & 58.6 \\
\hline 14 & 69.6 & 74.3 & 66.1 & 70.6 \\
\hline 16 & 73.3 & 80.9 & 69.6 & 76.9 \\
\hline 18 & 68.8 & 80.9 & 65.4 & 76.9 \\
\hline 20 & 58.3 & 73.6 & 55.4 & 69.9 \\
\hline 22 & 46.7 & 63.6 & 44.4 & 60.4 \\
\hline 24 & 35.1 & 52.2 & 33.4 & 49.6 \\
\hline 26 & 27.2 & 43.6 & 25.9 & 41.4 \\
\hline
\end{tabular}

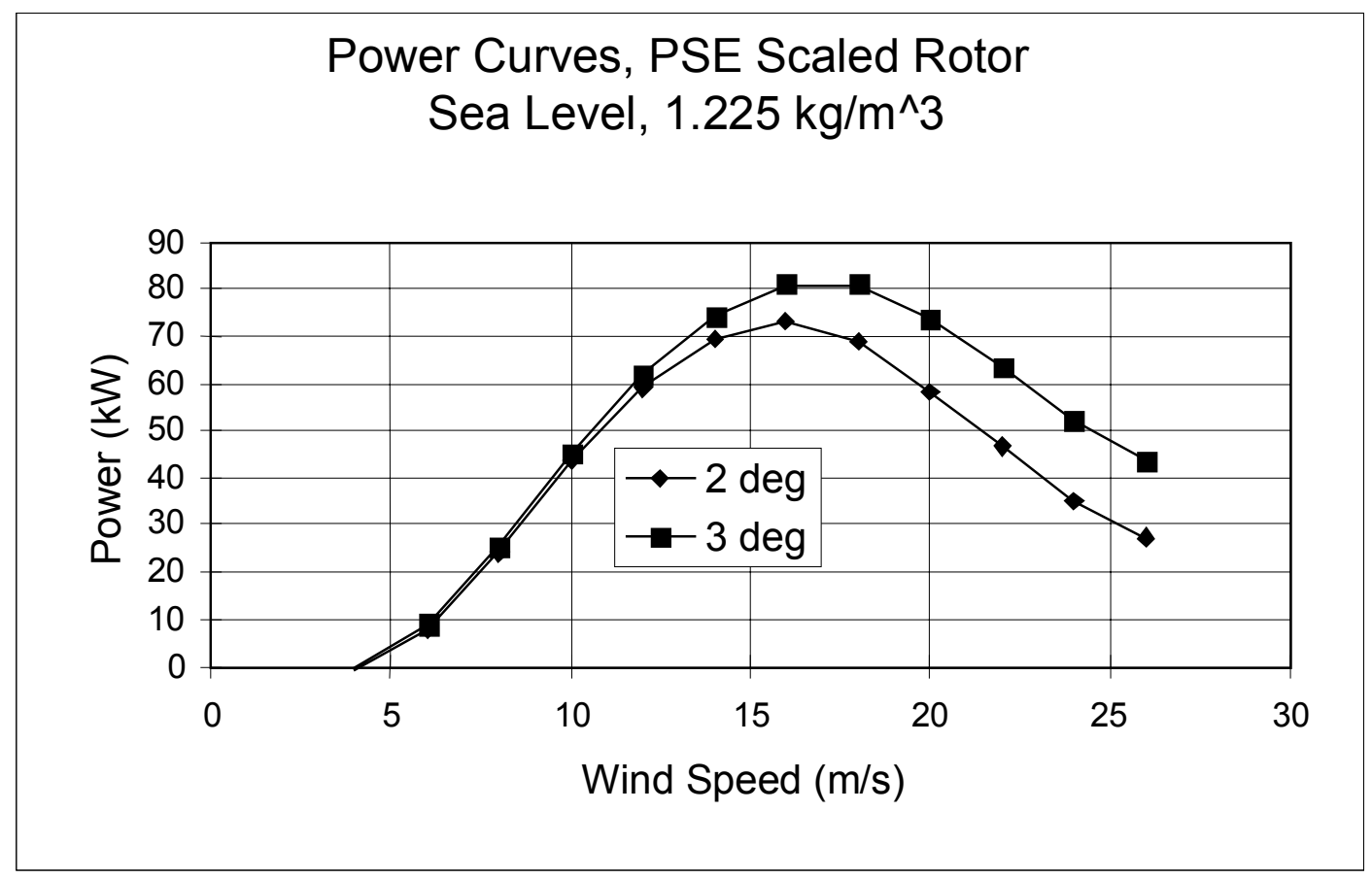

Figure 4-1. Power curve prediction, PSE scaled rotor, sea level 


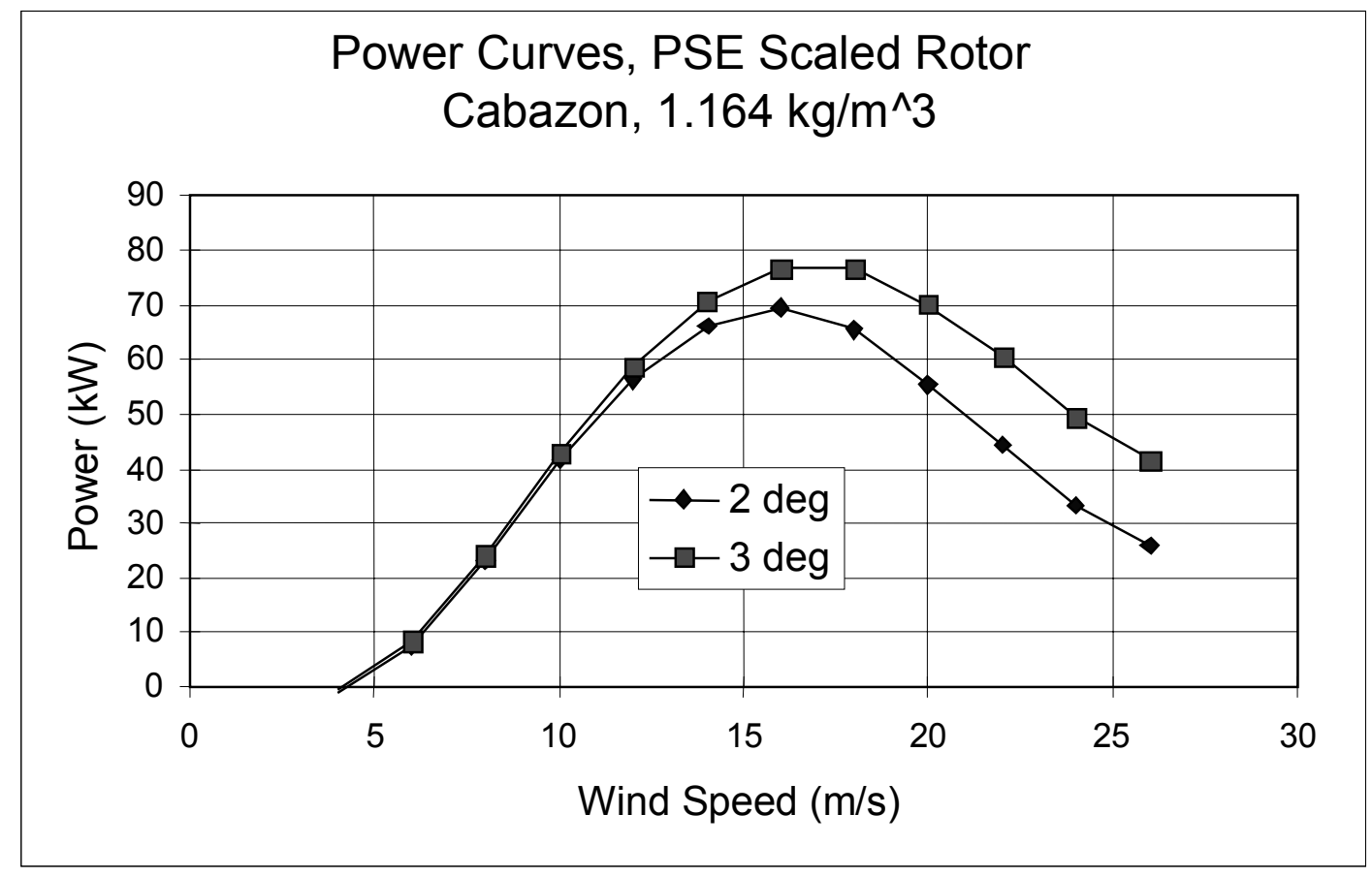

Figure 4-2. Power curve prediction, PSE scaled rotor, Cabazon site

\subsection{Spoiler-Flap}

We assumed the utility-grade turbine would require a low speed shaft braking device to provide a measure of safety for overspeed and comply with IEC 1400-1 international requirements. Aerodynamically clean blades are desirable from the dynamics and power production viewpoint, and thus it was decided to use a spoiler-flap-braking device that had minimal impact on the blade aerodynamics when in the stored position. Full blade pitch control was rejected as a possible solution due to its anticipated weight penalty and complexity.

\subsubsection{Spoiler-Flap Design Features}

The specific spoiler-flap design was selected from among a number of concepts tested at Wichita State University, References 7, and 8. The main features of the selected design are listed below:

- Single aerodynamic braking element ( trailing edge segment )

- Trailing edge deflects down

- Mid-device chordwise hinge position (pivot point)

- Held closed with electromagnet

- Device returns automatically to stowed position at low rpm

- Actuation system contained inside the airfoil

- Device lightly loaded under normal running (stowed position)

- Device is cut from base pultrusion 
The aerodynamic device is shown closed (stowed) in Figure 4-3. When the device is stowed, aerodynamic seals, made from mylar tape, bridge the gaps between the device and the base blade. The gaps are required to provide clearance during deployment. The device fully deployed at 90 degrees is shown in Figure 4-4.

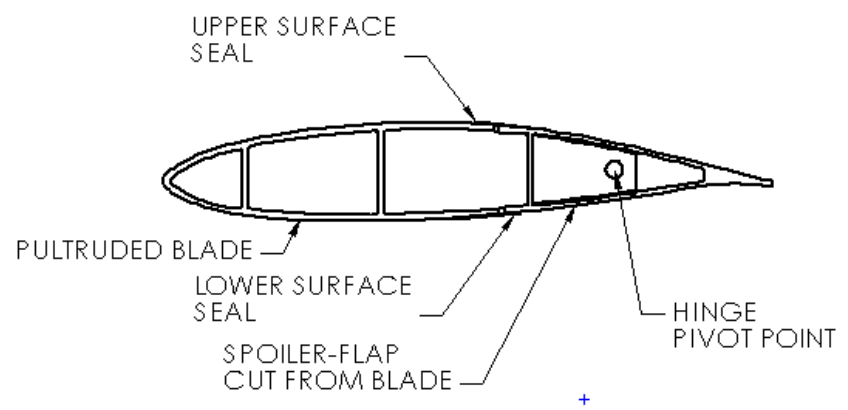

Figure 4-3. Spoiler-flap in stowed position

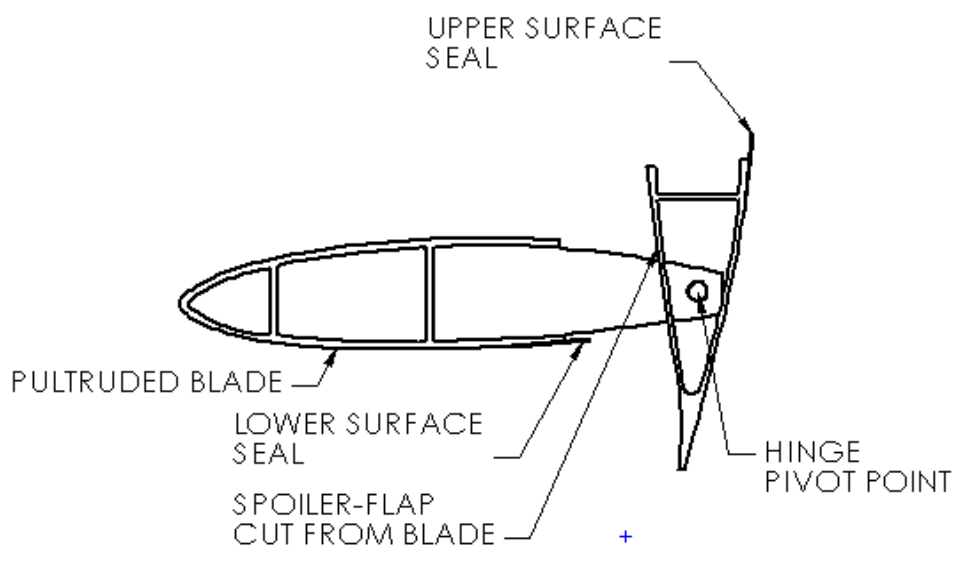

Figure 4-4. Spoiler flap in deployed position

\subsubsection{Spoiler-Flap Performance}

The aerodynamic performance data of the spoiler flap were obtained from Reference 9 . Wind-tunnel models of the device were tested on two stall-control airfoils, similar to the S822 airfoil selected for the scaled rotor. These were the S809 and S810 airfoils that had spoiler-flap chords of $0.40 \mathrm{c}$ and $0.45 \mathrm{c}$, respectively. The overall device size (chord and span as a percent of blade), and radial position on the blade, are defined by the required aerodynamic braking performance. The required performance is that which produces an acceptable freewheeling tip speed ratio (TSR).

The figure of merit for measuring the performance of an aerodynamic device is the coefficient of suction (Cs), where a negative value represents braking. The equation that defines $\mathrm{Cs}$ is given below.

$$
\mathrm{Cs}=\mathrm{Cl} \sin (\alpha)-\mathrm{Cd} \cos (\alpha)
$$




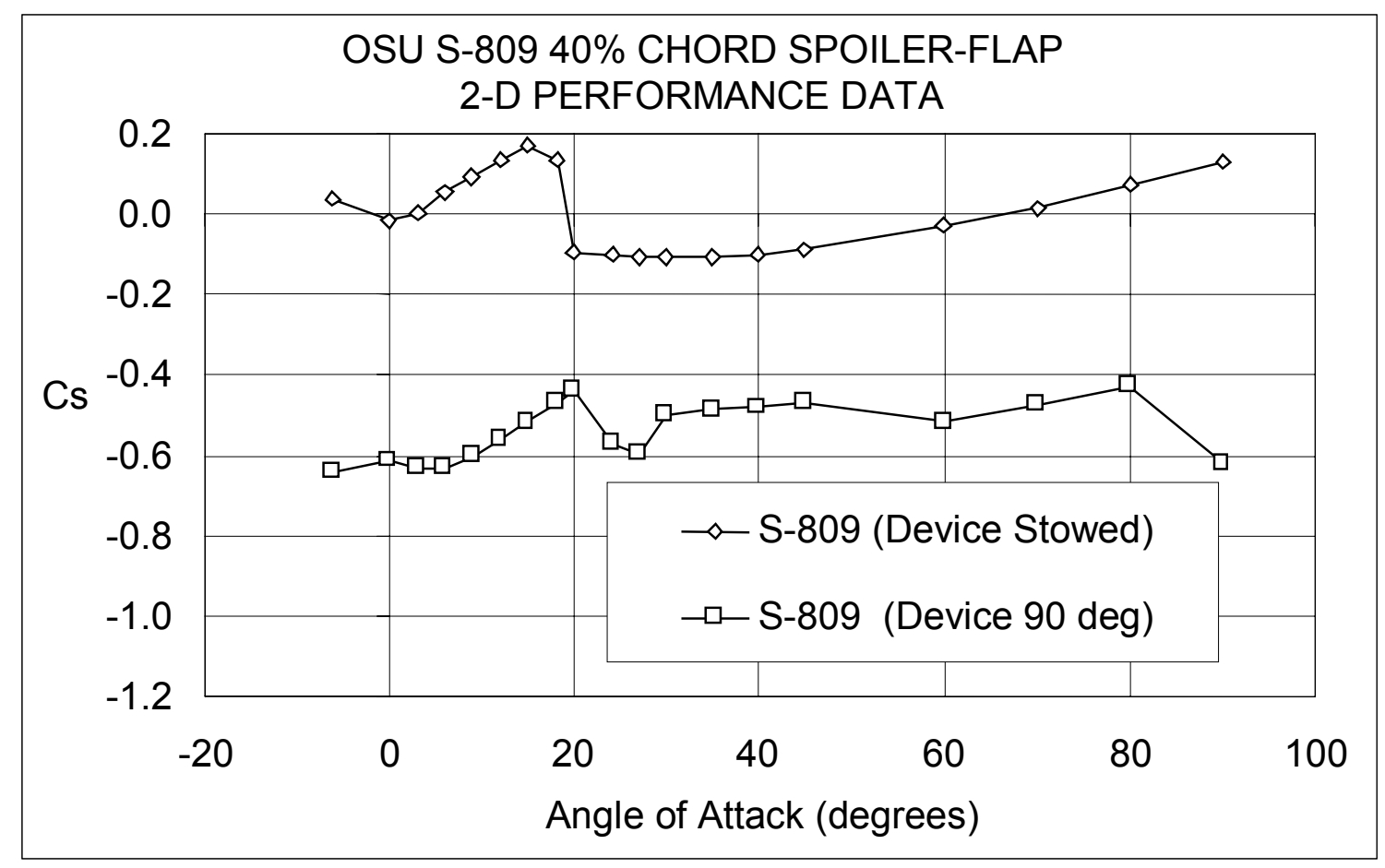

Figure 4-5. Spoiler-flap performance for the S809 airfoil

The data shown in Figure 4-5 are taken from the OSU tests of the S-809 airfoil with a 40\% spoiler-flap chord. The results are shown for both the stowed and deployed (at $90 \mathrm{deg}$ ) positions. The value of Cs for angles of attack (AOA) between 0 and $30 \mathrm{deg}$ is on the order of -0.5. This value of Cs is considered desirable for good braking. Since this is a 2-D aerodynamic coefficient, it is per unit span. The device should be positioned near the tip so that when deployed, it would replace the blade segment producing the highest power per unit span.

Figure 4-6 shows data taken from the Wichita State University (WSU) tests on the S810 airfoil with 40\% $\& 45 \%$ chord devices. These configurations were tested with hinge positions similar to those used in the S809 OSU test. The value of Cs for the S810 45\% chord model is significantly more negative than that for the S810 40\% chord model. Also, the S809 and S810 Cs data are similar for the $40 \%$ chord configuration, however, the S 810 Cs with the $45 \%$ chord is nearly 0.1 more negative than that for the S809 over the critical AOA range of 0 to 30 degrees. This increment in performance was desirable and was the reason the chord dimension of the device was set at approximately $45 \%$ of the blade chord.

Figure 4-7 presents the device incremental (the difference between closed and fully deployed) performance based on the 2-D aerodynamic data for the S810 45\% chord configuration. The data are the incremental change in performance of the aerodynamic coefficients (or DEL coefficients). These data can be applied (added) to an existing airfoil performance table $(\mathrm{Cl}, \mathrm{Cd})$ to provide an estimate of device performance for that particular airfoil with known aerodynamic coefficients.

The conservative designer would apply an uncertainty factor to this performance estimate. The factor would be an effort to account for three-dimensional (3-D) effects and general unknowns. 


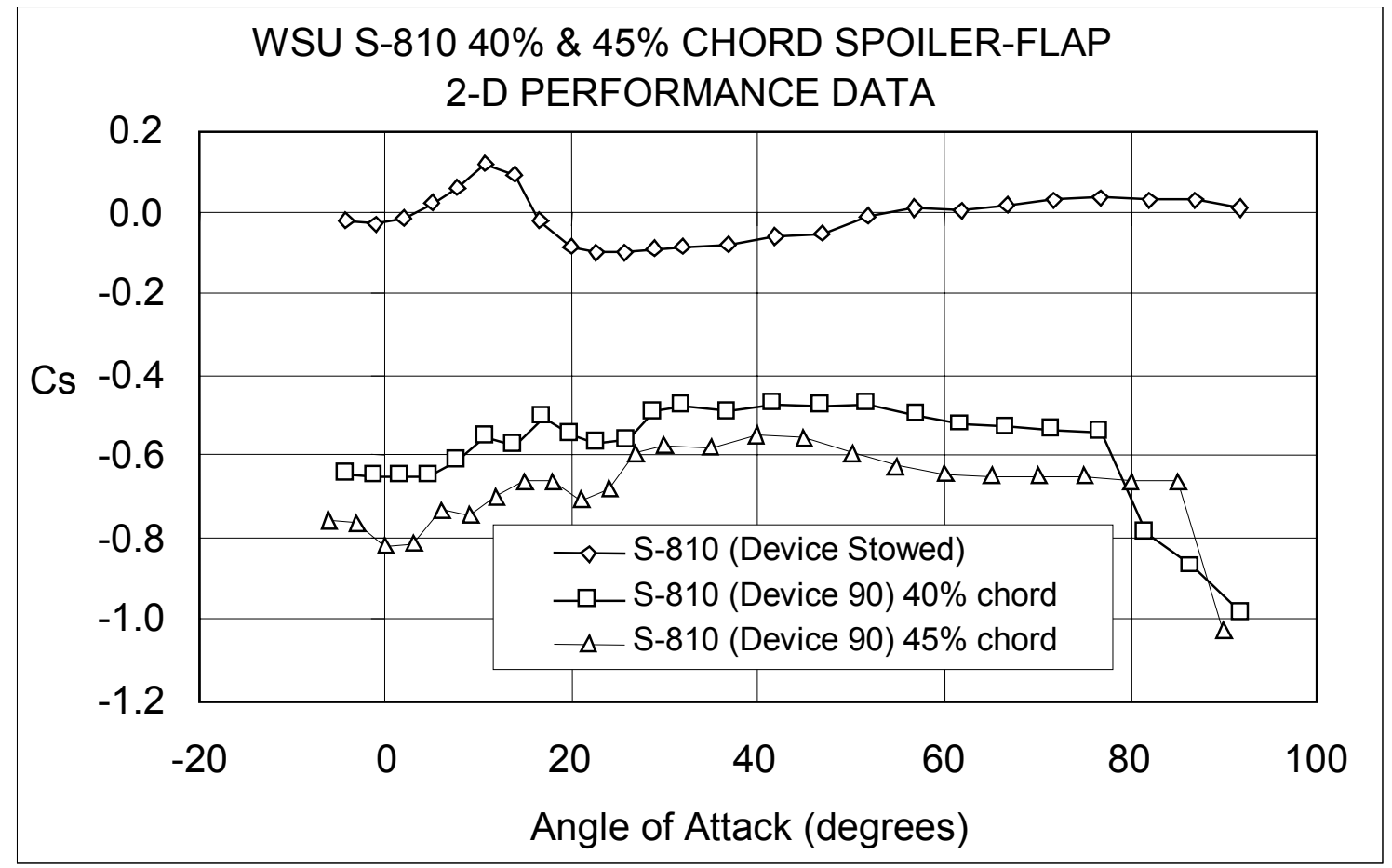

Figure 4-6. Spoiler-flap performance for $\$ 810$ airfoil

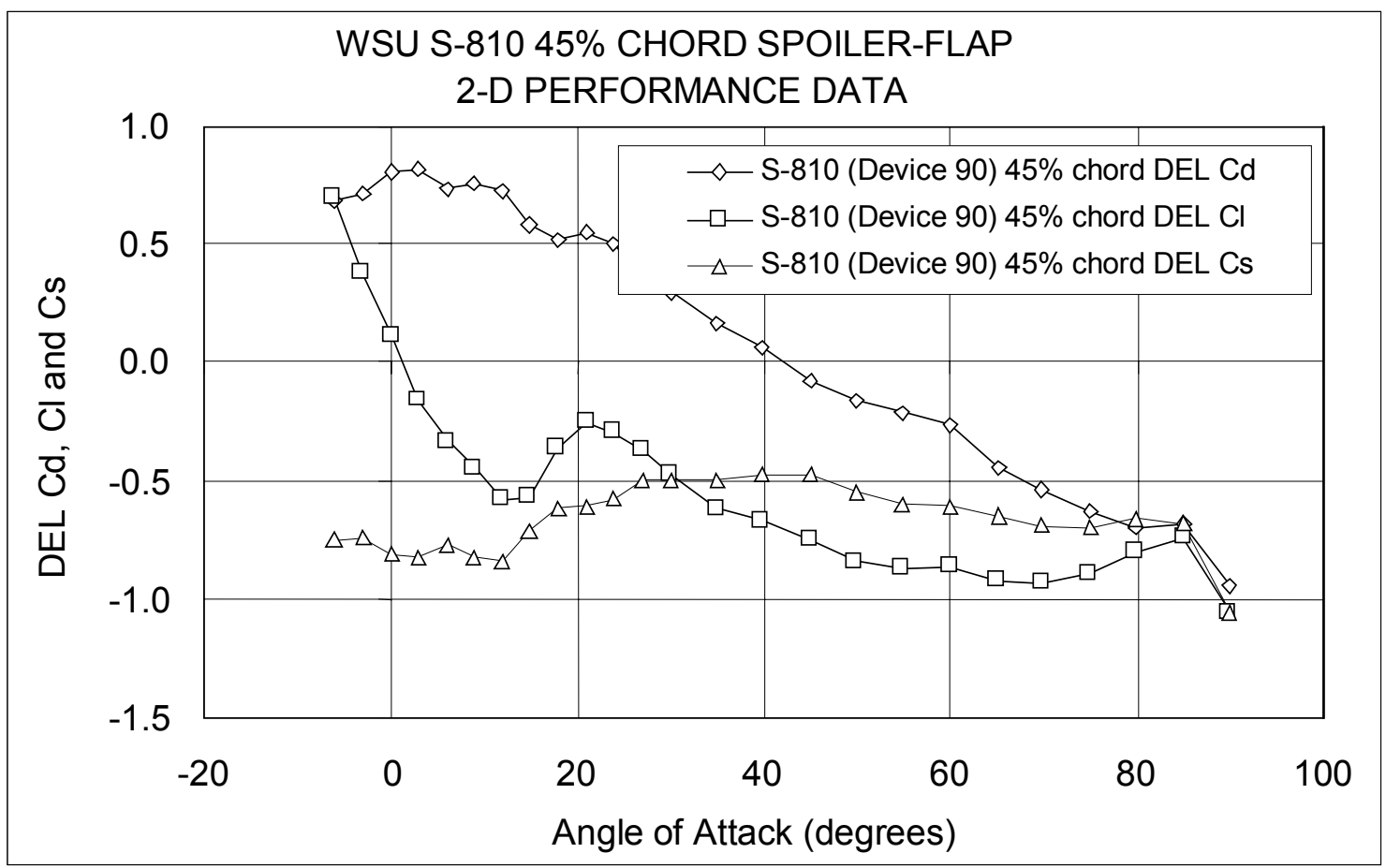

Figure 4-7. Incremental spoiler-flap performance data 
The estimated S822 airfoil $\mathrm{Cl}$ and Cd data shown in Figure 4-8 were used to find the required aerodynamic brake size and to predict the freewheeling TSR for the scaled rotor. This was done using PROP93 runs for the rotor. The brake was sized by adding the Figure 4-7 incremental data to the PROP93 airfoil tables at the outboard blade stations.

we believe that 3-D effects might reduce the effectiveness of the device compared to its performance using 2-D data. To allow for this, only $80 \%$ of the 2-D incremental data were used for performance calculations. The aerodynamic inputs to the PROP93 model for the deployed blade station are shown in Figure 4-9. These input data are used in the PROP93 performance code to estimate the device performance on the rotor. This in turn defines the span. PROP models were run to determine the equilibrium TSR for the rotor with the spoiler flaps deployed. The design required the equilibrium rotor rpm (with devices deployed) to remain at or below the normal operating rpm in all wind conditions. This corresponds to an equilibrium TSR of less than 2.0.

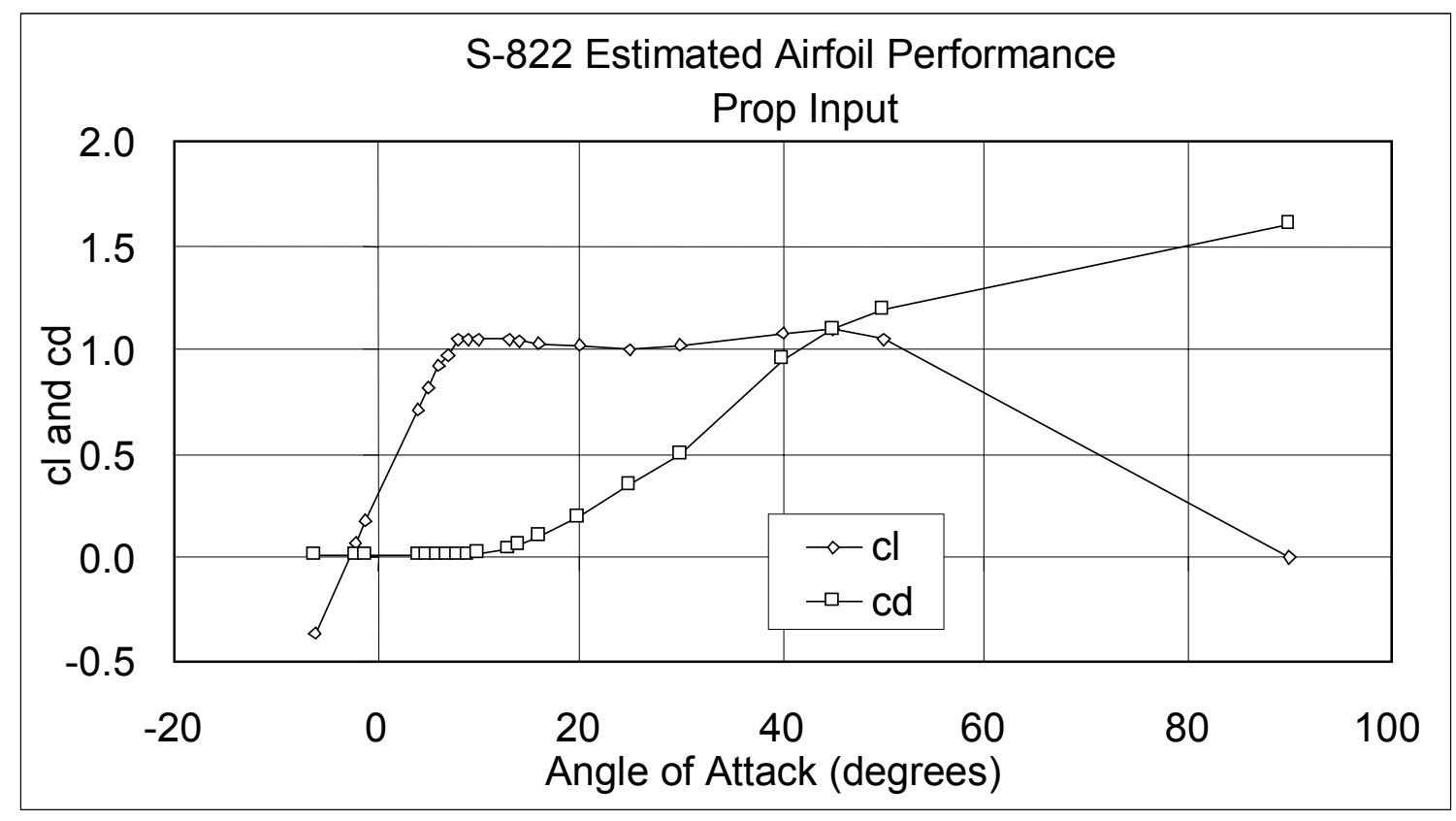

Figure 4-8. Estimated S822 airfoil data 


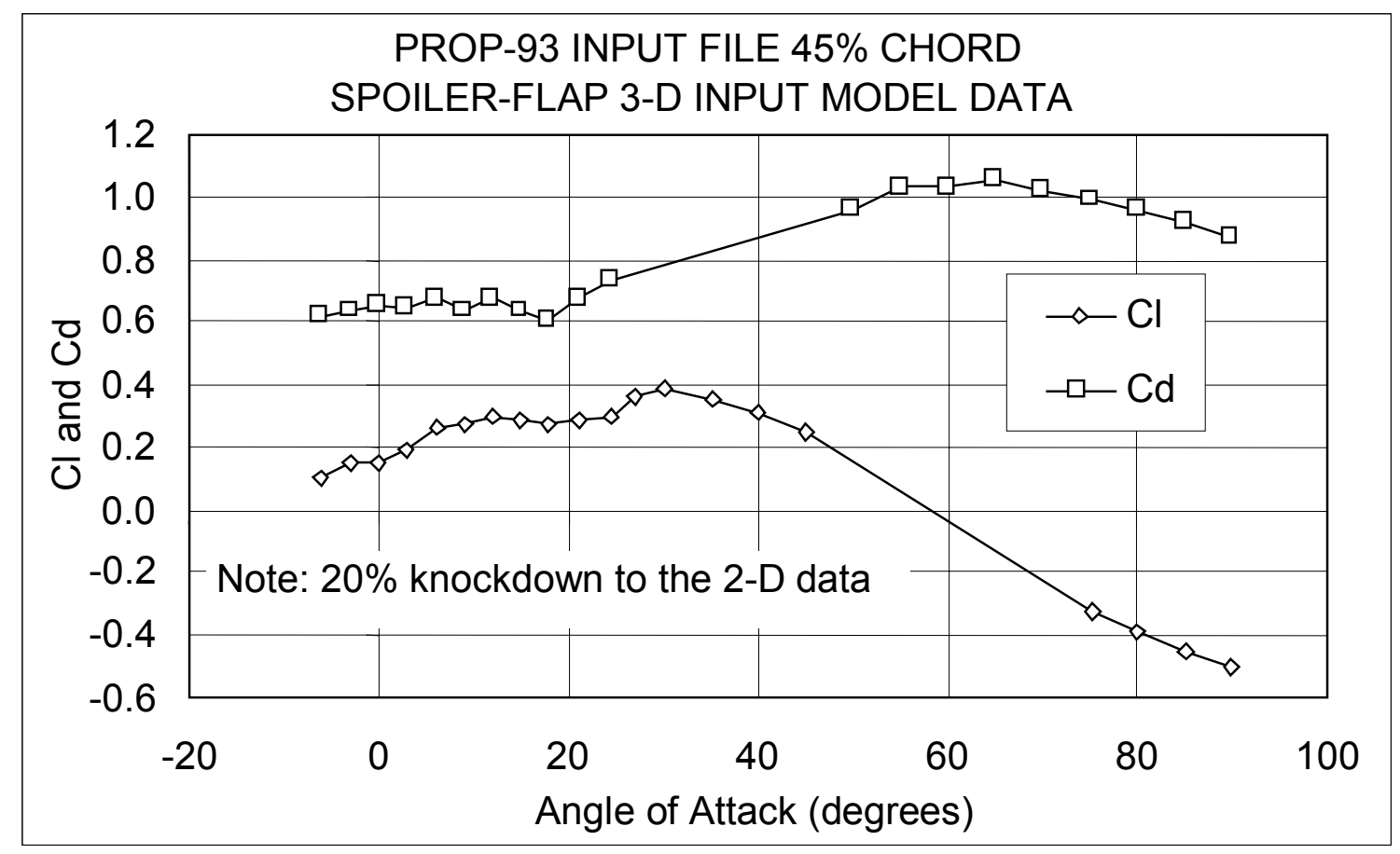

Figure 4-9. PROP93 airfoil data for spoiler flap deployed

\subsubsection{Overspeed Control Requirements}

The aerodynamic brake is required to protect the turbine in an overspeed condition created by loss of load and or a mechanical failure in the power train. The design goals are to minimize the device size and complexity without loss of effectiveness. The aerodynamic coefficients from Figure 4-9 were used to predict the rotor torque results in Figure 4-10. The data plotted in Figure 4-10 shows the effect of device span on rotor torque coefficient, and the minimum required device span length is $10 \%$ of the blade radius. The torque coefficient remains negative with the devices deployed and implies the rotor will have an equilibrium TSR less than 2.0. The equilibrium TSR occurs when the torque coefficient crosses zero. Because the data in Figure 4-10 predicts no crossing for the modeled TSR, $(2<\mathrm{TSR}<10)$, and it is known eventually there must be a crossing, it can be assumed to be below TSR $=2.0$. 


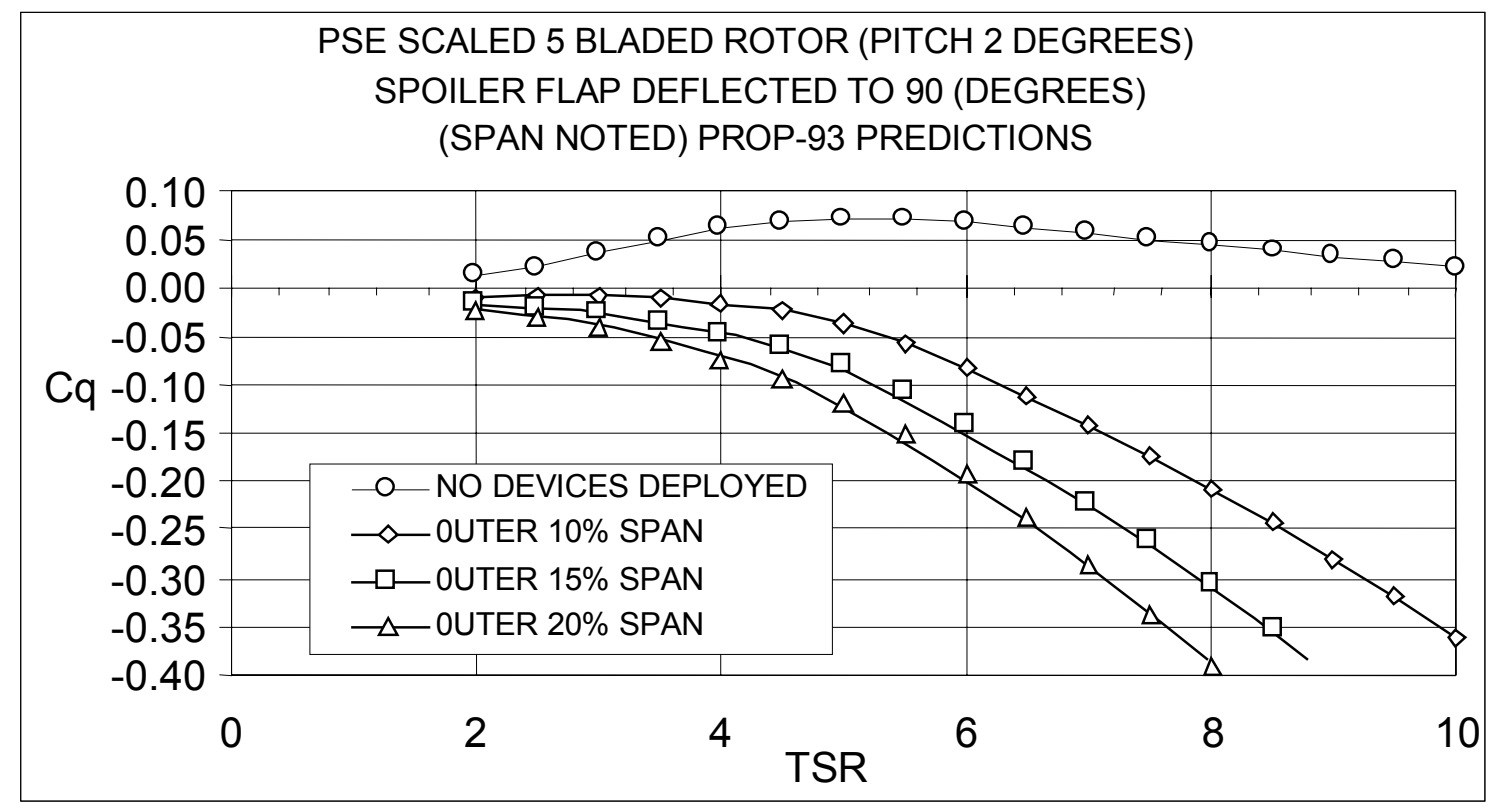

Figure 4-10. Effect of spoiler-flap span on torque coefficient

\subsubsection{Scaled-Rotor Spoiler-Flap Design Details}

Figure 4-11 shows the required cutting and machining operations to prepare the pultruded blade for the installation of the spoiler-flap and the actuation and attachment hardware. The large cut-away portion of the pultruded blade is the primary structure of the spoiler-flap. The pultruded blade was configured with three shear webs at $13 \%, 35 \%$, and $60 \%$ chord running the full length of the blade. The aft shear web formed the main spar of the spoiler-flap.

Aluminum ribs were machined to fit into the cavities in the blade and spoiler-flap. The ribs provided the load-path to support the actuation mechanism and carry the aerodynamic loads. Ribs at the inboard and outboard ends of the spoiler-flap provide support. The shear pin that supports the device at both ends also provides the spanwise retention. Bushings at each end provide sacrificial wear surfaces for the spanwise loads. The actuation system is contained in the aft cavity of the blade fixed segment. 


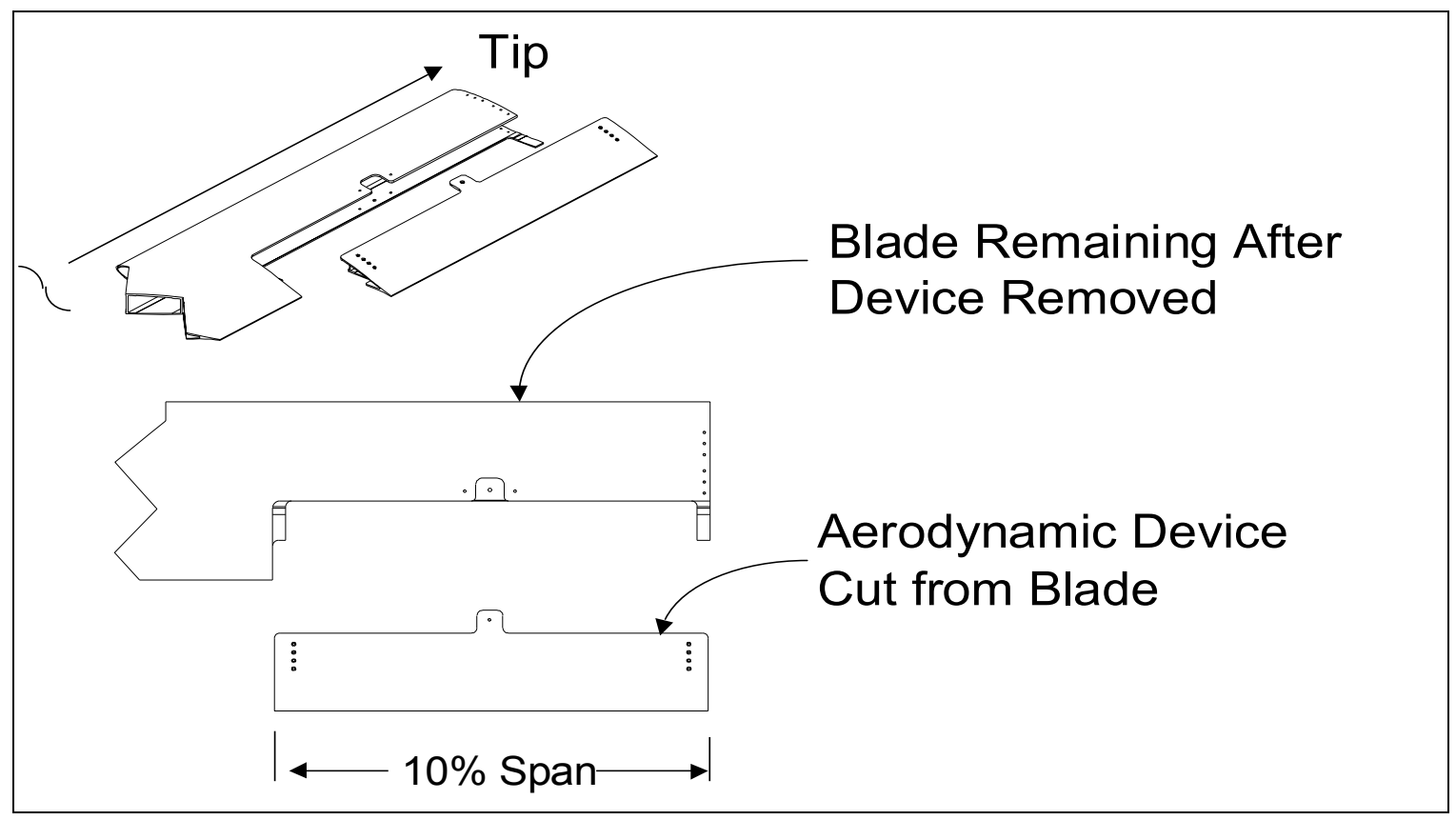

Figure 4-11. Blade preparation for spoiler-flap installation

Figure 4-12 shows the installation of the spoiler-flap. The entire actuation system and attachment hardware is shown in isometric view. Key structure and mechanism components are noted.

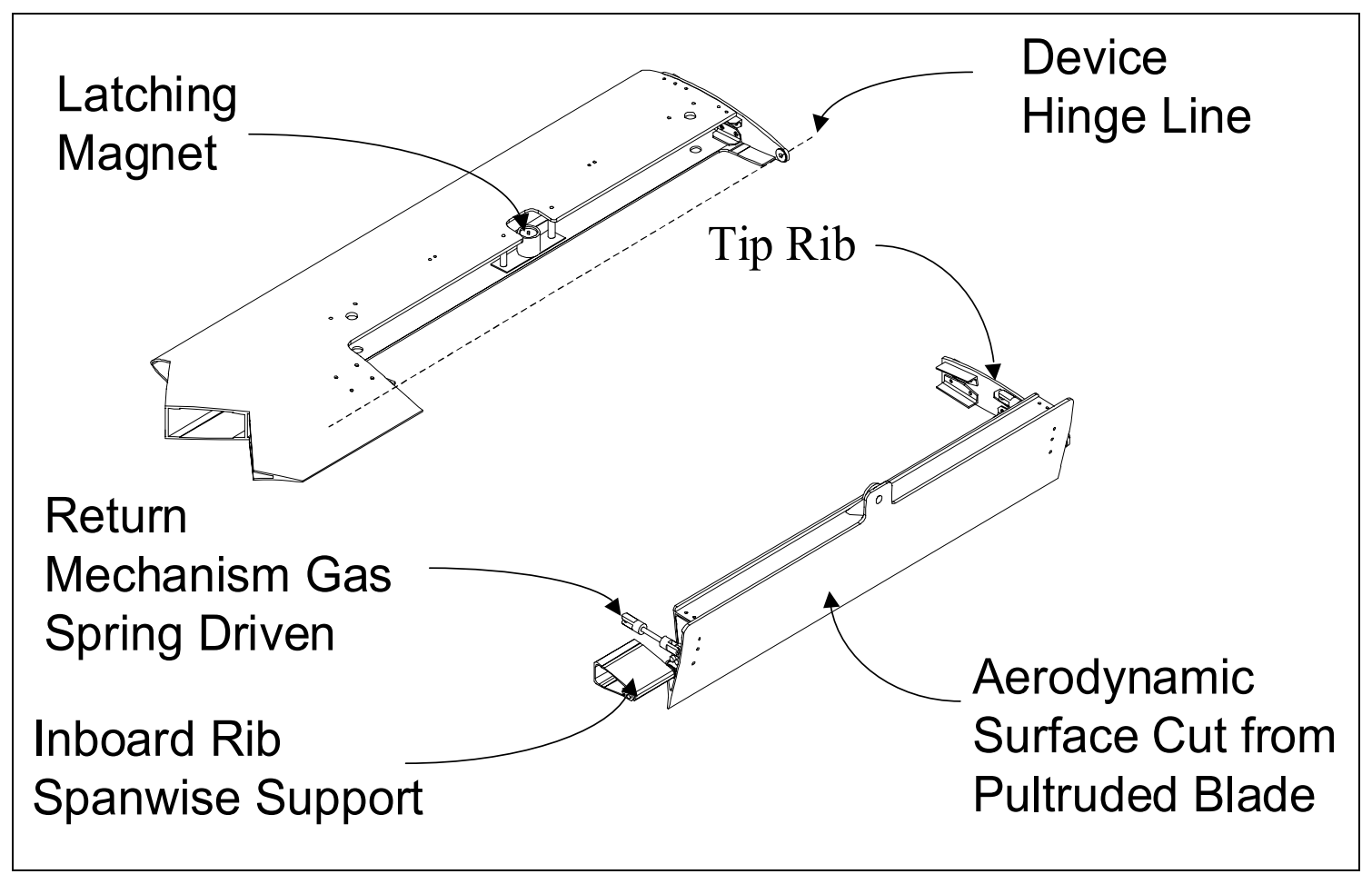

Figure 4-12. Spoiler-flap design installation details 


\subsubsection{Spoiler-Flap Actuation Mechanism}

The general operating modes of the spoiler-flap are

- Device closed and latched with electromagnet for power production. The magnet holds the device at mid span overcoming the device dynamics and the aerodynamic moment to keep the device sealed while running.

- Electromagnet deenergized and aerodynamic moment opens spoiler flap and holds it in open position. The device is acting as rotor aerodynamic brake.

- At low rpm, spoiler flap returns to the run position by a damped air spring. There must be enough force to return the device in all azimuth positions of the rotor, but a small enough force to not initiate premature device closing.

Figure 4-13 shows the three key components of the actuation system. These are

- Gas spring for returning device to the run position. The gas spring is oriented spanwise to preclude shaft bending due to inertial effects.

- Bellcrank for load amplification. Bellcrank used to change spring force from spanwise to chordwise direction and to reduce return loads.

- Device driver (adjustable link). The adjustable link used to account for manufacturing tolerances and complete the mechanism attachment to the device.

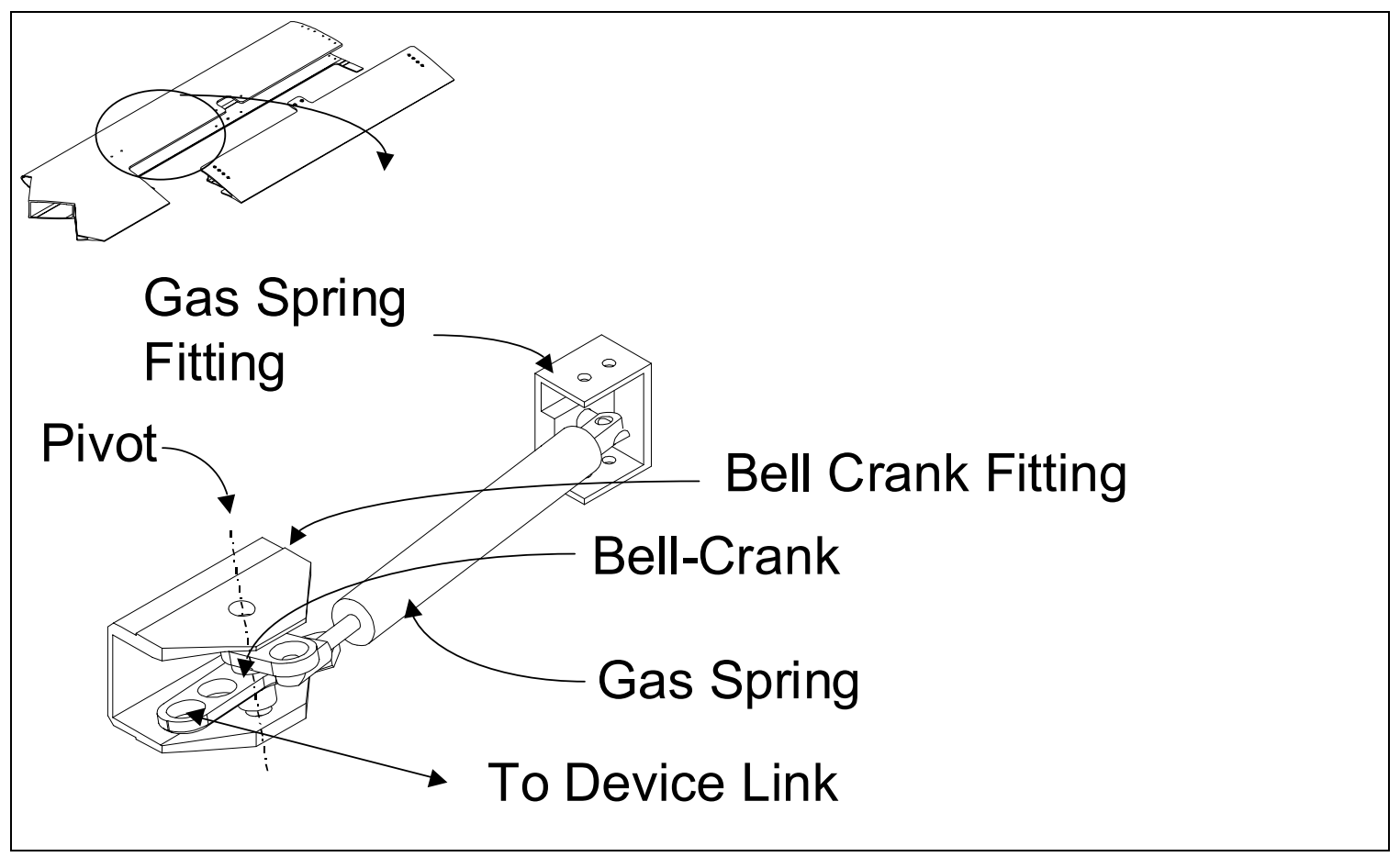

Figure 4-13. Spoiler-flap actuation mechanism 


\subsubsection{Spoiler-Flap Loads}

The mechanism and device structural loads were conservatively estimated since there were no measured loads available. All previous spoiler-flap data were wind tunnel balance measurements of the entire device and blade combined. A large normal force was assumed for the device design. The normal force was based on the normal force coefficient $(\mathrm{Cn})=2.2$. The normal force $\left(\mathrm{F}_{-} \mathrm{N}\right)$ shown in Figure 4-14 below is applied to the device at all possible angular positions. The nomenclature for the loads in Figure 4-14 is given below.

- $\mathrm{F}_{\text {mag }} \quad$ - reaction magnet force

- $\mathrm{T}_{\mathrm{q}_{-}} \quad$ - reaction torque inboard (i) and outboard (o)

- $\mathrm{R}_{\mathrm{V}} \quad$ - reaction shear force inboard (i) and outboard (o) ribs

- $\mathrm{P}_{\text {span }}$ - reaction to inertial loads

- $\mathrm{M}_{\mathrm{a}} \quad$ - inertial force due to rotation and mass

- $\mathrm{F}_{\mathrm{N}} \quad$ - normal force aerodynamic pressure

- $\mathrm{C}_{\mathrm{n}} \quad$ - normal force coefficient

- $\mathrm{C}_{\mathrm{hm}} \quad$ - hinge moment coefficient

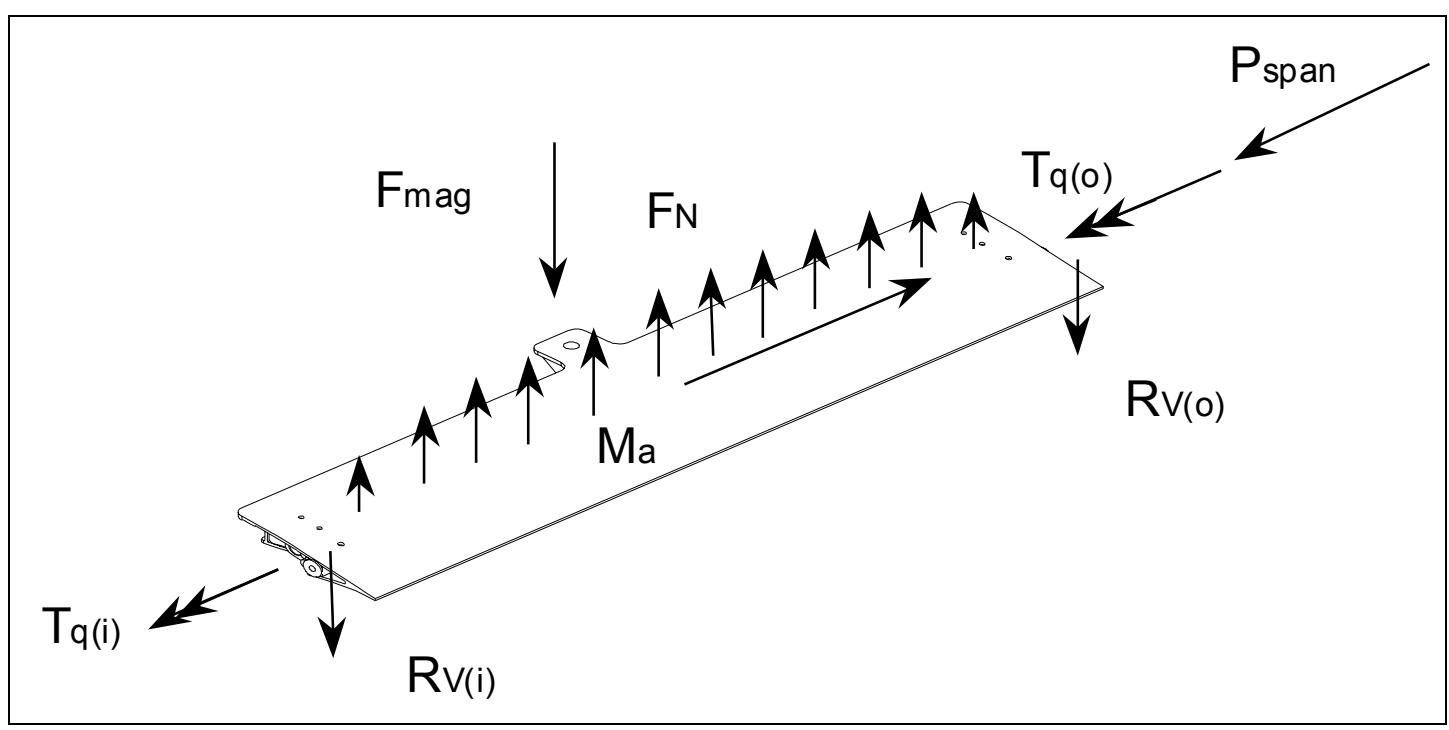

Figure 4-14. Device loads schematic

The spoiler-flap induces loads into the blade at the inboard and outboard ends of the device, however, they are not as significant as the normal operating loads at the $40 \%$ span location and thus did not impact the section design.

\subsubsection{Spoiler-Flap Fabrication}

The spoiler flaps were cut from the base pultrusion. The cutting jigs were created so that they mated with the outside surface of the airfoil. The jigs were configured so that the fiberglass cutting router could traverse the blades to produce the pattern defined by the drawing. The router bits were square cutting carbide tipped and the minimum diameter of ( 0.125 in.) was used for the final gap configuration. 


\subsection{Scaled-Rotor Fabrication}

\subsubsection{Blades}

Several U.S. pultrusion manufacturers with blade experience were available to provide the scaled blades. In the event that the utility-grade rotor might be manufactured in the future, it would be expedient to select a company that had experience with larger pultrusions. For this reason, Creative Pultrusions, Inc. (CPI) of Alum Bank, PA was selected. They produced pultrusions up to $4 \mathrm{ft}$ in chordwise dimension. Approximately thirty blades were successfully pultruded in March of 1996. The majority of these were made using vinyl/ester resin which CPI identified as producing a slightly higher strength composite than that employing the more commonly used polyester. Subsequent tests revealed the improvement was less than $10 \%$. In future production, the polyester system would be recommended due to its lower cost and smoother surface finish.

The blades were shipped to Stoddard International in Arlington, WA to add the inboard stiffeners, tips, and the spoiler flaps. The blade surface required sanding over the bonding area in order to remove the release agent, which migrates toward the blade surface during the pultrusion process. A root pad was applied over the first 12 inches of the blade, which provided a total thickness of 3 inches for mating with the hub plates. Outboard of the pad, the ply thickness tapered from 0.287 inches down to 0.041 inches at the $35 \%$ radius station. Unidirectional rovings were laid directly on the blade surface and wetted with a laminating epoxy system. A vacuum bag was then applied and the assembly allowed to cure at room temperature.

The blade tip had a span length of $173 \mathrm{~mm}(6.8$ "), which represents $2.2 \%$ of the radius. The leading edge was swept in a semi-circular pattern to the mid chord and then straight back to the trailing edge. Two halfshell female molds were used to fabricate the tips using a random mat material around a foam core. Aluminum clips with tapped holes and matching countersunk screw holes in the blade and tip surfaces were used to fasten the tips to the blade. A sketch of the tip and other blade components is shown in Figure 4-15.

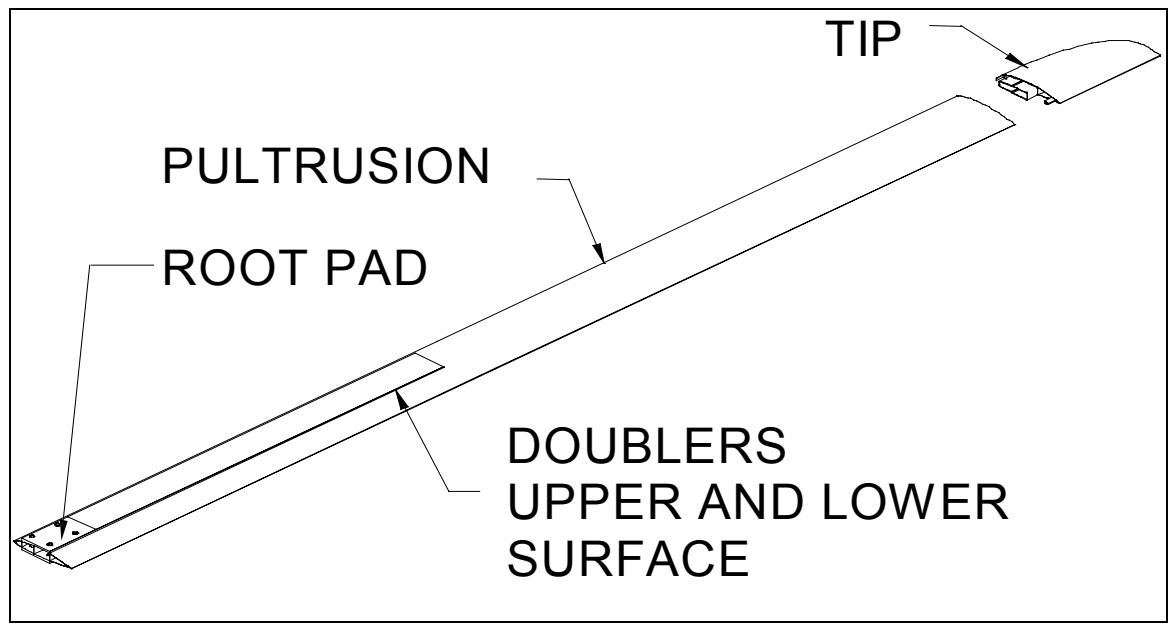

Figure 4-15. Blade components

Following the completion of the blade fabrication, Rich Osgood of NREL performed a frequency survey of one of the blades. The blade, with trailing edge down, was supported horizontally by bolting the roodend attachment cuff to a steel frame that was secured to the shop floor. Accelerometers were attached at 
10 locations along the blade span, and striking the blade tip with a calibrated hammer excited the various blade modes. A summary of the measured frequencies and damping characteristics are given in Table 4-3. The rotating frequencies calculated from the Flexdyne computer code are also included.

Table 4-4. Static and Rotational Frequencies of Scaled Blade

\begin{tabular}{|r|l|r|c|c|r|r|}
\hline Mode No. & Type & \multicolumn{2}{|c|}{ Stat.Freq. Damp.Freq. Crit.Damp. Rot.Freq. } & per rev \\
& & $\mathrm{Hz}$ & $\mathrm{Hz}$ & \multicolumn{1}{c|}{$\%$} & $\mathrm{~Hz}$ & at $69 \mathrm{rpm}$ \\
\hline 1 & 1st flat & 0.78 & 0.0432 & 1.420 & 1.62 & 1.41 \\
\hline 2 & 1st edge & 2.22 & 0.0433 & 1.950 & 3.17 & 2.76 \\
\hline 3 & 2nd flat & 4.19 & 0.0430 & 1.030 & 6.14 & 5.34 \\
\hline 4 & 3rd flat & 11.03 & 0.0575 & 0.522 & 15.18 & 13.20 \\
\hline 5 & 1st torsion & 19.29 & 0.1220 & 0.634 & 19.47 & 16.93 \\
\hline
\end{tabular}

\subsubsection{Scaled-Rotor Test Platform}

The scaled-rotor test platform was an existing $92 \mathrm{~kW}$ wind turbine located at the Cabazon windpark 10 miles west of Palm Springs, CA. The head assembly components were originally manufactured for Dynergy, Inc. in 1983. It uses a 2-stage helical transmission manufactured by Nuttall Gear Inc. with a Westinghouse generator flange-mounted directly to the transmission. Although originally fitted with a disk brake on the low-speed shaft, the configuration was modified to allow sliprings to be mounted on this shaft. The low-speed disk brake was removed and a high-speed brake was mounted on the front end of the double-shafted generator. This was a Stearns Series 86,000 spring-set electric brake rated at $600 \mathrm{ft}-\mathrm{lb}$. To adjust the rotor shaft rpm to $69 \mathrm{rpm}$, the high-speed pinion and mating bull gear had to be replaced. Nuttall supplied these parts, and they specified that the transmission rating would be downgraded from $92 \mathrm{~kW}$ to $80 \mathrm{~kW}$ as a result of the lower rpm.

The transmission and generator are mounted on a steel weldment that is connected to the tower through a yaw bearing. The assembly is set at a $5^{0}$ pitch relative to the yaw bearing to increase clearance between the blade tip and the tower. The tower is tubular corten steel with 12 sides and a 0.25 -in. wall. The diameter tapers from $0.82 \mathrm{~m}$ (32.2 in.) to $0.54 \mathrm{~m}$ (21.2 in.) with an overall height of $16 \mathrm{~m}$ (52.6 ft) that places the hub height at $16.8 \mathrm{~m}(55 \mathrm{ft})$. The five-sided hub was welded from steel plate and attached to the transmission shaft with a Dodge taper-lock coupling. The hub had a built-in pre-cone angle of $3^{0}$ and the blade cuffs were fastened to each of the five hub flats with five bolts. Two five-hole patterns were drilled into each hub flat to provide two pitch settings for each blade; the holes were also slotted which allowed a total pitch variation of $8^{0}$. Figure 4-16 is a photograph of the hub, which also shows the slipring assembly and the attached ADAS components.

The generator shaft extended through the Stearns brake cover approximately 1 in. on which was mounted a 60 -tooth sprocket. Adjacent to the sprocket, installed on the brake cover, was a magnetic pick-up that sent the 60-pulse per revolution signal to the turbine controller located in an enclosure adjacent to the test trailer. The controller was an off-the-shelf programmable model, which processed the rpm signal as required for the turbine operation. It was set to energize the generator at $1800 \mathrm{rpm}$ and de-energize it at $1795 \mathrm{rpm}$ after a 5-s delay. In addition, the brake was set to be applied at $1950 \mathrm{rpm}$. The spoiler-flap magnets were powered through a 12 -Volt transformer mounted on the rotor hub. They could be activated manually at the control panel and automatically deploy with loss of power. 


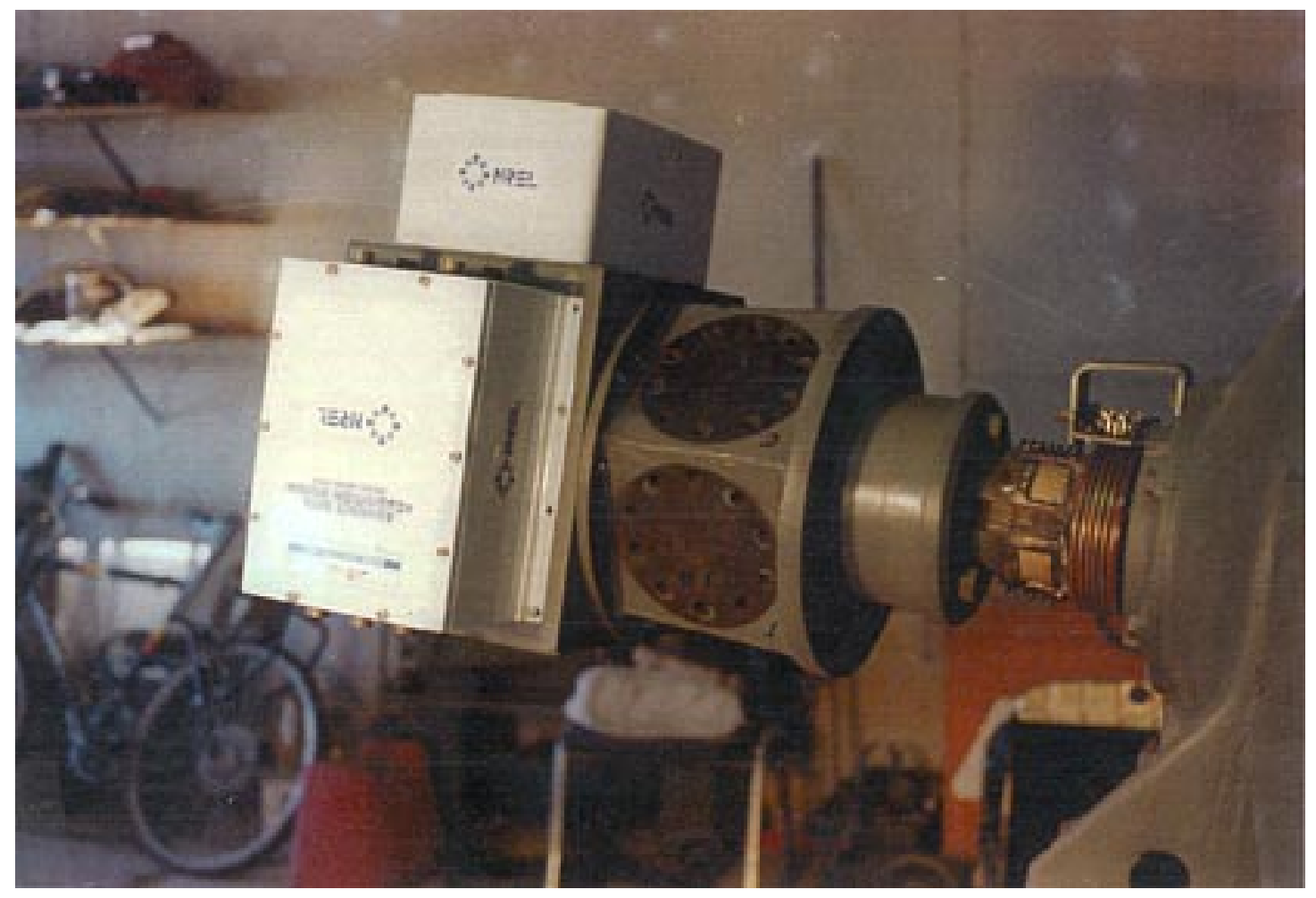

Figure 4-16. Scaled rotor hub assembly 


\section{Blade Static Test}

The subcontract called for a static test of a single blade to be performed at the NREL high-bay test facility at the NWTC in Golden, CO. One of the spare pultrusions was reinforced over the inboard region in the same manner as the five blades completed for the field-test rotor. The two center blade cells were foamed, as before, however the leading-edge ballast and spoiler flap were omitted. The purpose of the test was to simulate the blade moment distribution under static wind loading conditions and to measure the tip deflection and blade surface strains at various radial locations during the loading process. An additional objective was to load the blade to failure to observe the stress at the time of failure, as well as the location and mode of failure.

The configuration of the test blade, showing the seven strain-gage locations, is shown in Figure 5-1. The blade is cantilevered at the left and loaded by the whiffletree arrangement to the right. The test configuration and results were documented in an internal NREL report by Musial, Reference 10.

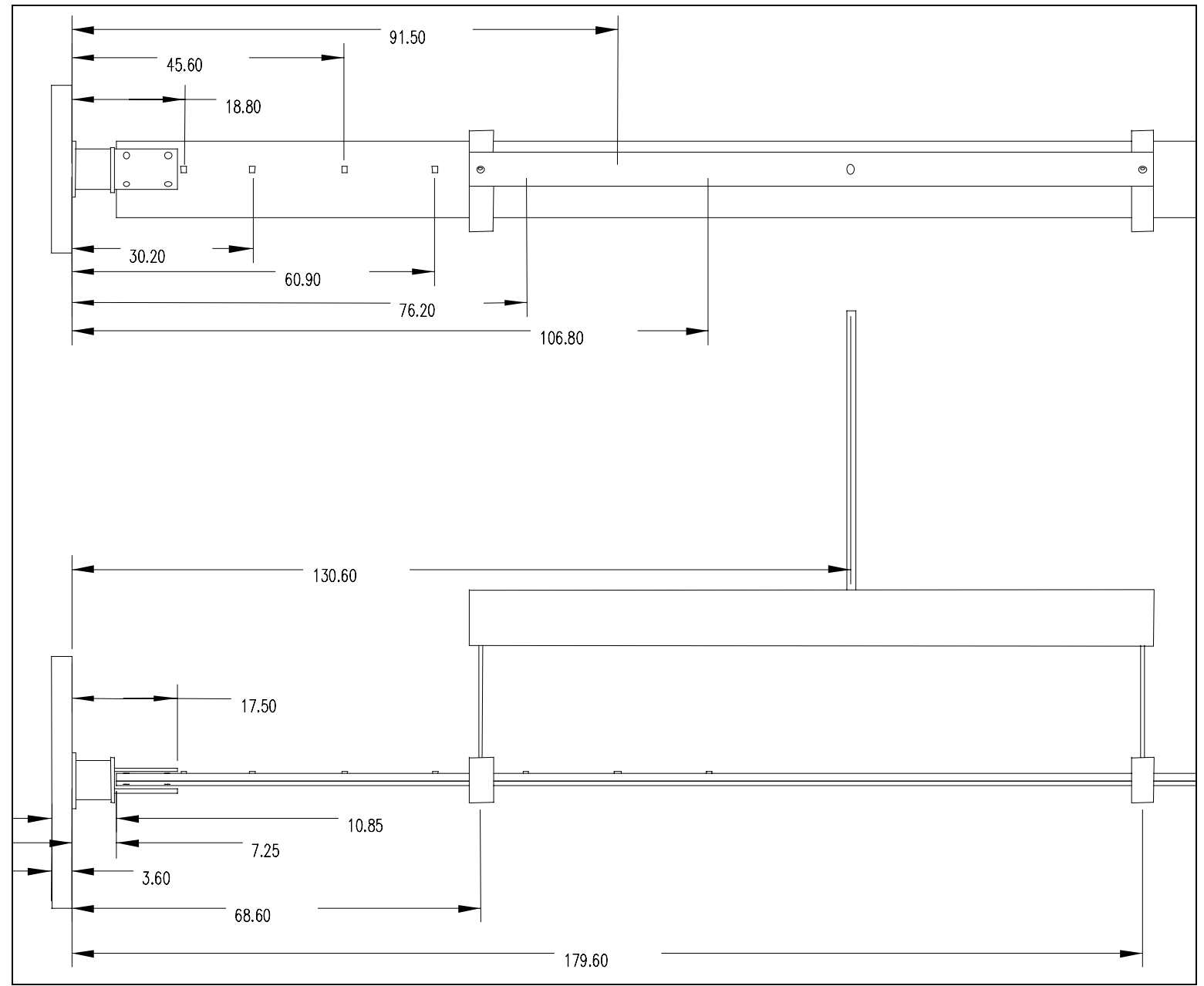

Figure 5-1. Static test configuration

The test found greater deflections at the whiffletree attachments than predicted by the linear analysis. The blade failed at a root moment value less than the design value. The actual failure value is an open question. The report suggests a $19 \%$ correction to the root moment. The failure occurred in the 
compression surface of the blade at very high strain, greater than $-13537 \mu \varepsilon$. The predicted strains were on the order of the $-7000 \mu \varepsilon$ based on beam theory and a fully effective section.

The actual configuration results in a less than fully effective section. As shown in Figure 5-2, the root fitting is comprised of two plates welded to a circular attachment block.

When the test was conducted, the crane was repositioned several times each time all of the gages responded to the motion. The difference in the applied moment would be the change in strain as a function of applied force at each station. This assumption is based on the belief that the gages are acting as a group of independent load cells. The bending gages showed less than $19 \%$ total variation in the strain at load for each gage. The exact value of the moment reduction would be different for each gage location and has not been determined here. The time histories were not reviewed. The exact value for the load (moment knockdown) would have been easier to determine if load cells were employed at each saddle attachment. The significant blade displacements make the resolution of the loads difficult. So for the rest of this test analysis, the full moment at the failure location has been used.

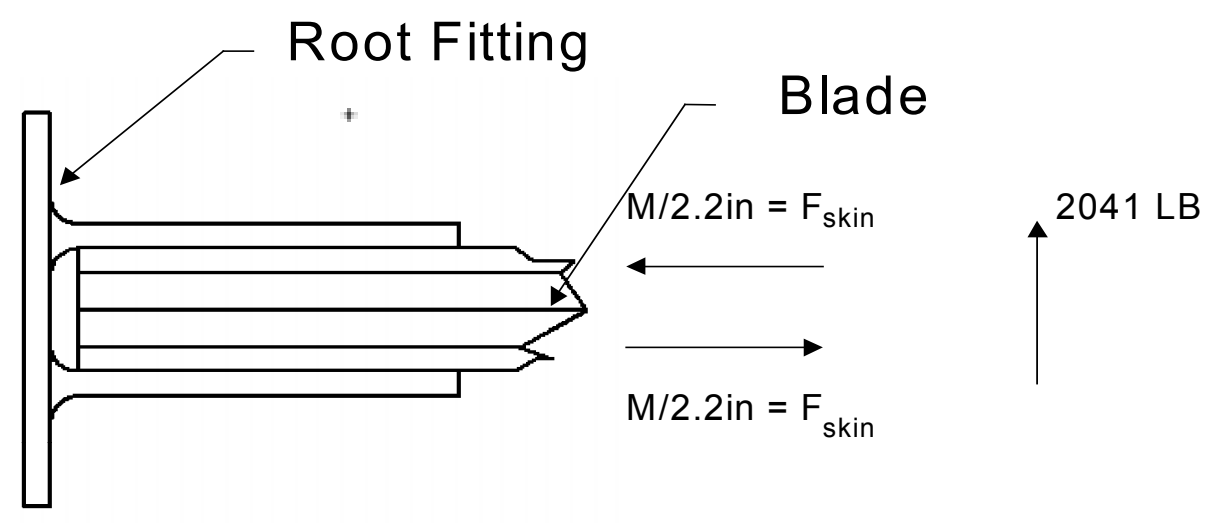

Figure 5-2. Blade root fitting

In the model shown in Figure 5-2, $\mathrm{F}_{\text {skin, }}$, the bending moment divided by the blade thickness, is essentially the compressive and tension load being carried by the upper and lower skins at the centroid of the effective area. In Figure 5-3, two possible failure stress levels are presented. These are based on the amount of the effective skin assumed and the doubler laminate properties. Stress value S1 is the value of the failure stress based on a fully effective skin/doubler at the blade maximum strain (failure) on the lowpressure skin. With this stress value, E1 (modulus of elasticity) for the skin/doubler can be back calculated. This E1 value is far below the value measured by MSU for just the upper skin without doublers. If it is assumed that the value is at least as great as the upper surface skin Emsu, and the measured failure strain is used to back calculate an effective area, an area of $67 \%$ of the skin/doubler total is found. The effective skin is far less than the entire skin/doubler. The apparent loss of effectiveness in the skin/doubler is a concern and should be investigated before the configuration of a future blade doubler is finalized. 


\begin{tabular}{|lll|}
$\mathrm{S} 1=3.614 \cdot 10^{4}$ & psi & $\mathrm{S}(\mathrm{MSU})=5.428 .10^{4} \mathrm{psi}$ \\
$\mathrm{E} 1=2.663 \cdot 10^{6}$ & psi & $\mathrm{E}(\mathrm{MSU})=4.10^{6} \mathrm{psi}$ \\
$\mathrm{A} 1=2.87 \mathrm{in}^{2}$ & & $\mathrm{~A}(\mathrm{MSU})=1.911 \mathrm{in}^{2}$ \\
\hline
\end{tabular}

Figure 5-3. PSE skin effective modulus of elasticity and area

The deflection of the blade was also greater than predicted. This excess displacement is possibly the result of a problem with the model used for the predictions of displacement and the effective section properties of the doubler-laden blade segment. Much of the excessive displacement can be accounted by simply load sharing the moment at the root fitting $10 \%$ in a vertical couple. This would yield a slope at the end of the root fitting that would fully account for the error in the outboard saddle. This same slope would account for $55 \%$ of the displacement error on the inboard saddle. The other $45 \%$ may be the result of load share in the applied loads and section property discrepancies previously discussed. 


\section{Scaled-Rotor Test}

Pre-test assembly and sensor installation were performed in an indoor maintenance facility near the test site. The components were transported to the test site in October 1996, and testing began in November. However, just prior to testing, the power to the site substation was turned off due to an unexpected contract dispute between the utility company and the windpark operator. There appeared to be no quick remedy to the problem, and since it was not feasible to relocate the equipment to a new site, it was decided to employ a portable generator to serve as the grid power supply. Subsequently, a $155 \mathrm{~kW}$ diesel generator and $300 \mathrm{~kW}$ load bank were leased and installed at the site.

A period of time was required to develop procedures for operating this hybrid system. Some technical problems developed with the leased equipment which resulted in a number of emergency shutdowns of the turbine. At each of these occurrences, the full mechanical disk brake was applied through the power train. This amounted to $600 \mathrm{ft}-\mathrm{lb}$ at the generator shaft and high-speed pinion of the transmission and $15,360 \mathrm{ft}-\mathrm{lb}$ at the low-speed shaft. Although the manufacturer indicated that this torque level did not exceed the transmission rating, it is believed that the pinion shaft developed cracks during these stops. This led to a complete fracture of this shaft later in the test, which resulted in a rotor overspeed and blade failure. This will be discussed later in this section.

\subsection{Test Site}

The test site is located in the narrowest region of the San Gorgonio Pass, 10 miles west of Palm Springs, $\mathrm{CA}$. The site is within an array of approximately 100 wind turbines of similar size. However, during the test, these turbines were not operating. Wind measurements during recent years have indicated that the average wind speed ranges from $7-8 \mathrm{~m} / \mathrm{s}$. The prevailing wind direction is from the west and the general level of turbulence is high. The floor of the desert in this area is flat, and plant life height is not higher than $8 \mathrm{ft}$. A photograph of the installation is shown in Figure 6-1. 


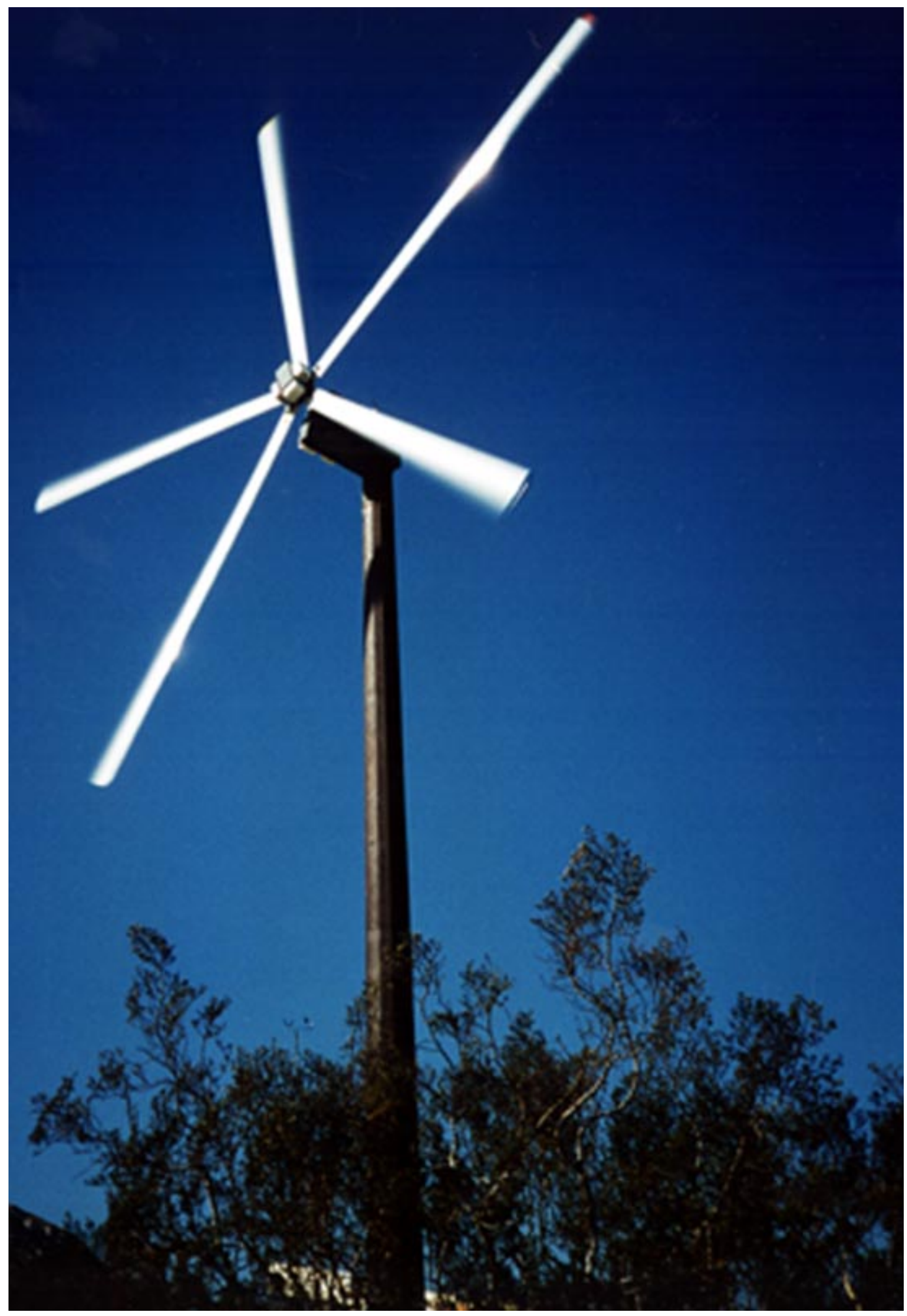

Figure 6-1. Scaled-rotor test turbine 


\subsection{Instrumentation}

The PSE scaled rotor test used a full suite of instrumentation to measure atmospheric conditions, turbine operation, and turbine structural loads. The sensor list is shown in Table 6-1 and detailed descriptions and specifications of all instrumentation are presented in Reference 11.

\subsubsection{Atmospheric Measurements}

Atmospheric conditions were measured on a meteorological tower $46 \mathrm{~m}(150 \mathrm{ft})$ upwind, $300^{\circ}$ true north of the test turbine. A sonic anemometer measured three directions of wind speed at $16.7 \mathrm{~m}(55 \mathrm{ft}) \mathrm{hub}$ height, with the u-axis aligned with prevailing wind, v-axis lateral, and $\mathrm{w}$-axis vertical. Later in the test a backup cup anemometer and wind vane were also used. Ambient temperature and barometric pressure were collected at $2 \mathrm{~m}(6.6 \mathrm{ft})$ above ground level.

\subsubsection{Turbine Operation Measurements}

Turbine operation measurements included rotor speed, rotor azimuth, yaw position and electrical power output. The rotor speed and azimuth channels failed to give accurate absolute readings because of nonferrous gear teeth on the rotor shaft sprocket. The signal did, however, provide relative blade azimuth position which was sufficient to determine the position of the instrumented blade (blade \#1). The rotor speed was determined from the generator shaft rpm. Early power readings were inaccurate because of voltage measurement too close to the diesel generator. This was corrected by moving the power transducer to the tower-base enclosure.

\subsubsection{Turbine Structural Loads Measurements}

Turbine structural loads were measured using full strain gage bridges on two blades, a spoiler flap, the mainshaft, and the tower, and using accelerometers on one blade and the nacelle. Blade loads included flatwise bending, edgewise bending, torsion on the root cuff and flatwise bending on the blade skin near the root of blade \#1, with duplicates of the flatwise channels on blade \#5. The spoiler-flap loads included flatwise bending at the spoiler flap midspan, and spoiler flap opening force with a load cell at the magnet striker plate. Mainshaft loads included torsion and bending moments in two directions. Tower loads included north-south and east-west bending moment at the tower base; similar tower top channels were lost to cable breakage. Acceleration measurements included flatwise and edgewise accelerations at the blade mid-span and tip, and nacelle yaw and tilt accelerations. 
Table 6-1. Test Instrumentation

\begin{tabular}{|c|c|c|c|c|c|c|c|}
\hline $\begin{array}{l}\text { Chan } \\
\text { No }\end{array}$ & $\begin{array}{c}\text { Channel } \\
\text { Name }\end{array}$ & $\begin{array}{c}\text { Channel } \\
\text { Description }\end{array}$ & $\begin{array}{c}\text { Sensor } \\
\text { Type }\end{array}$ & $\begin{array}{c}\text { Sensor } \\
\text { Location }\end{array}$ & $\begin{array}{l}\text { ADAS Signal } \\
\text { Cond Board }\end{array}$ & $\begin{array}{c}\text { ADAS } \\
\text { Location }\end{array}$ & $\begin{array}{l}\text { Excitation } \\
\text { [volts] }\end{array}$ \\
\hline 1 & TIME & Test time, sec & computer clock & & & & \\
\hline 2 & 1BFCUFF & \#1 blade cuff flat bending, ft-lbf & full-bridge strain gage & \#1 blade on steel cuff & analog, strain & 1 rotor hub & 10 \\
\hline 3 & 1BFSKIN & \#1 blade skin root flat bending, ft-lbf & full-bridge strain gage & \#1 blade skin 2" from cuff & analog, strain & 1 rotor hub & 10 \\
\hline 4 & 1BEDGE & \#1 blade cuff edge bending, ft-lbf & full-bridge strain gage & \#1 blade on steel cuff & analog, strain & 1 rotor hub & 10 \\
\hline 5 & 1BTORQ & \#1 blade cuff torsion, ft-lbf & full-bridge strain gage & $\# 1$ blade on steel cuff & analog, strain & 1 rotor hub & 10 \\
\hline 6 & FLAPLD & Spoiler flap tongue force, Ibf & precision load cell & $\begin{array}{l}\text { \#1 blade @ flap electromagnet striker } \\
\text { plate }\end{array}$ & analog, transducer & 1 rotor hub & 10 \\
\hline 7 & FLAPANG & Spoiler flap angle, deg & linear transducer & \#1 blade @ flap gas spring & analog, transducer & 1 rotor hub & 10 \\
\hline 8 & 5BFCUFF & \#5 blade cuff flat bending, ft-lbf & full-bridge strain gage & \#5 blade on steel cuff & analog, strain & 1 rotor hub & 10 \\
\hline 9 & 5BFSKIN & \#5 blade skin root flat bending, $\mathrm{ft}-\mathrm{lbf}$ & full-bridge strain gage & $\# 5$ blade skin 2" from cuff & analog, strain & 1 rotor hub & 10 \\
\hline 10 & LSSTRQ & Low speed shaft torque, ft-lbf & full-bridge strain gage & Low speed shaft outboard of sliprings & analog, strain & 2 rotor hub & 10 \\
\hline 11 & LSSOOB & Low speed shaft $0^{\circ}$ bending, ft-lbf & full-bridge strain gage & Low speed shaft $\left(0^{\circ}\right.$ to blade $\left.\# 1\right)$ & analog, strain & 2 rotor hub & 10 \\
\hline 12 & LSS90B & Low speed shaft $90^{\circ}$ bending, ft-lbf & full-bridge strain gage & Low speed shaft $\left(90^{\circ}\right.$ to blade $\left.\# 1\right)$ & analog, strain & 2 rotor hub & 10 \\
\hline 13 & 1BXACCM & Blade midspan $\mathrm{X}$ accel [edgewise], $\mathrm{g}$ & solid state accelerometer & \#1 blade midspan & analog, transducer & 2 rotor hub & 10 \\
\hline 14 & 1BYACCM & Blade midspan $\mathrm{Y}$ accel [flapwise], $\mathrm{g}$ & solid state accelerometer & \#1 blade midspan & analog, transducer & 2 rotor hub & 10 \\
\hline 15 & 1BXACCT & Blade tip X accel [edgewise], g & solid state accelerometer & \#1 blade tip & analog, transducer & 2 rotor hub & 10 \\
\hline 16 & 1BYACCT & Blade tip Y accel [flapwise], g & solid state accelerometer & \#1 blade tip & analog, transducer & 2 rotor hub & 10 \\
\hline 17 & FLAPMOM & Spoiler flap bending moment, ft-lbf & full-bridge strain gage & \#1 blade spoiler flap mid-span & analog, strain & 2 rotor hub & 10 \\
\hline 18 & TTOPNS & Tower top NS bending, ft-lbf & full-bridge strain gage & Tower top (North \& South) & analog, strain & 3 nacelle & 10 \\
\hline 19 & TTOPEW & Tower top EW bending, ft-lbf & full-bridge strain gage & Tower top (East \& West) & analog, strain & 3 nacelle & 10 \\
\hline 20 & ROTRAZ & Rotor azimuth position, deg & Hall effect proximity sensors & Low speed shaft/hub interface & digital, quadrature & 3 nacelle & digital \\
\hline 21 & YAWPOS & Nacelle yaw position, deg & Hall effect proximity sensors & Yaw gear and bearing & digital, quadrature & 3 nacelle & digital \\
\hline 22 & YAWERR & Nacelle yaw error, deg & ratiometric wind direction sensor & Nacelle wind vane & analog, transducer & 3 nacelle & 5 \\
\hline 23 & YAWACC & Nacelle yaw angular acceleration, $\mathrm{g}$ & angular accelerometer & Nacelle frame on tower CL & analog, transducer & 3 nacelle & 5 \\
\hline 24 & TLTACC & Nacelle tilt angular acceleration, $g$ & angular accelerometer & Nacelle frame on tower $\mathrm{CL}$ & analog, transducer & 3 nacelle & 5 \\
\hline 25 & HSSS & High speed shaft speed, rpm & Hall effect proximity sensor & High speed shaft & digital, freq counter & 3 nacelle & digital \\
\hline 26 & TBASNS & Tower base NS bending, ft-lbf & full-bridge strain gage & Tower base (North \&South) & analog, strain & 4 tower base & 10 \\
\hline 27 & TBASEW & Tower base EW bending, ft-lbf & full-bridge strain gage & Tower base (East \& West) & analog, strain & 4 tower base & 10 \\
\hline 28 & PWROUT & Turbine power output, kW & ac kilowatt transducer & Main terminals & analog, watt transducer & 4 tower base & self powered \\
\hline 29 & U HUB & Hub height axial wind speed, $\mathrm{m} / \mathrm{s}$ & NREL/ATI sonic anemometer & Meteorological tower @ hub height [55 ft] & analog, transducer & 4 tower base & self powered \\
\hline 30 & V HUB & Hub height lateral wind speed, $\mathrm{m} / \mathrm{s}$ & NREL/ATI sonic anemometer & Meteorological tower @ hub height [55 ft] & analog, transducer & 4 tower base & self powered \\
\hline 31 & W HUB & Hub height vertical wind speed, $\mathrm{m} / \mathrm{s}$ & NREL/ATI sonic anemometer & Meteorological tower @ hub height [55 ft] & analog, transducer & 4 tower base & self powered \\
\hline 32 & AIRTMP & Ambient air temperature, deg $C$ & RM Young platinum rtd probe & Meteorological tower @ 2 m & analog, transducer & 4 tower base & 2.5 \\
\hline 33 & AIRPRS & Ambient air pressure, mbar & AIR precision barometer & Meteorological tower @ $2 \mathrm{~m}$ & analog, transducer & 4 tower base & 5 \\
\hline 34 & HUBWND & Hub height wind speed, m/s & Maximum 40 anemometer & Meteorological tower @ hub height [55 ft] & digital, freq counter & 5 met base & self powered \\
\hline 35 & HUBWNS & Hub height wind direction, deg & SWI/NRG 200P met vane & Meteorological tower @ hub height [55 ft] & analog, transducer & 5 met base & 5 \\
\hline
\end{tabular}




\subsubsection{Spoiler Flaps}

The aerodynamic opening moment on the spoiler flap is intended to deploy it. The sensor used to identify the actual moment on the device during power production was a load cell used in place of the magnet latch on the \#5 blade as shown in Figure 6-2. The spoiler flap on this blade remained closed during the course of the test so that the opening moments could be measured for all test conditions.

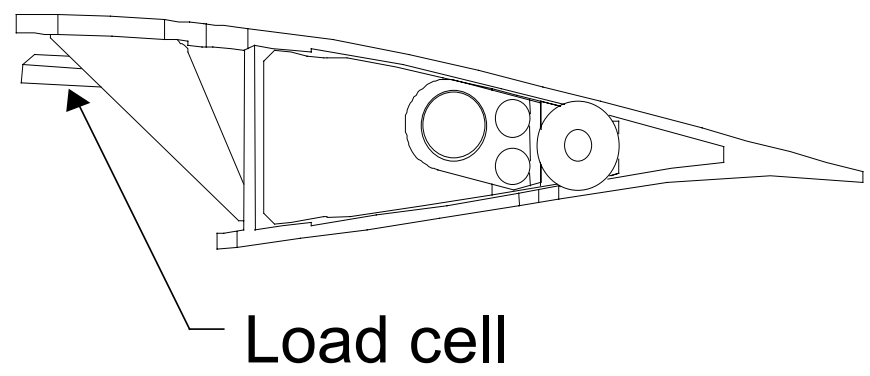

Figure 6-2. Spoiler-flap opening moment load cell

The bending loads in the spoiler flap were measured by bending strain gage installed at the center span as depicted in Figure 6-3. The device was instrumented and calibrated over the expected range of the loads.

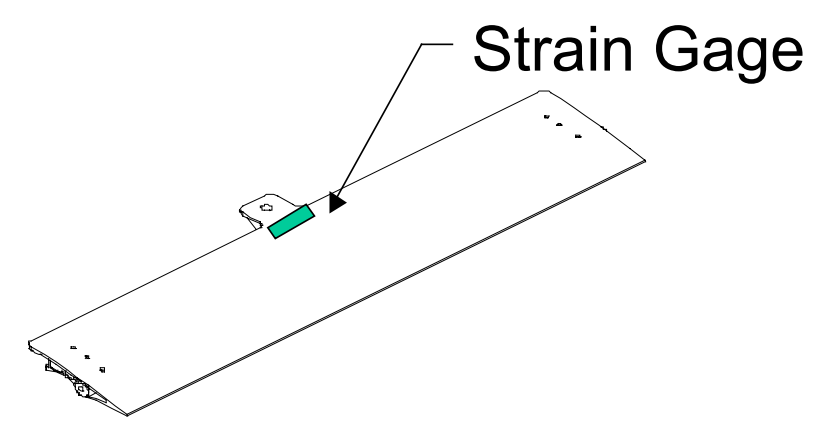

Figure 6-3. Spoiler-flap bending gage

The angular position of the spoiler flap relative to the blade was measured by an LVDT located in the actuation system on the \#1 blade. The deployment rate could also be determined from this sensor. 


\subsection{Calibration}

The calibration procedures and results are summarized in Table 6-2. Manufacturer calibrations were used for all turbine operation and meteorological sensor slopes, whereas their offsets were controlled through shop or field alignment as follows:

- Rotor azimuth and yaw position: locate proximity sensor reset bolt for $0^{\circ}$.

- Yaw error: locate base rotation for $0^{\circ}$ when vane points upwind along shaft axis.

- Sonic anemometer: orient u-axis toward turbine (along prevailing wind direction) and w-axis vertical.

- Temperature: immerse in ice bath.

- Wind vane: locate base rotation for $0^{\circ}$ when vane points away from turbine (along prevailing wind direction, upwind).

- Power and cup anemometer: zero set in manufacturers' calibration.

- Accelerometers: verify slope and offset by rotating in earth gravity field.

The calibration results include rotor azimuth and speed slopes (both for 1 bolt and for 60 teeth on the generator shaft) in response to various attempts to obtain accurate signals. All load channels had the slopes calibrated using end-to-end pull tests with ADAS voltage readouts:

- For blade bending moment gages, the blade root cuff was secured to a test stand before loading the blade just inboard of the spoiler flap in flatwise and edgewise directions with a winch and load cell.

- Blade torsion was applied with a $6 \mathrm{ft}$ beam (moment arm) attached just inboard of the spoiler flap and a system of cables and pulleys.

- The spoiler flap was loaded at its mid-span and at its tongue using a winch and load cell.

- The low-speed-shaft was loaded in torsion through an edgewise pull on a blade attached to the hub (blade) and reacted by the nacelle weight.

- The low speed shaft bending moments were applied by lifting on the hub with a gantry crane and load cell.

- The tower was loaded by yawing the nacelle and rotor, with known weights and centers of gravity.

Load channel offsets were calibrated by performing slow rotations of the rotor and the nacelle during two low-wind opportunities, on December 12, 1996 - December 13, 1996, and December 19, 1996 -

December 20, 1996. The December 12-13 offsets apply to data files dated December 6, 1996 - December 16, 1996. The December 19-20 offsets apply to data files dated December 17, 1996 - December 21, 1996. 
Table 6-2. Sensor Calibration

\begin{tabular}{|c|c|c|c|c|c|c|c|c|c|c|}
\hline No. & DAM & Name & Units & $\begin{array}{c}\text { Slope, EU/V } \\
1 \text { tooth }\end{array}$ & $\begin{array}{c}\text { Slope, EU/V } \\
60 \text { tooth }\end{array}$ & $\begin{array}{c}\text { Offset, EU } \\
12 / 12 / 96\end{array}$ & $\begin{array}{r}\text { Offset, EU } \\
12 / 21 / 96\end{array}$ & Calibration Procedure & Load Application & Offset Procedure \\
\hline 2 & 1 & 1 1bflat 1 cuff & $\mathrm{ft}-\mathrm{lbf}$ & 1257900 & & 1350 & 2330 & flatwise pull near blade tip & winch, load cell & blade slow rotation \\
\hline 3 & & 2 1bflat2 skin & $\mathrm{ft}-\mathrm{lbf}$ & 189400 & & -300 & 500 & flatwise pull near blade tip & winch, load cell & blade slow rotation \\
\hline 4 & & 31 bedge cuff & $\mathrm{ft}-\mathrm{lbf}$ & 1179600 & & -2100 & -2200 & edgewise pull near blade tip & winch, load cell & blade slow rotation \\
\hline 5 & & 4 1btorq cuff & $\mathrm{ft}-\mathrm{lbf}$ & 1573050 & & -1100 & 1000 & twist blade via yoke jig near tip & winch, load cell & blade slow rotation \\
\hline 6 & & 5 flap load cell & Lbf & -3671.8 & & -7 & -12 & pull on flap & winch, load cell & blade slow rotation \\
\hline 7 & & 6 flap angle & Deg & -75.259 & & -44.893 & -44.893 & rotate flap & digital protractor, $0.1^{\circ}$ & release and close \\
\hline 8 & & 7 5bflat1 cuff & $\mathrm{ft}-\mathrm{lbf}$ & 995804 & & 700 & 1820 & flatwise pull near blade tip & winch, load cell & blade slow rotation \\
\hline 9 & & 8 bfflat2 skin & $\mathrm{ft}-\mathrm{lbf}$ & 189496 & & 0 & 650 & flatwise pull near blade tip & winch, load cell & blade slow rotation \\
\hline 10 & 2 & 1 Issq & $\mathrm{ft}-\mathrm{lbf}$ & -24265000 & & 43900 & 43400 & edgewise pull near blade tip & winch, load cell & blade slow rotation \\
\hline 11 & & 2 lss $00 \mathrm{~b}$ & $\mathrm{ft}-\mathrm{lbf}$ & -2828400 & & 300 & 400 & flatwise pull near blade tip & winch, load cell & blade slow rotation \\
\hline 12 & & 3 Iss $90 \mathrm{~b}$ & $\mathrm{ft}-\mathrm{lbf}$ & 2805300 & & $\mathrm{x}$ & $\mathrm{x}$ & flatwise pull near blade tip & winch, load cell & blade slow rotation \\
\hline 13 & & $41 \mathrm{bx}$ acc mid & G & 1.004 & & -2.5231 & -2.5231 & align sensor up, horiz, down & in shop, gravity $=1 \mathrm{~g}$ & parked, no wind \\
\hline 14 & & 51 by acc mid & G & 0.9889 & & -2.4718 & -2.4718 & align sensor up, horiz, down & in shop, gravity $=1 \mathrm{~g}$ & parked, no wind \\
\hline 15 & & $61 \mathrm{bx}$ acc tip & G & 0.9993 & & -2.4657 & -2.4657 & align sensor up, horiz, down & in shop, gravity $=1 \mathrm{~g}$ & parked, no wind \\
\hline 16 & & 7 by acc tip & G & 0.9931 & & -2.4554 & -2.4554 & align sensor up, horiz, down & in shop, gravity $=1 \mathrm{~g}$ & parked, no wind \\
\hline 17 & & 8 flap bend mom & in-lbf & 153900 & & 190 & 164 & pull on flap & winch, load cell & blade slow rotation \\
\hline 18 & 3 & 1 ttop NS & $\mathrm{ft}-\mathrm{lbf}$ & & & $\mathrm{x}$ & $\mathrm{x}$ & yaw slow rotation & nacelle weight and CG & yaw slow rotation \\
\hline 19 & & 2 ttop EW & $\mathrm{ft}-\mathrm{lbf}$ & & & $\mathrm{x}$ & $\mathrm{x}$ & yaw slow rotation & nacelle weight and CG & yaw slow rotation \\
\hline 20 & & 3 azimuth & Deg & 13.645 & 0.22742 & 0 & 0 & rotate shaft through $360^{\circ}$ & shop rotation & pass shaft reset bolt \\
\hline 21 & & 4 yaw pos & Deg & 0.8910891 & & -40 & 80 & rotate mainframe through $360^{\circ}$ & shop rotation & pass yaw reset bolt \\
\hline 22 & & 5 yaw err & Deg & -36 & & 213 & 270 & rotate vane through $360^{\circ}$ & shop rotation & vane $0^{\circ}$ position \\
\hline 23 & & 6 SS accel & G & 5.1624 & & -12.8 & -12.8 & align sensor up, horiz, down & in shop, gravity $=1 \mathrm{~g}$ & parked, no wind \\
\hline 24 & & 7 FA accel & G & 5.136 & & -12.8 & -12.8 & align sensor up, horiz, down & in shop, gravity $=1 \mathrm{~g}$ & parked, no wind \\
\hline 25 & & 8 HSS speed & Rpm & 2400 & 40 & 0 & 0 & & & \\
\hline 26 & 4 & 1 tbas NS & $\mathrm{ft}-\mathrm{lbf}$ & 41111000 & & 50000 & 40100 & yaw slow rotation & nacelle weight and CG & yaw slow rotation \\
\hline 27 & & 2 tbas EW & $\mathrm{ft}-\mathrm{lbf}$ & 41111000 & & -110000 & -81400 & yaw slow rotation & nacelle weight and CG & yaw slow rotation \\
\hline 28 & & 3 power & $\mathrm{KW}$ & 16 & & 0 & 0 & manufacturer's calibration & factory & parked rotor \\
\hline 29 & & $4 \mathrm{u}$ & $\mathrm{m} / \mathrm{s}$ & 10 & & 0 & 0 & manufacturer's calibration & wind tunnel & no wind \\
\hline 30 & & $5 v$ & $\mathrm{~m} / \mathrm{s}$ & 10 & & 0 & 0 & manufacturer's calibration & wind tunnel & no wind \\
\hline 31 & & $6 \mathrm{w}$ & $\mathrm{m} / \mathrm{s}$ & 3 & & 0 & 0 & manufacturer's calibration & wind tunnel & no wind \\
\hline 32 & & 7 temperature & $\operatorname{deg} C$ & 100 & & -50 & -50 & apply freezing and boiling water & $0^{\circ}$ and $100^{\circ} \mathrm{C}$ & shop calibration \\
\hline 33 & & 8 pressure & Mbar & 52 & & 800 & 800 & manufacturer's calibration & factory & factory calibration \\
\hline 34 & 5 & 2 WD vane & Deg & 36 & & 0 & 0 & rotate vane through $360^{\circ}$ & shop rotation & no wind \\
\hline 35 & & 3 WS cups & $\mathrm{m} / \mathrm{s}$ & 0.375 & & 0 & 0 & manufacturer's calibration & wind tunnel & vane $0^{\circ}$ position \\
\hline
\end{tabular}




\subsection{Test matrix}

The planned test matrix is shown in Table 6-3 with a compilation of actual data sets collected. The testplan focused on $40 \mathrm{~Hz}$ loads data, given the concerns about flexible rotor dynamics, stall flutter, and the new spoiler flap approach to aerodynamic braking. Performance testing was not included in the testplan.

Due to lack of high wind speeds and the eventual transmission failure, only $53 \%$ of all planned data sets were collected, and $64 \%$ of required and desired data sets were collected. Between 11/17/96 and 12/21/96 48 data sets were collected with wind speeds ranging from 0 to $18 \mathrm{~m} / \mathrm{s}$, with peaks up to $24 \mathrm{~m} / \mathrm{s}$ and turbulence intensities of $12 \%$ to $19 \%$. Most of the data were collected in daytime and transition periods, as conditions allowed. Turbine conditions tested include:

- Normal operation: 4-16 m/s, 27 sets

- Parked rotor upwind and downwind: $4-16 \mathrm{~m} / \mathrm{s}, 18$ sets

- Starts with motoring: $4-12 \mathrm{~m} / \mathrm{s}, 8$ sets

- Shutdowns with spoiler flaps: $4-16 \mathrm{~m} / \mathrm{s}, 5$ sets

- Overspeed operation with flaps deployed: $10-16 \mathrm{~m} / \mathrm{s}, 3$ sets.

The test demonstrated yaw stability and rotor dynamic stability under the conditions tested, but stability at higher winds remains to be demonstrated. The test also demonstrated stable spoiler flap operation. However, periodic closing of the flaps, thus compromising braking action, indicates a design modification is necessary. Missing data sets include normal operation above $16 \mathrm{~m} / \mathrm{s}$, spoiler flap deployment above $16 \mathrm{~m} / \mathrm{s}$ and $0^{\circ}$ pitch data. Also, long-duration performance data need to be collected to provide a reliable power curve, particularly at the higher winds that were not present during this test. 
Table 6-3. Test Matrix

\begin{tabular}{|c|c|c|c|c|c|c|c|c|c|c|c|c|}
\hline \multirow[t]{2}{*}{ Test Configuration } & \multicolumn{4}{|c|}{ Data Collection Plan } & \multicolumn{4}{|c|}{ Relative Priority } & \multicolumn{4}{|c|}{ Sets Collected } \\
\hline & $4-8 \mathrm{~m} / \mathrm{s}$ & $8-12 \mathrm{~m} / \mathrm{s}$ & $12-16 \mathrm{~m} / \mathrm{s}$ & $>16 \mathrm{~m} / \mathrm{s}$ & $4-8$ & $8-12$ & $12-16$ & $>16$ & $4-8$ & 8-12 & $12-16$ & $>16$ \\
\hline 1 Normal Operation & $\begin{array}{lll}\mathrm{D} & \mathrm{T} & \mathrm{N} \\
4 & 4 & 4\end{array}$ & $\begin{array}{lll}\mathrm{D} & \mathrm{T} & \mathrm{N} \\
4 & 4 & 4\end{array}$ & $\begin{array}{lll}\mathrm{D} & \mathrm{T} & \mathrm{N} \\
4 & 4 & 4\end{array}$ & $\begin{array}{lll}\mathrm{D} & \mathrm{T} & \mathrm{N} \\
4 & 4 & 4\end{array}$ & A & A & A & $B$ & 10 & 8 & 5 & 0 \\
\hline $\begin{array}{l}2 \text { Locked Rotor Stand-By } \\
\text { (Rotor Downwind) }\end{array}$ & 2 sets & 2 sets & 2 sets & 2 sets & $B$ & $B$ & B & $A$ & 2 & 5 & 1 & 0 \\
\hline $\begin{array}{l}3 \text { Locked Rotor Stand-By } \\
\text { (Rotor Upwind) }\end{array}$ & 2 sets & 2 sets & 2 sets & 2 sets & C & C & C & C & 1 & 1 & 0 & 0 \\
\hline 4 Start-Up & 2 sets & 2 sets & 2 sets & 2 sets & $A$ & $A$ & $A$ & $A$ & 1 & 6 & 0 & 0 \\
\hline 5 Shut-Down & 2 sets & 2 sets & 2 sets & 2 sets & A & A & $A$ & A & 2 & 0 & 1 & 0 \\
\hline 6 Spoiler-flap Deployment & 2 sets & 2 sets & 1 set & $1 \mathrm{set}$ & D1 & $\mathrm{D} 2$ & D3 & D4 & 0 & 1 & 2 & 0 \\
\hline \multicolumn{2}{|c|}{$\begin{array}{l}\text { Notes: The tests will conform to the } 1990 \\
\text { IEA recommendations for fatigue testing } \\
\text { of wind turbines. } \\
\text { Configurations } 1,2,3 \text {, and } 6 \text { require } 10 \text {-min } \\
\text { data sets; } 4 \text { and } 5 \text { require } 2 \text {-min data sets. }\end{array}$} & \multicolumn{3}{|c|}{$\begin{array}{l}\text { A } 4-8 \mathrm{~m} / \mathrm{s} \\
\text { B } 8-12 \mathrm{~m} / \mathrm{s} \\
\text { C } 12-16 \mathrm{~m} / \mathrm{s} \\
D>16 \mathrm{~m} / \mathrm{s}\end{array}$} & \multicolumn{4}{|c|}{$\begin{array}{l}\text { Time of Day: } \\
D \text { Day ( } 9 \text { am to } 4 \text { pm) } \\
T \text { Transition ( } 4 \text { pm to } 2 \\
N \text { Night ( } 2 \text { am to } 9 \text { am) }\end{array}$} & \multicolumn{4}{|c|}{$\begin{array}{l}\text { A Required } \\
\text { B Desired } \\
\text { C If available } \\
\text { D At end of test }\end{array}$} \\
\hline
\end{tabular}

Filename: 11173AD1 consists of:

4-digit date, followed by one character each for: configuration, wind speed, time of day, and data set number. 


\subsection{Test}

\subsubsection{Procedures}

Before commencing full operational testing, system functionality and safety were verified through the following checkout procedures:

1. Motor up in low or no wind and observe rotor aeroelastic behavior.

2. Motor up in low or no wind with spoiler magnets de-energized and observe behavior.

3. Operate in low winds, deploy flaps and monitor behavior and loads.

4. Allow overspeed by opening contactor and recover normal speed by closing contactor.

5. Allow overspeed and deploy flaps at $25 \%$ overspeed - prepare to close contactor if problem occurs.

6. Test emergency brake by applying $50 \%$ of capacity (release single solenoid) in low winds and measure braking time - prepare to apply full brake and/or flaps.

Once checkout testing demonstrated safe operation of the turbine and its safety systems, operational testing followed, using these procedures:

1. Turn on power to all systems and look for open circuits or faults.

2. Do slow rotation of rotor and nacelle to obtain start and end zeros.

3. Collect standard data runs with 10-minute records sampled at $160 \mathrm{~Hz}$ and pre-averaged and stored at $40 \mathrm{~Hz}$.

4. Collect 2-min records for start and stop sequences.

5. Shut off and secure all systems before leaving the site.

\subsubsection{Data Acquisition}

All sensors were conditioned and data collected by a Zond Advanced Data Acquisition System (ADAS) and then fed to a desktop computer. The test utilized five Data Acquisition Modules (DAMs) which digitize the analog input signals and transmit them using an error checking RS-422 protocol to the host computer. The use of remote DAMs designed for harsh environments allowed the system to record data near the source, and thereby reduced cable length and measurement noise. Each DAM performs signal conditioning, $160 \mathrm{~Hz}$ sampling, anti-alias filtering, and analog-to-digital conversion for eight input channels.

Two DAMs were installed on the rotor hub, one in the turbine nacelle, one at the tower base, and one at the meteorological tower base. Slip-rings on the mainshaft provided power and communication to the rotor DAMs. The ADAS synchronizes the channels and collects simultaneous data. The desktop computer controls and communicates with the DAMs and provides the user interface.

All channels were collected at $40 \mathrm{~Hz}$ in 10-min files. A complete list of test files collected is presented in Table 6-4. 
Table 6-4. PSE Test Data Files

\begin{tabular}{|c|c|c|c|c|c|}
\hline Filename & Test Type & WD & Notes & Filename & Test Type \\
\hline cal_bld1 & shop calibration & & & 1215e15.def & ADAS def file \\
\hline cal_bld1_2 & shop calibration & & & 12121adg & blade rotation \\
\hline cal_bld1_accc & shop calibration & & & $1220 \mathrm{br} 1$ & blade rotation \\
\hline cal_bld5 & shop calibration & & & 11172ad1 & downwind standby \\
\hline cal_Iss & shop calibration & & & 11172ad2 & downwind standby \\
\hline flap_ang & shop calibration & & & 12062bd1 & downwind standby \\
\hline wind_ang & shop calibration & & loosened flap spanwise bolts $11 / 9$ & $12102 \mathrm{bd} 1$ & downwind standby \\
\hline ye_ang & shop calibration & & removed second gas springs $11 / 16$ & $12102 \mathrm{bd} 2$ & downwind standby \\
\hline $11 \overline{17} 2 \mathrm{ad} 1$ & downwind standby & W & wattmeter wired wrong & $12102 b t 1$ & downwind standby \\
\hline 11172ad2 & downwind standby & W & & $12102 \mathrm{bt} 2$ & downwind standby \\
\hline 11173ad1 & upwind standby & W & & 12102ct1 & downwind standby \\
\hline 11173ad2 & upwind standby & W & & 1221ra0 & flaps deployed \\
\hline 11234ad1 & start - xxx & W & ADAMs $1 \& 2$ bad & 1221ra1 & flaps deployed \\
\hline 1125mot1 & motoring flaps & & & 1221ra2 & flaps deployed \\
\hline 1125 mot2 & motoring flaps & & & 1125 mot 1 & motoring flaps \\
\hline $12062 b d 1$ & downwind standby & W & light rain & 1125 mot2 & motoring flaps \\
\hline $12102 \mathrm{bd} 1$ & downwind standby & W & & 1213yr1 & nacelle rotation \\
\hline $12102 \mathrm{bd} 2$ & downwind standby & W & & 1219yr1 & nacelle rotation \\
\hline $12102 b t 1$ & downwind standby & W & & 12121ad1 & run \\
\hline $12102 \mathrm{bt} 2$ & downwind standby & W & & 12121at1 & run \\
\hline $12102 c t 1$ & downwind standby & W & & 12121at2 & run \\
\hline 12115at1** & stop & WSW & flaps and brake & 12121at3 & run \\
\hline $12121 \mathrm{ad} 1^{* *}$ & run & WNW & & 12121at4 & run \\
\hline 12121adg & blade rotation & WNW & flap may be deployed & $12121 \mathrm{bd} 1$ & run \\
\hline 12121at1** & run & WNW & & $12121 \mathrm{bd} 2$ & run \\
\hline 12121at2** & run & WNW & & $12121 \mathrm{bd} 3$ & run \\
\hline 12121at3** & run & WNW & & $12181 \mathrm{ad} 1$ & run \\
\hline 12121at4** & run & WNW & & 12181ad2 & run \\
\hline $12121 \mathrm{bd} 1^{* *}$ & run & NW & light mist & 12181ad3 & run \\
\hline $12121 \mathrm{bd} 2^{* *}$ & run & W & & 12181ad4 & run \\
\hline $12121 \mathrm{bd} 3^{* *}$ & run & WNW & & 12181at1 & run \\
\hline $1213 y r 1$ & nacelle rotation & W & & $12181 \mathrm{bd} 1$ & run \\
\hline $12143 b d 1$ & upwind standby & NE & very gusty, hybrid system problems & $12181 \mathrm{bd} 2$ & run \\
\hline $12145 \mathrm{~cd} 1$ & stop - xxx & SE & very gusty, ADAM 3 bad & $12181 \mathrm{bd} 3$ & run \\
\hline $12145 c d 2$ & $x x x$ & & ${ }^{*}$ not convertible & $12181 \mathrm{bd} 4$ & run \\
\hline $12152 \mathrm{bd} 1$ & $x x x$ & & ${ }^{*}$ no ADAM 3 & $12211 \mathrm{bd} 1$ & run \\
\hline $12152 \mathrm{~cd} 1$ & $x x x$ & & * no ADAM 3 & $12211 \mathrm{~cd} 1$ & run \\
\hline 12154bt1 & start & $E$ & & $12211 \mathrm{~cd} 2$ & run \\
\hline 1215e15.def & ADAS def file & & fixed wattmeter wiring & $12211 \mathrm{~cd} 3$ & run \\
\hline $12165 a d 1$ & stop & & ADAM power supply problems & $12211 \mathrm{~cd} 4$ & run \\
\hline $12171 \mathrm{ad} 1$ & $x x x$ & & ${ }^{*}$ not convertible & $12211 \mathrm{~cd} 5$ & run \\
\hline $12174 \mathrm{bd} 1$ & start & & & cal bld1 & shop calibration \\
\hline $12174 b t 1$ & start & & Stop and restart & cal_bld1_2 & shop calibration \\
\hline $12181 \mathrm{ad} 1$ & run & $\mathrm{E}$ & flaps may have opened & cal_bld1_accc & shop calibration \\
\hline $12181 \mathrm{ad} 2$ & run & ENE & & cal_bld5 & shop calibration \\
\hline $12181 \mathrm{ad} 3$ & run & $\mathrm{E}$ & & cal_Iss & shop calibration \\
\hline $12181 \mathrm{ad} 4$ & run & $\mathrm{E}$ & flaps at $9 \mathrm{~min}$ & flap_ang & shop calibration \\
\hline 12181at1 & run & ENE & gusty, self-start & wind_ang & shop calibration \\
\hline 12181at2 & $x x x$ & & ${ }^{*}$ not convertible & ye_ang & shop calibration \\
\hline $12181 \mathrm{bd} 1$ & run & $E$ & $12 \mathrm{~m} / \mathrm{s}, 65 \mathrm{~kW}$ & $11 \overline{2} 34 \mathrm{ad} 1$ & start \\
\hline $12181 \mathrm{bd} 2$ & run & $\mathrm{E}$ & Gustier & $12154 \mathrm{bt} 1$ & start \\
\hline $12181 \mathrm{bd} 3$ & run & ENE & $40 \mathrm{~kW}$ at start & $12174 \mathrm{bd} 1$ & start \\
\hline $12181 \mathrm{bd} 4$ & run & ESE & dead wind at times & $12174 b t 1$ & start \\
\hline $12184 b t 1$ & start & & & $12184 b t 1$ & start \\
\hline $1219 y r 1$ & nacelle rotation & & added ADAM 5 with cups and vane & $12214 \mathrm{bd} 1$ & start \\
\hline $1220 \mathrm{br} 1$ & blade rotation & & & 12115at1 & stop \\
\hline $12211 \mathrm{bd} 1^{* *}$ & run & W & possible open flap & $12145 \mathrm{~cd} 1$ & stop \\
\hline $12211 \mathrm{~cd} 1^{* *}$ & run & W & 19 min long & $12165 \mathrm{ad} 1$ & stop \\
\hline $12211 \mathrm{~cd} 2^{* *}$ & run & W & $80 \mathrm{~kW}$ & 11173ad1 & upwind standby \\
\hline $12211 \mathrm{~cd} 3^{* *}$ & run & W & & 11173ad2 & upwind standby \\
\hline $12211 \mathrm{~cd} 4^{* *}$ & run & W & & $12143 \mathrm{bd} 1$ & upwind standby \\
\hline $12211 \mathrm{~cd} 5^{* *}$ & run & W & & $12145 \mathrm{~cd} 2$ & $x x x$ \\
\hline $12214 \mathrm{bd} 1^{* *}$ & start & WSW & & $12152 \mathrm{bd} 1$ & $x x x$ \\
\hline $1221 \mathrm{ra0}$ & flaps deployed & W & high speed shaft broken & $12152 \mathrm{~cd} 1$ & $x x x$ \\
\hline 1221ra1 & flaps deployed & W & high speed shaft broken & 12171ad1 & $x x x$ \\
\hline 1221ra2 & flaps deployed & W & high speed shaft broken & 12181at2 & $x x x$ \\
\hline
\end{tabular}




\subsubsection{Data Reduction}

The ADAS software delivered rather cryptic binary raw data. To extract useful information from these data, several steps were required:

1. Process the slope and offset data and set up an ADAS definition file.

2. Run the ADAS convert utility to extract ASCII data in engineering units.

3. Run summary statistics on each data set to determine mean, standard deviation, minimum, and maximum for each channel.

4. Plot sample time histories and compare with structural models.

5. Bin power and load channels against wind speed and plot general power and load curves.

6. Compute and plot power spectra for all channels for a sample operating data file.

7. Rainflow count all loads data and compute annual fatigue spectra.

8. Compare fatigue spectra to material SN curves with appropriate de-rating and safety factors.

9. Pre-average data at one-second, one-minute, and ten-minute intervals and compute and compare power curves.

\subsection{Accident}

During testing in relatively high winds $(\sim 15 \mathrm{~m} / \mathrm{s})$, on December 22,1996 , the generator shaft that holds the high speed pinion failed, and caused the rotor to go into overspeed. The pinion, which mates with the high-speed bull gear in the transmission, was special ordered from the manufacturer, Nuttall Gear, to provide the necessary step-up ratio to match the full-scale rotor tip speed. It is secured to the shaft with a locknut and torque is transmitted through a spline fit. The shaft had to be machined down to a smaller diameter to match the pinion. This process resulted in a relatively small radius at the point where it is cantilevered from the main body of the generator rotor. We believe cracks were initiated at this point during the many full-brake stops that occurred during test start-up phase when problems were experienced with the hybrid power system.

As soon as the rotor became decoupled from the generator and mechanical brake it entered an overspeed condition, reaching speeds in excess of $200 \%$ normal. Power to the hub-mounted DAMs and the spoiler flaps was not interrupted during this event so that the holding magnets stayed energized and the spoiler flaps remained in the stowed position. Within a few seconds, they were manually deployed which brought the rpm down to a safe condition.

After approximately 24 hours of operating in a freewheeling mode, one blade failed at its root attachment to the hub and the resulting imbalance caused the remaining blades to fail. Data recorded during this event revealed that the rotor speed reached levels well above the design rpm with spoiler flaps deployed. This was true even with only four of the five devices operating. The \#5 blade device was held in the stowed position by a load cell. The spoiler-flap angle sensor on the \#1 blade showed that the flap was not remaining in its fully deployed position. It would fully deploy at the higher rpm, the rotor would slow producing higher angles of attack, and it appeared that the flow in the flap region, combined with the flap return spring, were causing the flap to partially close. This would result in the rotor accelerating to a relatively high rpm before the flap would again fully deploy. The rotor continued to cycle in this manner until the failure occurred. The blade edgewise strain gage indicated that the first edgewise mode was responding at its natural frequency, which is $2 \mathrm{P}$ at $150 \%$ rotor speed. A 4 -second sample of blade bending moment data is shown in Figure 6-4. Here the edgewise mode is responding at its natural frequency which is about $2.8 \mathrm{~Hz}$ while the flatwise is responding primarily at $1 \mathrm{P}$. The edgewise gravity moment is $+/-1200 \mathrm{ft}-\mathrm{lb}$, yet the root moments reached $+/-6500 \mathrm{ft}-\mathrm{lb}$ indicating a significant amplification. At $90 \mathrm{rpm}$, the gravity excitation would be close to one half the edgewise natural frequency which could produce amplification of the edgewise response. If the rotor had approached $300 \%$, speed the edgewise 
frequency would have been at $1 \mathrm{P}$ and coalescence with the $1 \mathrm{P}$ gravity force would have occurred. It is unlikely any blade operating under these conditions would have survived more than a few hundred revolutions. However, it is not known whether the RPM reached this level. The deformation in the failed blade cuff indicated the failure mode was in the edgewise direction.

We believe the overspeed would have remained below 125\% of normal had the spoiler flaps remained in their fully deployed positions. At that rotor speed, well away from an edgewise resonance, no damage would be expected. A design solution would simply involve a latching mechanism that holds the device at full deployment after reaching that position. The latch could then be released automatically at low rpm allowing the flap to return to the stowed position.

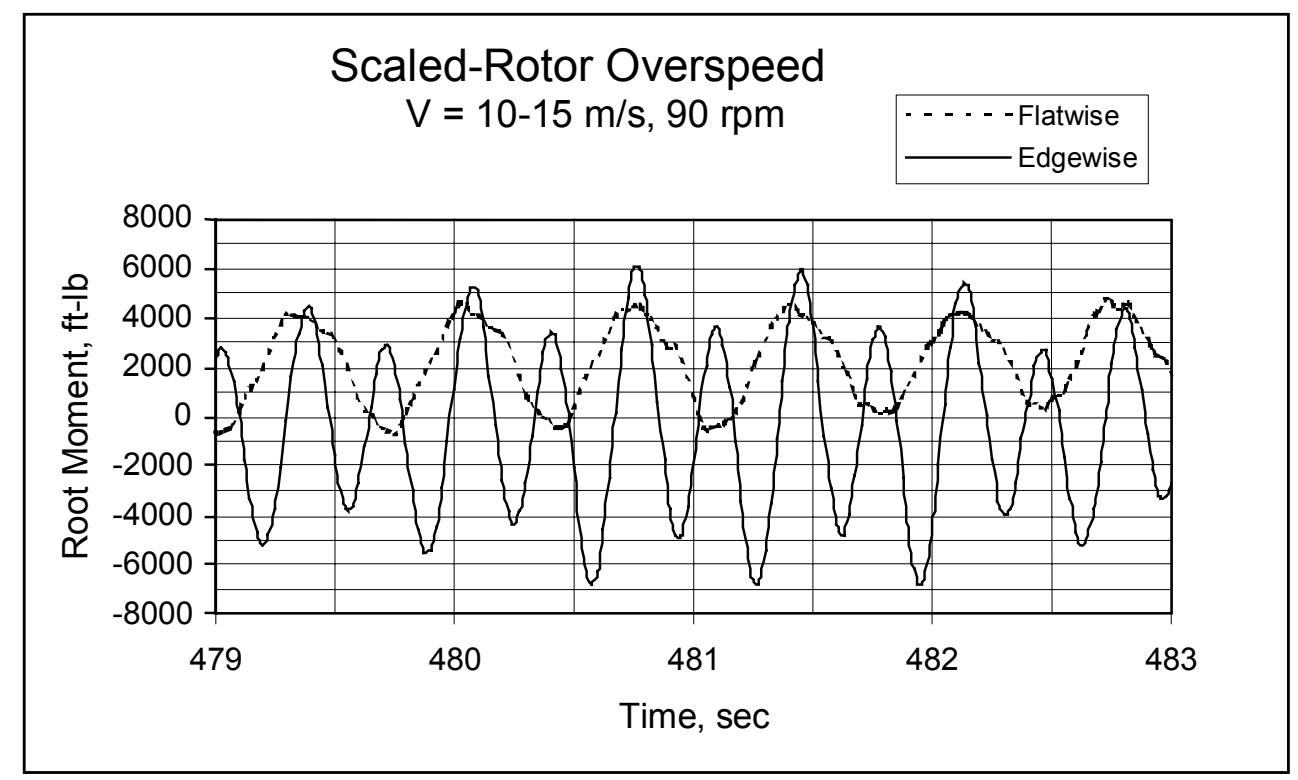

Figure 6-4. Flatwise and edgewise moments in overspeed

\subsection{Correlation}

\subsubsection{Performance}

Unfortunately, this test collected only 70 min of good power data with winds in the prevailing direction, whereas reliable power curves require several days' data. However, the data show reasonable correlation with design estimates in the limited range of available wind speeds $(11-19 \mathrm{~m} / \mathrm{s})$. Test data show power up to $70 \mathrm{~kW}$ at $19 \mathrm{~m} / \mathrm{s}$, but lack enough higher wind speed data to see how well the rotor stalls.

When binning $40 \mathrm{~Hz}$ power data against wind speed in unsteady wind, the time lag for wind to move from the meteorological tower to the wind turbine causes the average power for the whole data set to spread among all bins, giving a horizontal line for the power curve. Data must be pre-averaged on the order of the time lag to improve its correlation for binning. Figure 6-5 shows how power curves for preaveraging intervals of 1 second $(1 \mathrm{~Hz}), 10 \mathrm{~s}$ and $1 \mathrm{~min}$ tilt left as the interval increases. An approximate wind time lag can be found by dividing wind speed into the tower distance, i.e., for $30 \mathrm{mph}$, time equals $140 \mathrm{ft}$ divided by $44 \mathrm{ft} / \mathrm{s}$ equals $3.4 \mathrm{~s}$. 


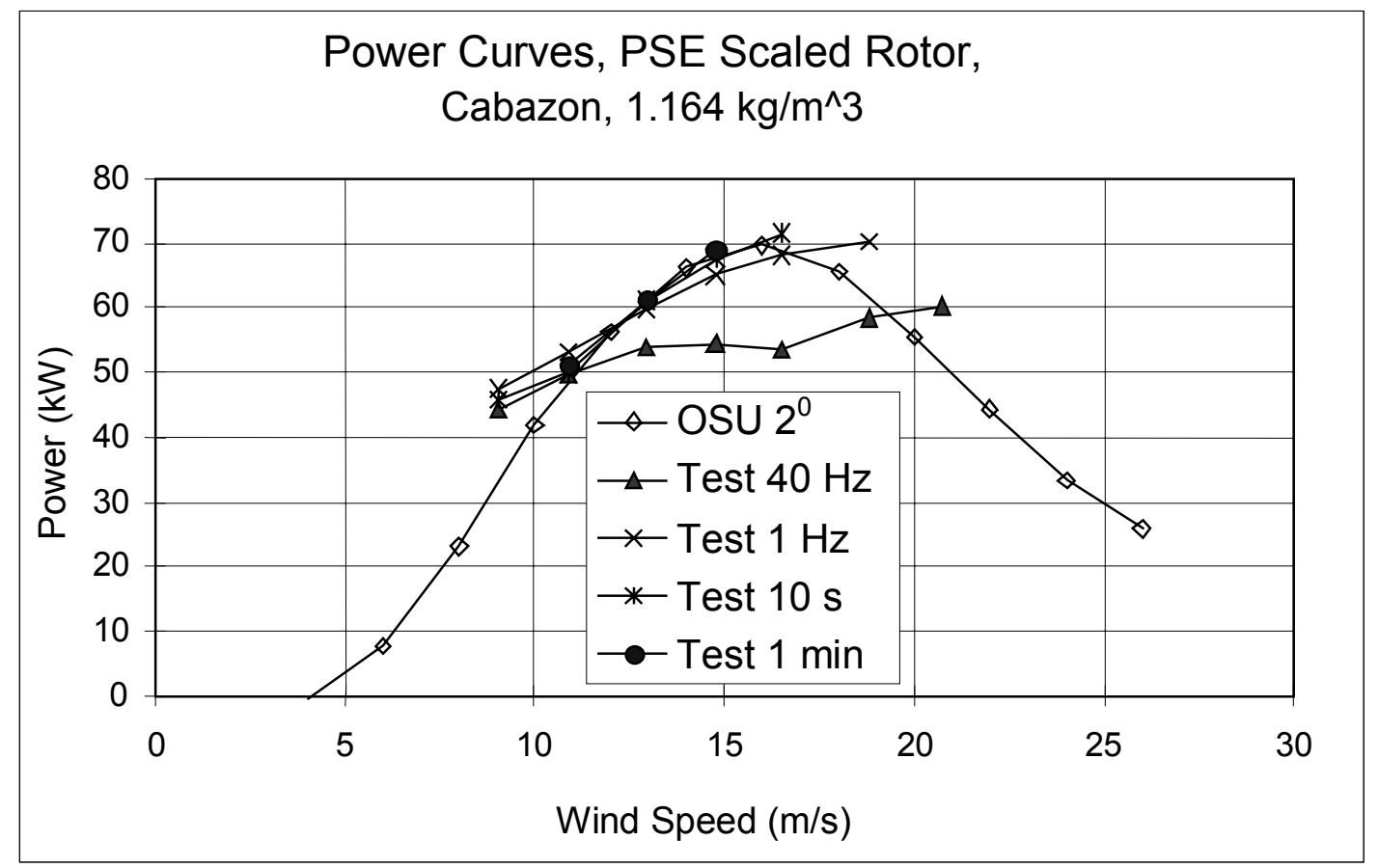

Figure 6-5. Power curve correlation

\subsubsection{Loads}

The load profiles shown in Figures 6-6 through 6-9 benefited from a larger selection of data, as those sensors were functional for $140 \mathrm{~min}$ of data collection with winds in the prevailing direction. In general, visual correlations are good.

The tested torque curve in Figure 6-6 runs slightly below the PROP93 model at $11-17 \mathrm{~m} / \mathrm{s}$, and may indicate some power shortfall in that region. Some of the discrepancy could be due to improper modeling of the inboard blade aerodynamics where the stiffeners are attached. The tested root edge bending moment curve in Figure 6-9 is similar to the torque curve, but somewhat higher relative to its PROP93 model, perhaps as a result of some calibration uncertainty.

The tested thrust curve in Figure 6-7 runs about 20\% below the PROP93 model. Some of this could be due to the stiffener aerodynamics as stated above for the power discrepancy. Also, the PROP93 model assumes a rigid rotor and locked yaw, whereas the flexible blades and yaw freedom would allow some load relief. Similarly, the tested root flap bending moment curve in Figure 6-8 runs about $67 \%$ below that of the PROP93 model. This would be expected since the rigid PROP93 blade does not allow centrifugal relief of the bending moments. Allowing a blade flap degree of freedom in a YAWDYN model gives much lower root flap bending moments. 


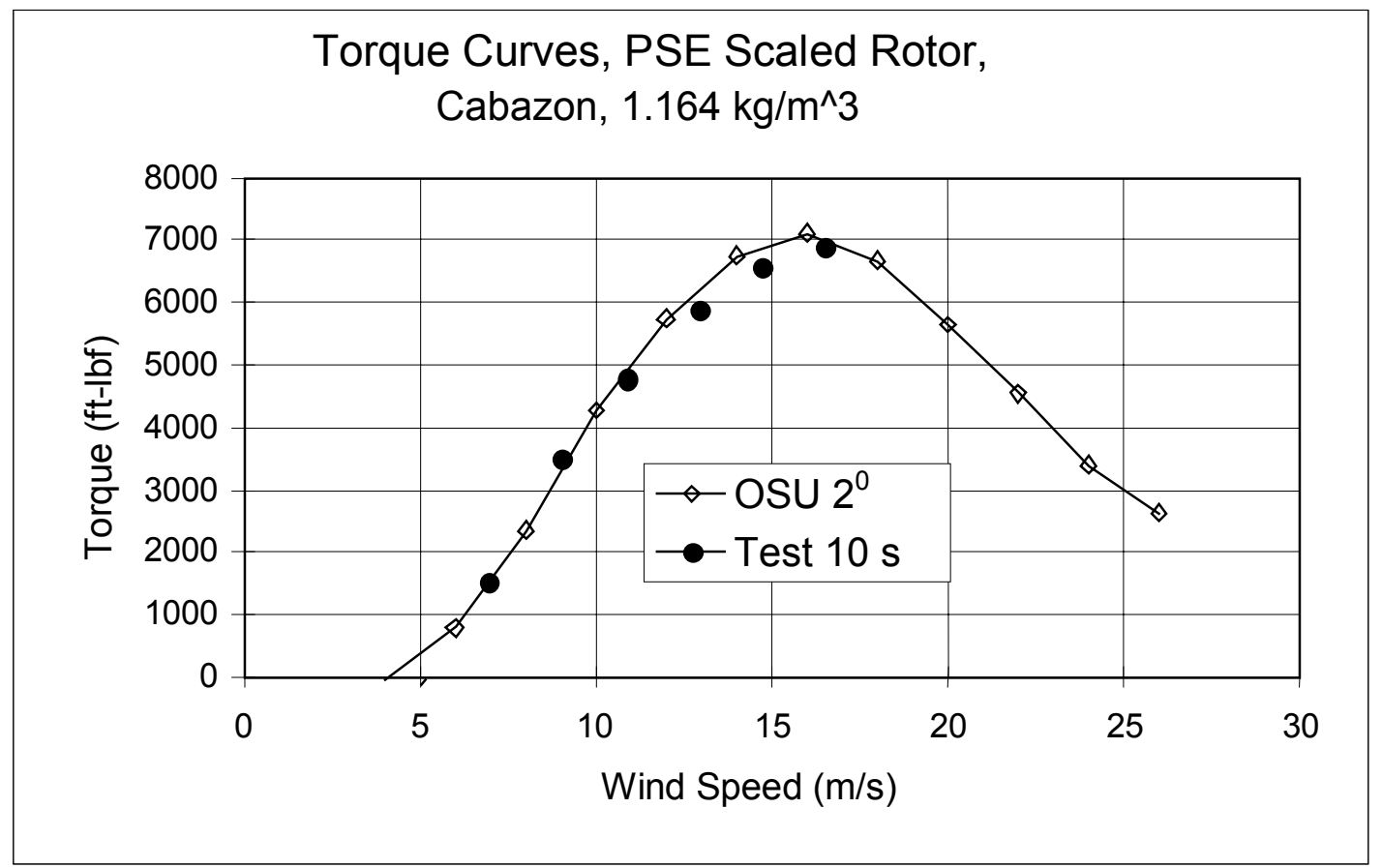

Figure 6-6. Rotor torque

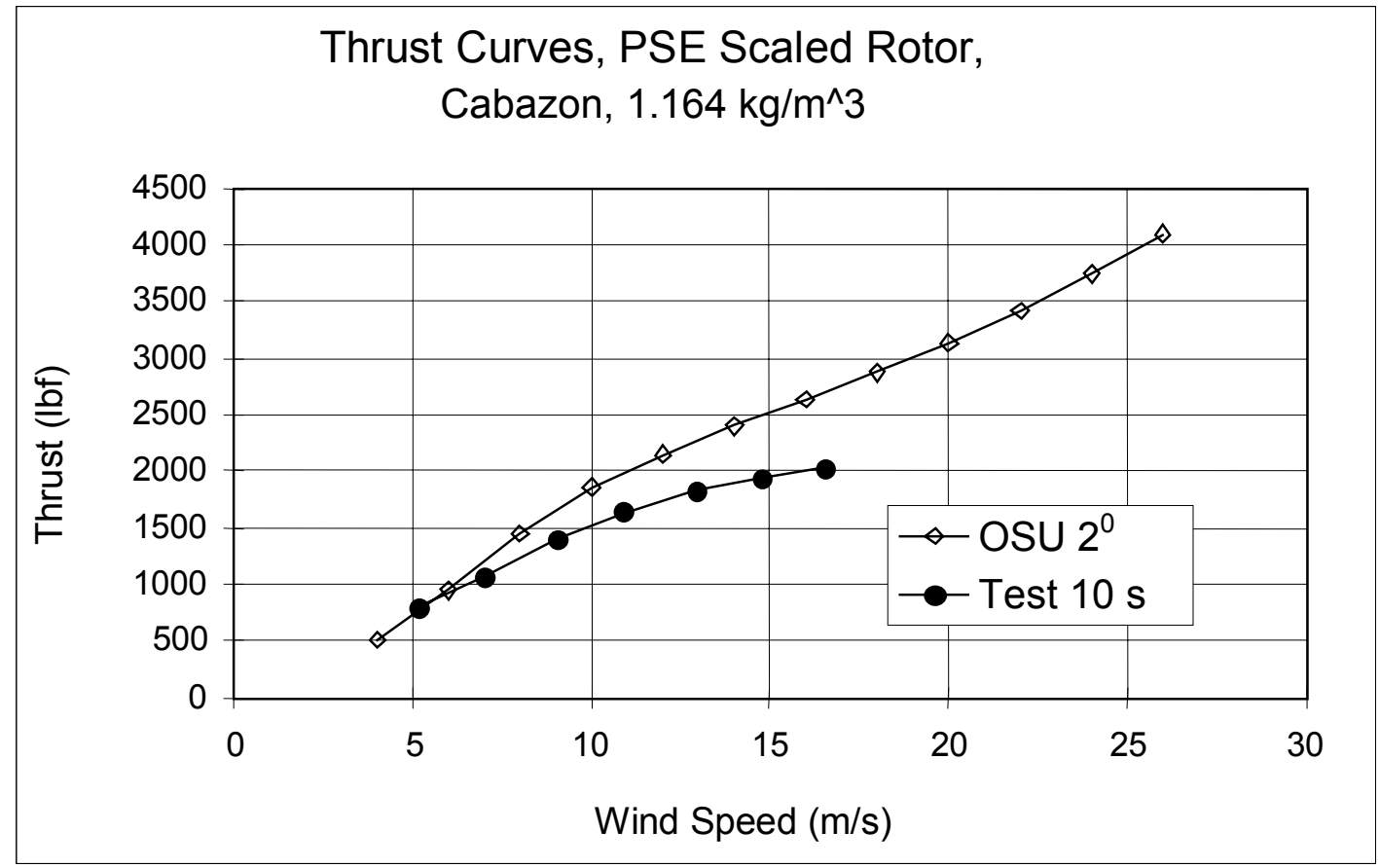

Figure 6-7. Rotor thrust 


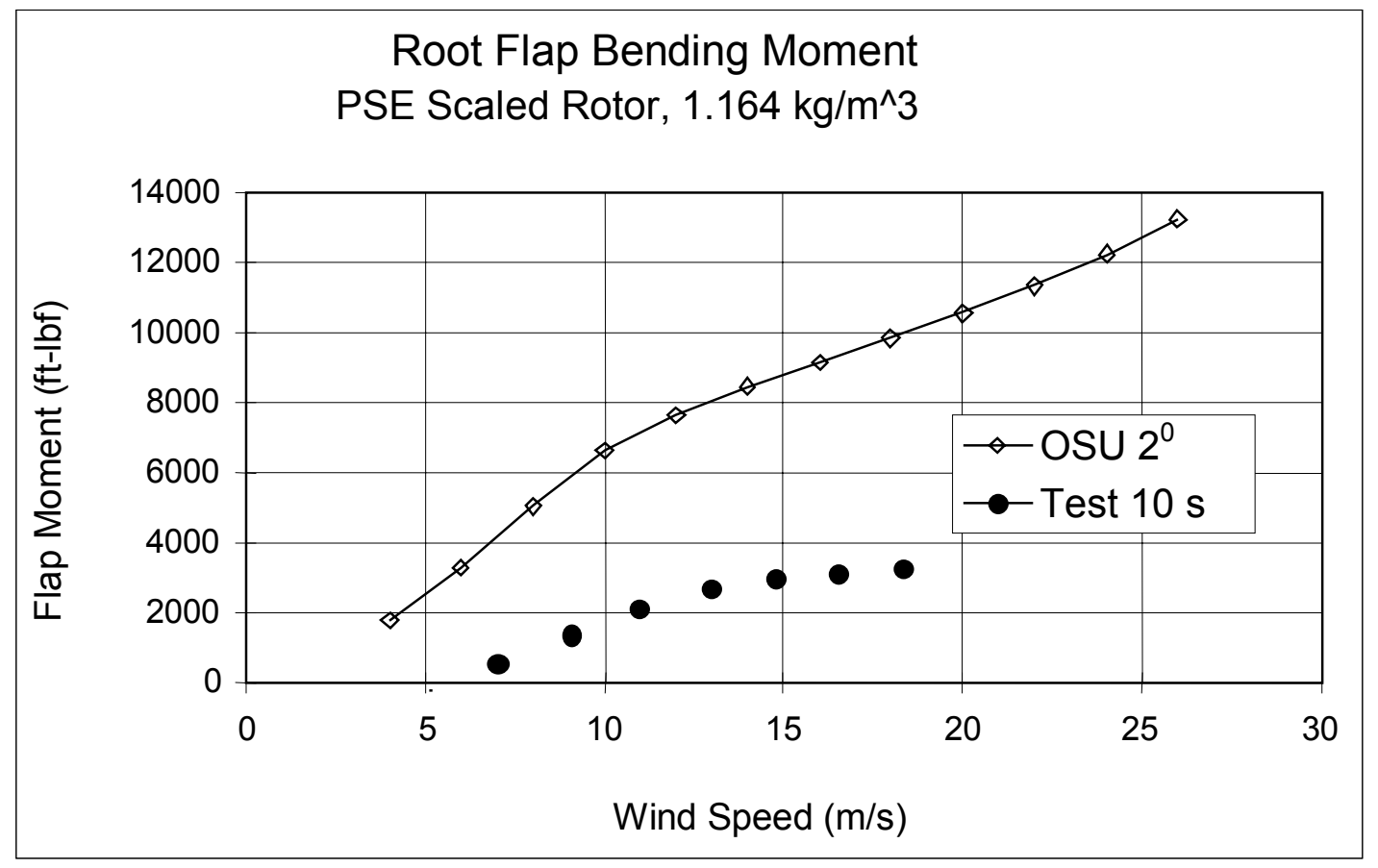

Figure 6-8. Root flat bending moment

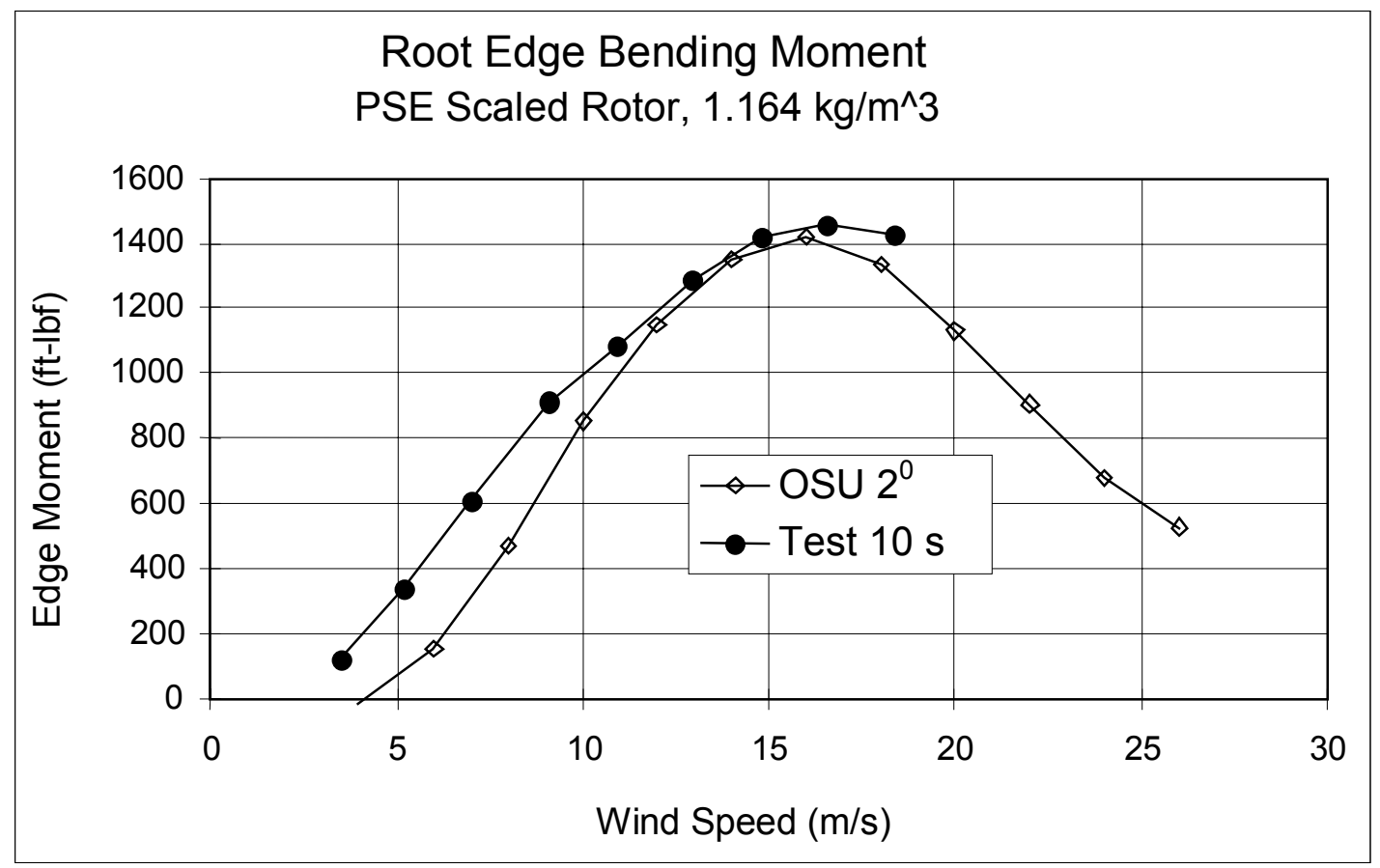

Figure 6-9. Root edge-bending moment 


\subsubsection{Blade Stresses}

\subsubsection{Flexdyne Aeroelastic Analysis}

Presented in this section is a description of the Flexdyne (FD) wind turbine analysis, including its basic approach, principal assumptions, and features. Also presented is some limited correlation of Flexdyne results with scaled-rotor test results. The Flexdyne analysis was developed by Peter Arcidiacono for PS Enterprises, References 12 and 13.

A potentially significant limitation of many wind turbine analyses is the neglect of blade flexibility effects, including torsion. As wind turbines increase in diameter and weight savings are pursued, such effects are of greater concern, particularly with simplified designs having flexible blades rigidly attached to the hub. Flexdyne was developed to address this limitation. A further objective of the effort was to develop a computer code for solving the resulting equations on a personal computer. This code would allow the transient and steady state responses of the system as well as its performance under steady wind conditions to be determined.

Flexdyne is a modal analysis in which the differential equations of motion for the coupled bending torsional deformations of wind turbine blades having chordwise mass unbalance and subjected to yaw motions about a vertical tower are solved by numerical integration. Coupling with the yaw degree of freedom is accomplished by taking advantage of the wide separation of blade and yaw natural frequencies. This separation allows simulation of multiple blades by suitably summing single blade results. Further details are presented in References 12 and 13 on the equations and the associated computer program developed for use on a personal computer using Lotus 123.

Principal assumptions are listed below:

1. The rotor has a constant angular velocity and the hub is fixed except for a yaw degree of freedom about a vertical tower axis.

2. The blade has a straight, radial elastic axis so that blade deflections can be considered to be the superposition of orthogonal translations of and a rotation about the elastic axis.

3. Steady, two-dimensional aerodynamic theory including stall effects is applicable. Three separate sets of airfoil data can be used to account for airfoil and/or Reynolds Number variation.

4. Self-induced rotor inflow is determined by a modified blade-element momentum theory. Thus, wind velocity components in the plane of the disk are assumed to be relatively small compared to the wind component normal to the disk.

5. Ambient wind modeling includes the effects of ground boundary layer, tower shadow, and both prescribed and random gusts. At any point in time, the wind varies only with vertical position. The wind front encompasses the entire rotor.

6. Principal blade flexibility effects are simulated using a finite summation of blade natural modes. The number of modes included is five: nominally three flatwise, one edgewise, and one torsion.

7. The azimuth increment used in the numerical integration process is fixed at 15 degrees. This is done to save computation time but requires a "static" solution of the modes having frequencies above about 5 per revolution. In a static solution, modal acceleration terms are neglected in the numerical integration of the equations of motion. 
Flexdyne has the following principal capabilities:

1. Twenty blade segments

2. Up to 6 blades

3. Up to 54 revs for a single wind condition

4. Yaw degree of freedom, inertia, natural frequency, and damping computations

5. Three wind components (one normal to rotor plane and two orthogonal inplane)

6. Nonlinear blade section aerodynamics

7. Blade twist and taper

8. Multiple airfoils along the span

9. Modified blade element-momentum self-induced flow

10. Wind shear effects

11. Tower shadow effects

12. A variety of wind time history models:

13. Test wind data (which can be scaled if desired)

14. Ramp or sinusoidal gusts

15. Random turbulent winds

16. Approximate cycle counting routines for flatwise and chordwise moments

17. Radial and azimuthal distributions of blade aerodynamic parameters

18. Rotating and fixed system moments and shears

19. Graphs of input and output

20. A user-driven control macro and a user-friendly interface

21. Relatively fast computation time (6 to $15 \mathrm{~s}$ per revolution on $266 \mathrm{Mhz}, 64 \mathrm{k}$ RAM, Pentium II computer)

22. Supporting utility programs for calculating input blade modal parameters

23. Complete user's manual including equations of motion.

\subsubsection{Correlation with Scaled-Rotor Test Results}

The following discusses the results of a limited effort to correlate the latest version of Flexdyne with results from the scaled-rotor test. Emphasis is on root flatwise and edgewise moment cycle count correlation. The approach used for counting Flexdyne cycles is an approximate one, see Reference 13. The correlation obtained using both test wind and Flexdyne-generated random wind models as excitation sources is presented. In addition, some time history comparisons of blade moments, yaw angle and power are also presented. All blade moments are shown for the $2.5 \%$ span station.

Blade root flatwise moment cycle per hour correlation is presented in Figure 6-10 for a nominal $11 \mathrm{~m} / \mathrm{s}$ test point (PSE12211 cd1 data file) for the scaled rotor. The Flexdyne results were obtained using test wind measurements taken $45 \mathrm{~m}$ upstream of the rotor hub. Note that the test cycle per hour results are based on ten minutes of operation while the Flexdyne values are based on 3.3 min of simulated operation. The Flexdyne results "converged" after about 2 to $3 \mathrm{~min}$. The correlation shown is quite reasonable. 


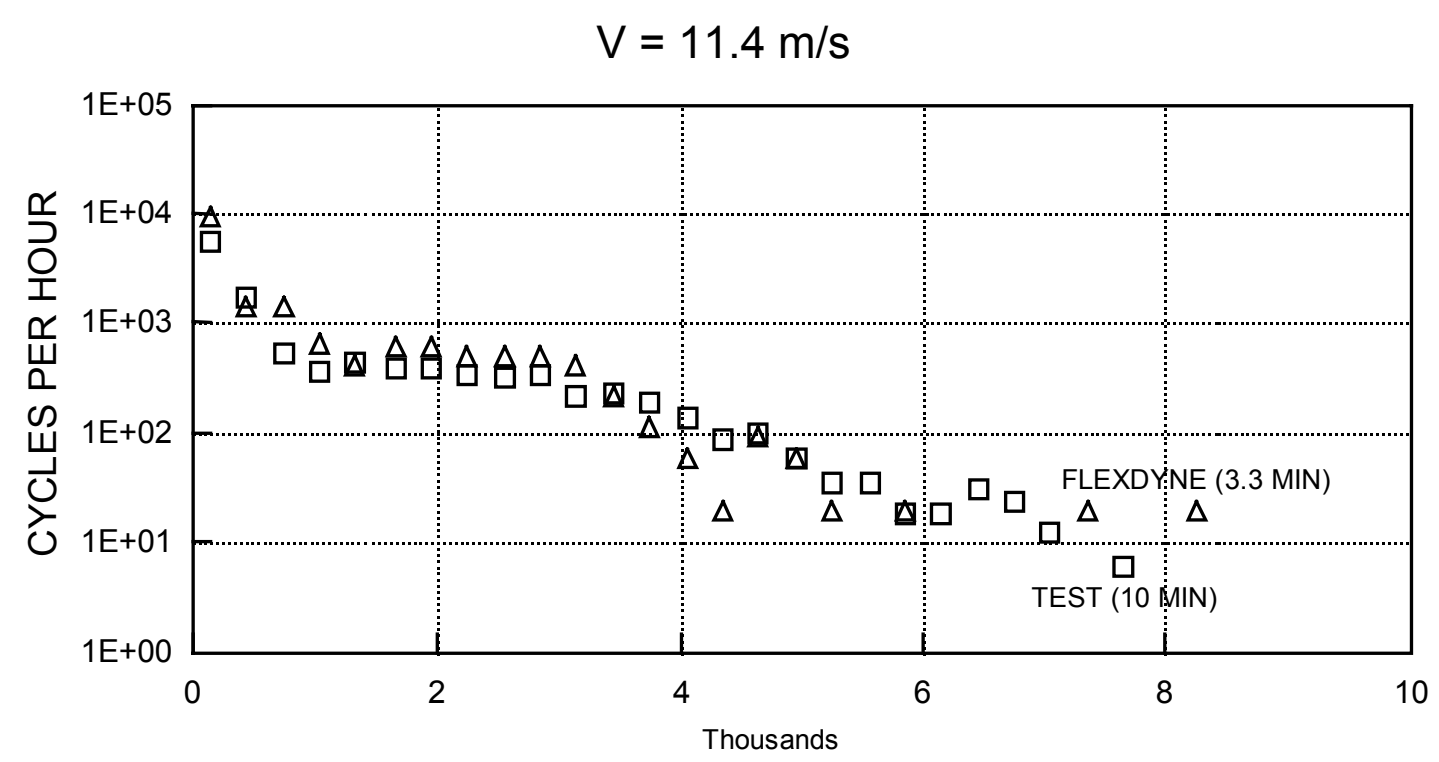

FLATWISE MOMENT PEAK-TO-PEAK AMPLITUDE (300 FT-LB BIN), FT-LBS

Figure 6-10. Comparison of root flatwise cycles/hour results, $\mathrm{V}=11.4 \mathrm{~m} / \mathrm{s}$

Figure 6-10 compared root flatwise moment test results with those computed by Flexdyne using test wind data as input. Flexdyne has a feature that allows a linear scaling of the test wind velocity time history. This permits a different mean wind condition to be easily simulated. Figure 6-11 compares test results for a $7 \mathrm{~m} / \mathrm{s}$ operating condition with Flexdyne results obtained using the $11 \mathrm{~m} / \mathrm{s}$ wind time history scaled to a $7 \mathrm{~m} / \mathrm{s}$ level. The comparison is considered good.

Previous results compared Flexdyne results obtained using test wind time histories as the wind model. Flexdyne also has the capability of generating a random wind model. Figure 6-12 compares the results obtained for the $11 \mathrm{~m} / \mathrm{s}$ case when the following random wind model was used:

- High frequency max turbulence wind velocity/steady wind velocity $=0.07$.

- Low frequency max turbulence wind velocity/steady wind velocity $=0.43$.

- High frequency turbulence wind angle $\max$ variation $=20^{\circ}$.

- Low frequency turbulence wind angle max variation $=40^{\circ}$.

- Azimuth increment at which high frequency turbulence randomly changes $=45^{\circ}$.

- Azimuth increment at which low frequency turbulence randomly changes $=1080^{\circ}$. 


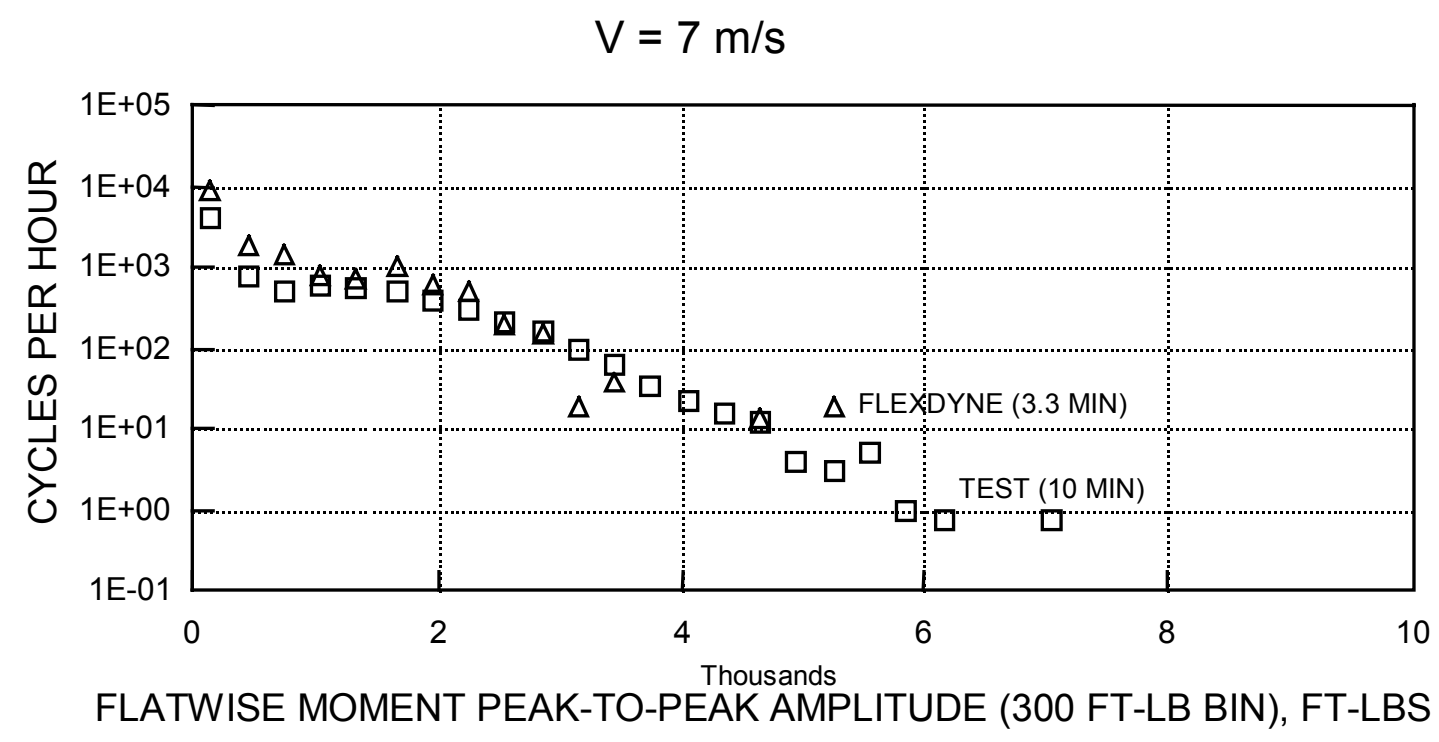

Figure 6-11. Comparison of root flatwise cycles/hour results, $V=7 \mathrm{~m} / \mathrm{s}$

These values were selected from cursory observation of the general characteristics of the test wind time histories. No attempt was made to optimize the parameters. The model makes random step changes in velocity and angle at the azimuth increments noted. It was found that the random wind model gave "converged" results with about 2.5 to $3 \mathrm{~min}$ of simulated operation (equivalent to 3 to 4 sequential 54-rev Flexdyne cases).

The Flexdyne results with the random wind are seen to be conservative (i.e., high) in the mid-to-high moment amplitude range. This may be due to the wind model parameters selected and/or due to the fact that the random wind model causes step changes in velocity and angle to occur. Systematic investigation of the random wind model parameters is needed to determine if improved correlation can be obtained.

Shown below are comparisons of test edgewise moment cycles at the root of the blade with Flexdyne results obtained using the test wind model (Figure 6-13) and using the random wind model (Figure 6-14). The correlation using the test wind in Flexdyne is not as good as that achieved for the flatwise moment cycles. There is an underprediction of the low moment amplitude cycles (due to the absence of the second edgewise mode in Flexdyne in these calculations). On the other hand, the moderate-to-high moment cycles are overpredicted. Possible factors affecting the overprediction include:

- The value of structural damping assumed (1.5\%)

- The tower shadow factor assumed (0.5)

- The test cycles were counted using a more rigorous algorithm than that used in Flexdyne

- The Flexdyne results were based on a shorter period of operation.

The Flexdyne results using the random wind model are quite conservative. 


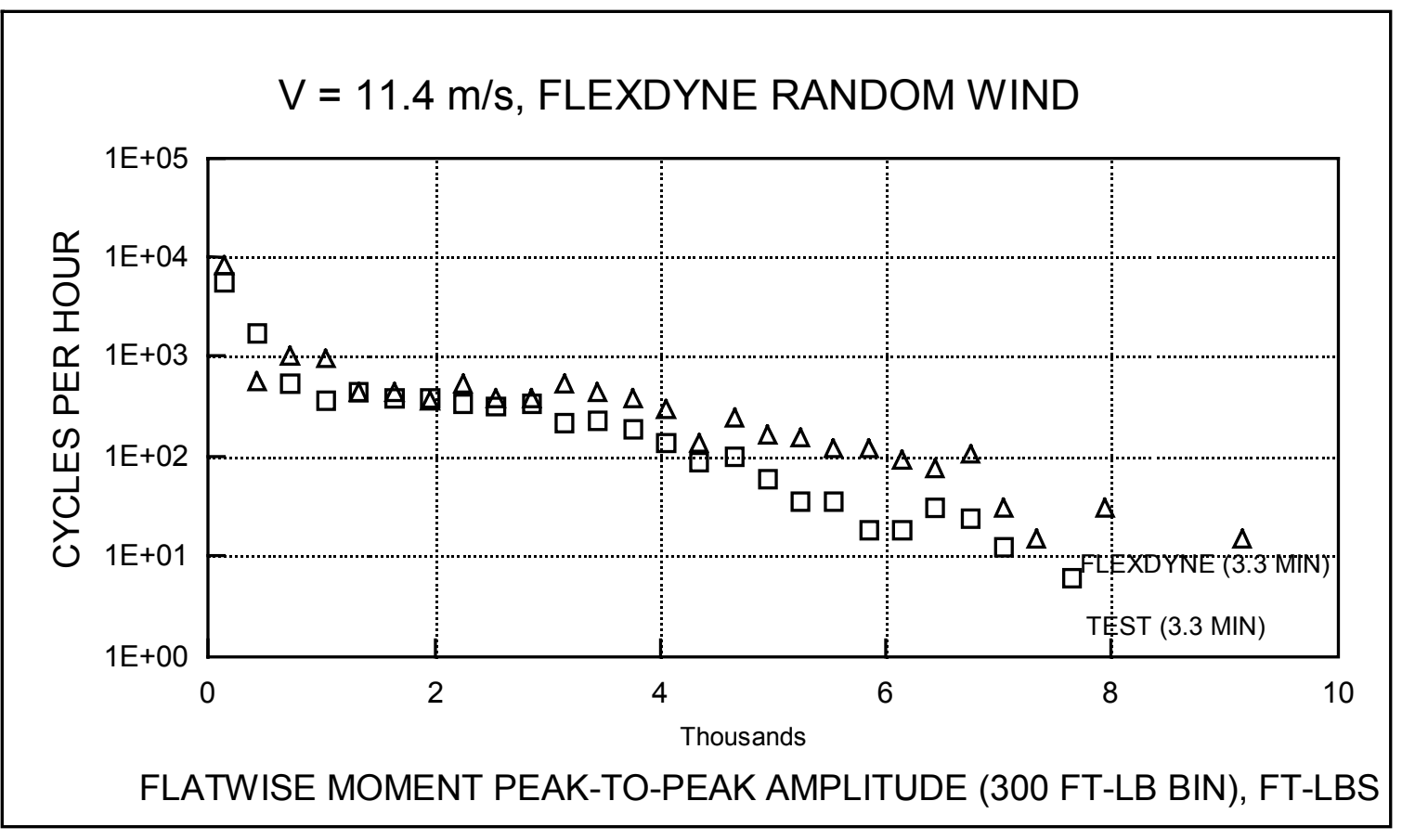

Figure 6-12. Comparison of root flatwise cycles/hour results using random wind

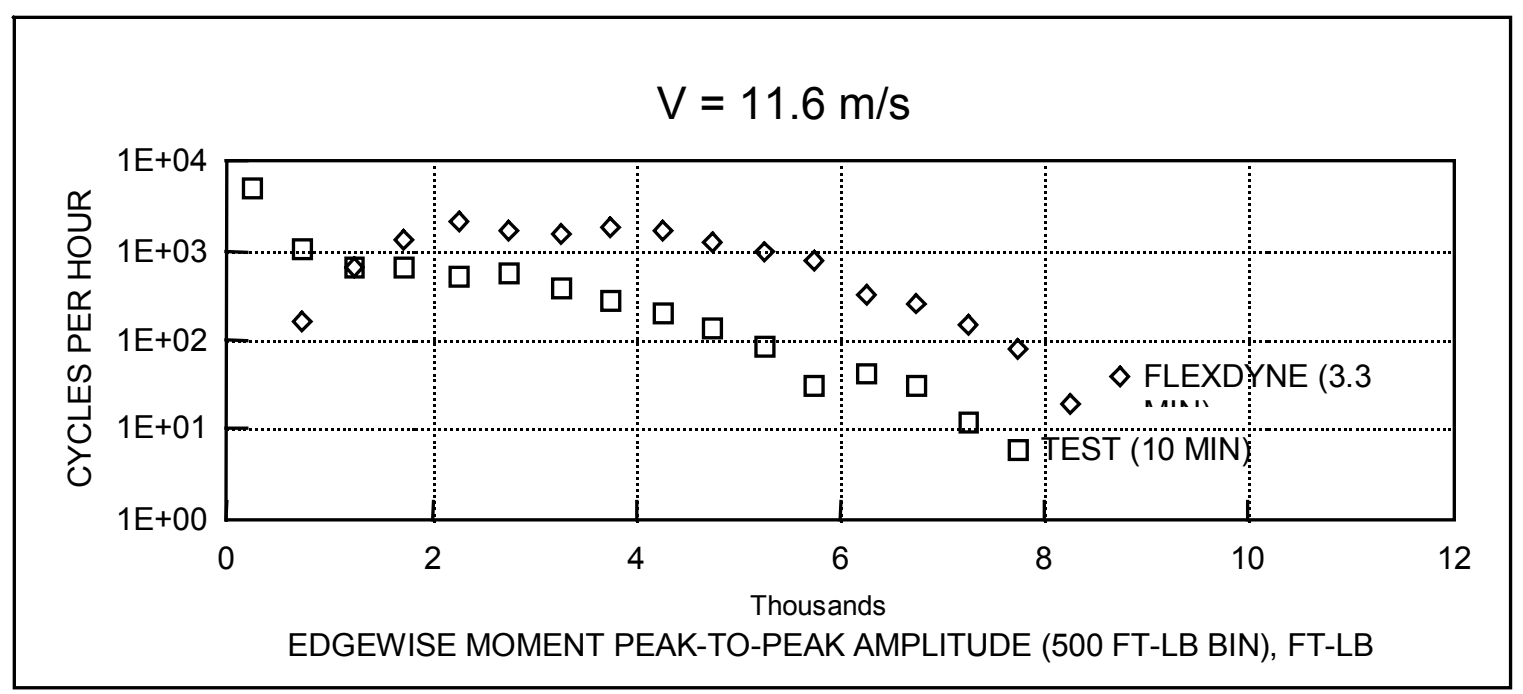

Figure 6-13. Comparison of root edgewise cycles/hour results using test wind 


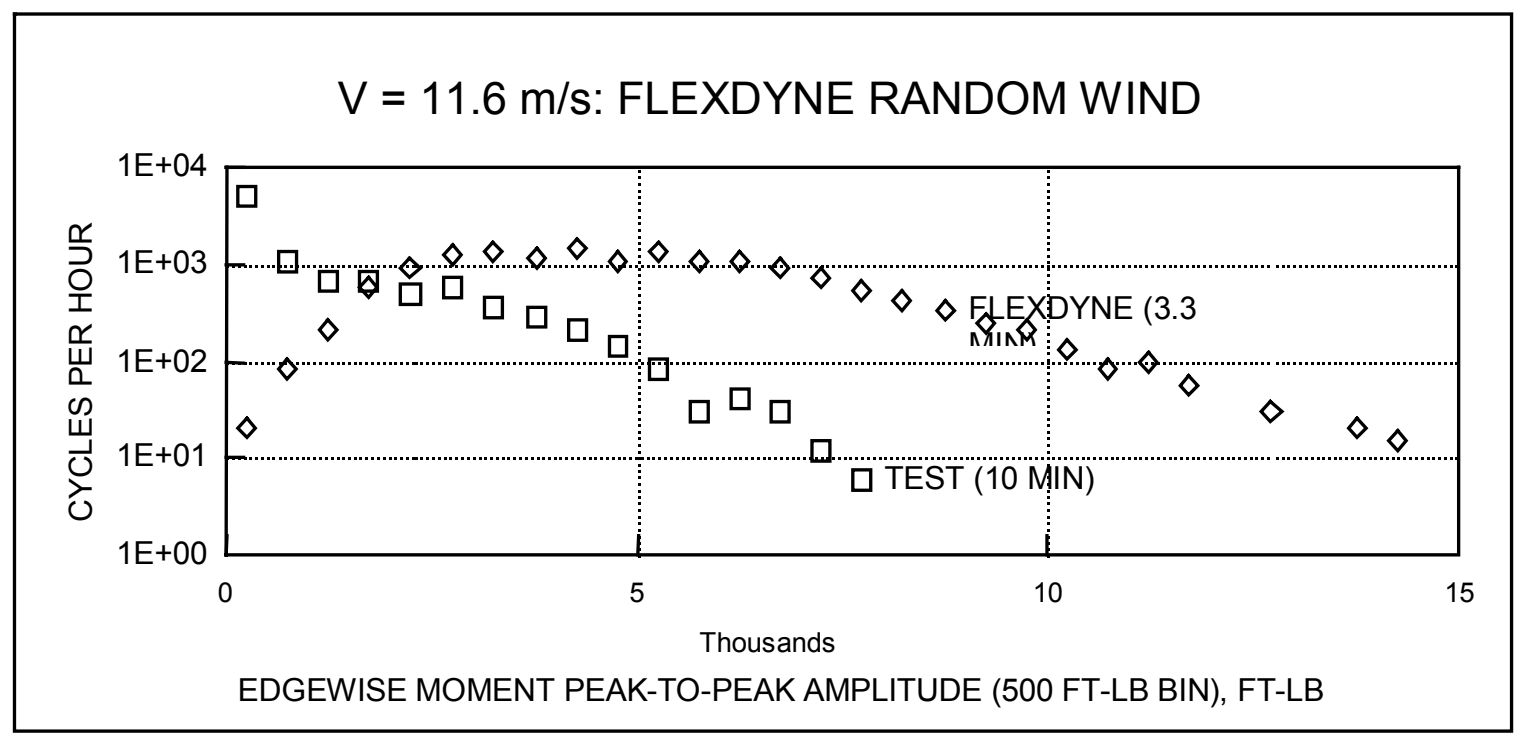

Figure 6-14. Comparison of root edgewise cycles/hour results using random wind

Figures 6-15 and 6-16 below compare sample root flatwise moment time histories from test and from Flexdyne (using the test wind model) for revolutions 185 to 215 . Aside from the same general magnitude level, evidence of some beating, and the dominance of the $1 \mathrm{p}$ component, there is little direct detail correlation.

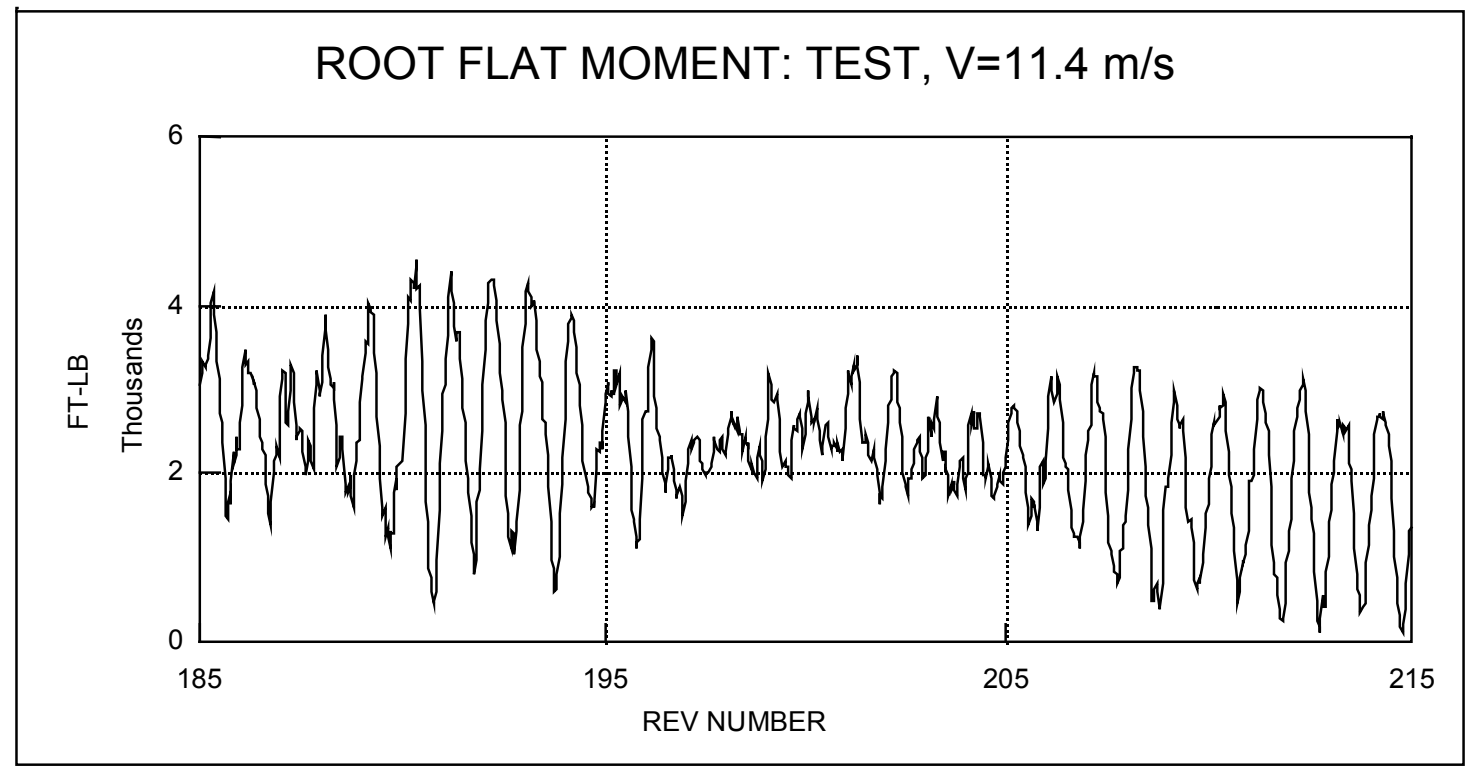

Figure 6-15. Root flatwise moment time history for revs 185-215: test 


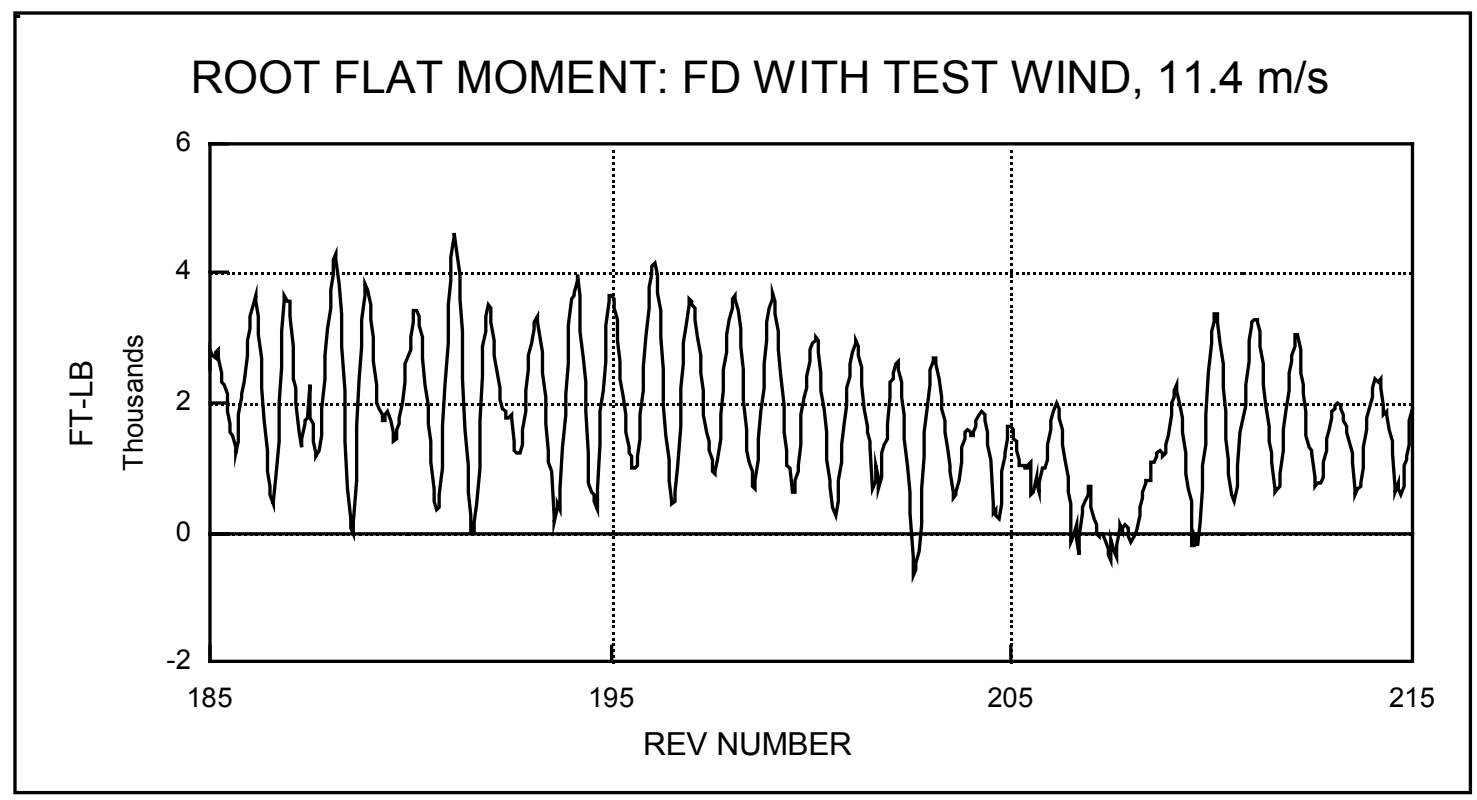

Figure 6-16. Root flatwise moment time history for revs 185-215: Flexdyne with test wind model

Figures 6-17 and 6-18 compare sample root edgewise moment time histories from test and from Flexdyne (using the test wind model) for revolutions 185 to 215. Similarities are seen in the general magnitude levels, the dominance of the $1 \mathrm{p}$ and 1 st edgewise mode natural frequency components, and evidence of areas of 1 st edgewise mode transient response.

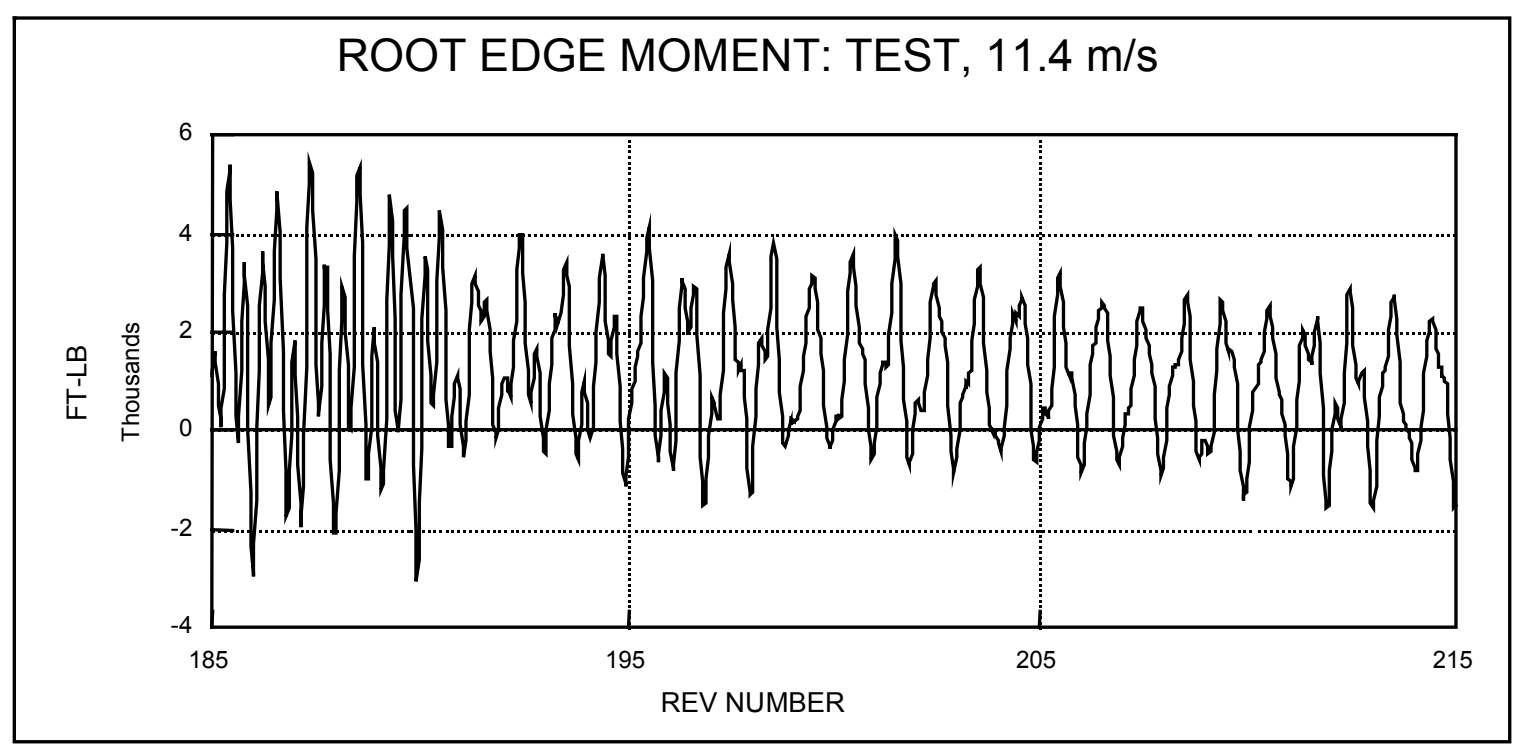

Figure 6-17. Root edgewise moment time history for revs 185-215: test 


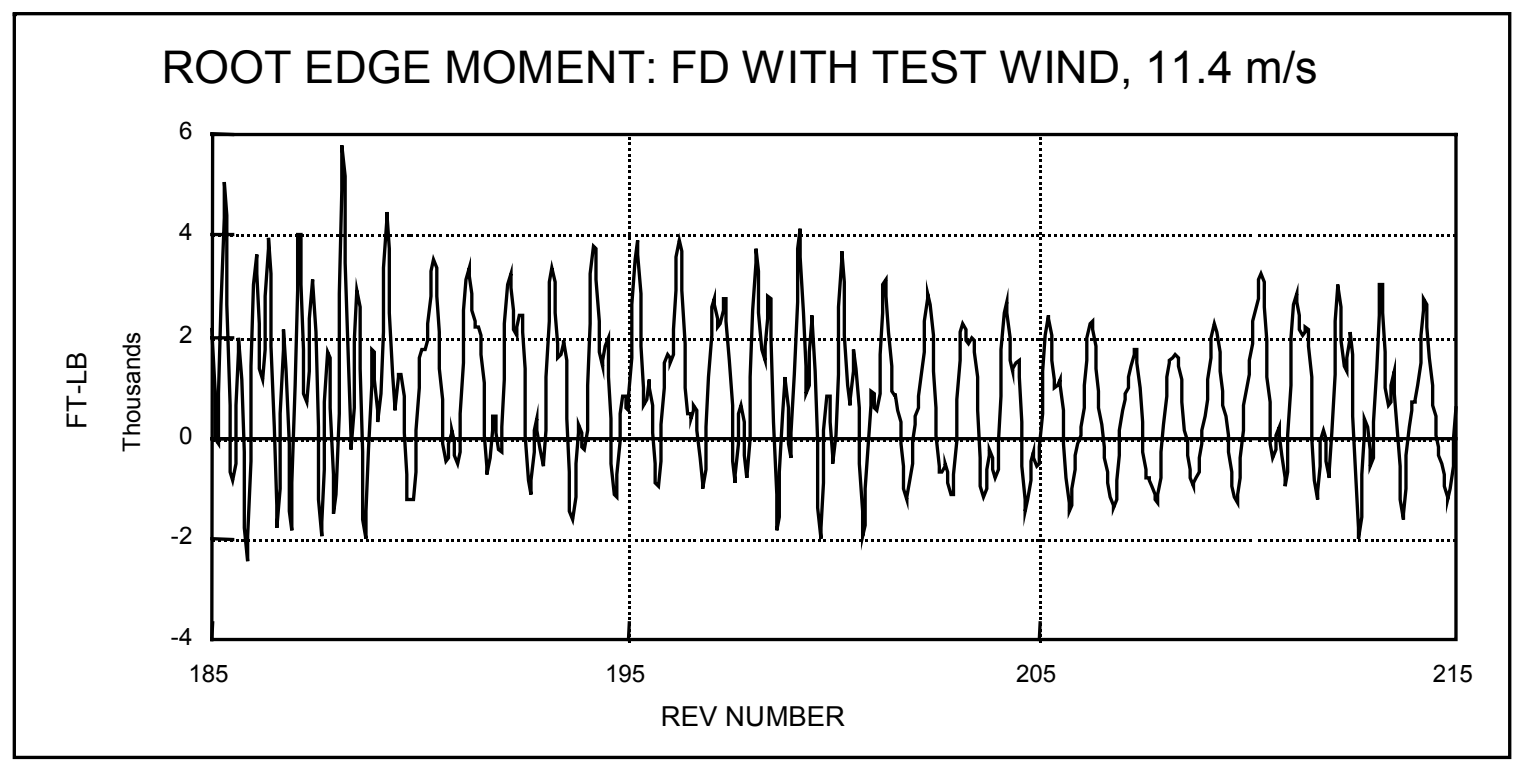

Figure 6-18. Root edgewise moment time history for revs 185-215: Flexdyne with test wind model

Previous time history comparisons of flatwise and edgewise moments showed the general nature of the moments over many revolutions. Figures 6-19 and 6-20 show a comparison of only 3 revolutions to illustrate more detailed features of the moments. Flexdyne agrees well for these revolutions.

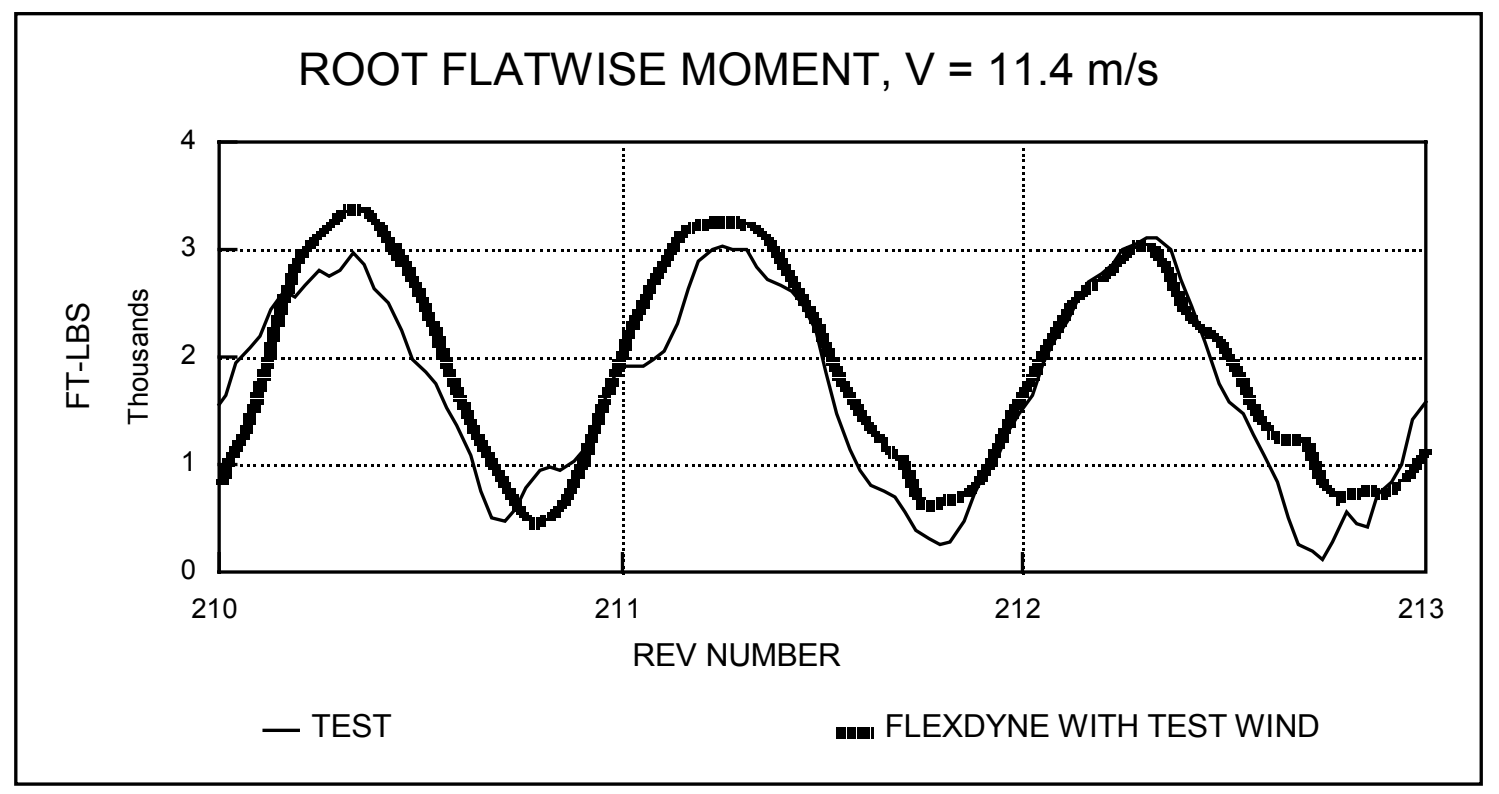

Figure 6-19. Root flatwise moment time history for revs 210-213: test 


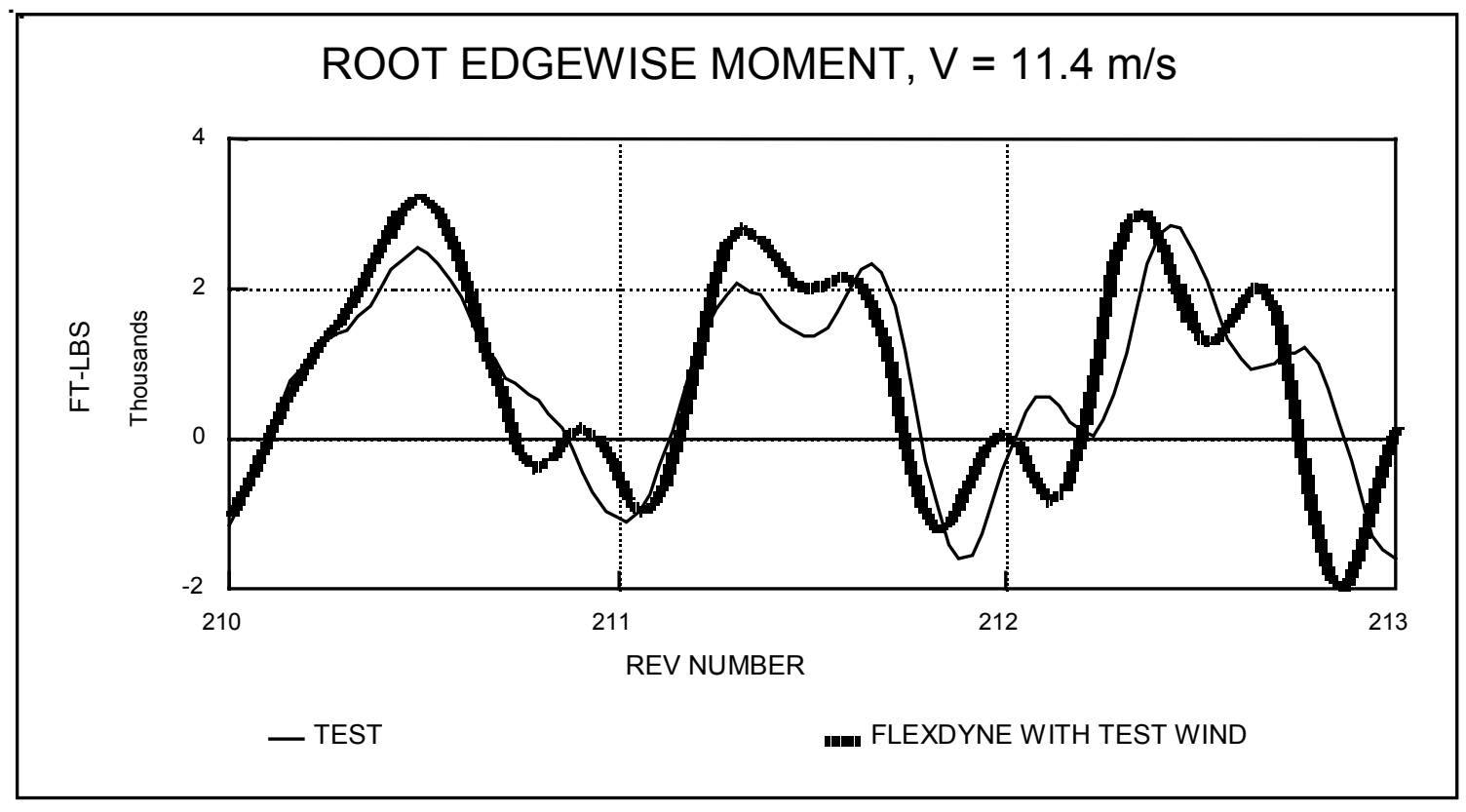

Figure 6-20. Root edgewise moment time history for revs 210-213: Flexdyne with test wind model

Figure 6-21 compares the root torsion moment from test and from Flexdyne (using the test wind model) for the $11.4 \mathrm{~m} / \mathrm{s}$ test condition. Flexdyne is seen to significantly underpredict the test torsion moment amplitude. The reason for this is believed to be the contamination of the test moment signal by flatwise and edgewise moment calibration interactions. The torsion moment is orders of magnitude smaller than the latter moments. Thus, normally small calibration interaction effects can be significant and may be difficult to extract.

Figure 6-22 shows the yaw angle time history for revs 1 - 200 from test. Figure 6-23 shows the corresponding time history computed by Flexdyne using the test wind model. Flexdyne results correlate reasonably well in terms of the amplitude and the general frequency characteristics.

Figures 6-24 and 6-25, respectively, compare the test power time history (for revs 120 - 220) with Flexdyne results using the test wind model. While Flexdyne captures some of the general characteristics of the power time history, the Flexdyne fluctuations are somewhat larger. 


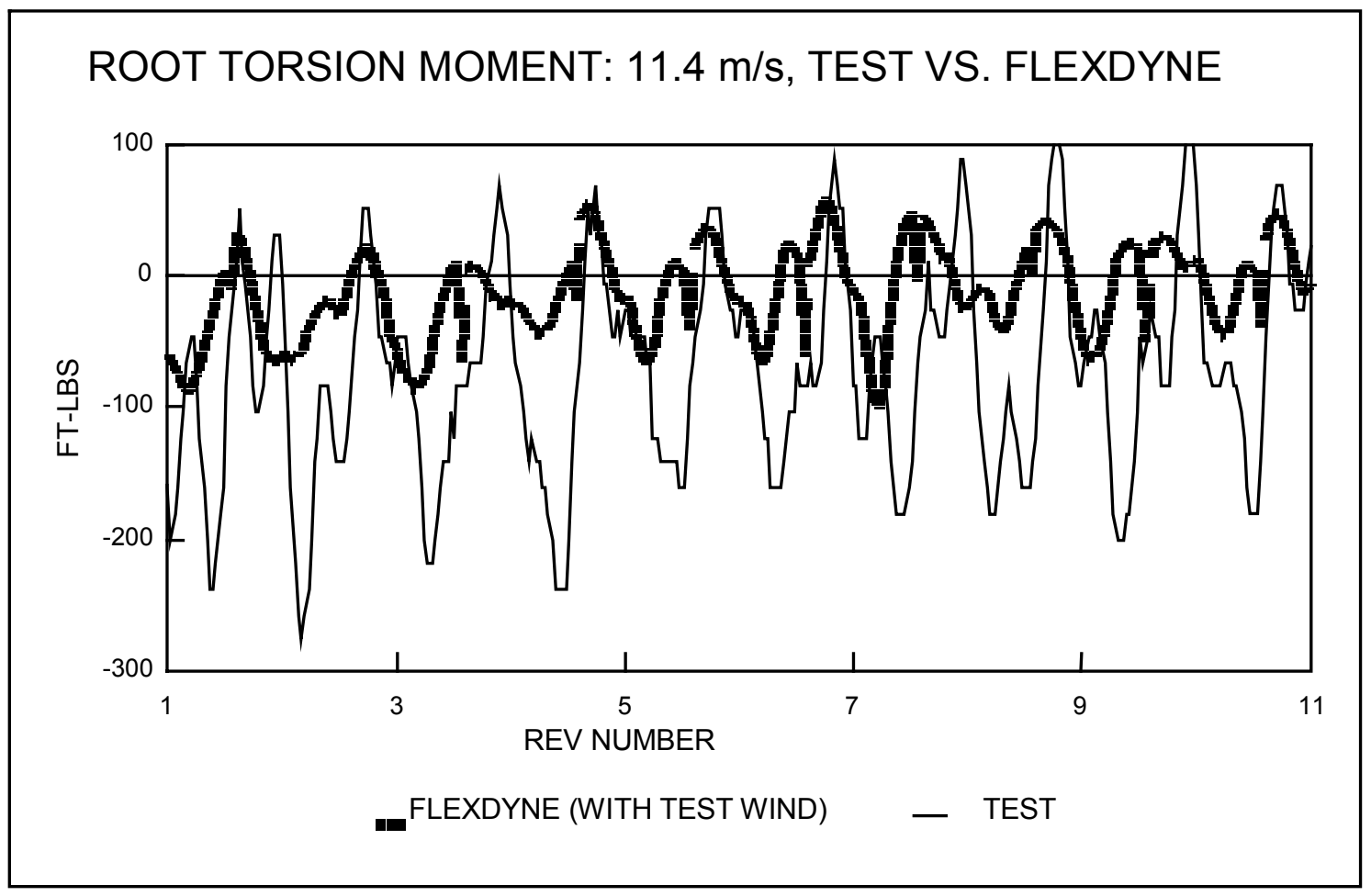

Figure 6-21. Root torsion moment time history for revs 1-11

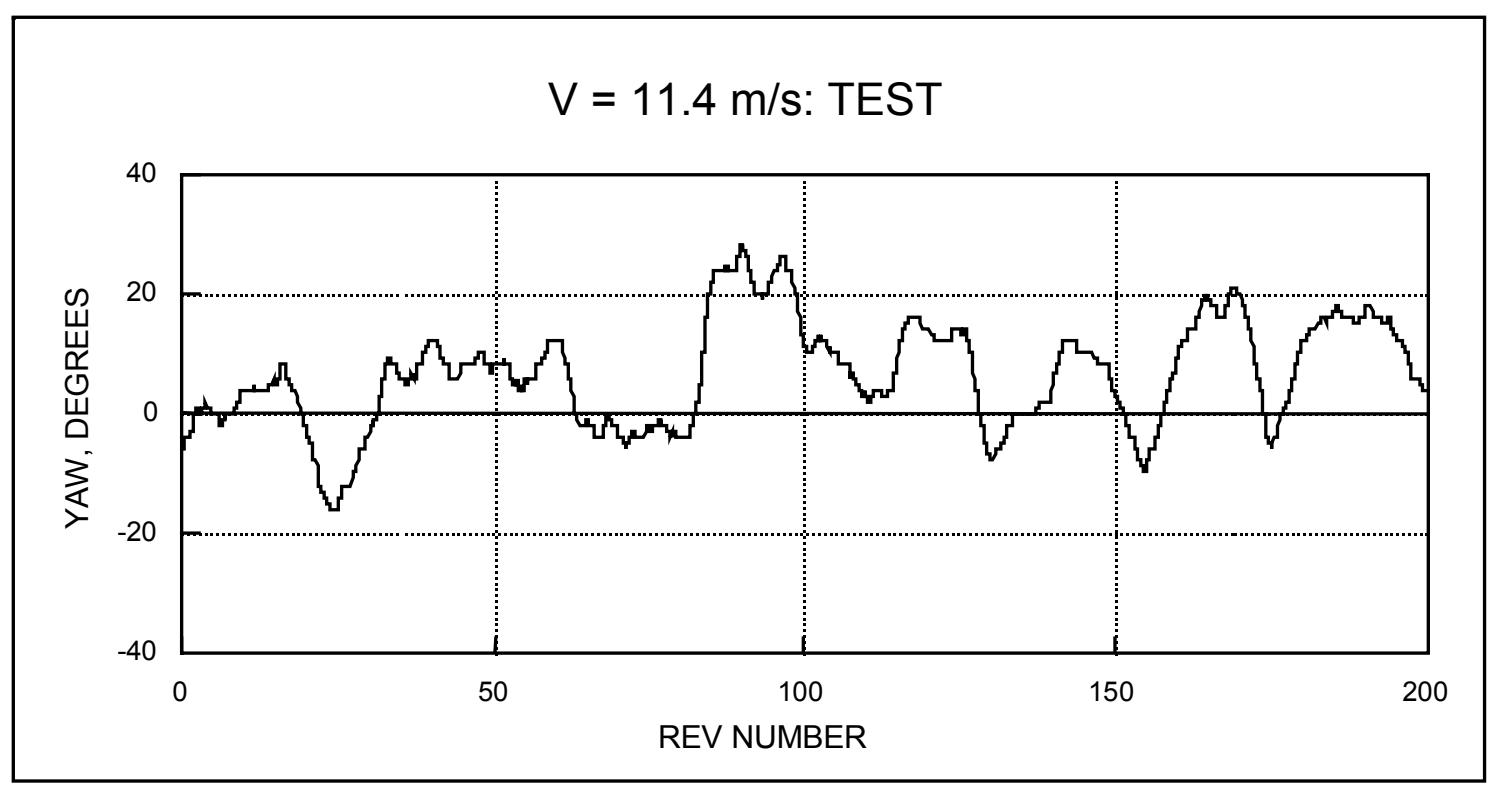

Figure 6-22. Yaw angle time history for revs 1-200: test 


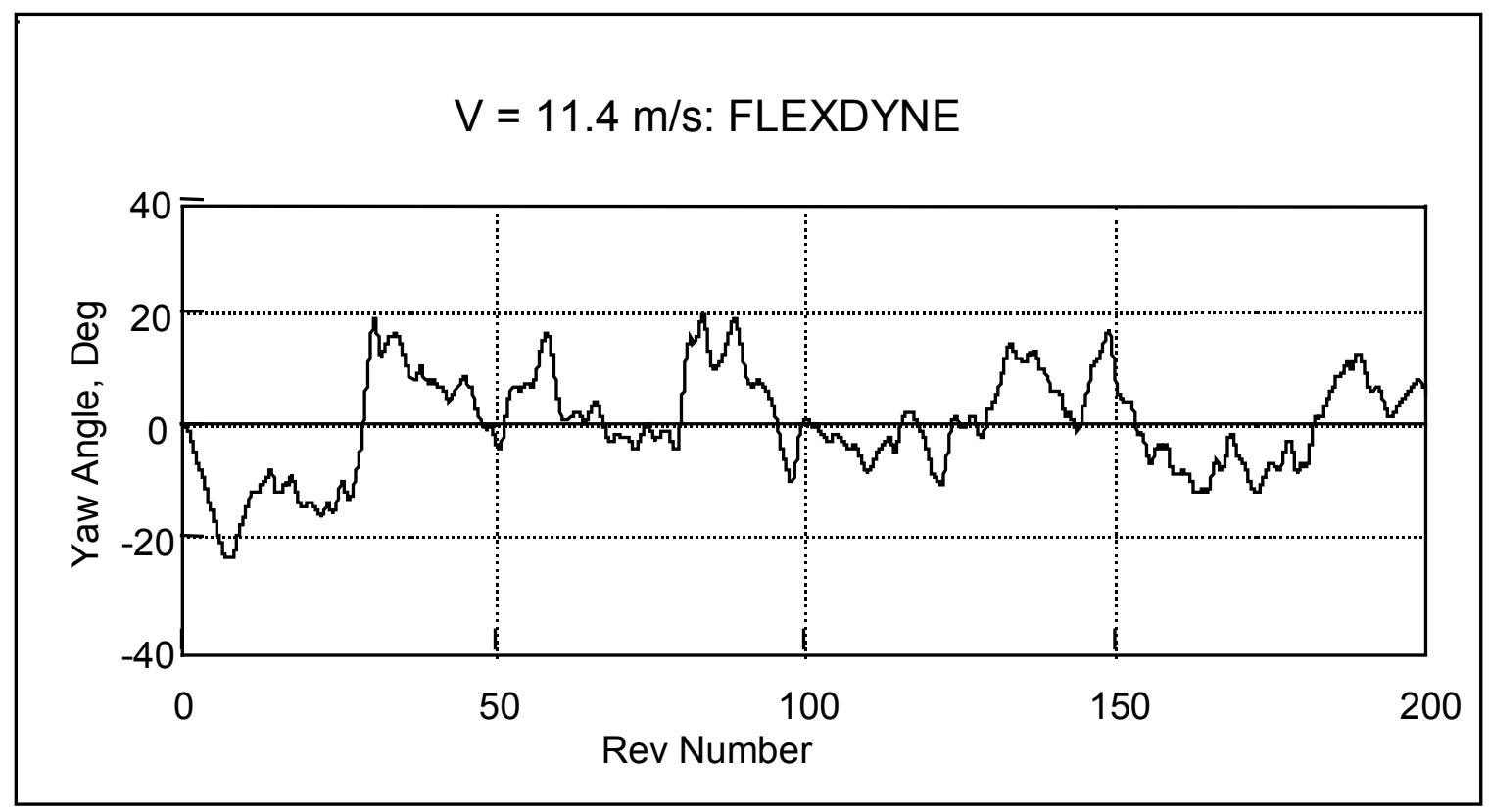

Figure 6-23. Yaw angle time history for revs 1-200: Flexdyne (with test wind)

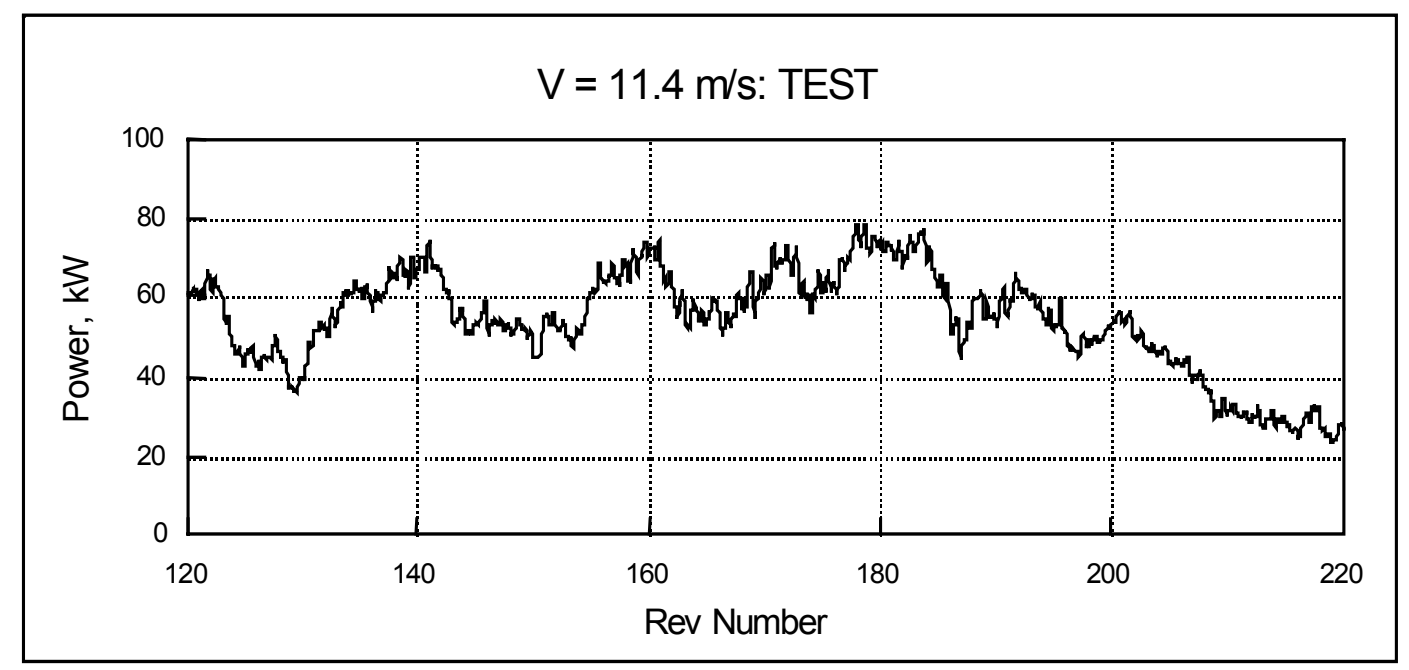

Figure 6-24. Power time history for revs 120-220: test 


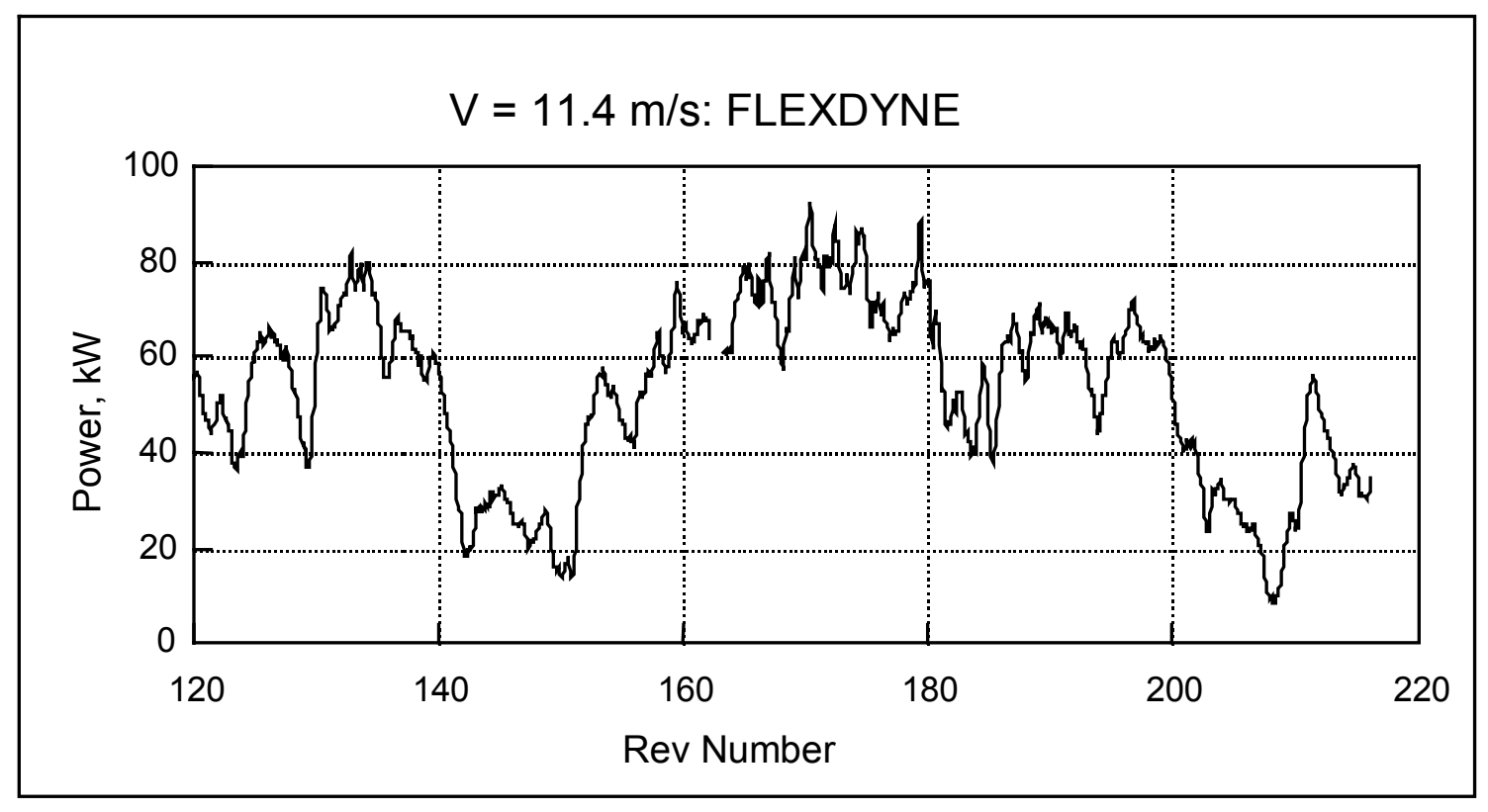

Figure 6-25. Power time history for revs 120-220: Flexdyne (with test wind)

\subsubsection{Concluding Remarks}

The Flexdyne correlation results presented above are considered encouraging. Flexdyne, using a relatively short simulated operation time, captured many of the features of the test data. Correlation is definitely improved using the test wind data as input as opposed to using the Flexdyne random wind model (although the latter remains to be optimized). Currently, predicted edgewise moment cycles show the greatest departure from test results; however, the departure is largely in the conservative direction and can probably be reduced by fine tuning the structural damping assumed and/or improving the Flexdyne cycle counting algorithm. Scaling of the test wind from one operating condition appears to provide a relatively quick way to estimate loads for other operating conditions. Although correlation over a wider range of operating conditions is always desirable, the results obtained demonstrate the potential of Flexdyne and indicate that certain key assumptions within the program are reasonable. These assumptions include the stall model (steady), the self-induced inflow model (blade element-momentum), the wind model (varies only with height at any point in time), and the yaw dynamic response model (based on separation of yaw and blade natural frequencies). As a result, it appears that Flexdyne can be a useful analysis at least for preliminary design purposes.

\subsubsection{Spoiler Flaps}

Following the transmission failure, several minutes of data were taken in the freewheeling state with the (four) spoiler flaps deployed. Figure 6-26 shows the measured tip speed ratios at zero torque with the torque coefficient predicted using the PROP93 performance code. 


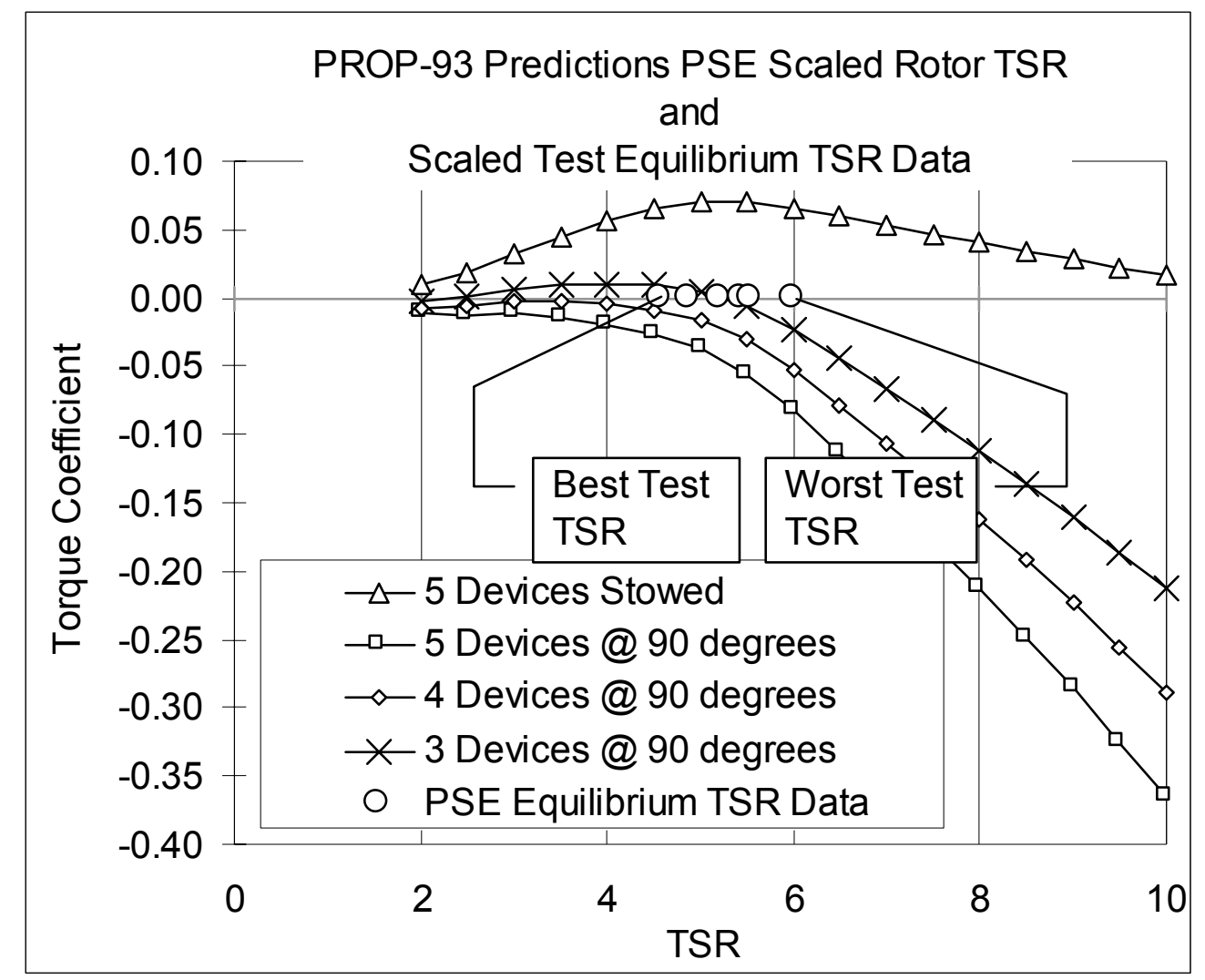

Figure 6-26. Spoiler-flap performance comparison

The results show that the rotor with four devices deployed performed only as well as what was predicted for three devices. This discrepancy is believed due to the fact that the device did not remain in the fully deployed position during the overspeed condition. This can be seen in Figure 6-27 where the flap angle oscillates between $90^{\circ}$ and $50^{\circ}$. At any position less than $90^{\circ}$, the flap has reduced effectiveness.

The plot of data in Figure 6-27 is device position, rpm, and TSR based on a time stepping dynamic model of the worst performance expected. There was no aerodynamic or friction damping assumed. 


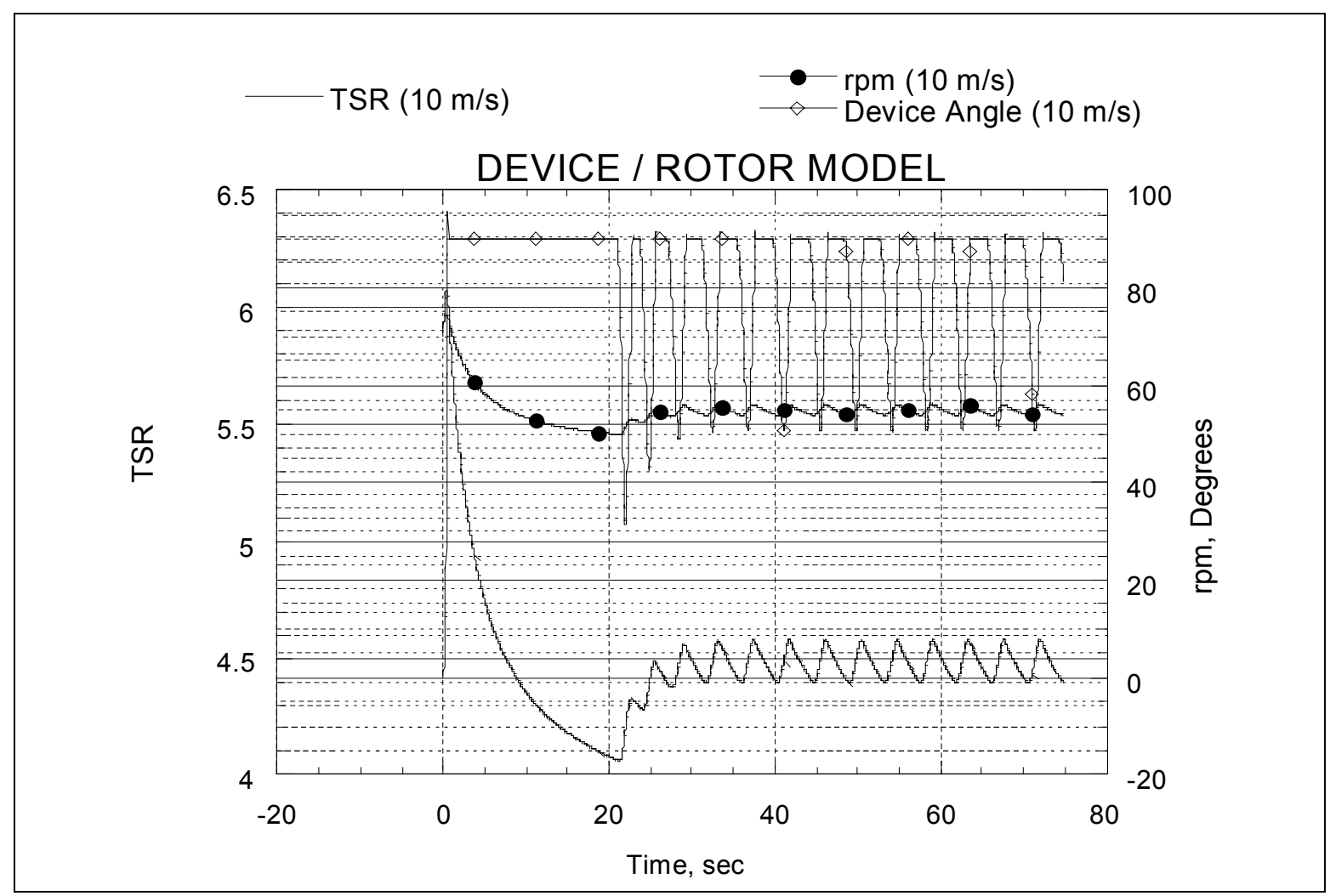

Figure 6-27. Brake dynamics including hinge moments, return spring, no damping

The actual data for the device is shown in Figure 6-28 below. Note that the device was not damped much more than in Figure 6-27. The device appeared to be opening and closing in the runaway event, this is even more evident in Figure 6-29. The device is not staying open and the TSR (as noted in Figure 6-26) is in the range of $4.5-6$. The low speed shaft bending reversals are used as an rpm reference because the rpm sensor was inoperative. 


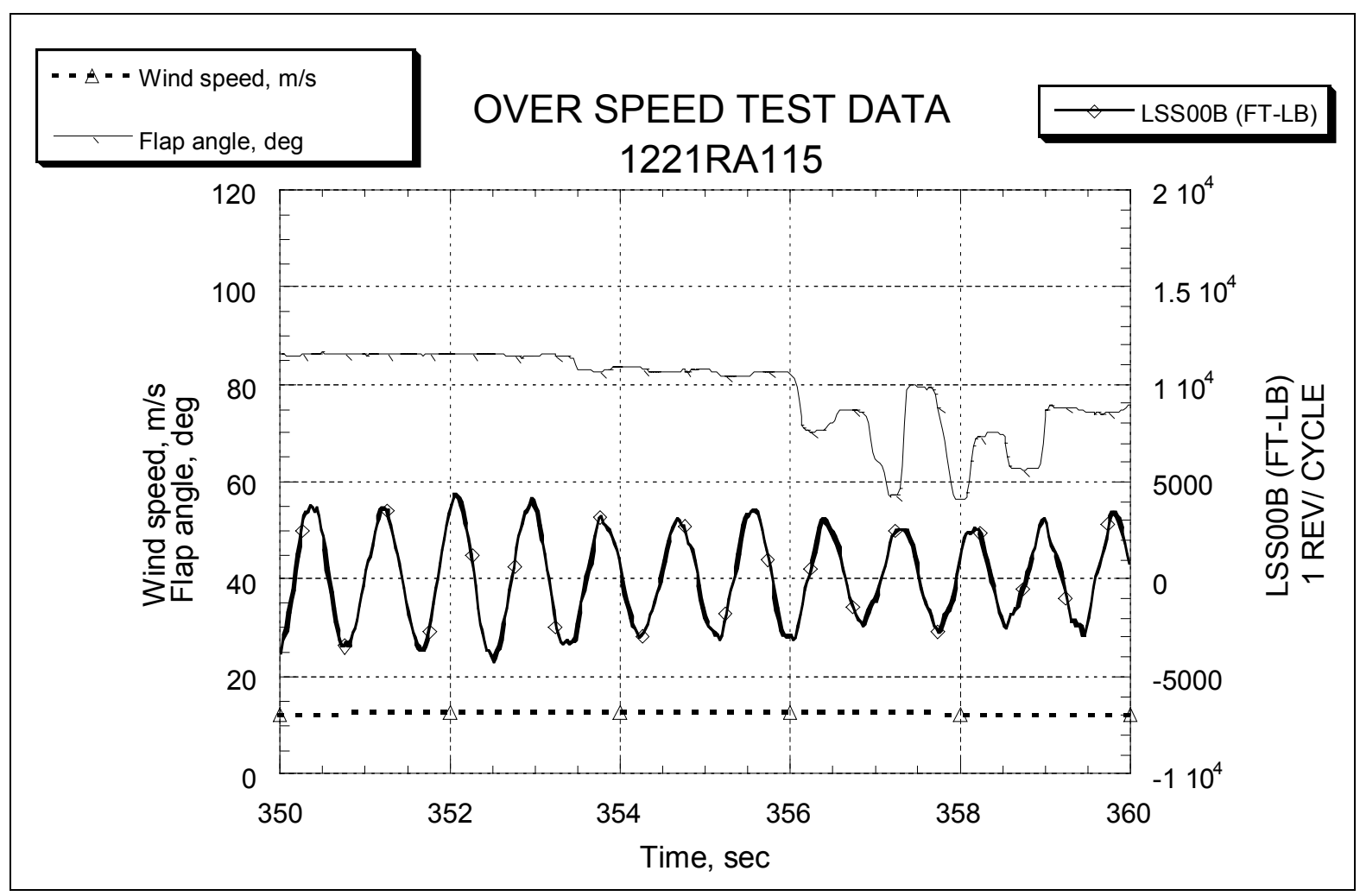

Figure 6-28. Flap angle during overspeed

The device is shown during a brake event test in Figure 6-30. The devices were deployed at time 141 and the power change was $-41 \mathrm{~kW}$. This is $10.25 \mathrm{~kW} /$ device if all were deployed. The value of Cs the devices were producing is calculated below. The value of Cs is less than the modeled value $(\mathrm{Cs}=.64)$ near $3^{0}$ angle of attack. It is not certain that all devices were deployed or deployed fully.

\begin{tabular}{|lll|}
\hline RPM $:=69$ & $\mathrm{R}_{\text {eff }}=7.315 \mathrm{~m}$ & Power $:=10.25 \cdot 10^{3} \cdot \mathrm{W}$ \\
$\omega:=2 \cdot \pi \cdot \frac{\mathrm{RPM}}{60 \cdot \mathrm{s}}$ & $\mathrm{V}:=\mathrm{R}_{\mathrm{eff}} \omega$ & \\
$\mathrm{c}=0.345 \mathrm{~m}$ & $\mathrm{~V}=52.857 \cdot \frac{\mathrm{m}}{\mathrm{s}}$ & Torque $:=\frac{\text { Power }}{\omega}$ \\
Span $=0.762 \mathrm{~m}$ & $\mathrm{q}:=\frac{1}{2} \cdot \rho \cdot \mathrm{V}^{2}$ & Torque $=1.419 \cdot 10^{3} \cdot \mathrm{N} \cdot \mathrm{m}$ \\
\hline Cs $:=\frac{\text { Torque }}{\mathrm{q} \cdot \mathrm{c} \cdot \text { Span } \cdot \mathrm{R}} \mathrm{eff}$ & $\mathrm{Cs}=0.439$ \\
\end{tabular}




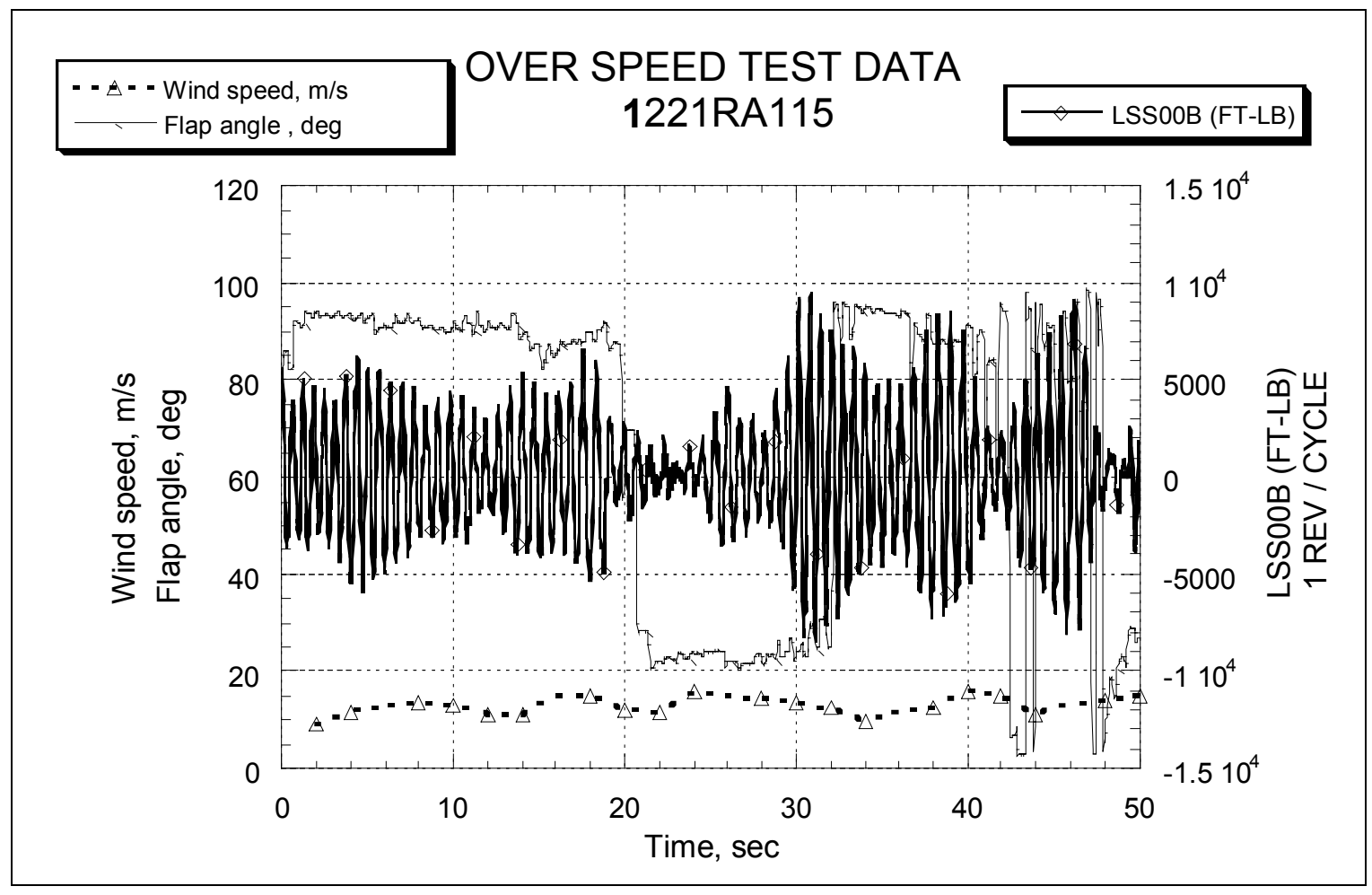

Figure 6-29. Spoiler-flap dynamics for the first 50-sec of the runaway event

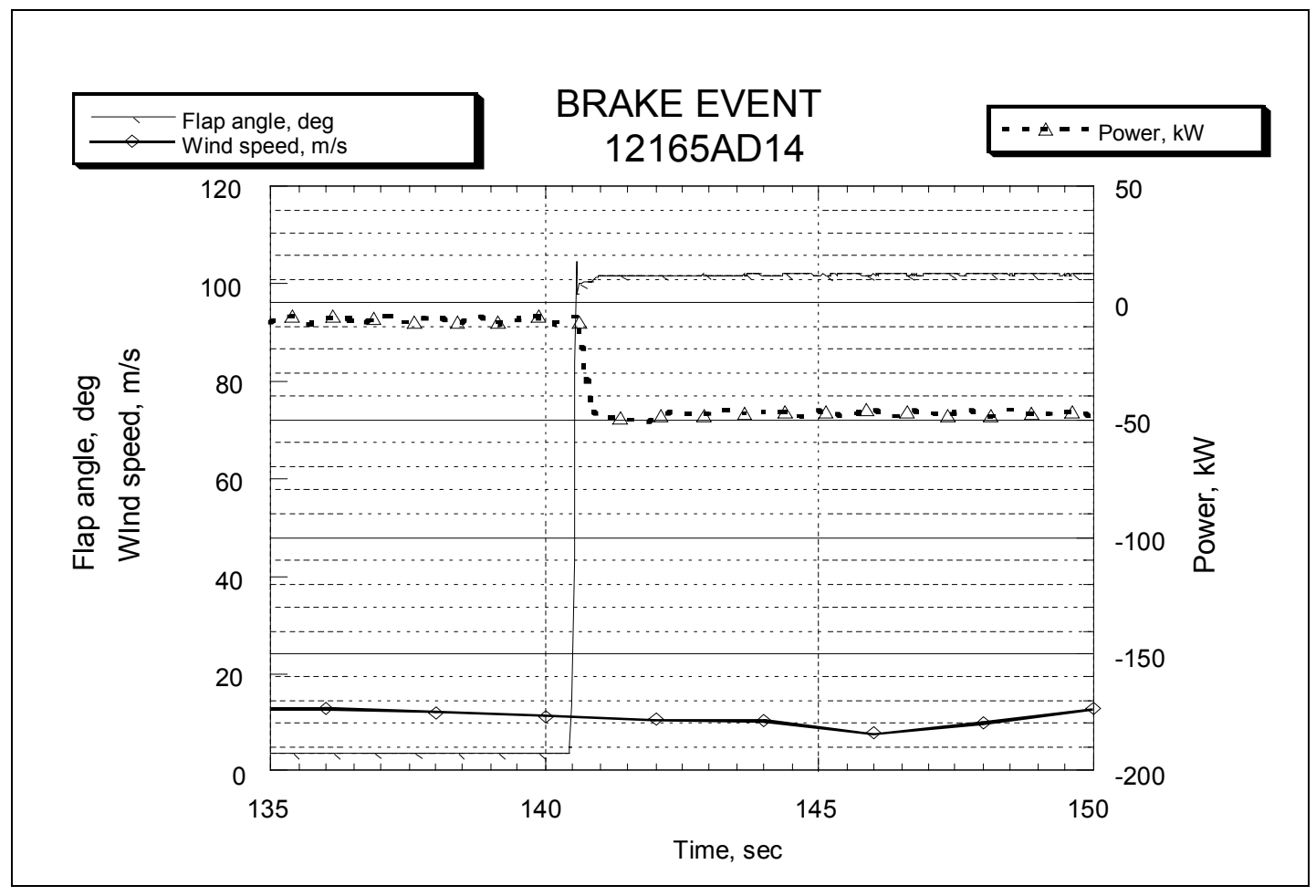

Figure 6-30. Brake event test in near calm wind 
The device deployed bending loads are shown in Figure 6-31 below. These were measured at nearly constant inflow wind speeds from the few braking events that were recorded. The bending loads greater than 300 in-lb. were recorded at rpm $>69$ in an overspeed condition. The other loads are at operating $\mathrm{rpm}=69$. With wind speed variation minimal, the device-bending load is nearly constant for a constant $\mathrm{rpm}$. The design loads were more than twice the measured loads. This is a reasonable margin for ultimate loads. Not enough fatigue data were collected due to the short duration of the test.

The opening force data for the device was less than expected. In Figure 6-32 the measured data is shown, for the device that was held closed with a load cell. These data show that the force is negative at low wind speeds and neutral or slightly positive at higher wind speeds. The more positive the force the greater the opening moment. The passive device opening system was not working as designed. The devices did open when the magnets were deenergized, however they did not stabilize in the fully opened position as required to maintain a safe rpm.

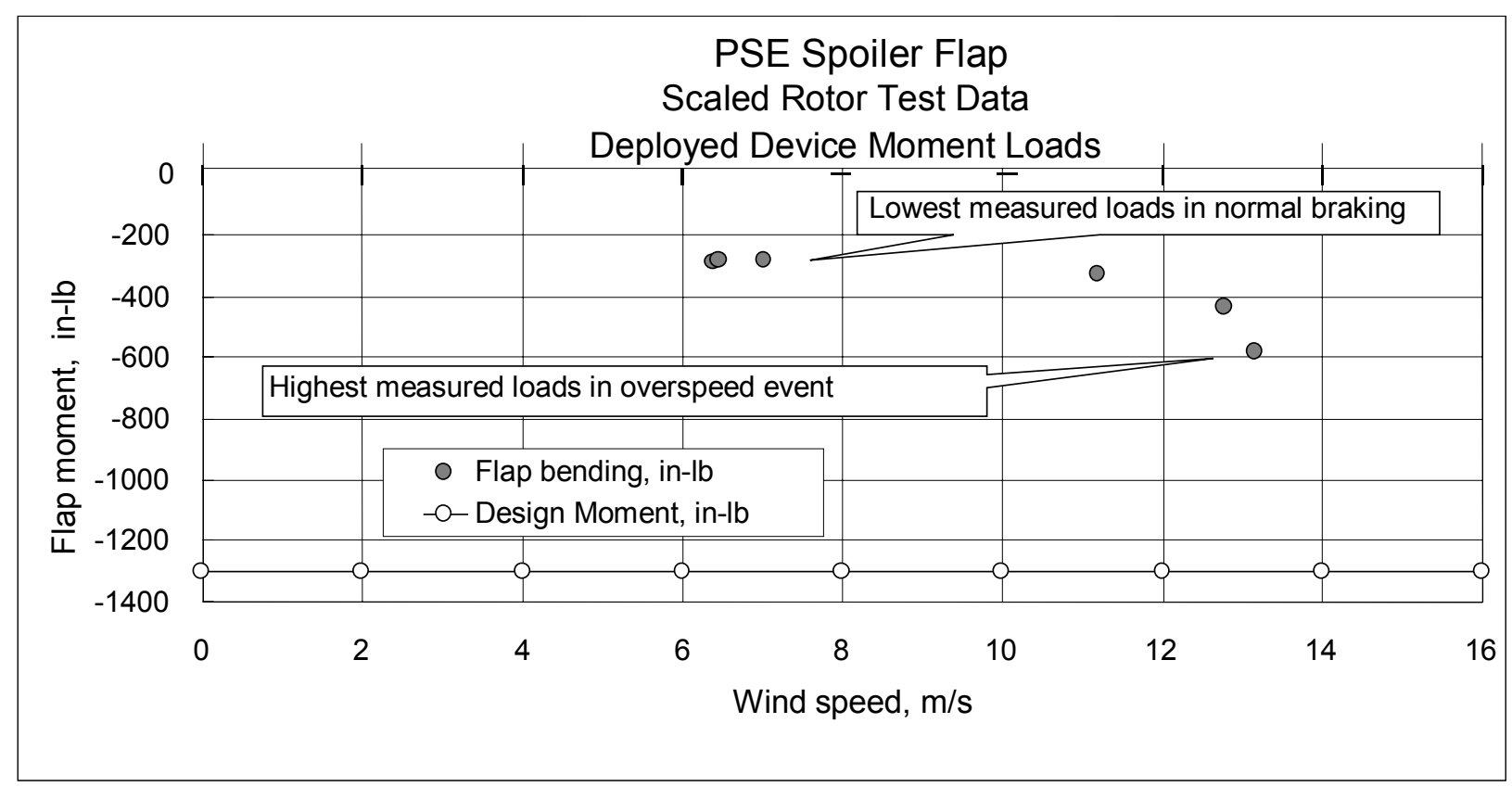

Figure 6-31. Spoiler-flap device deployed moment loads 


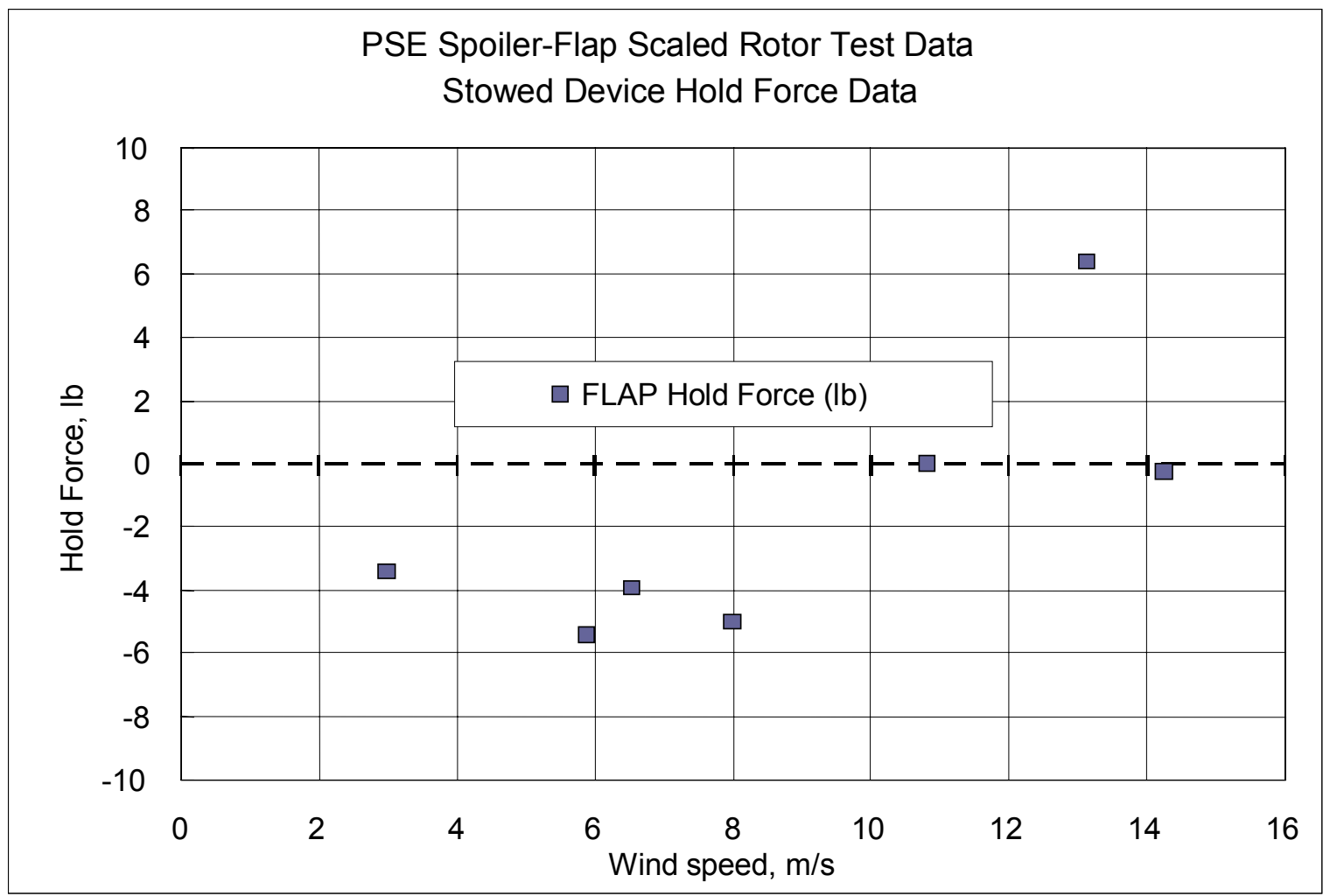

Figure 6-32. Spoiler-flap device stowed hold force

Lessons learned during the test are:

- Aerodynamic deployment moment of current design insufficient.

- Device requires positive positioning "inertial deployment".

- The best recorded performance of the rotor/spoiler flaps compared well with PROP93 predictions.

- Attachment to blade was structurally sound.

- Device / blade dynamics were not critical during or while deployed. The devices worked effectively when fully open, however design needs to be modified to hold them fully deployed.

\subsection{Frequency Spectra}

Power spectral densities were computed for all channels for a single 10-min data set with an average horizontal wind speed of $12.2 \mathrm{~m} / \mathrm{s}$, and are shown in Figures 6-33 to 6-50. Before discussing these results, it is useful to determine the rotor numbers in normal operation. The nominal rotor speed of $69 \mathrm{rpm}$ gives the following rotor numbers:

\begin{tabular}{|c|c|c|c|}
\hline$\underline{\text { Rotor No }}$ & Frequency, $\mathrm{Hz}$ & $\underline{\text { Rotor No }}$ & Frequency, $\mathrm{Hz}$ \\
\hline $1 \mathrm{P}$ & 1.15 & $6 \mathrm{P}$ & 6.90 \\
\hline $2 \mathrm{P}$ & 2.30 & $7 \mathrm{P}$ & 8.05 \\
\hline $3 \mathrm{P}$ & 3.45 & $8 \mathrm{P}$ & 9.20 \\
\hline $4 P$ & 4.60 & $9 \mathrm{P}$ & 10.35 \\
\hline $5 \mathrm{P}$ & 5.75 & $10 \mathrm{P}$ & 11.50 \\
\hline
\end{tabular}


Looking at the root flap bending moment spectra, a large spike shows up at $1 \mathrm{P}$ as expected, with smaller harmonics at $2 \mathrm{P}$ through $6 \mathrm{P}$. The $1 \mathrm{P}$ spike has a wide enough base skewed toward $2 \mathrm{P}$ to indicate the blade's flap fundamental, which is shown as $1.6 \mathrm{~Hz}$ in section 4.3.1. Wide humps also occur at $5 \mathrm{~Hz}$ and $12.5 \mathrm{~Hz}$, indicating the blade's second and third flap modes. These fall between the non-rotating test values and the Flexdyne rotating estimates given in section 4.3.1. Blade 5's spectra are essentially identical to those of blade 1 .

The root edge bending moment spectrum shows a large spike at $1 \mathrm{P}$ and smaller ones at $2 \mathrm{P}$ and $3 \mathrm{P}$, with wide humps at $3 \mathrm{~Hz}$ and $18 \mathrm{~Hz}$. Three $\mathrm{Hz}$ matches well with the rotating edge fundamental computed by Flexdyne, and $18 \mathrm{~Hz}$ is likely the second edge mode. The blade torsion spectrum is very similar to the edge-bending spectrum, indicating strong geometric coupling.

The spoiler flap tongue force and bending moment spectra show elements of both the flap and edge bending spectra. The flap angle spectrum is quite benign.

The low speed shaft torque spectrum includes the 1P spike and smaller 2P, 3P, 4P, and 6P spikes. The wider humps occurring at $1 \mathrm{~Hz}$ and $5 \mathrm{~Hz}$ might indicate possible drivetrain natural frequencies, but they could just be artifacts of flap and edge bending moments. The low speed shaft bending moment spectrum is very similar to the low speed shaft torque spectrum.

Nacelle yaw position and yaw error spectra are extremely benign. Nacelle acceleration spectra indicate spikes at $1 \mathrm{P}, 2 \mathrm{P}$, and $5 \mathrm{P}$. The yaw accelerations show possible resonances at $1 \mathrm{~Hz}, 2 \mathrm{~Hz}, 4 \mathrm{~Hz}, 6 \mathrm{~Hz}$, and $12 \mathrm{~Hz}$. The pitch accelerations show possible resonances at $1 \mathrm{~Hz}, 5.5 \mathrm{~Hz}, 7.5 \mathrm{~Hz}$, and $13 \mathrm{~Hz}$.

The tower base bending spectra show small spikes at 1P, 2P, and 5P, with minimal resonances at $1 \mathrm{~Hz}$, $2.5 \mathrm{~Hz}, 6.5 \mathrm{~Hz}, 7.5 \mathrm{~Hz}, 12 \mathrm{~Hz}$, and $14 \mathrm{~Hz}$. Tower thrust repeats the resonances at $1 \mathrm{~Hz}, 6.5 \mathrm{~Hz}, 7.5 \mathrm{~Hz}, 12$ $\mathrm{Hz}$, and $14 \mathrm{~Hz}$.

The electrical power spectrum contains small spikes at $1 \mathrm{P}, 2 \mathrm{P}$, and $4 \mathrm{P}$, and is otherwise extremely clean. This would imply that the shaft torque channel was picking some cross talk from shaft bending, unless the generator or wattmeter has somehow filtered the data.

The horizontal wind speed spectrum shows the expected smooth exponential descent, with a dip at $10 \mathrm{~Hz}$, the bandwidth of the sonic anemometer.

The title numbers on each figure indicate the test file designation. 


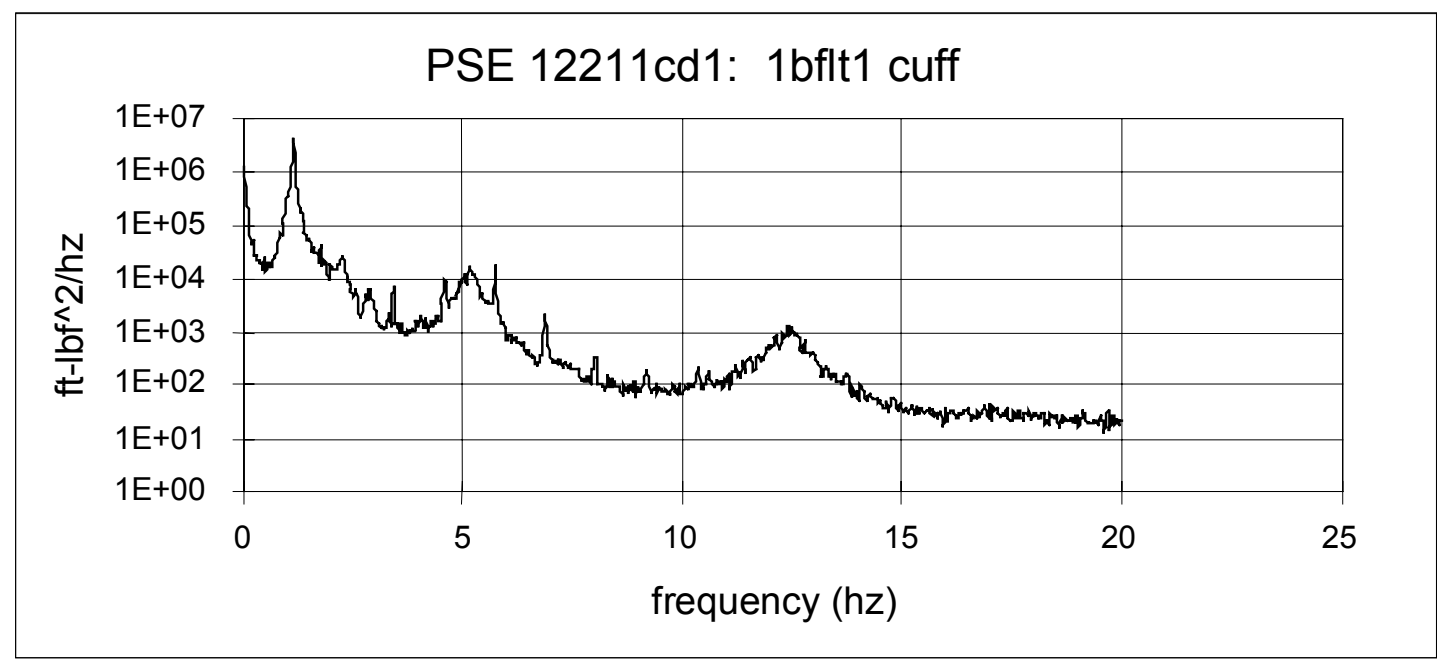

Figure 6-33. PSD of cuff root flap bending moment

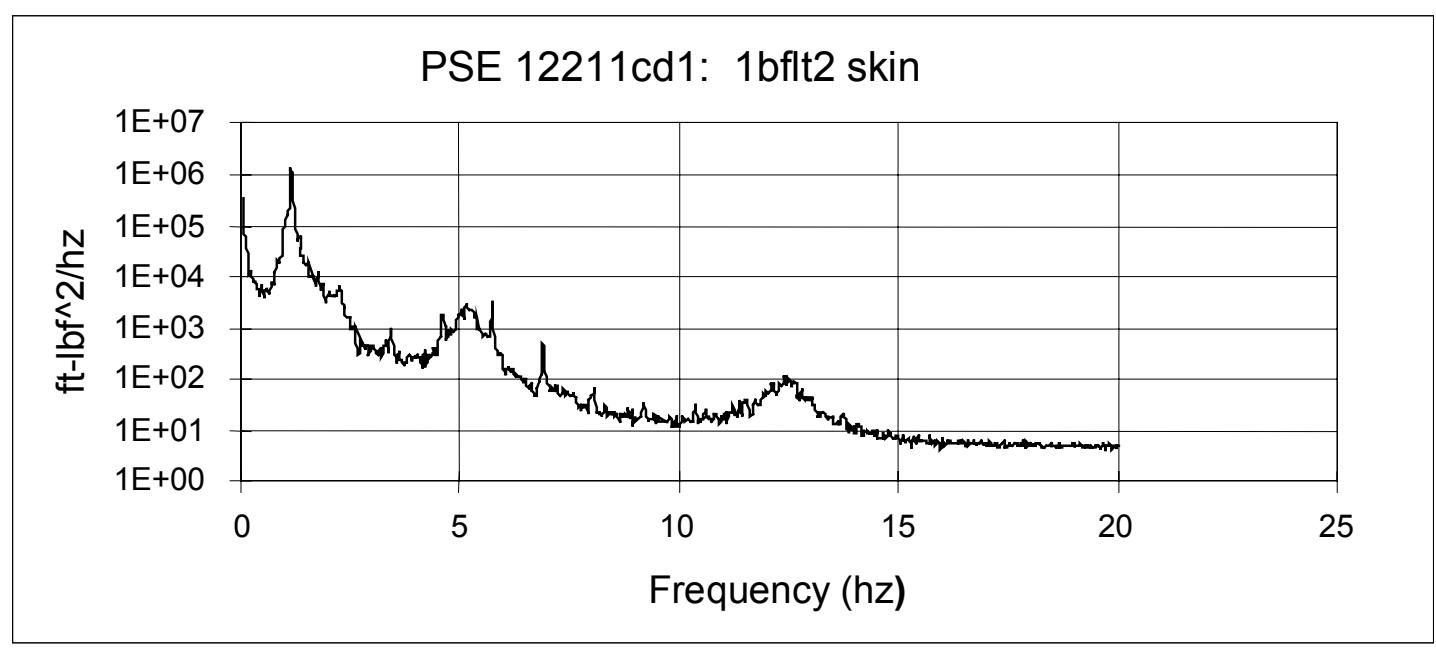

Figure 6-34. PSD of skin root flap bending moment

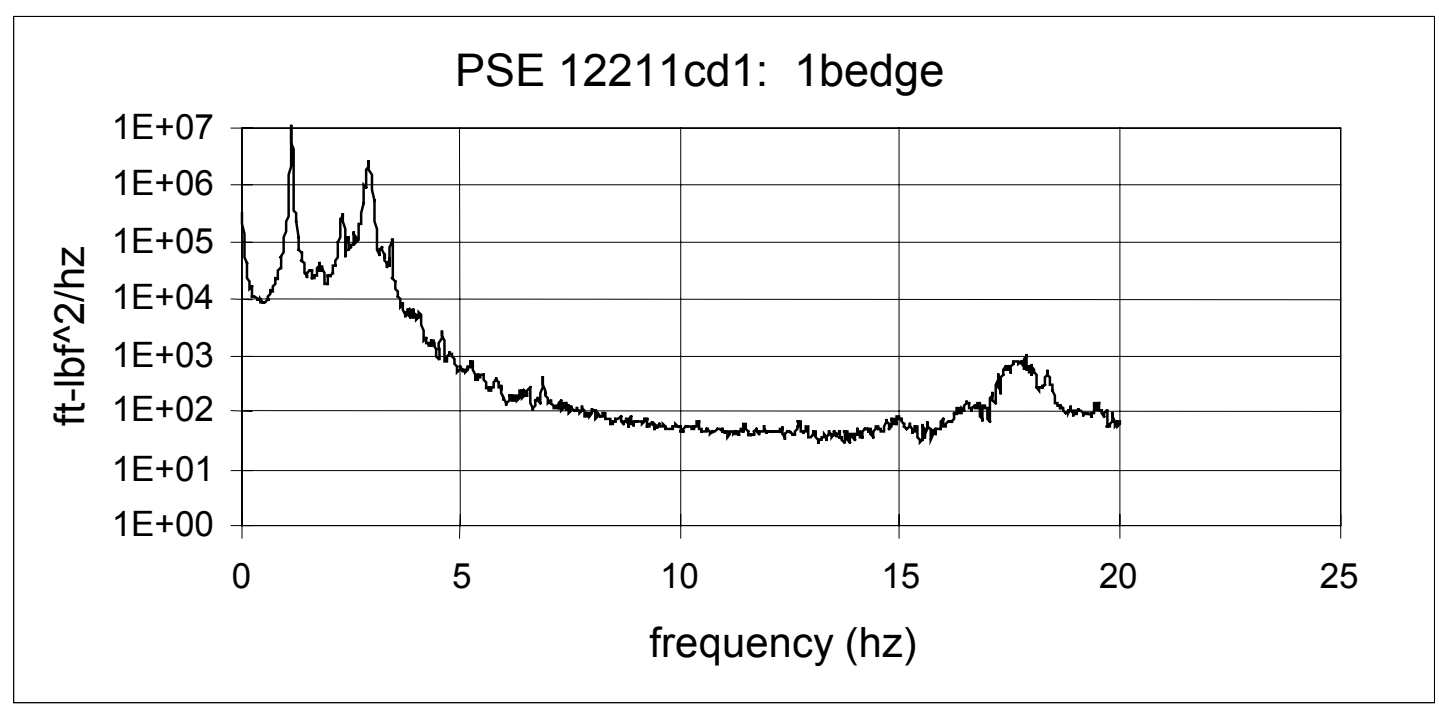

Figure 6-35. PSD of cuff root edge bending moment 


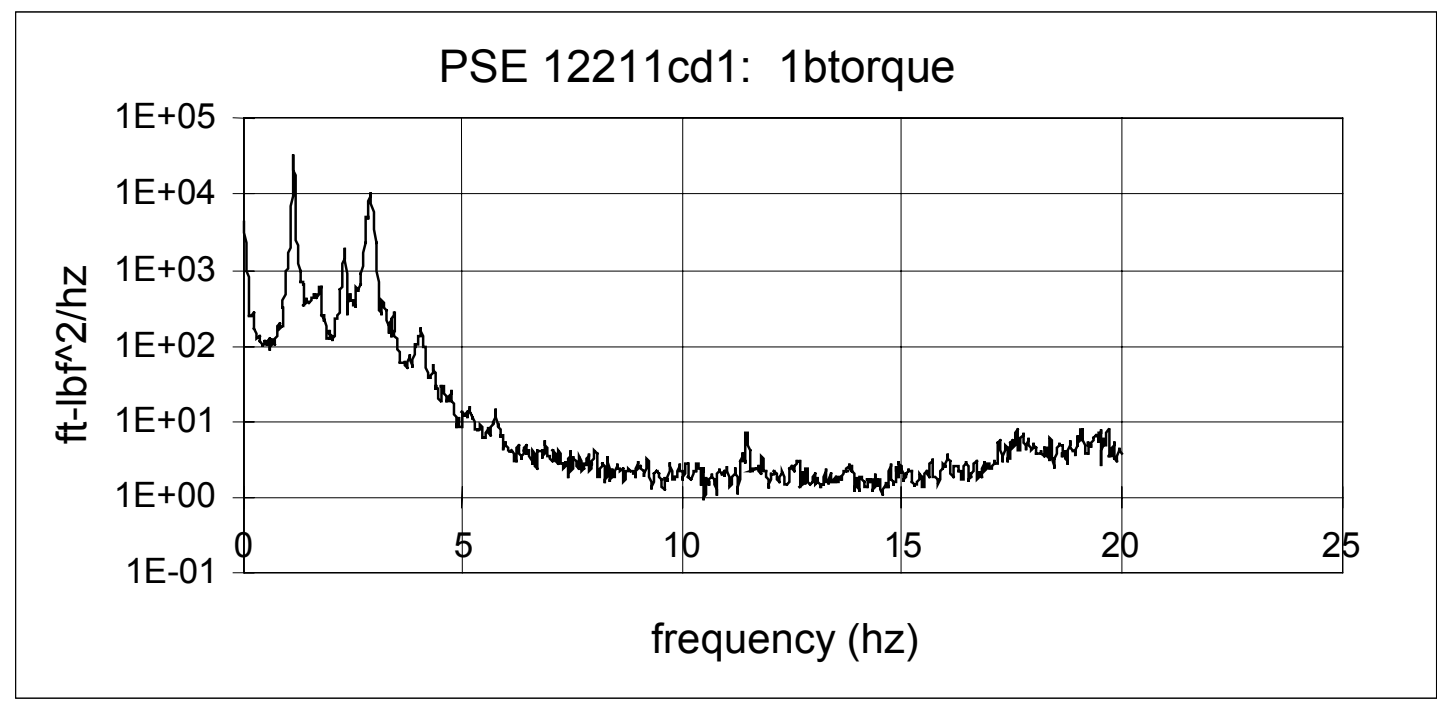

Figure 6-36. PSD of cuff blade torsion

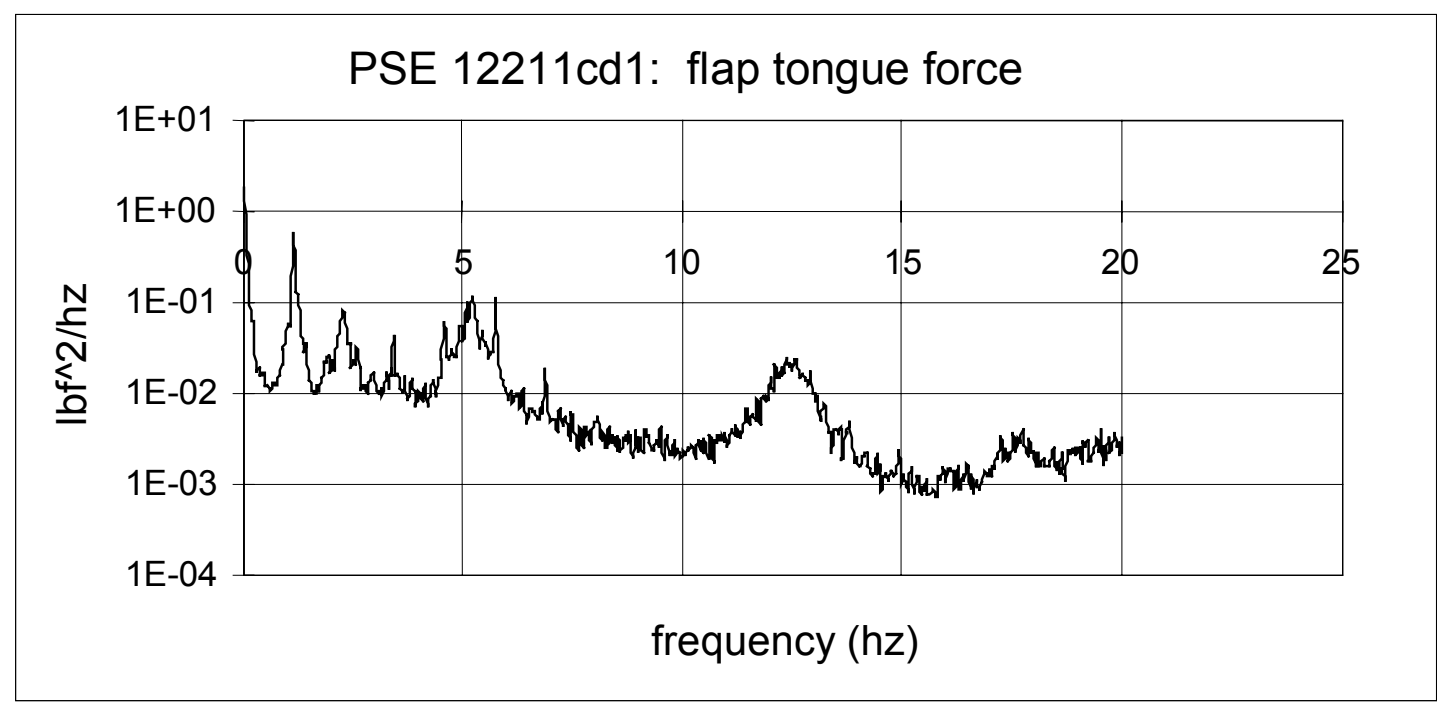

Figure 6-37. PSD of spoiler-flap tongue force

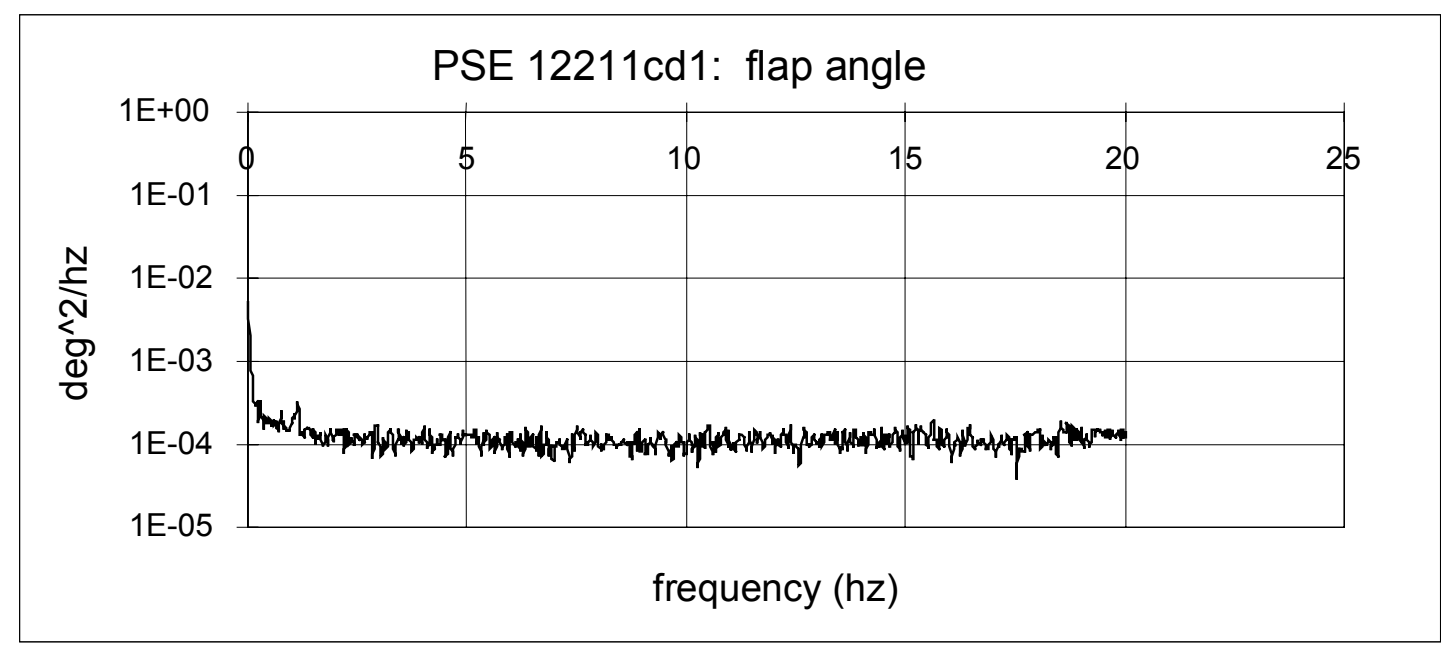

Figure 6-38. PSD of spoiler-flap angle 


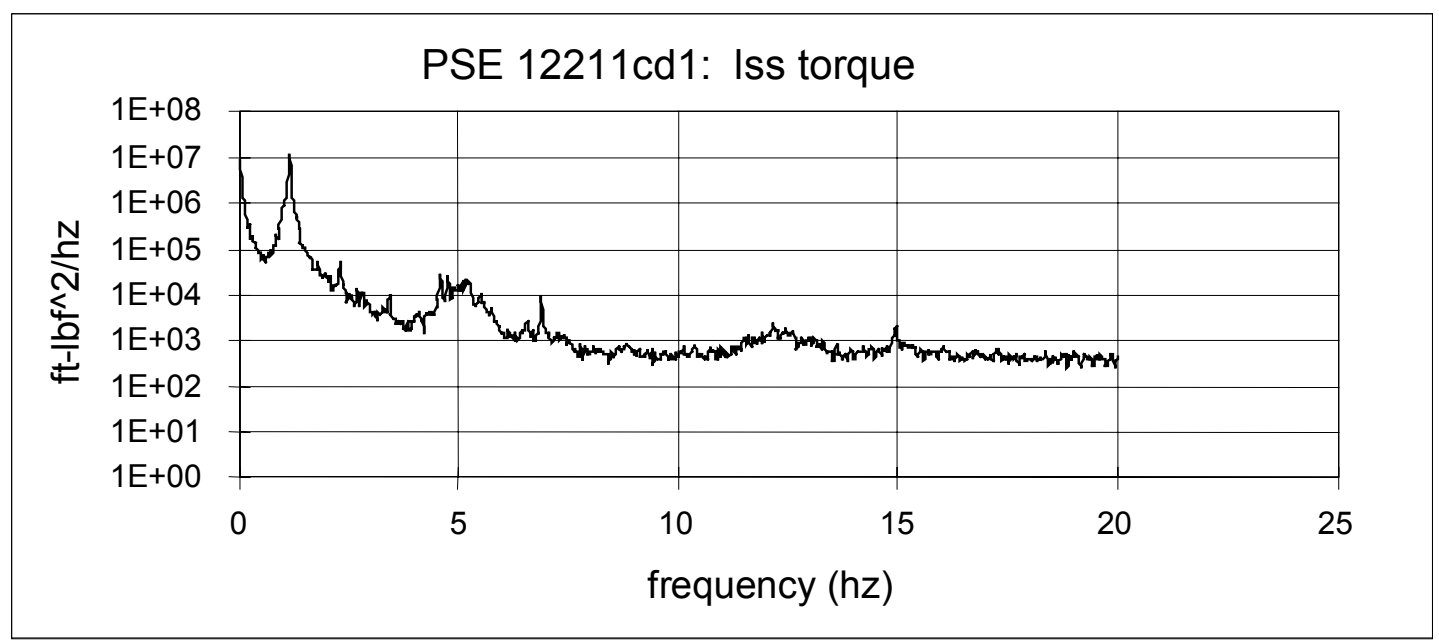

Figure 6-39. PSD of low speed shaft torque

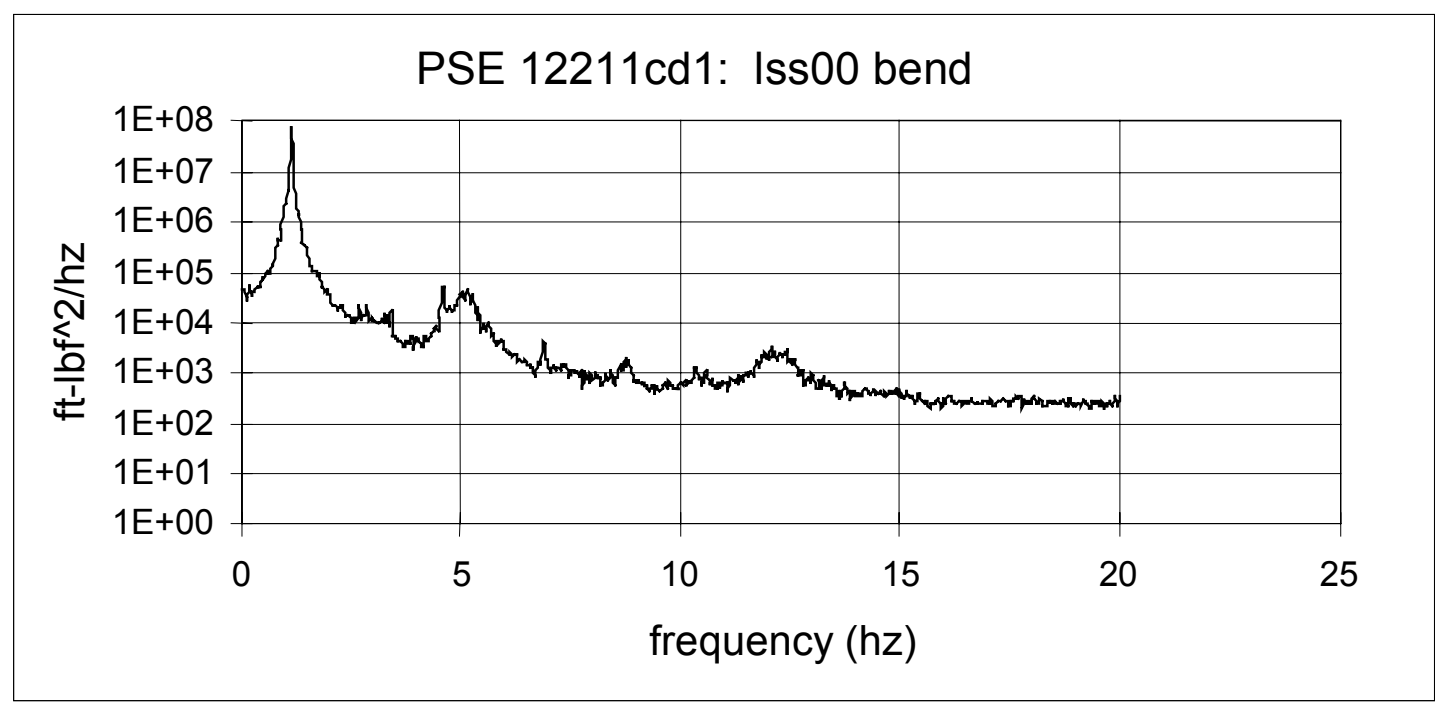

Figure 6-40. PSD of low speed shaft 0 deg bending moment

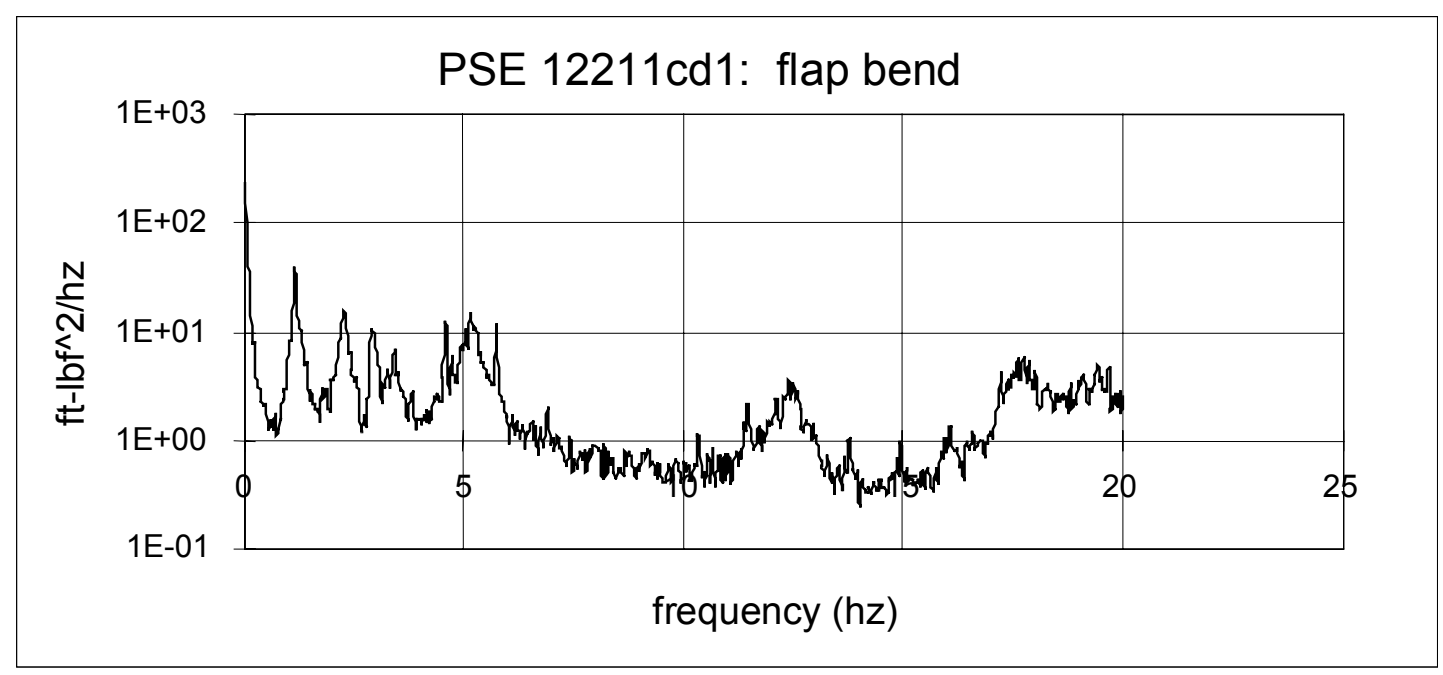

Figure 6-41. PSD of spoiler-flap bending moment 


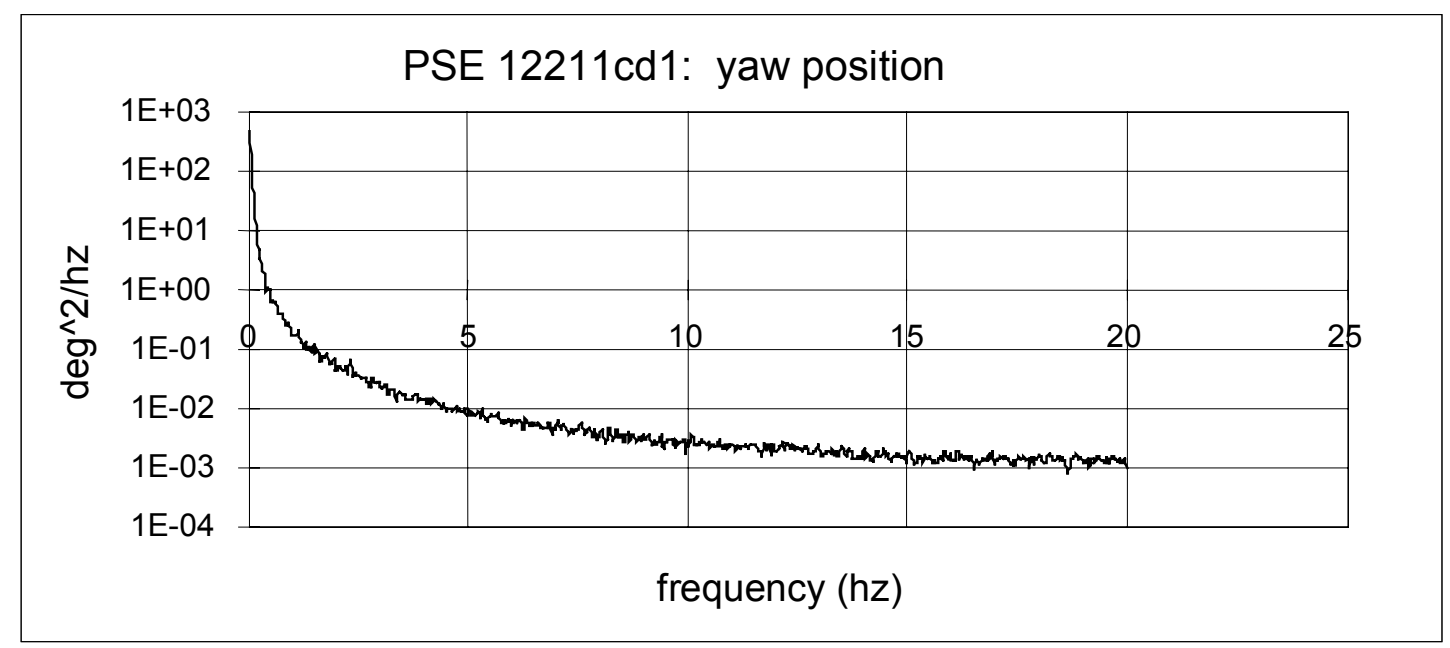

Figure 6-42. PSD of yaw position

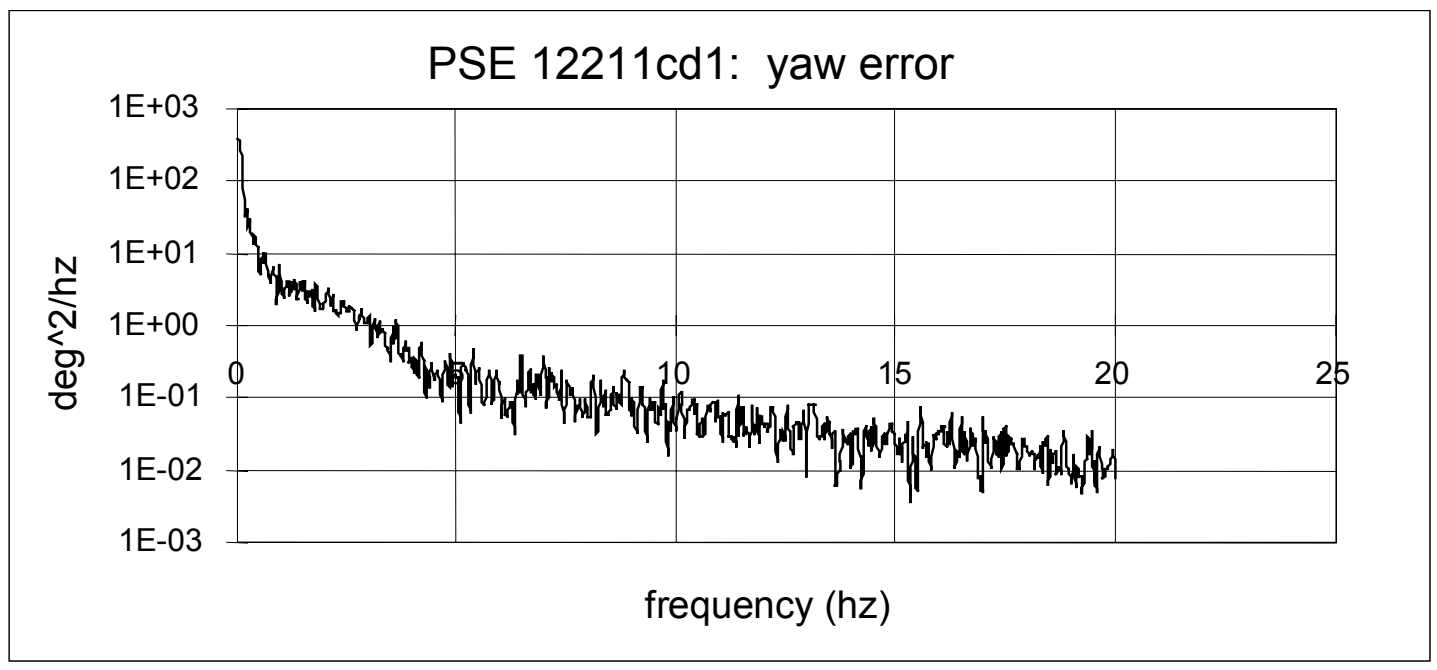

Figure 6-43. PSD of yaw error

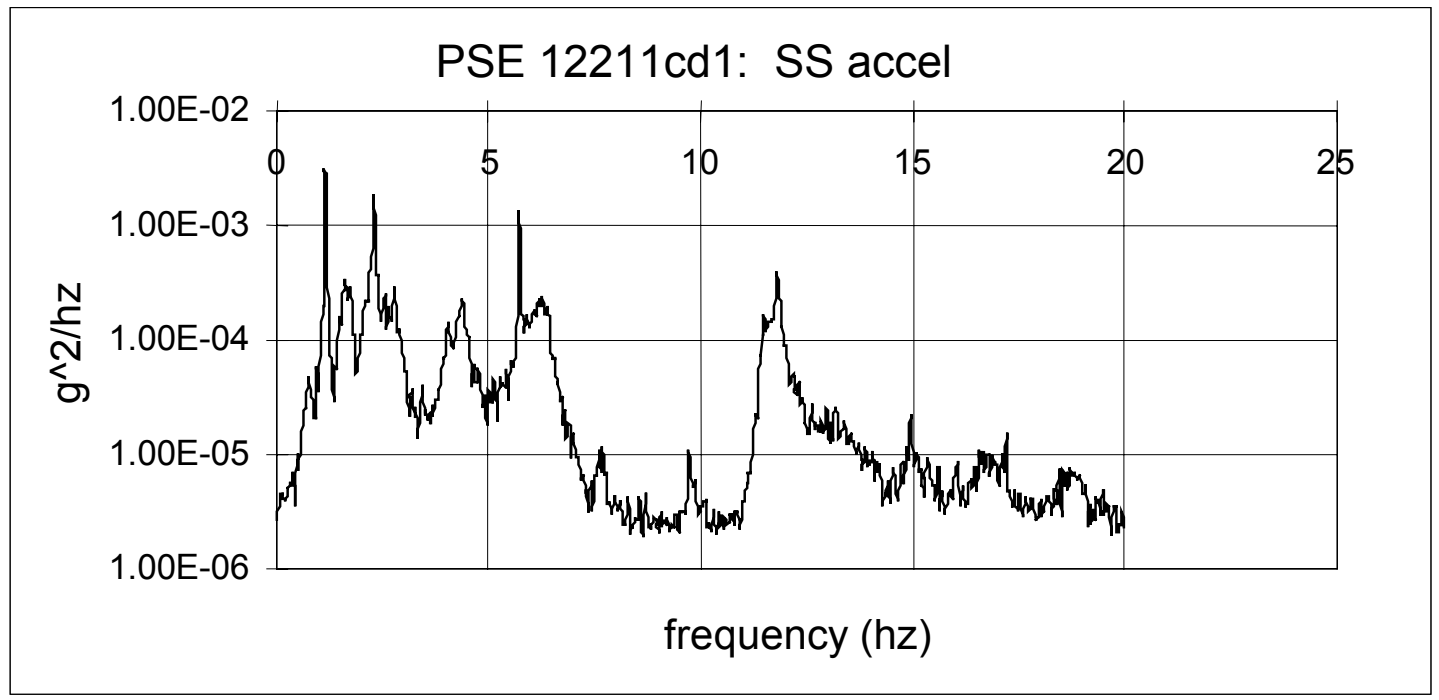

Figure 6-44. PSD of nacelle yaw acceleration 


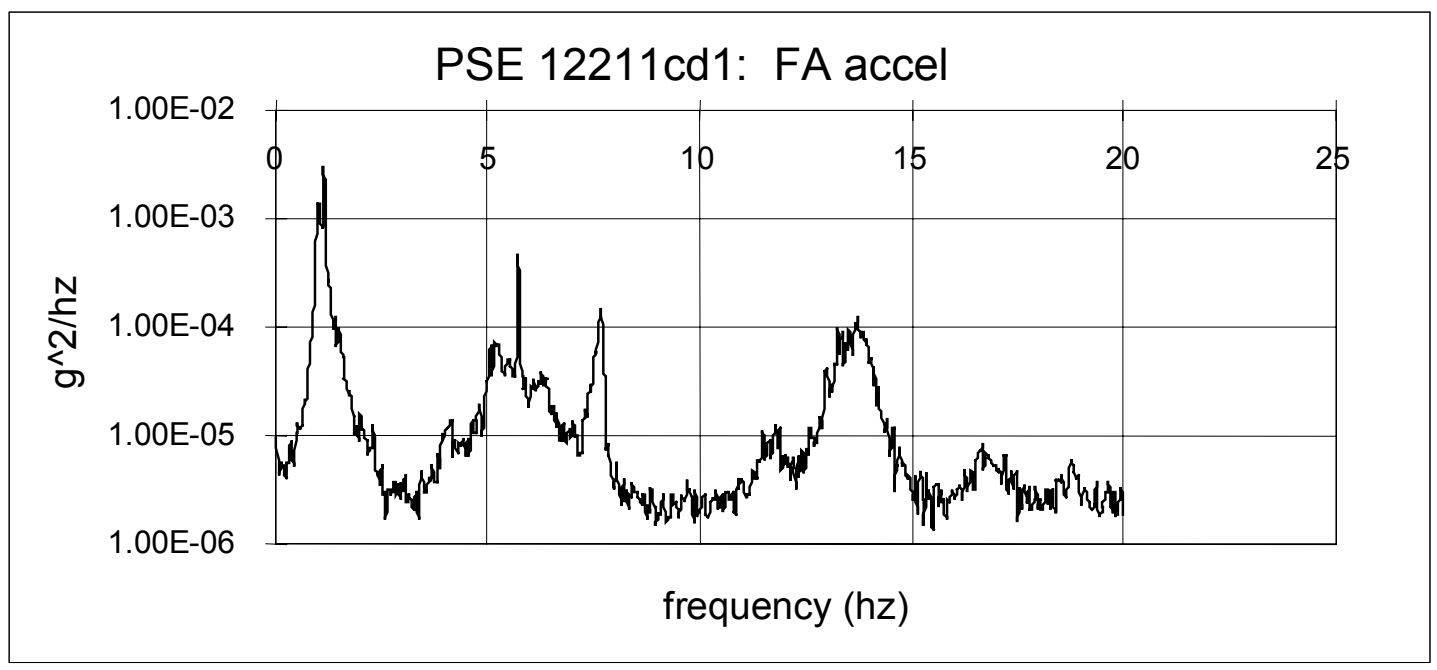

Figure 6-45. PSD of nacelle tilt acceleration

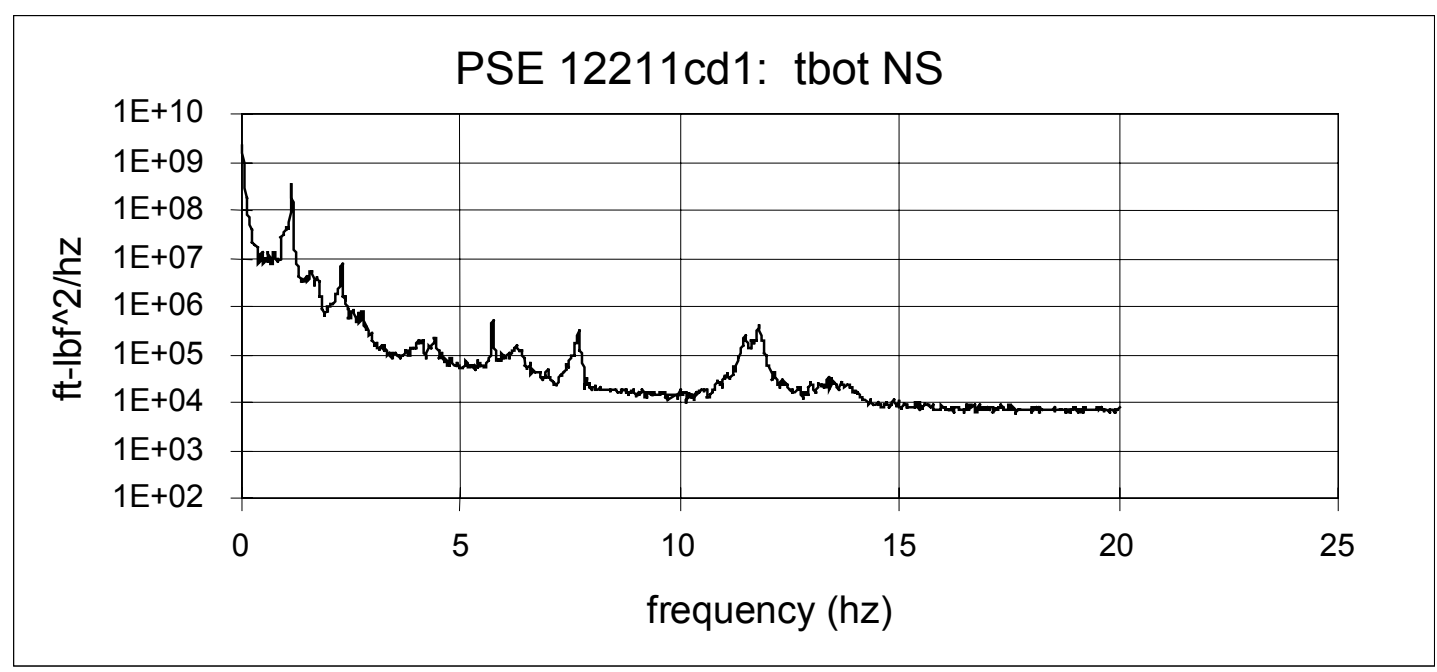

Figure 6-46. PSD of tower base NS bending moment

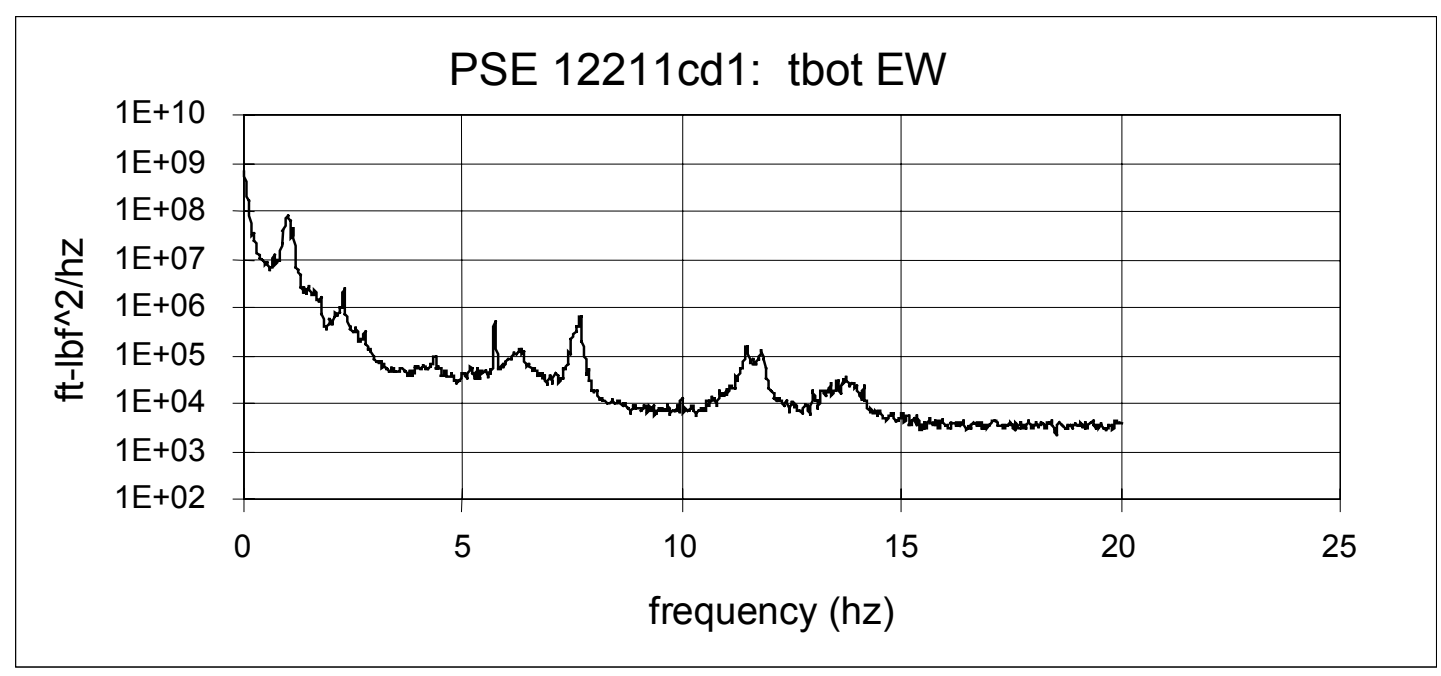

Figure 6-47. PSD of tower base EW bending moment 


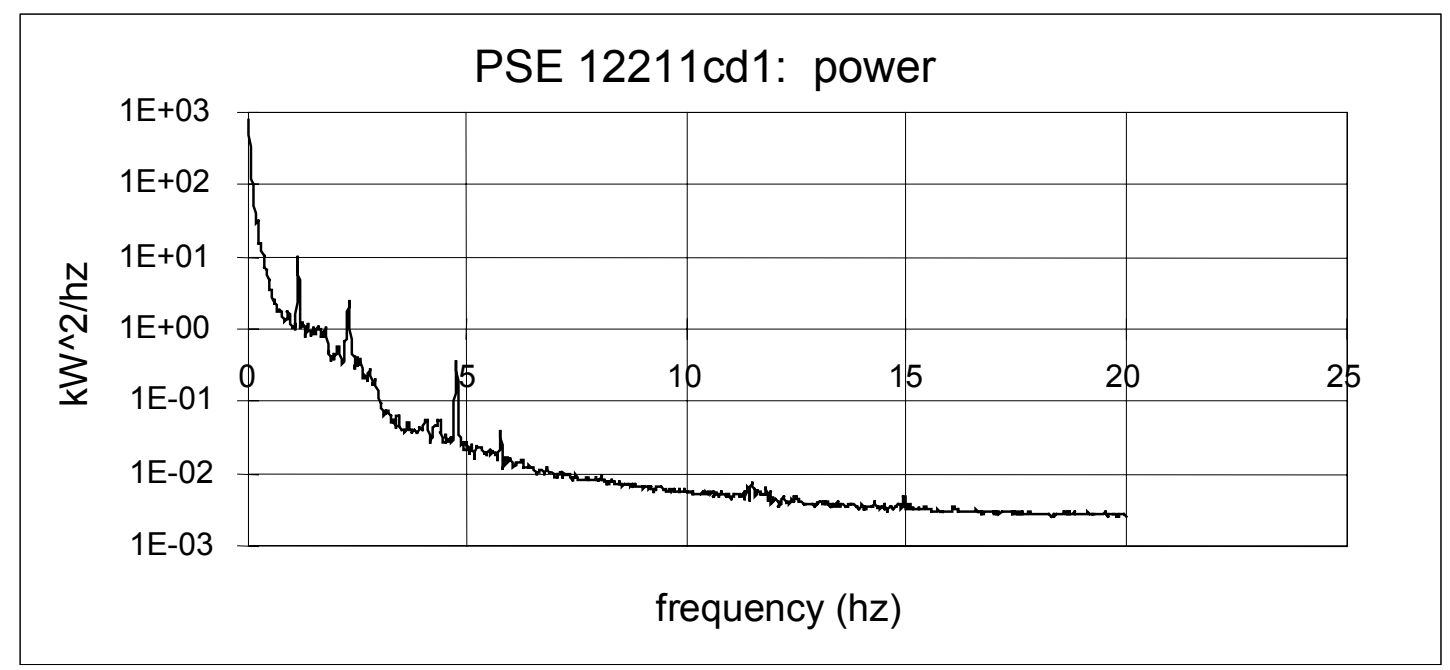

Figure 6-48. PSD of electrical power

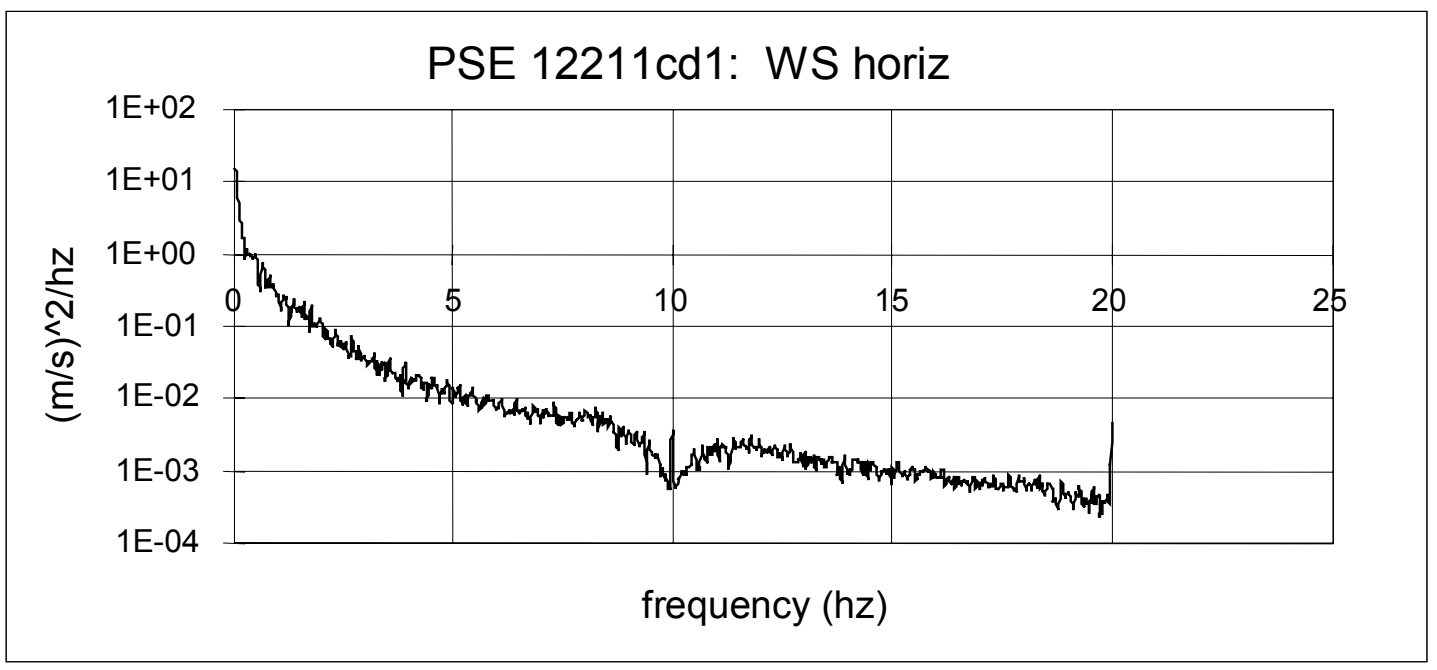

Figure 6-49. PSD of horizontal wind speed

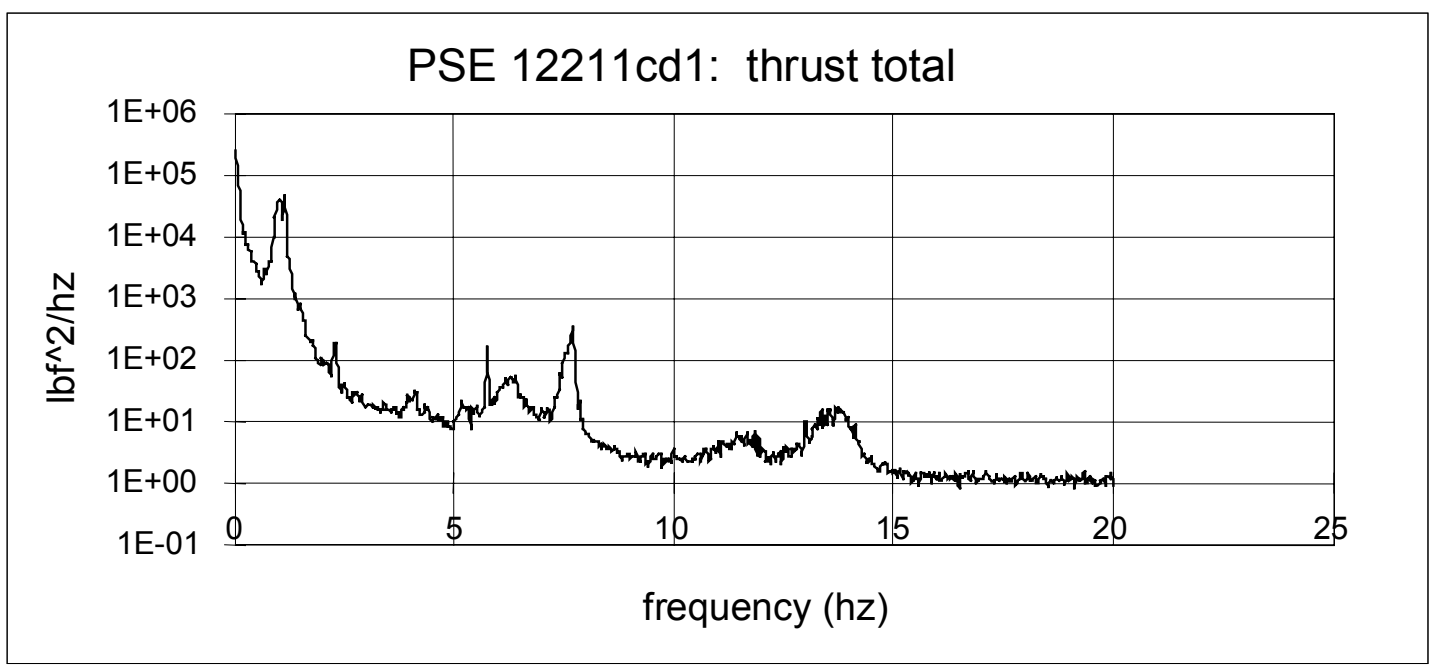

Figure 6-50. PSD of total thrust at tower base 


\section{Pultruded Blade Feasibility Study}

A study was conducted by a number of independent consultants to provide an unbiased assessment of the commercial viability of a wind turbine rotor utilizing pultruded blades. Experience of turbines employing this technology during the ' 80 s was not good. There has been evidence of tower strikes, upwind running, and stall flutter. Rotors of this era were extremely flexible, and the problems they experienced are a direct result of that flexibility. Recent designs pursued by PS Enterprises have been significantly stiffer, and the field tests of the scaled rotor were encouraging, in that it demonstrated stable operation, and there was no evidence of unusual yaw behavior or tower strikes. Since pultrusion technology shows such promise as a low cost blade manufacturing process, several key industry consultants were employed to examine in more detail the specific problem areas experienced by the earlier designs. Also studied was the performance penalty suffered by straight pultruded blades, a novel design modification to recover this lost performance, and the cost of two pultruded rotors and how they compare with two contemporary turbines. The novel design for enhancing the performance of straight blades consisted of a twisted tapered shell (or fairing) bonded over the inner $40 \%$ of the blade. It was shown that this modification, called the hybrid blade, could recover $80 \%$ of the lost performance of the straight blade.

This study indicated the feasibility of using rotors with pultruded blades for turbines up to $29 \mathrm{~m}$ diameter and ratings of $300 \mathrm{~kW}$. Since the trend in the industry has been toward larger systems, one megawatt and up, there is interest in the potential of pultruded blades being used for large turbines. Creative Pultrusions indicated that the current state-of-the-art in chordwise dimension for pultruded parts is about $4 \mathrm{ft}$. Considering aeroelastic constraints, the maximum length of a blade having a 4 - $\mathrm{ft}$ chord would be about 90 $\mathrm{ft}$. This translates to a 55-m diameter rotor that would have a rating of the order of $1 \mathrm{MW}$. A preliminary design of this size blade was performed and the weight was estimated to be $1390 \mathrm{~kg}$ (3060 lbs). The cost for a completed blade, including inboard stiffeners, is estimated at about $\$ 10,000$.

The results of this study are reported in two interim contract reports, References 1 and 2. A summary of the conclusions is given in the list below, and pertinent weight and cost comparisons are made in Table 71. PSE in the table refers to rotors using pultruded blades with root fairing.

- Performance degrades by $10 \%-15 \%$ for straight pultrusions

- Performance degrades by 2\%-5\% for hybrid blades

- Proper design ensures yaw stability and avoids tower strikes

- Blade weight decreased by $43 \%$ going from 3 to 5 blades

- Rotor $\$ / \mathrm{kWh}$ was independent of number of blades for the $15-\mathrm{m}$ rotor

- Pultrusion of 1-MW-scale blades is possible

- For rotors with the same number of blades, weight is comparable to contemporary turbines

- Overall blade cost reduced by $55 \%$ to $74 \%$ for configurations studied

- Excellent fatigue life indicated. 
Table 7-1. Weight and Cost Comparison of Pultruded and Non-pultruded Rotors

\begin{tabular}{|c|c|c|c|c|c|}
\hline \multicolumn{6}{|c|}{ 15m Rotor } \\
\hline & Model X & PSE & PSE & PSE & PSE w/o fairing \\
\hline No. of blades & 3 & 3 & 4 & 5 & 4 \\
\hline Blade wt., lb & 315 & 307 & 194 & 105 & 135 \\
\hline All blades & 946 & 921 & 776 & 525 & 540 \\
\hline Hub wt. & 401 & 779 & 615 & 440 & 615 \\
\hline Rotor wt. & 1347 & 1700 & 1391 & 965 & 1155 \\
\hline Blade cost & $\$ 3,168$ & $\$ 1,426$ & $\$ 1,332$ & $\$ 922$ & $\$ 531$ \\
\hline All blades & $\$ 9,507$ & $\$ 4,278$ & $\$ 4,528$ & $\$ 4,608$ & $\$ 2,124$ \\
\hline Hub cost & $\$ 1,700$ & $\$ 1,624$ & $\$ 1,459$ & $\$ 1,251$ & $\$ 1,459$ \\
\hline Rotor cost & $\$ 11,207$ & $\$ 5,902$ & $\$ 5,987$ & $\$ 5,859$ & $\$ 3,583$ \\
\hline $\mathrm{kWh} / \mathrm{m}^{\wedge} 2$ & 1058 & 1010 & 1020 & 1030 & 920 \\
\hline$\$ / k W h$ & 0.060 & 0.033 & 0.033 & 0.032 & 0.022 \\
\hline \multicolumn{5}{|c|}{ 29m Rotor } & \\
\hline$b=2$ & Model Y & PSE & PSE w/o fair & & \\
\hline Blade wt.,Ib & 706 & 867 & 957 & & \\
\hline All blades & 1412 & 1734 & 1914 & & \\
\hline Hub wt. & 669 & 2780 & 2780 & & \\
\hline Rotor wt. & 2081 & 4514 & 4694 & & \\
\hline Blade cost & $\$ 7,450$ & $\$ 2,709$ & $\$ 2,047$ & & \\
\hline All blades & $\$ 14,900$ & $\$ 5,418$ & $\$ 4,094$ & & \\
\hline Hub cost & $\$ 1,823$ & $\$ 3,241$ & $\$ 3,241$ & & \\
\hline Rotor cost & $\$ 16,723$ & $\$ 8,659$ & $\$ 7,335$ & & \\
\hline kWh/m^2 & 1028 & 1005 & 822 & & \\
\hline$\$ / k W h$ & 0.0250 & 0.0130 & 0.0135 & & \\
\hline
\end{tabular}




\section{Conclusions}

An investigation was completed to evaluate various issues pertaining to the use of pultruded blades for wind turbine rotors. The unfortunate operating history of wind turbines using these blades in the eighties, created primarily by inadequate research and insufficient experience, had placed a large burden on the technology to overcome. However the important advantages of pultruded blades, low weight and cost, were clearly demonstrated. This NREL subcontract was directed at performing much of the engineering that was needed to produce reliable designs, so that these advantages could be exploited.

The technical areas that were studied included materials, blade design, stall flutter, yaw stability, tower strikes, performance, airfoils, blade aerodynamics, hub design, rotor weight, modifications to improve performance, and rotor costs. In support of these analytical efforts, several test programs were conducted. These were pultruded material strength and fatigue tests at Montana State University, a static test at the NREL blade test facility, and a field test of a 15.5-m rotor dynamically scaled from a 33-m utility-grade design.

Supporting studies were also completed by a number of independent consultants who are recognized experts in specific areas of wind engineering. In general, there was no technical issue revealed by any of the studies or tests that would be considered a 'fatal flaw' in the concept. Furthermore, cost studies comparing rotors using pultruded blades with rotors having conventional tapered/twisted blades showed exceptional reductions in specific costs (rotor cost $/ \mathrm{kWh}$ ). Specifically, the following conclusions were drawn:

- Pultruded material demonstrates good strength and fatigue properties

- Static blade test exhibits high elasticity but need for careful root design to minimize stress rise at hub

- Field test of five-bladed 15.5-m rotor demonstrated stable operation

- Field test showed good correlation with predicted performance and blade moments

- Performance degrades by $10 \%-15 \%$ for straight pultrusions compared to those with twist and taper

- Performance degrades by $2 \%-5 \%$ for hybrid blades with root fairing

- Proper design ensures yaw stability and avoids tower strikes

- Blade weight decreased by $43 \%$ going from 3 to 5 blades

- Rotor $\$ / \mathrm{kWh}$ was independent of number of blades for the $15-\mathrm{m}$ rotor

- Pultrusion of 1-MW-scale blades is possible

- For rotors with the same number of blades, weight is comparable to contemporary turbines

- Overall blade cost reduced by $55 \%$ to $74 \%$ for configurations studied

- Excellent fatigue life indicated. 


\section{References}

1. Cheney, M.C.; Olsen, T.; Quandt, G.; Zuteck, M.; Deering, K.; Knapp, T.; Hansen, C.; Selig, M.; (June 1998). Feasibility Study of Pultruded Blades for Wind Turbine Rotors. Work performed by PS Enterprises, Inc. under NREL Subcontract No. AAA-4-12272-04.

2. Hansen, C.; Minnema, J. (June 1998). Stability Analysis Report. Work performed for PS Enterprises, Inc. under NREL Subcontract No. AAA-4-12272-04.

3. Cheney, M. (July 1994). Baseline Turbine Assessment. Work performed by PS Enterprises, Inc. under NREL Subcontract No. AAA-4-12272-04

4. Mandell, J.; Samborsky, D. (December 1997). DOE/MSU Composite Material Fatigue Database: Test Methods, Materials, and Analysis. DOE/Sandia Subcontract No. DE-AC04-94AL85000.

5. Ramsey, R.; Gregorek, G. (May 1995). Effects of Grit Roughness and Pitch Oscillations on the S813 Airfoil. NREL/TP-442-8168. Golden, CO: National Renewable Energy Laboratory. Work performed by Ohio State University.

6. McCarty, J. (1993). PROP93 Version 1.0 Wind Turbine Performance Code. Canyon, TX: Alternative Energy Institute.

7. Miller, L.S. (1995). Experimental Investigation of Aerodynamic Devices for Wind Turbine Rotational Speed Control: Phase 1. NREL/TP-441-6913. Golden, CO: National Renewable Energy Laboratory.

8. Miller, L.S. (1996). Experimental Investigation of Aerodynamic Devices for Wind Turbine Rotational Speed Control: Phase 2. NREL/TP-441-6913. Golden, CO: National Renewable Energy Laboratory.

9. Griffen, D.A. (1997). Experimental Investigation of Aerodynamic Devices for Wind Turbine Applications: NREL/SR-440-22253. Golden, CO: National Renewable Energy Laboratory.

10. Musial, W.; Hughes, S.; Johnson, J.; Jenks, M.; DeShay, D.; Egging, N.; (23 April 1997). PS Enterprises - $85 \mathrm{~kW}$ Blade Full Scale Static-Testing. NREL internal report.

11. Jackson, K.; Stoddard, F. (July 1996). Scaled-Rotor Test Plan. Work performed for PS Enterprises, Inc. under NREL Subcontract No. AAA-4-12272-04.

12. Arcidiacono, Peter J. (March 1996). Differential Equations of Motion for a Wind Turbine Having Flexible Blades. Work performed for PS Enterprises, Inc. under NREL Subcontract No. AAA-412272-04.

13. Arcidiacono, Peter J. (July 1998). User's Guide for Flexdyne. Work performed for PS Enterprises, Inc. under NREL Subcontract No. AAA-4-12272-04. 


\section{REPORT DOCUMENTATION PAGE}

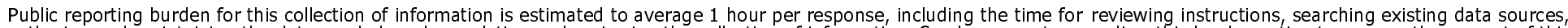

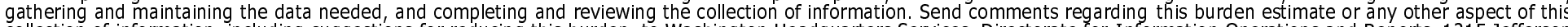

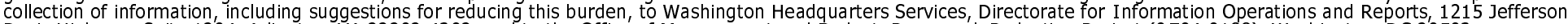

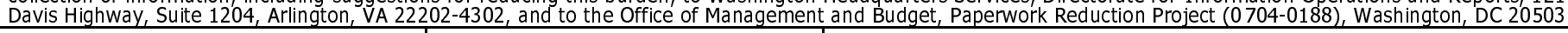
1. AGENCY USE ONLY (Leave blank)
2. REPORT DATE
3. REPORT TYPE AND DATES COVERED
Subcontract Report

4. TITLE AND SUBTTLE

Analysis and Tests of Pultruded Blades for Wind Turbine Rotors

6. AUTHOR(S)

M.C. Cheney

PS Enterprises

Glastonbury, Connecticut

T. Olsen, G. Quandt, P. Arcidiacono

7. PERFORMING ORGANIZATION NAME(S) AND ADDRESS(ES)

PS Enterprises

8. PERFORMING ORGANIZATION REPORT NUMBER

P.O. Box 837

Glastonbury, CT 06033-0837

9. SPONSORING/MONITORING AGENCY NAME(S) AND ADDRESS(ES)

National Renewable Energy Laboratory

1617 Cole Blvd.

Golden, CO 80401-3393

5. FUNDING NUMBERS

WE902320

AAA-4-12272-04

11. SUPPLEMENTARY NOTES

NREL Technical Monitor: P. Migliore

12a. DISTRIBUTION/AVAILABILTYY STATEMENT

National Technical Information Service

U.S. Department of Commerce

5285 Port Royal Road

Springfield, VA 22161

13. ABSTRACT (Maximum 200 words)

PS Enterprises, Inc. investigated a flexible, downwind, free-yaw, five-blade rotor system employing pultruded blades. A rotor was designed, manufactured and tested in the field.

10. SPONSORING/MONITORING AGENCY REPORT NUMBER

SR-500-25949 manufacti

14. SUBJECT TERMS

wind energy, wind turbines, wind turbine rotors, wind turbine design

15. NUMBER OF PAGES

17. SECURITY CLASSIFICATION OF REPORT
18. SECURITY CLASSIFICATION OF THIS PAGE
19. SECURITY CLASSIFICATION OF ABSTRACT 12b. DISTRIBUTION CODE

NSN 7540-01-280-5500

Standard Form 298 (Rev. 2-89)

Prescribed by ANSI Std. Z39-18 